

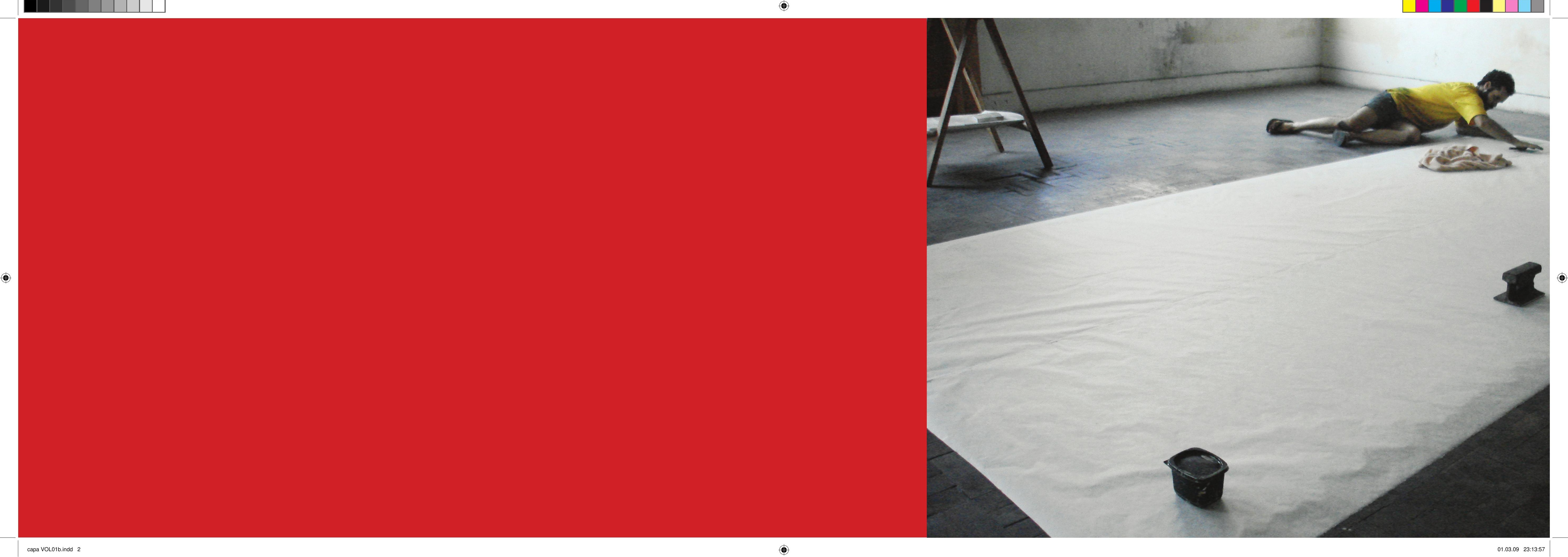




\section{ATELIÊ SANTOS}

*

vol. 01 


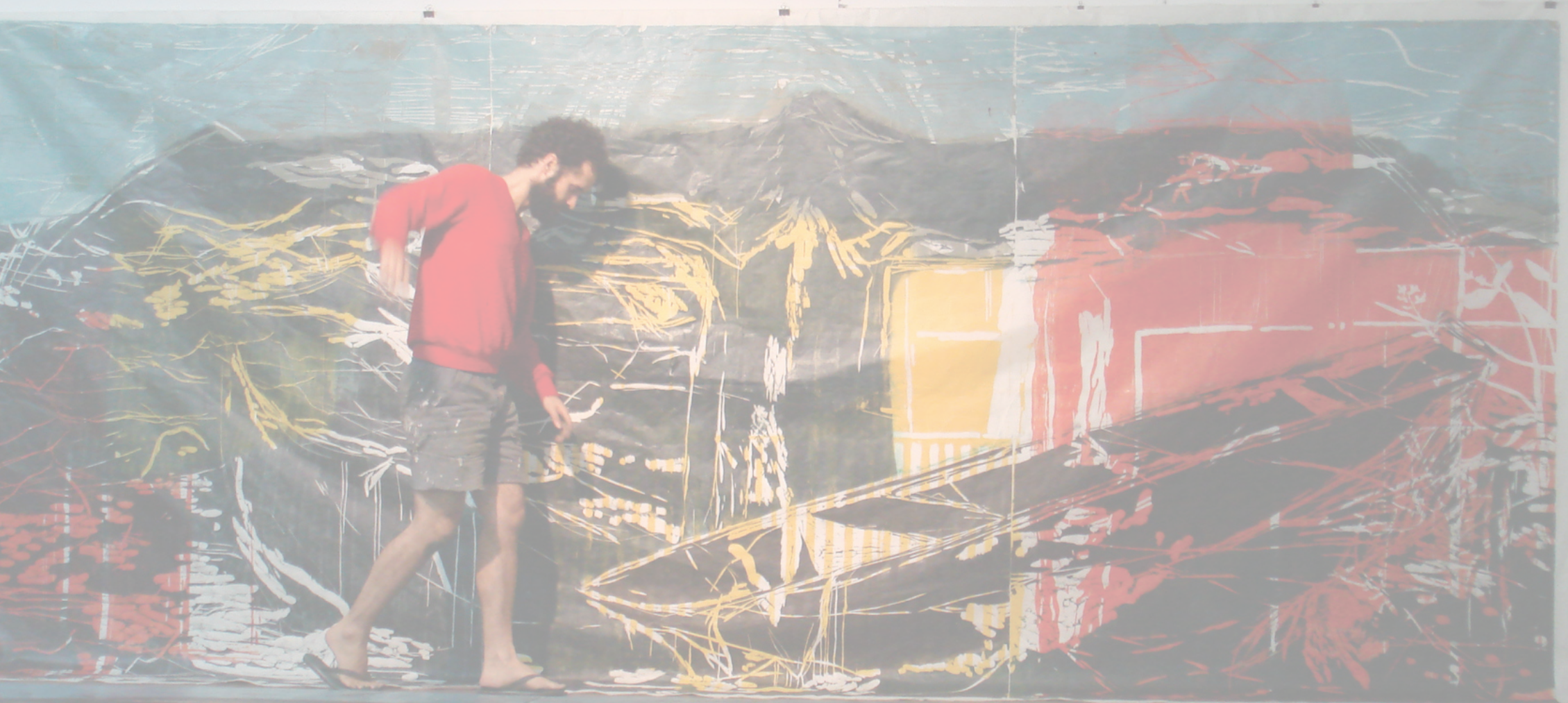




\title{
A madeira e a luz - ATELIÊ SANTOS
}

\section{FABRICIO DE JESUS BARRIO LOPEZ}

Dissertação de mestrado apresentada ao Departamento de Artes Plásticas da Escola de Comunicação e Artes da Universidade de São Paulo

\author{
orientador
}

Prof. Dr. LUIZ CLAUDIO MUBARAC

\section{POÉTICAS VISUAIS}

ECA - USP

2009

vol. 01 


\section{banca examinadora}

Prof. Dr. Evandro Carlos F. Poyares Jardim

Prof. Dr. Marcelo Mattos Araújo 
Apresentação

Os dois volumes que integram esta dissertação compreendem a produção visual realizada entre 2003 - 2008, e a implantação de um ateliê no centro histórico da cidade de Santos, no bairro do Valongo, a partir de 2007.

Através de documentação fotográfica e anotações sobre o processo, o primeiro caderno constitui uma sucessão de ações relacionadas a ocupação do próprio ateliê e a produção neste lugar, tendo como foco o desenho, a xilogravura e a pintura.

O segundo caderno apresenta uma seleção de trabalhos em pequenos e grandes formatos, dando ênfase a sobreposição de camadas de cor e possíveis aproximações entre a xilogravura e a pintura.

palavras chave: xilogravura / cor / grande formato / ateliê 


\section{Abstract}

The two volumes of this dissertation comprise the author's artistic production from 2003 to 2008, as well as the implementation of an arts workshop in the historical downtown of the city of Santos, in the Valongo district, from 2007 onward.

By means of photographic documentation and process notes, the first volume comprises a series of actions related to the setting up of the workshop itself and the artistic production which has taken place there, focusing on drawing, painting and woodcut.

The second volume introduces a selection of works, in small and large formats, emphasizing color overlaying and the possible connections between woodcut and painting.

key words: woodcut / color / grand scale / arts workshop 

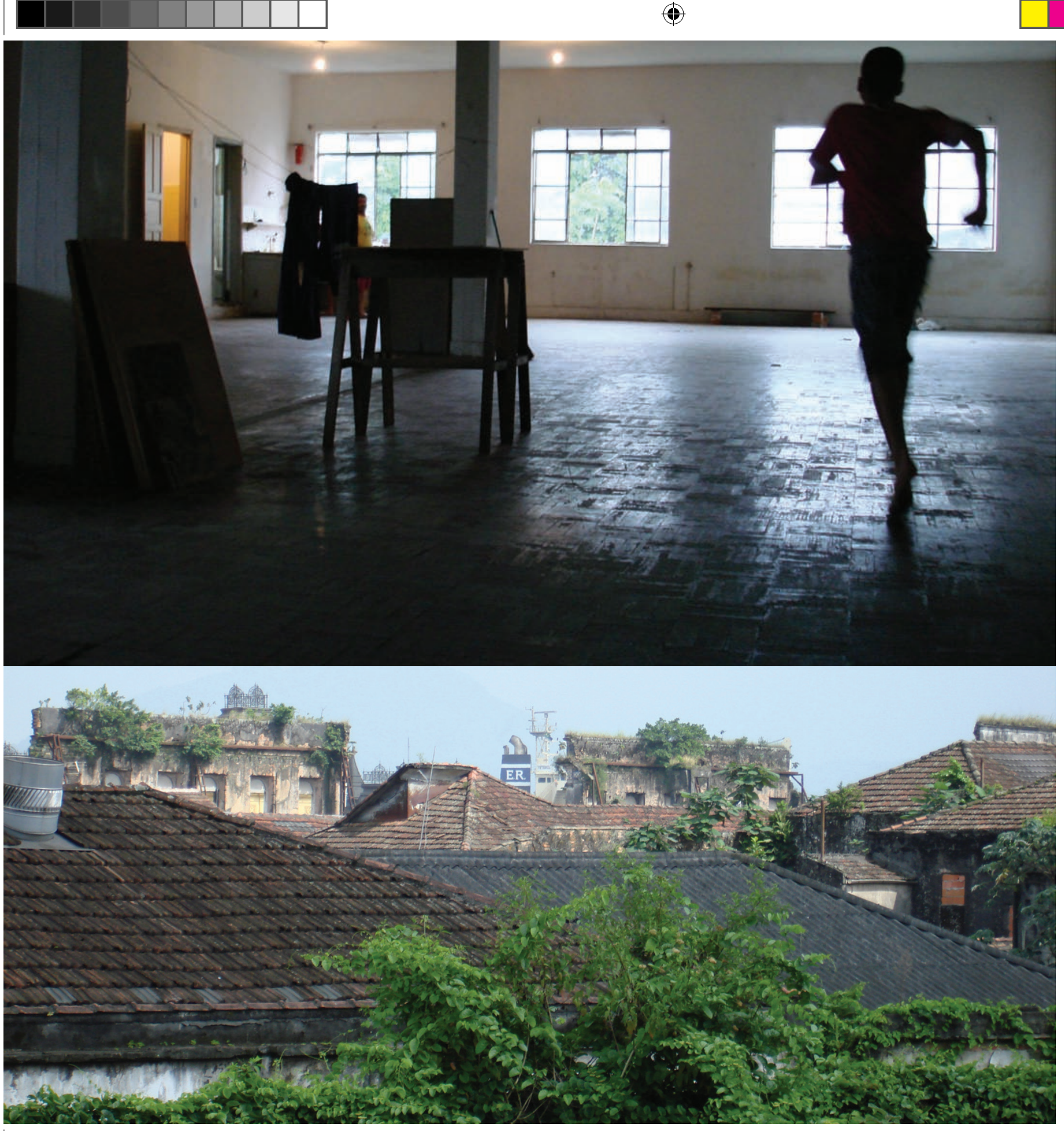


\section{Sumário}

- $\quad$ O CORPO

- $\quad$ A TALHA E 0 GeSTO 21

- NAVEGAÇÃO DE CABOTAGEM - rema, rema , remador

35

- A SEGUNDA PELE

54

- VALONGO - ATELIÊ SANTOS "Ateliê filtro coral na cidade marisco"

73

- $\quad$ COR - paleta portuária

105

- BIBLIOGRAFIA

122 
- $\quad$ CORPO

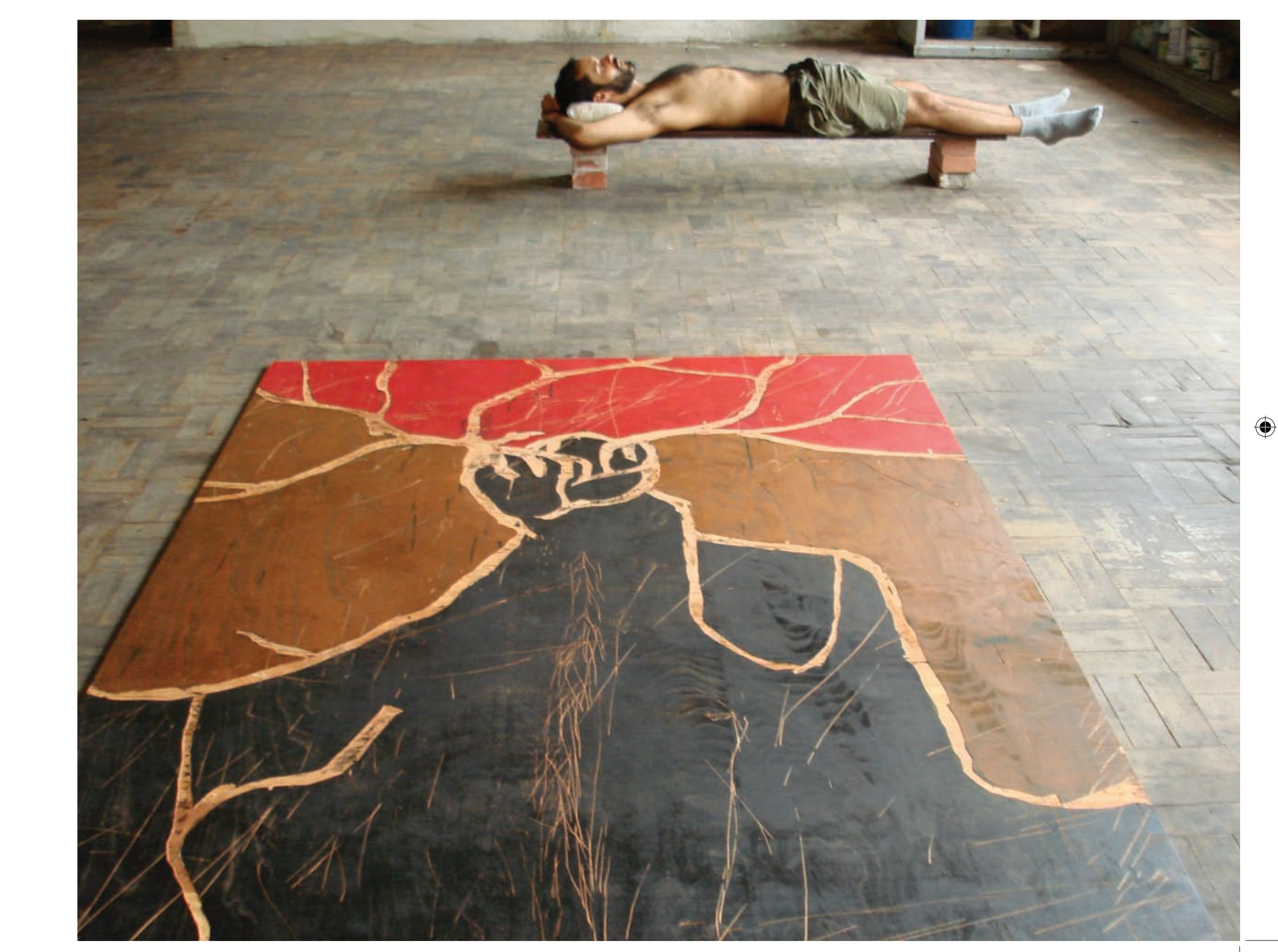



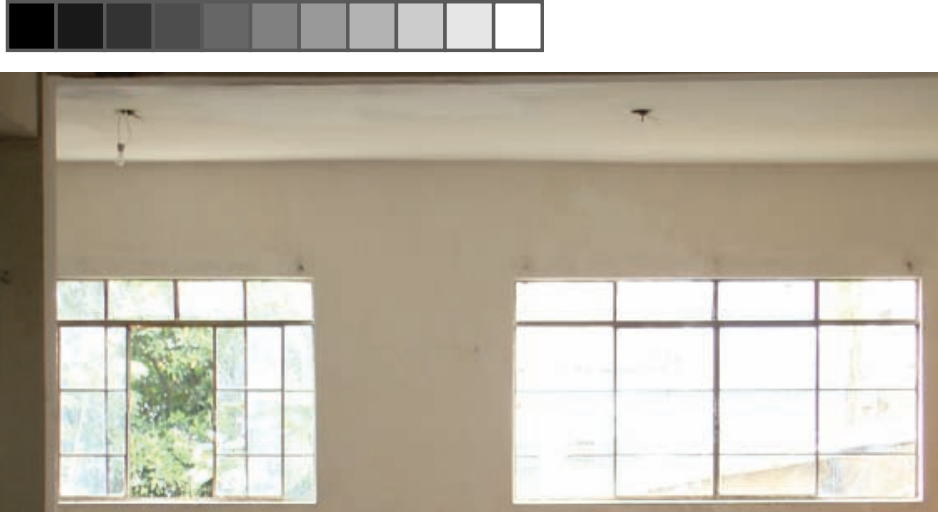

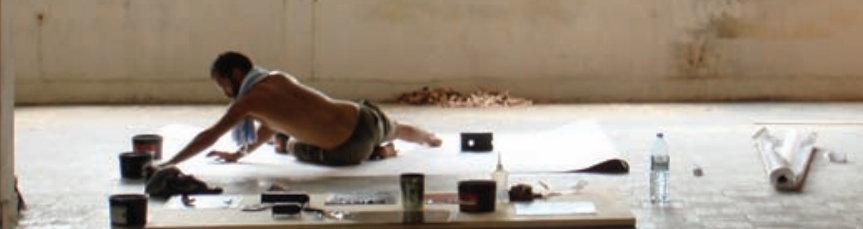

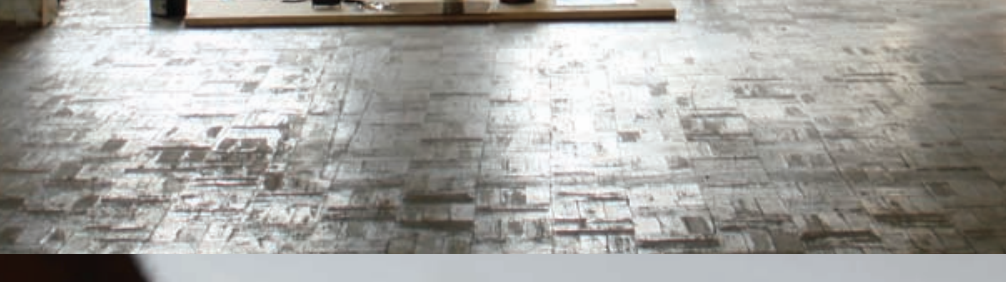

(1)
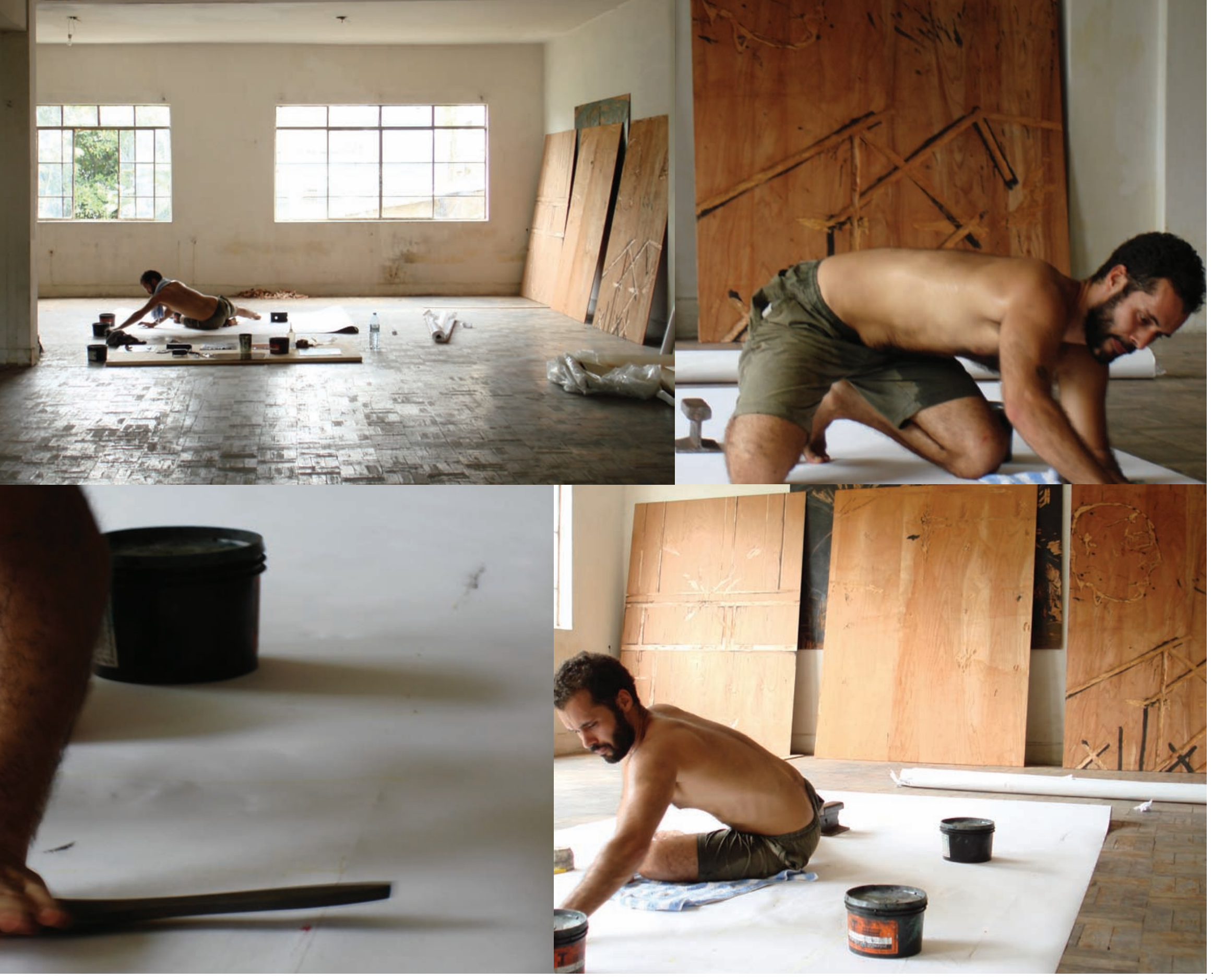

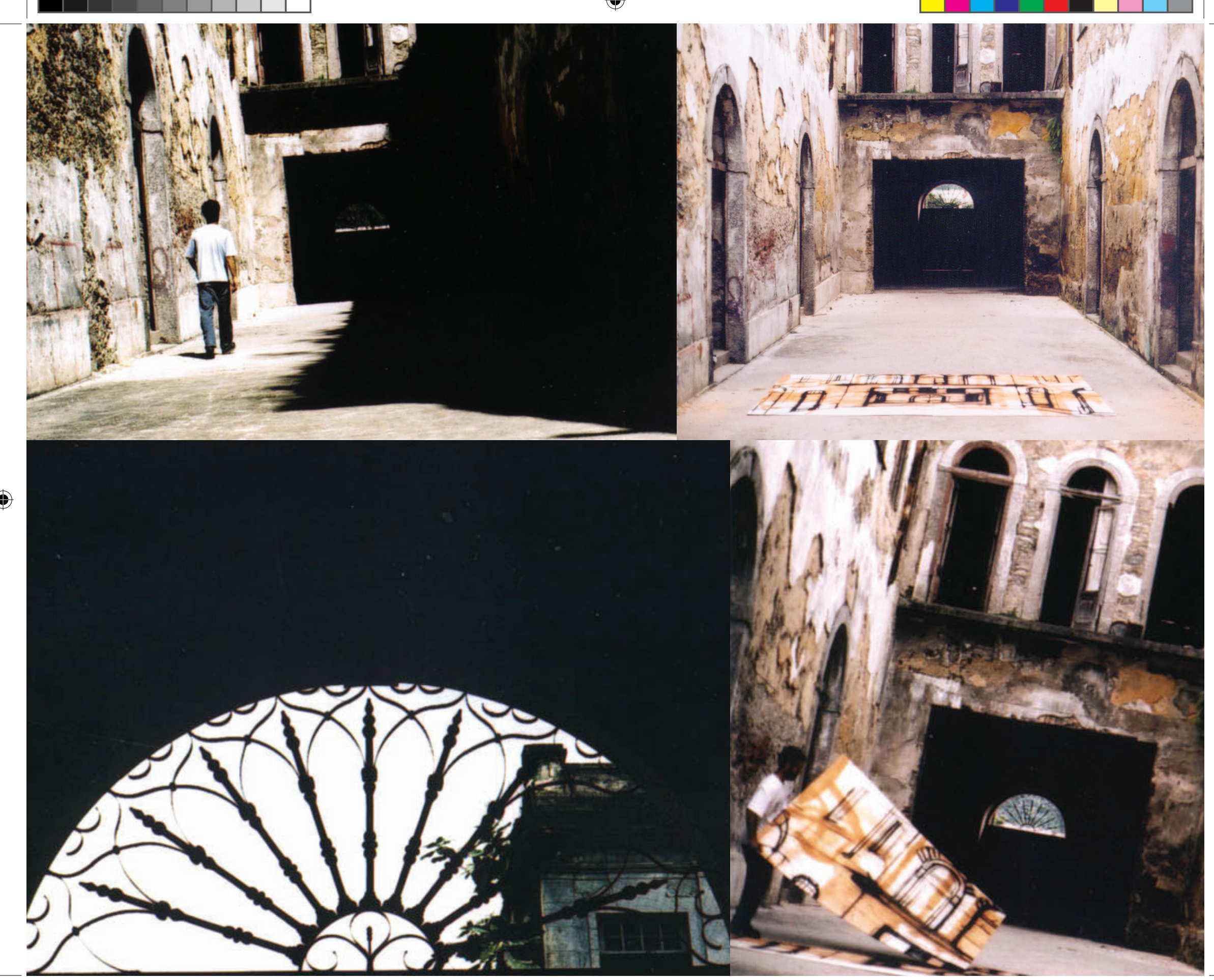

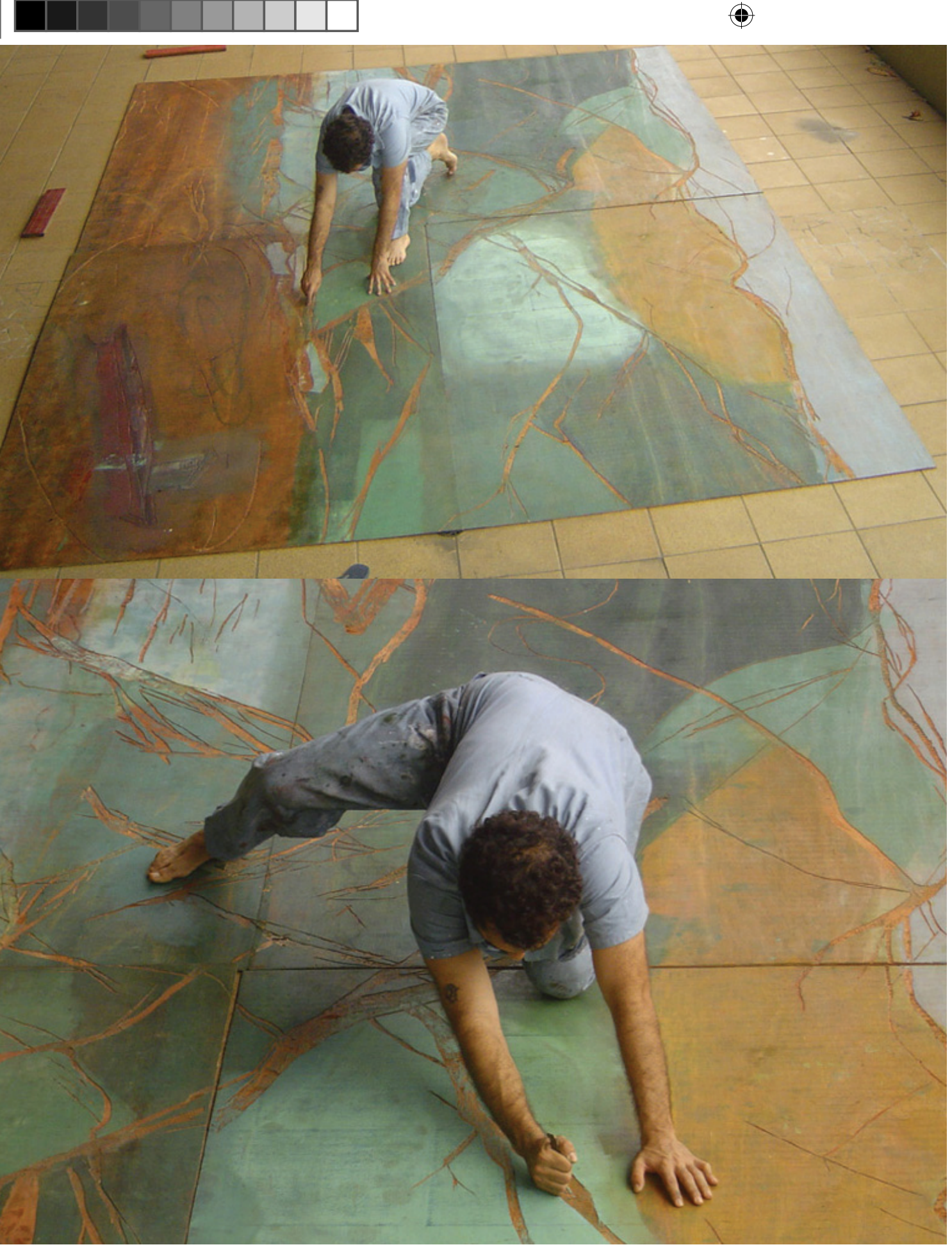


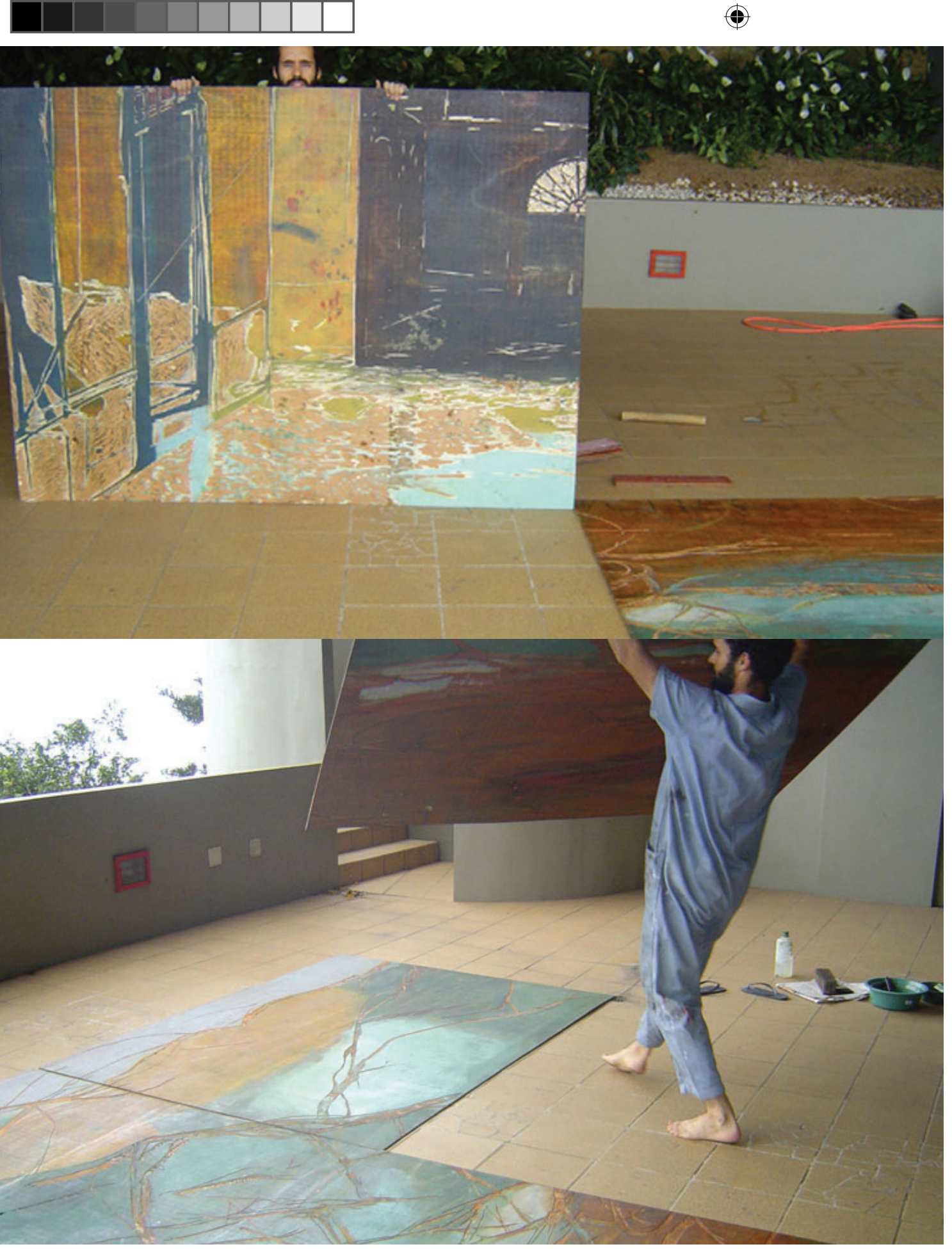


\begin{tabular}{|l|l|l|l|l|l|l|l|}
\hline & I
\end{tabular}

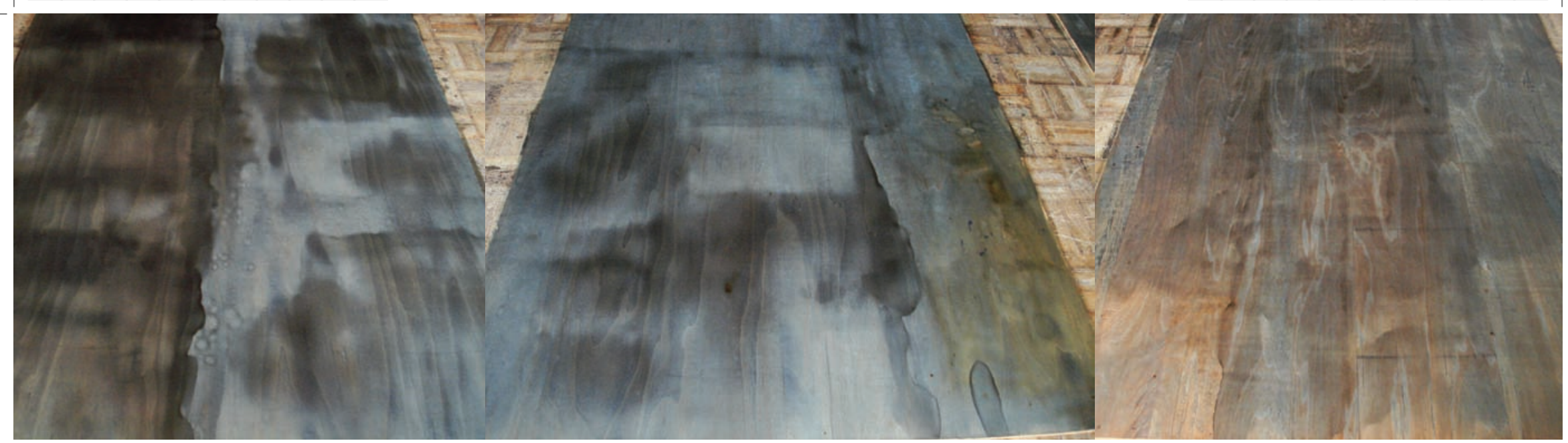


- $\quad$ a talha e 0 gesto

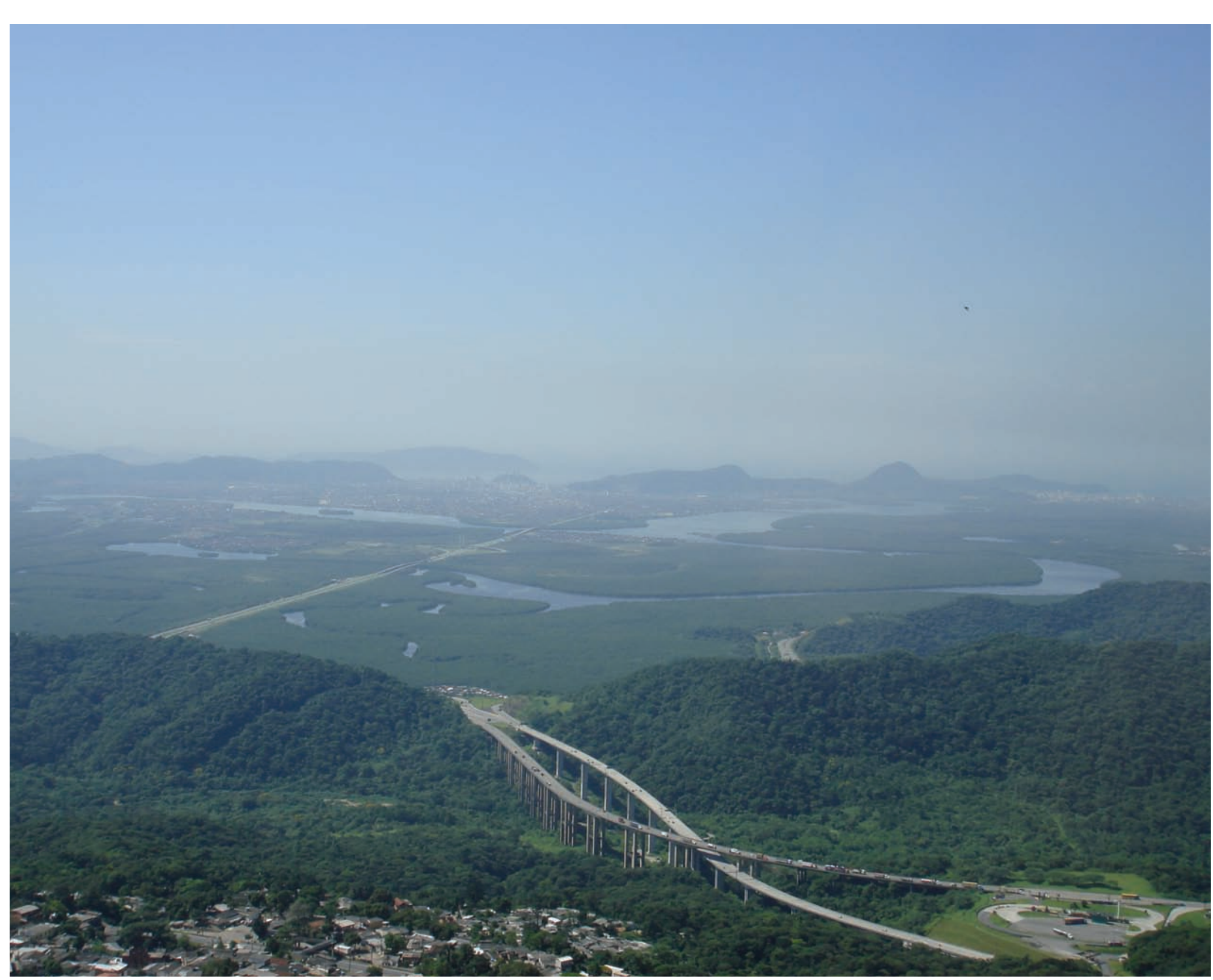




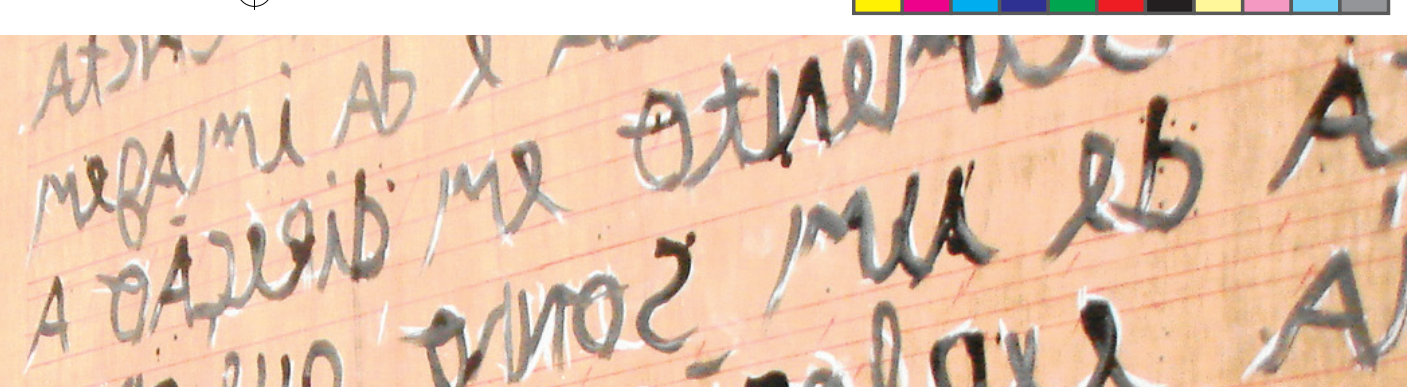

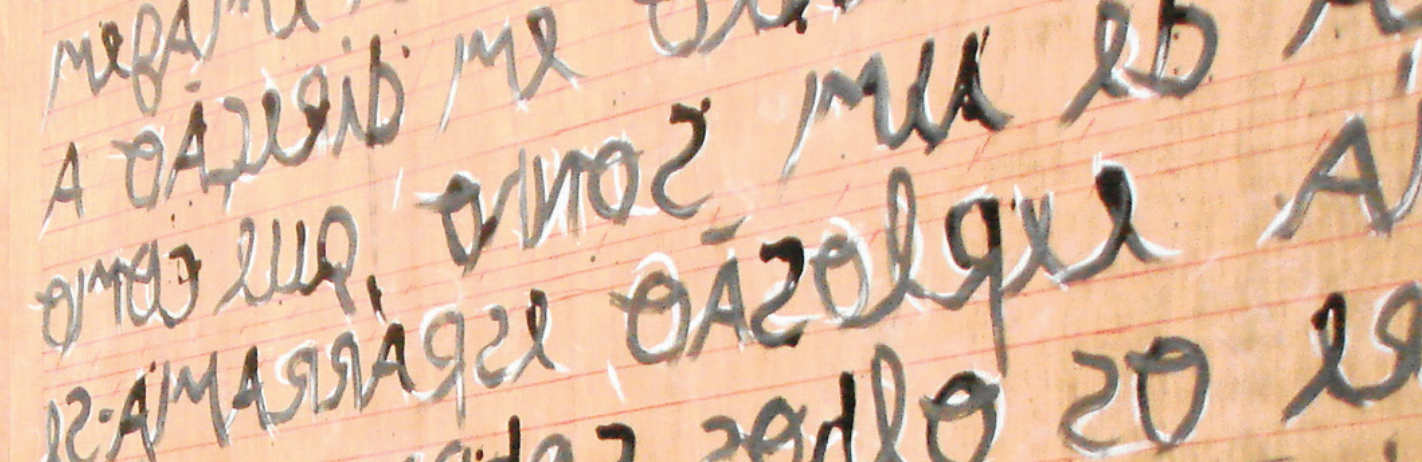

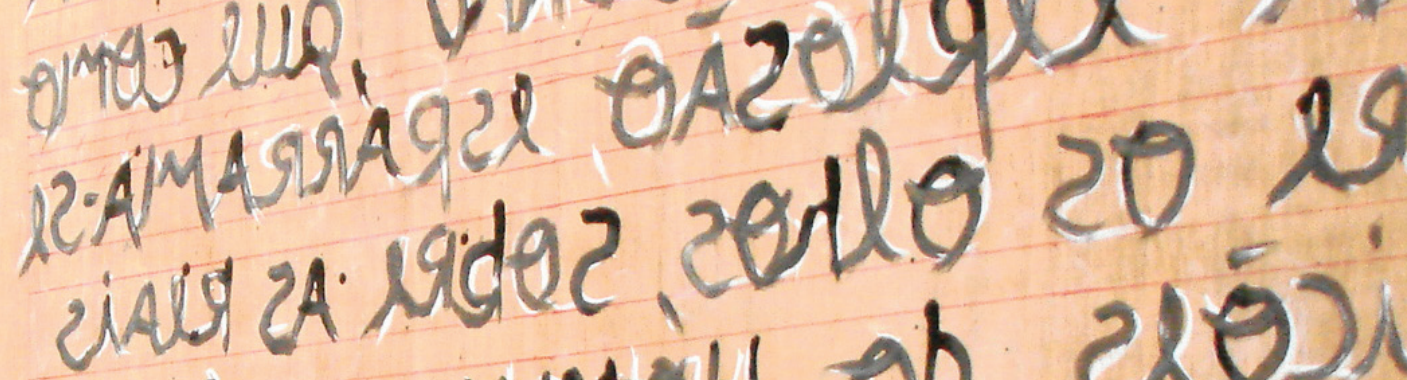

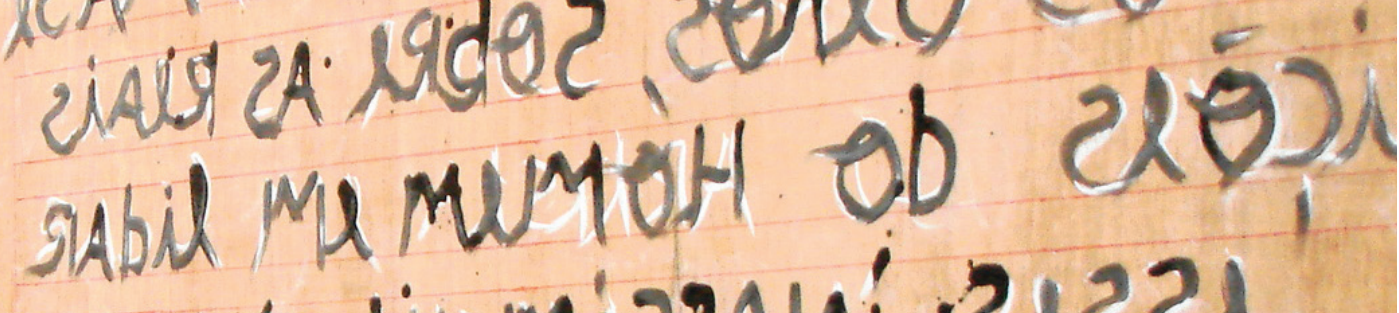
zobet zotismiszan: zic2a

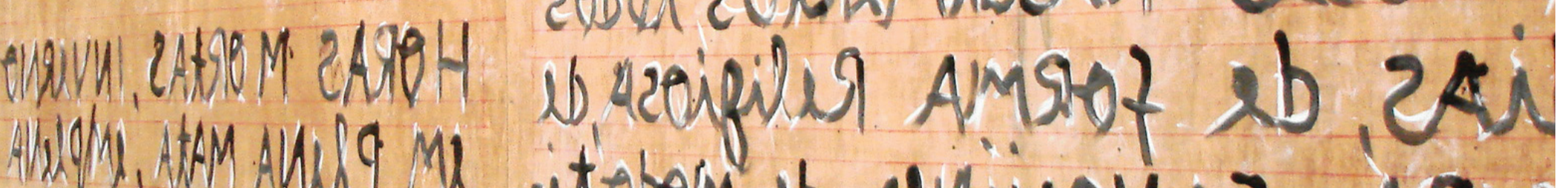

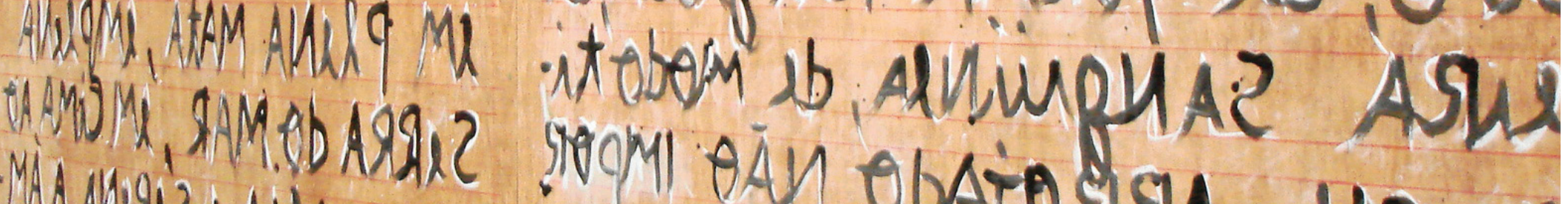

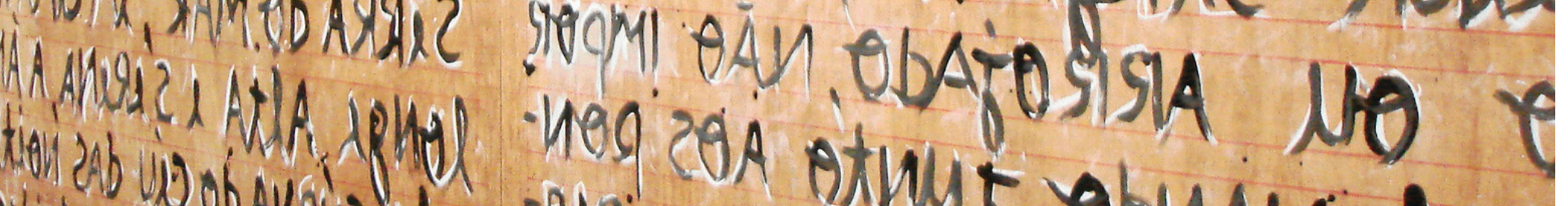

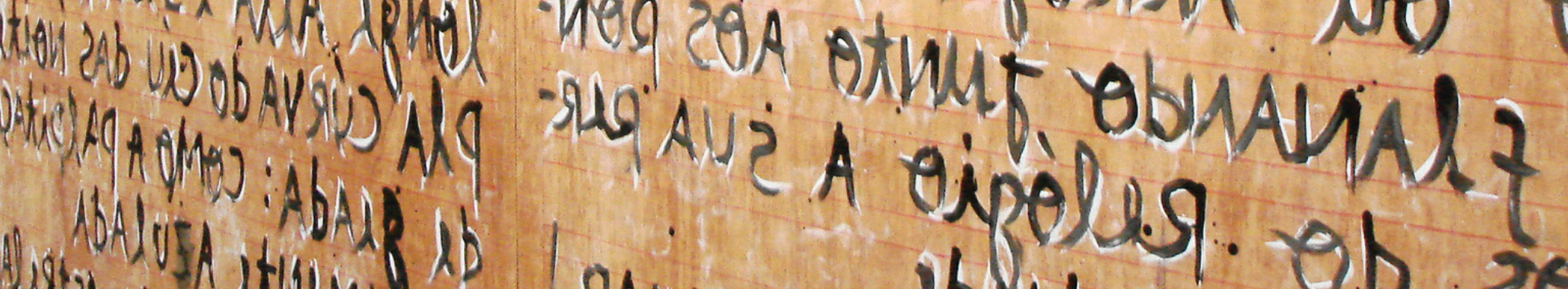

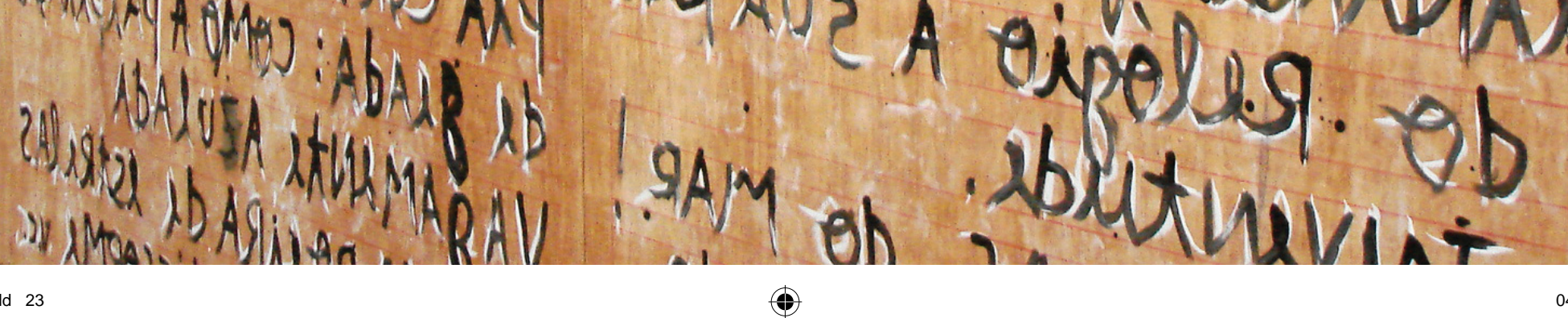


"A felicidade de percorrer a serra, ir ao encontro de algo familiar, a mudança da luz, temperatura, humor, os pensamentos desaguam no estuário e o mar está mais próximo, ecoando sua presença de sal, de corpo-universo multidirecional, sem lado, nem cima ou baixo" 


\section{1}

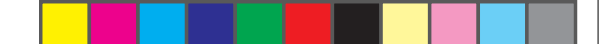
- $1+x^{2}$

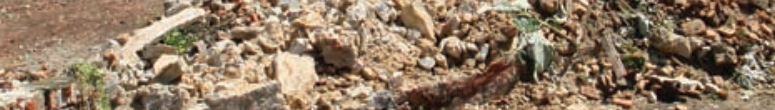

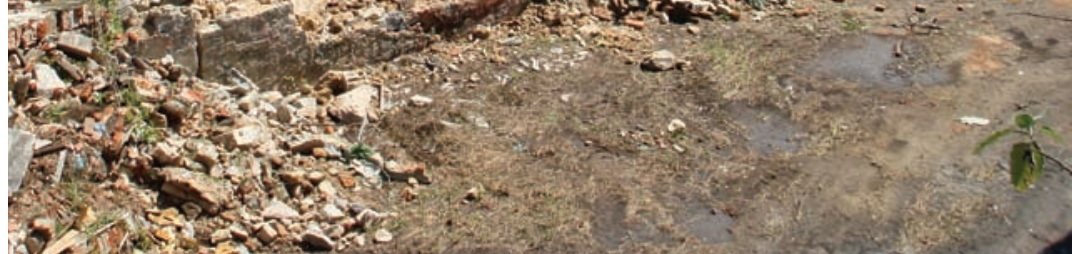

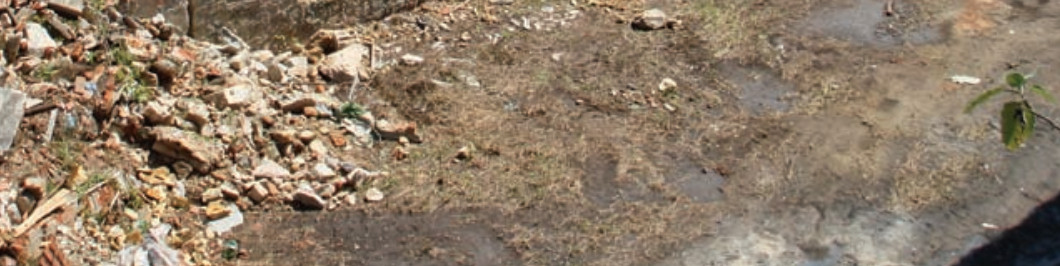

T.4.

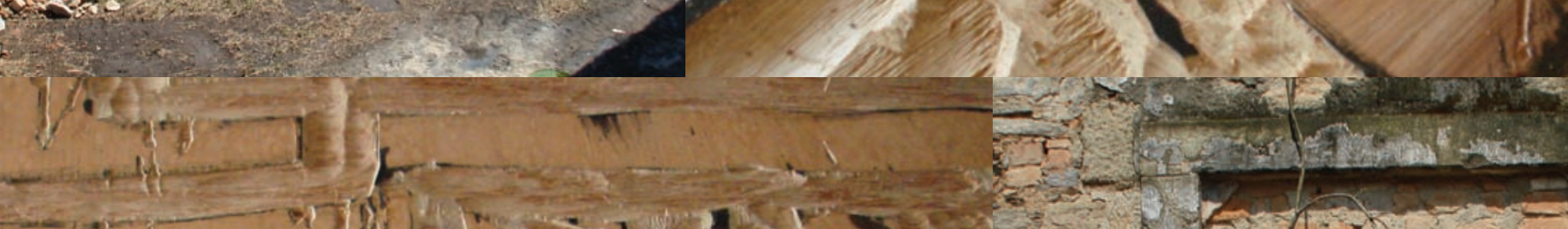

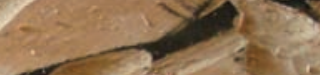

E-

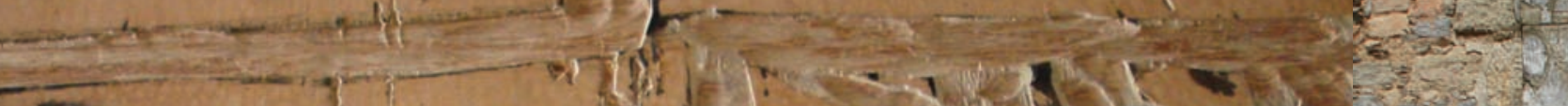

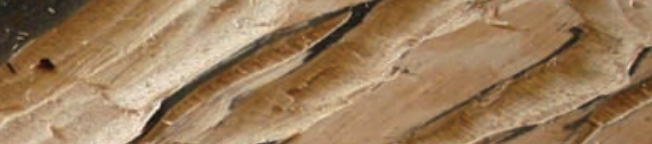

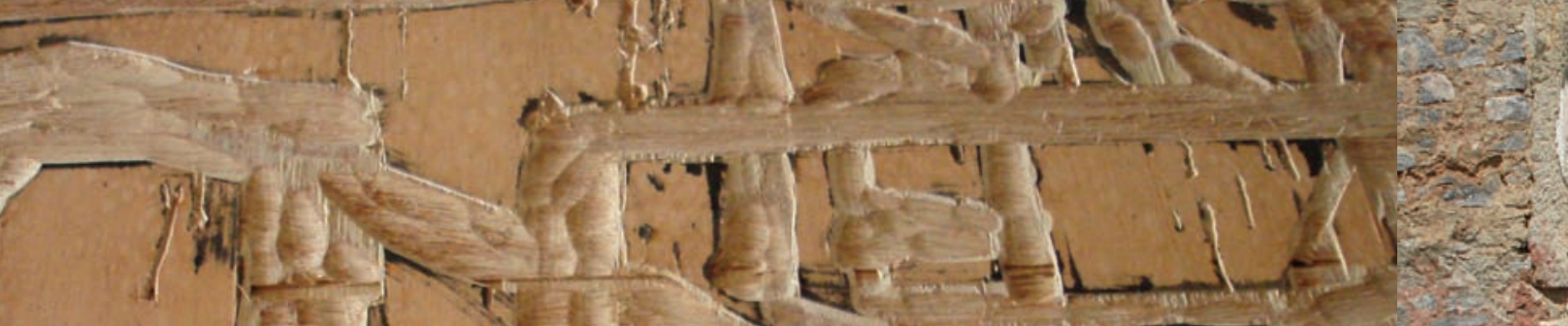
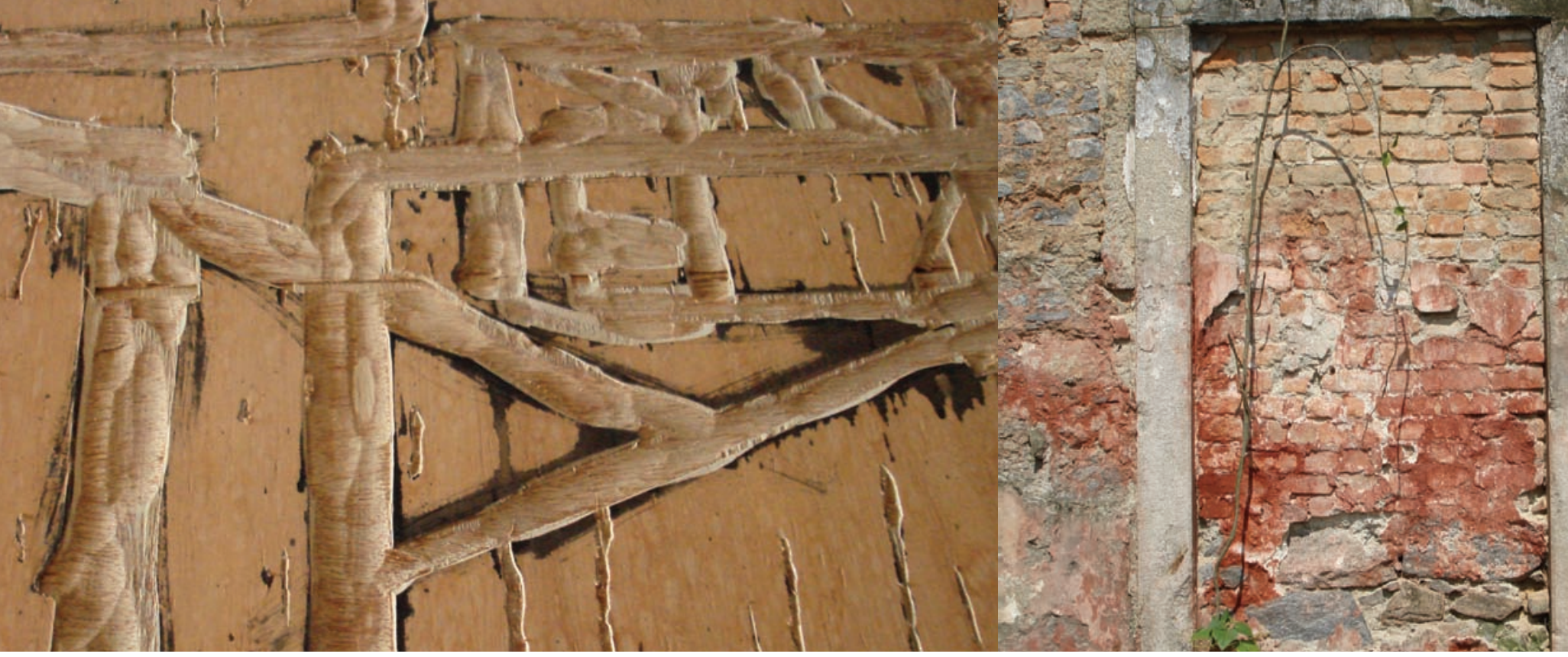


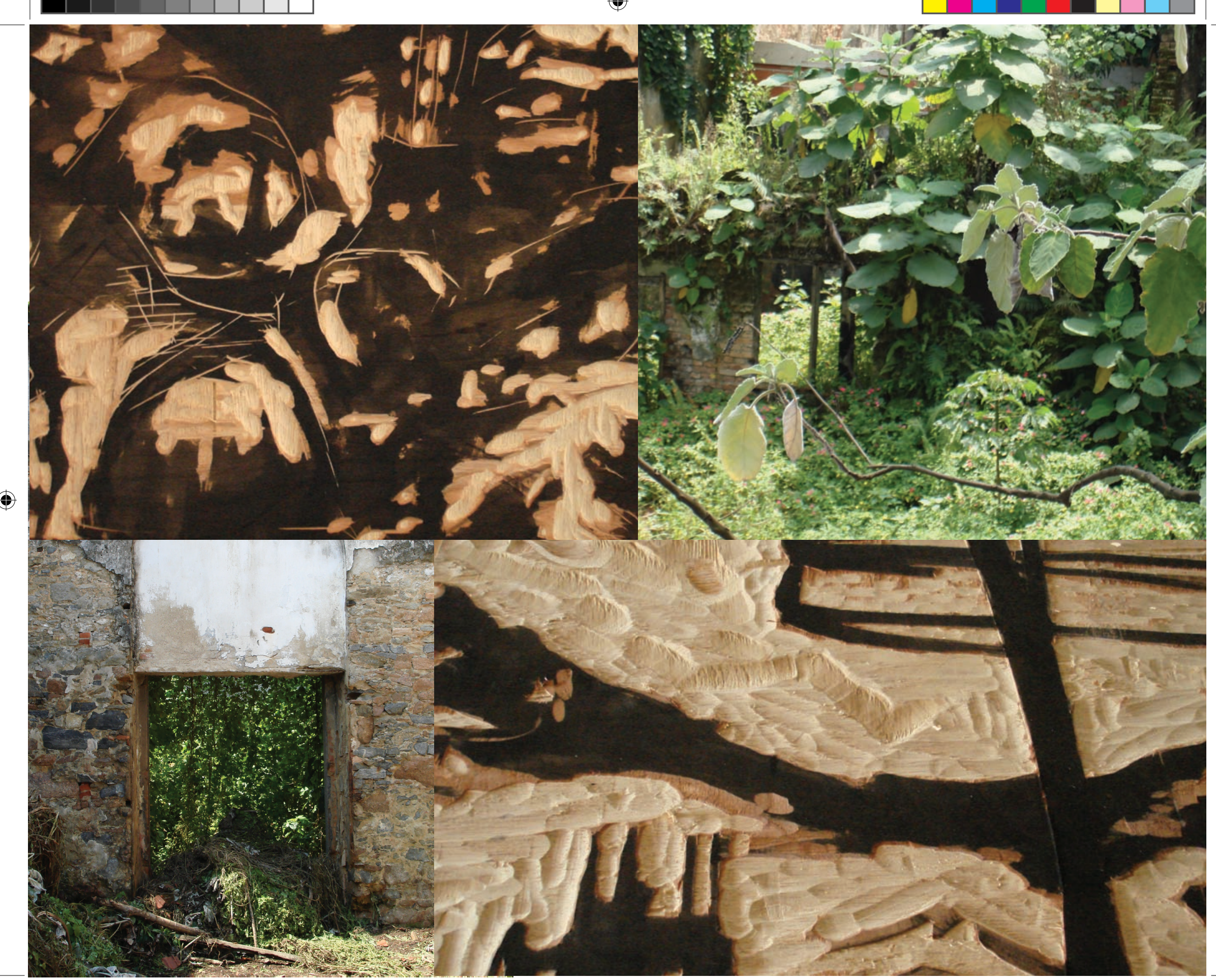




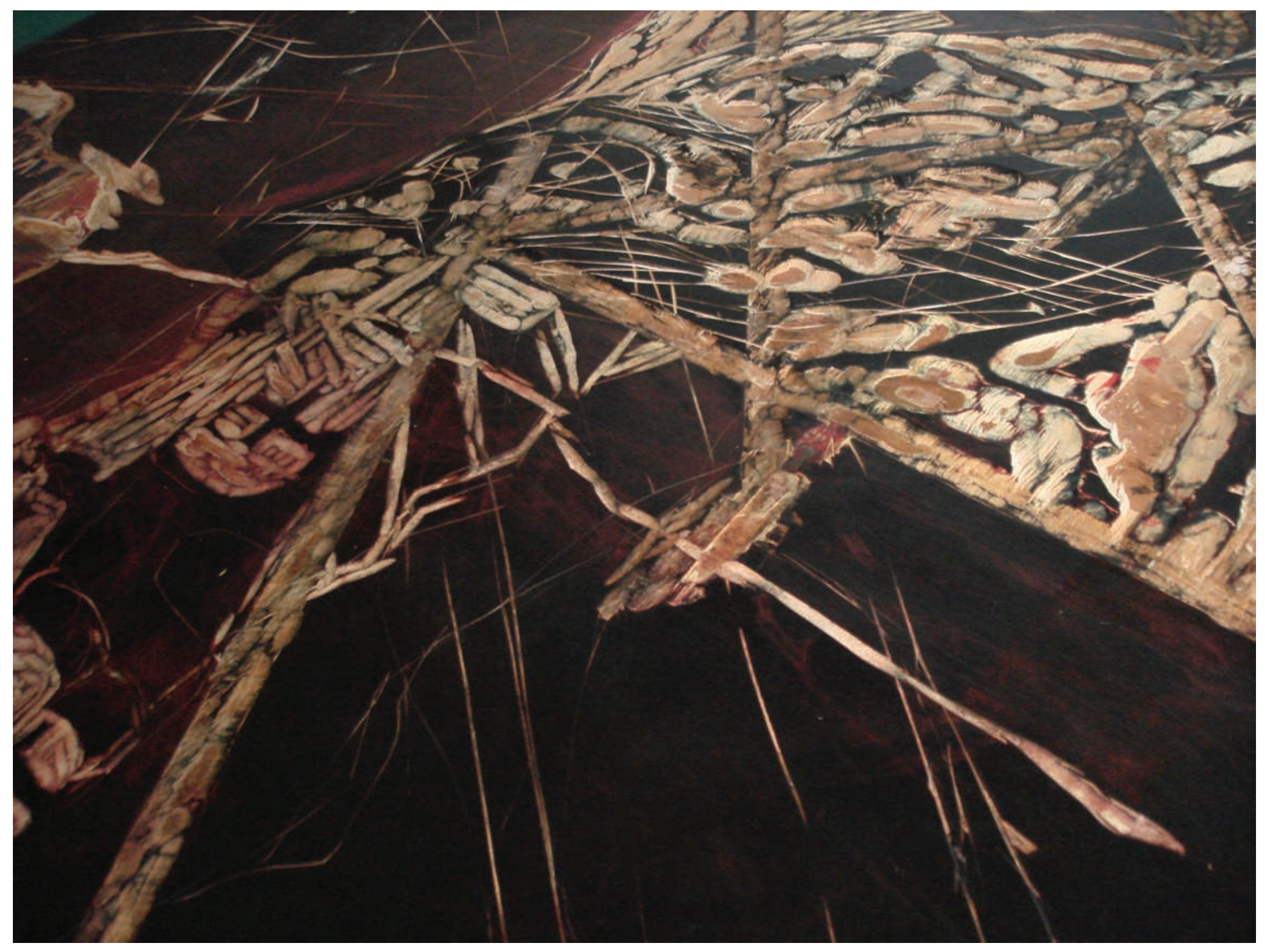



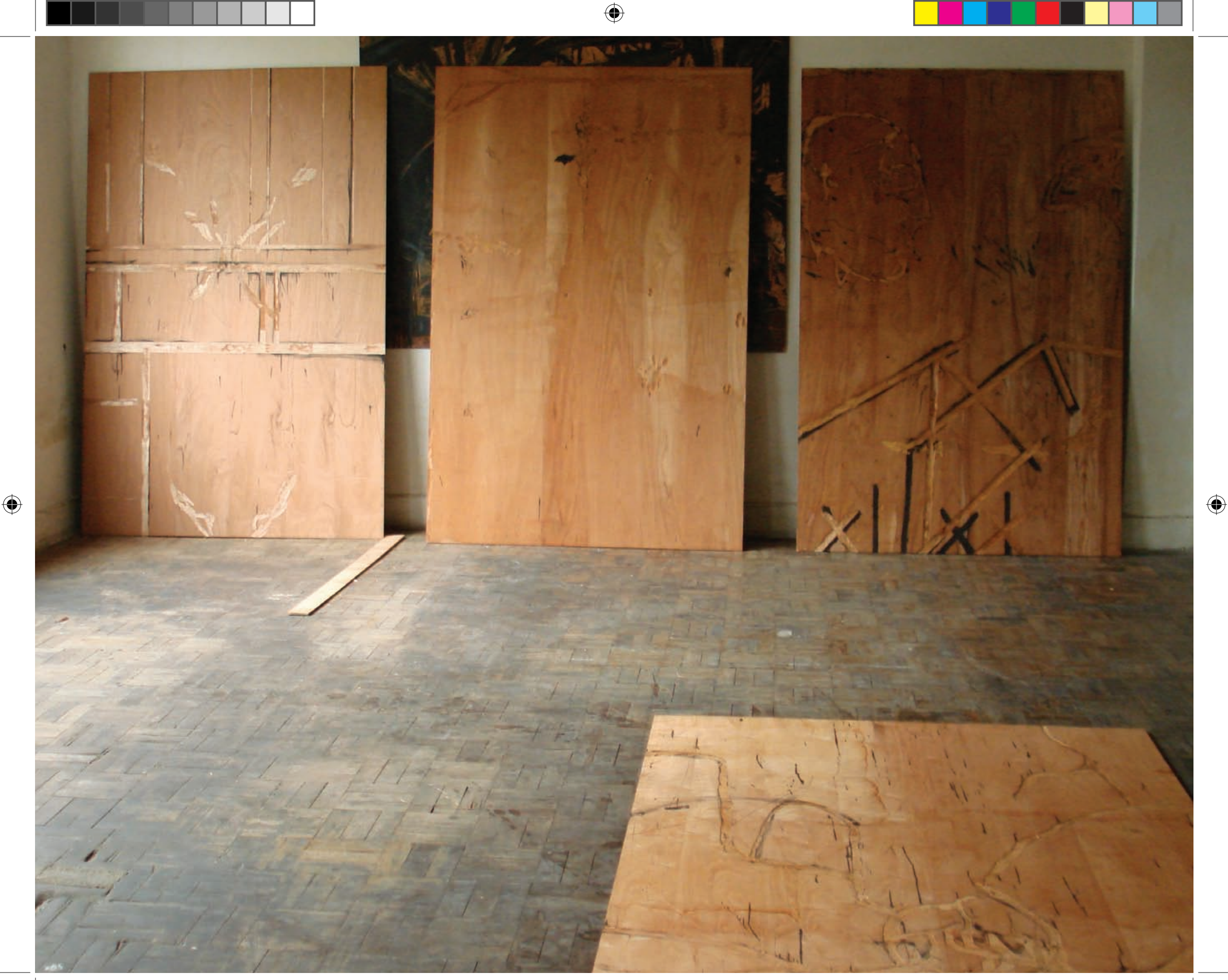


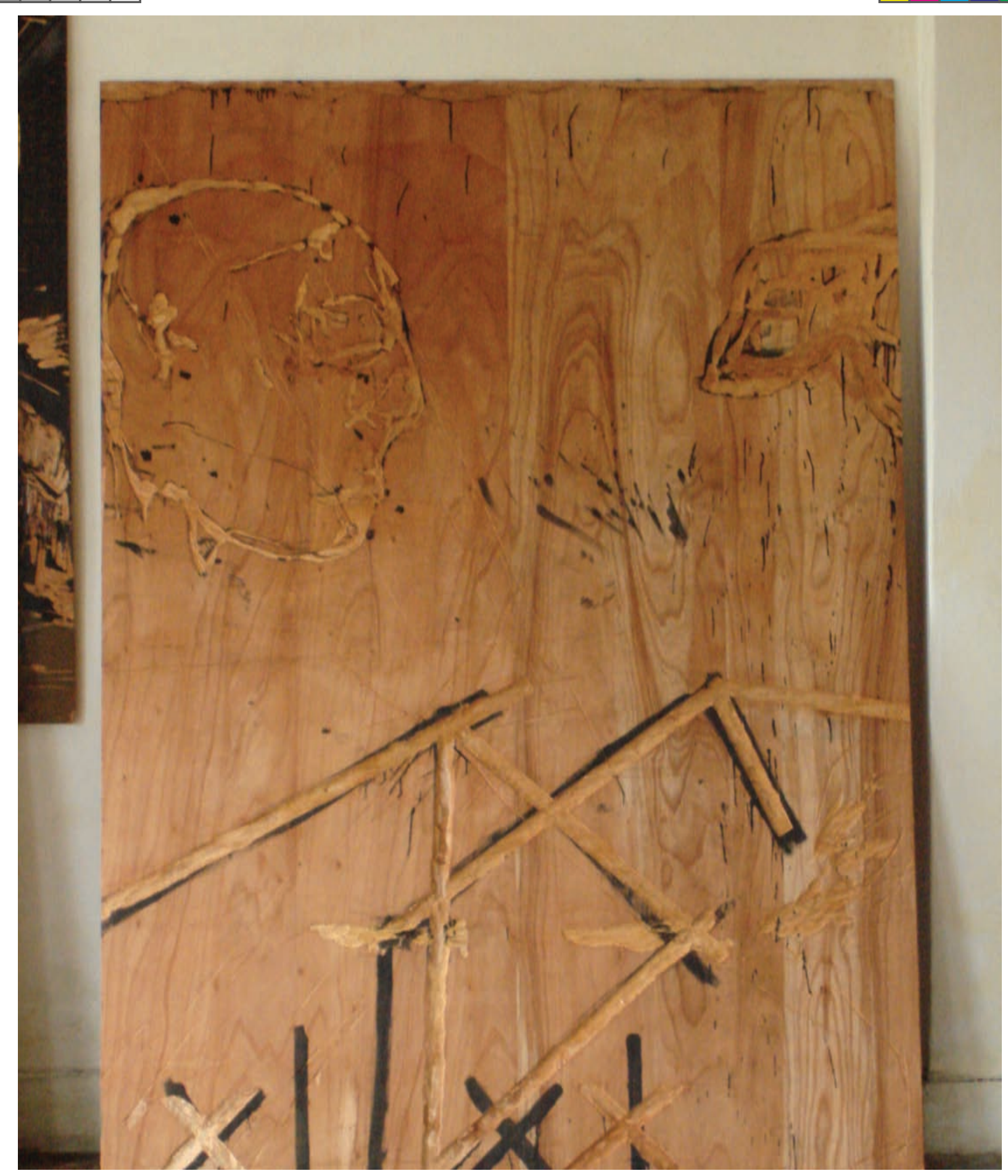




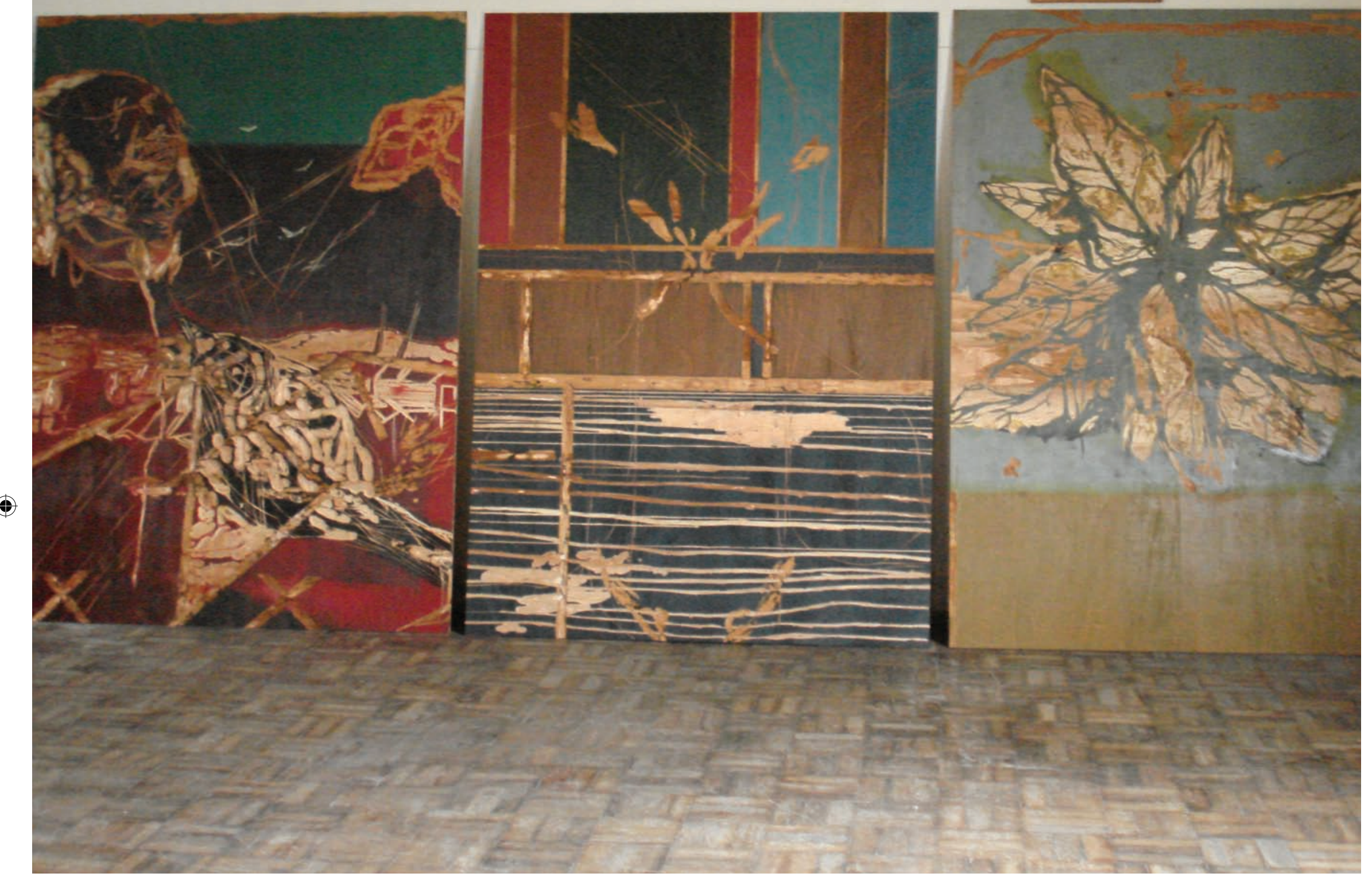



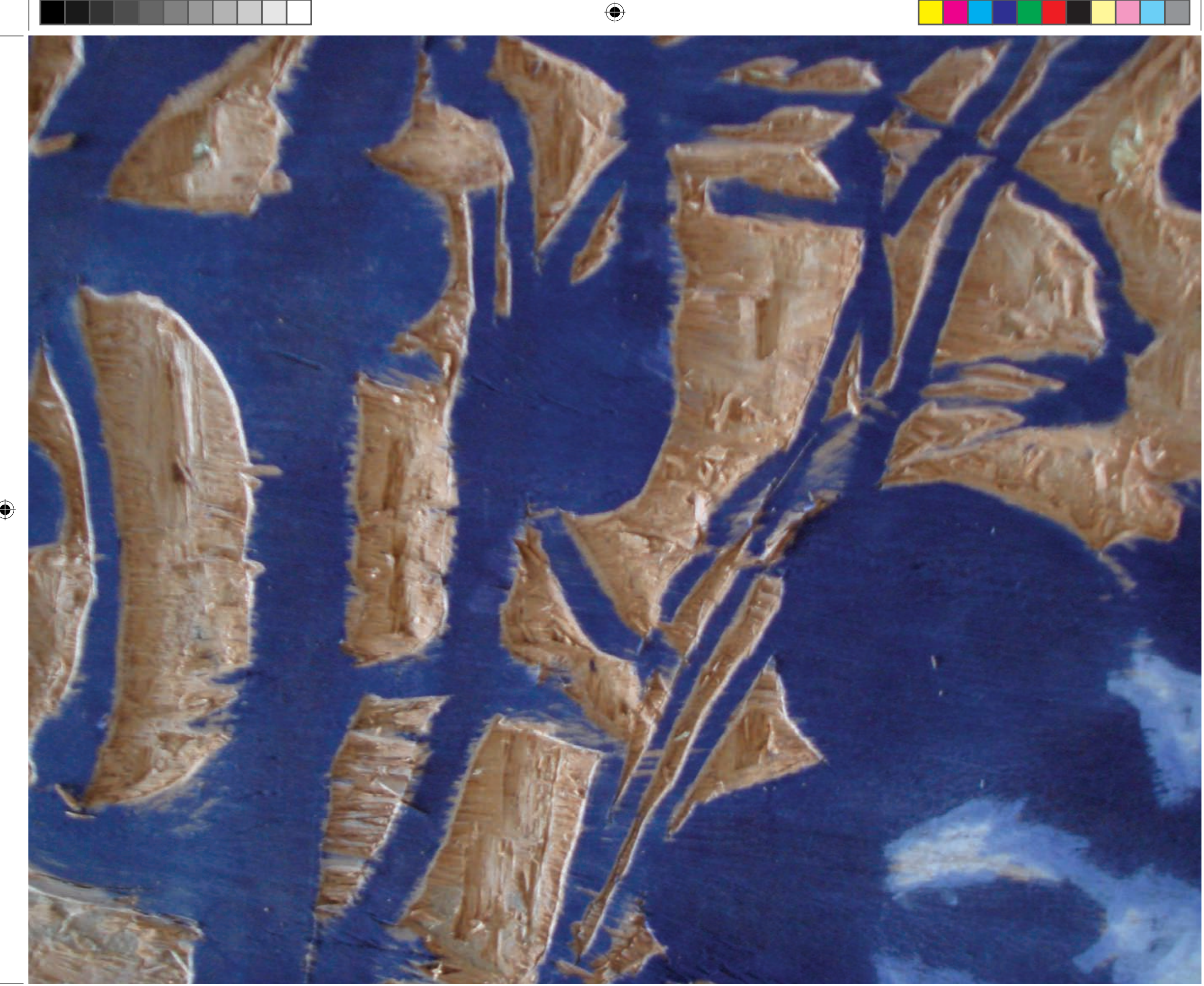


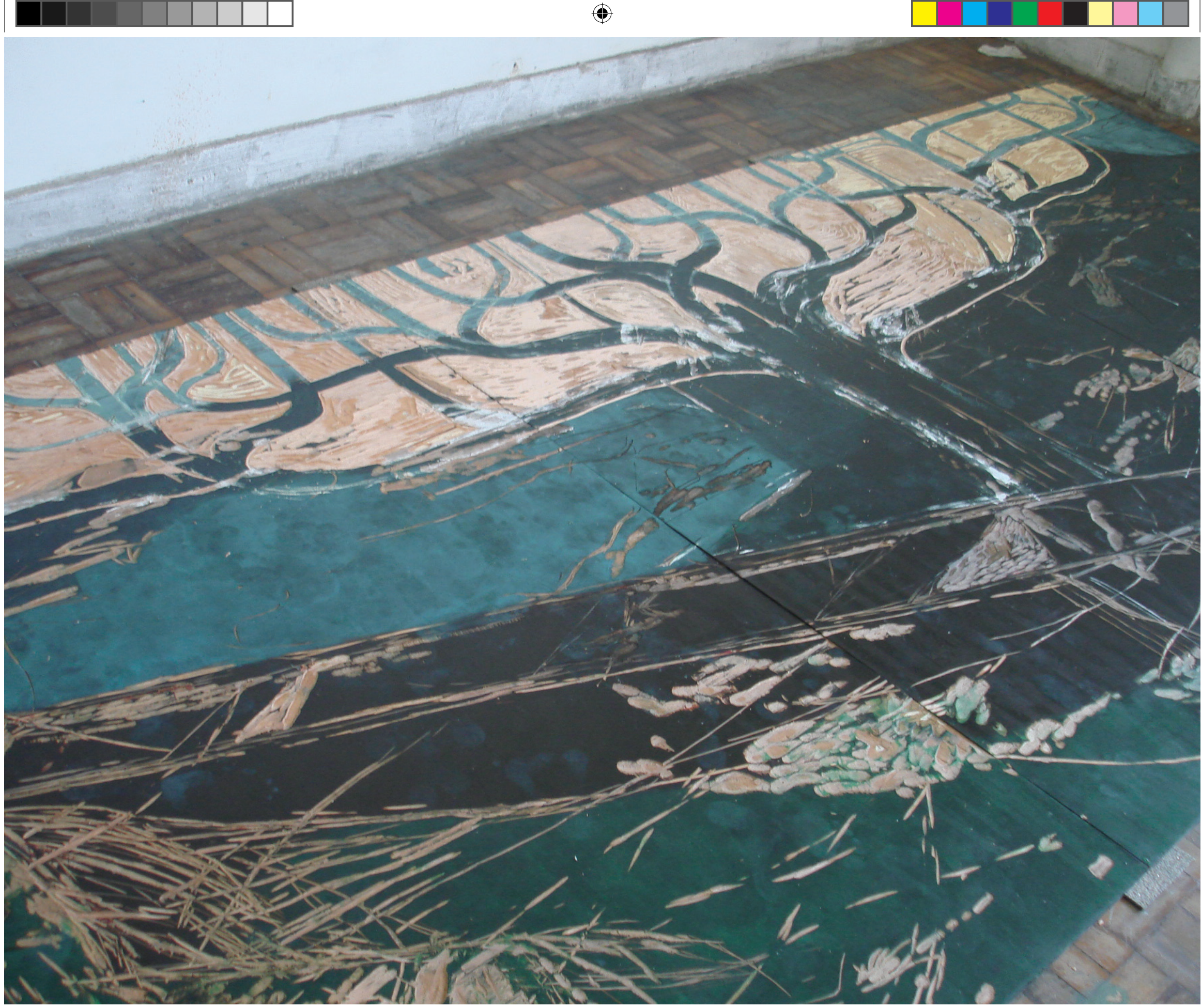


- NAVEGAÇÃO DE CABOTAGEM - rema, rema, remador

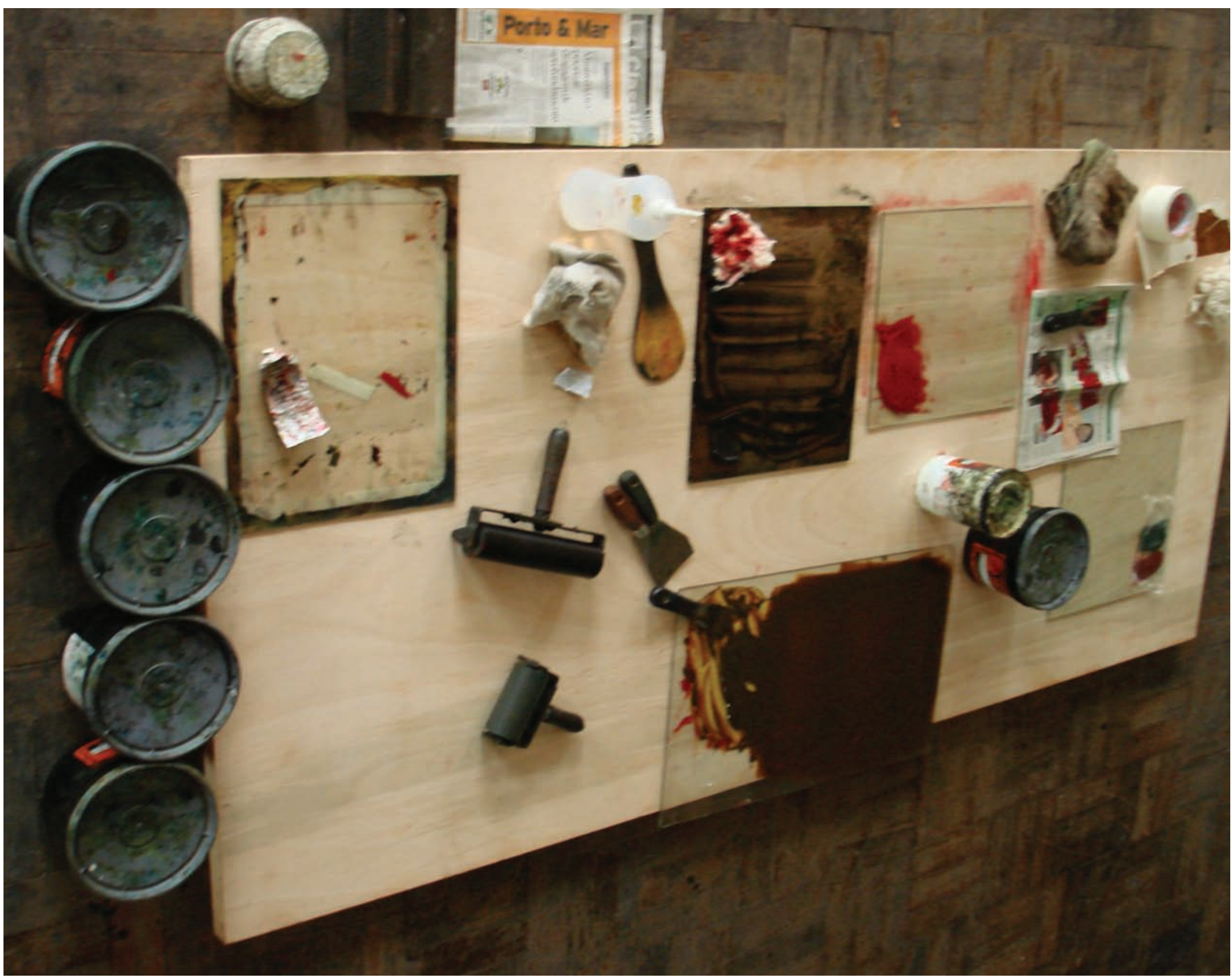



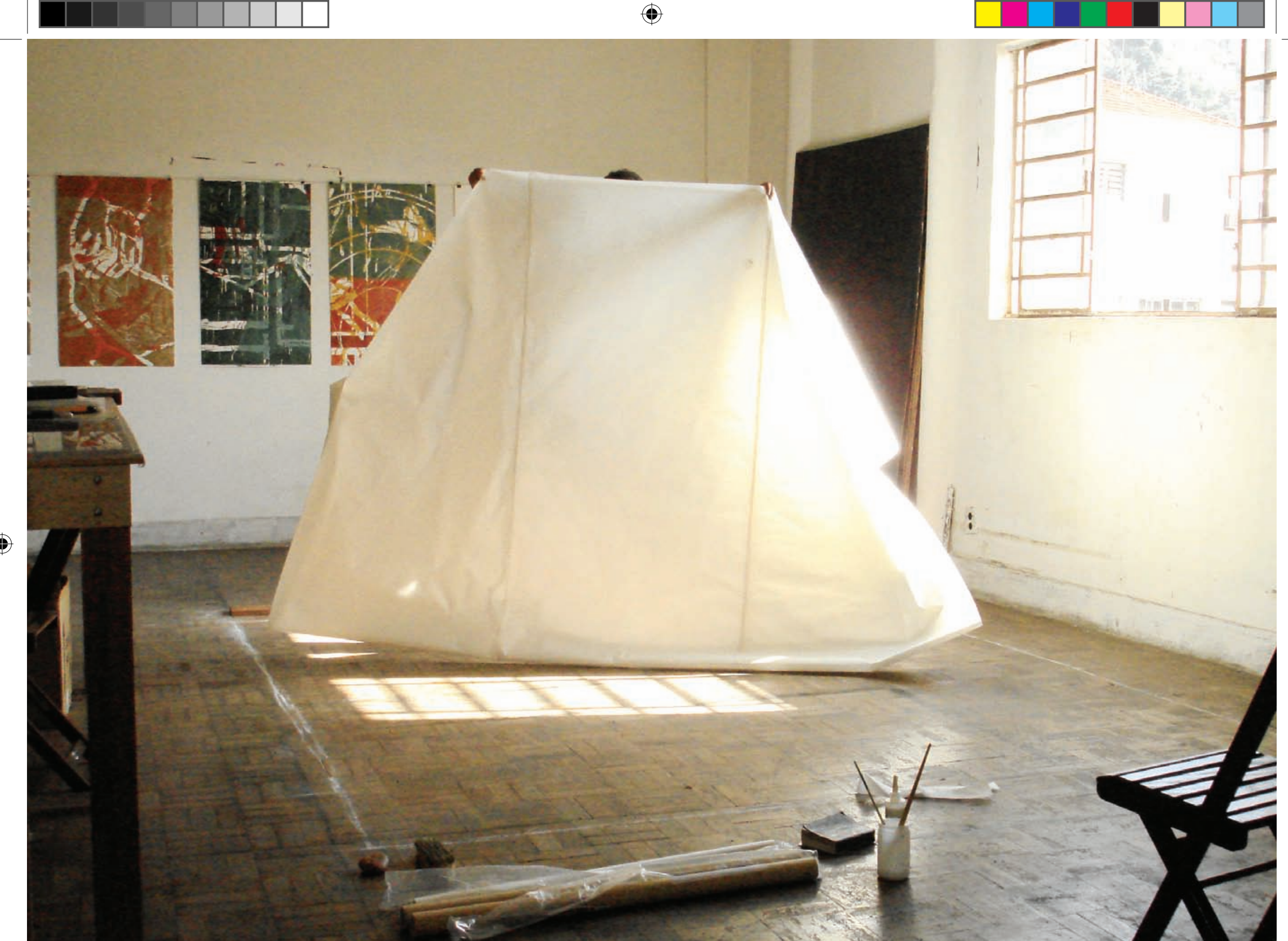
"A mecânica do papel - a sobreposição de camadas, impressões retiradas de diversas matrizes de madeira fazem o papel trabalhar até o limite. As fibras reagem no vinco e no rasgo da cor, compondo o painel como uma vela de barco impressa. Não é possível domar o papel, é preciso dançar com ele...

0 esforço necessário para conseguir extrair da madeira a presença da ação estampada no corpo do papel.

Percorrer um campo, uma salina, um deserto branco contraindo-se, despejando o corpo que respira sem horizonte.. no fim algo perde-se imediatamente, para ser recuperado em outro instante, em outro tempo." 



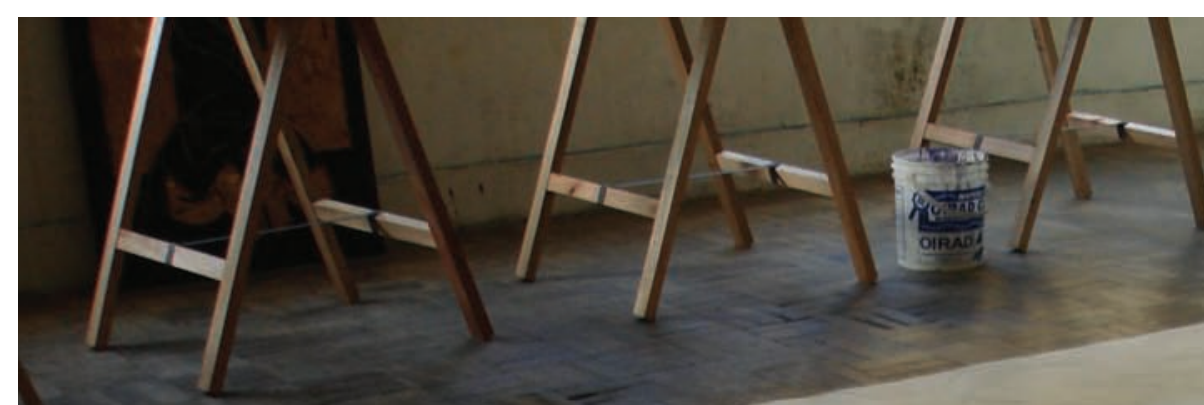

(๑)
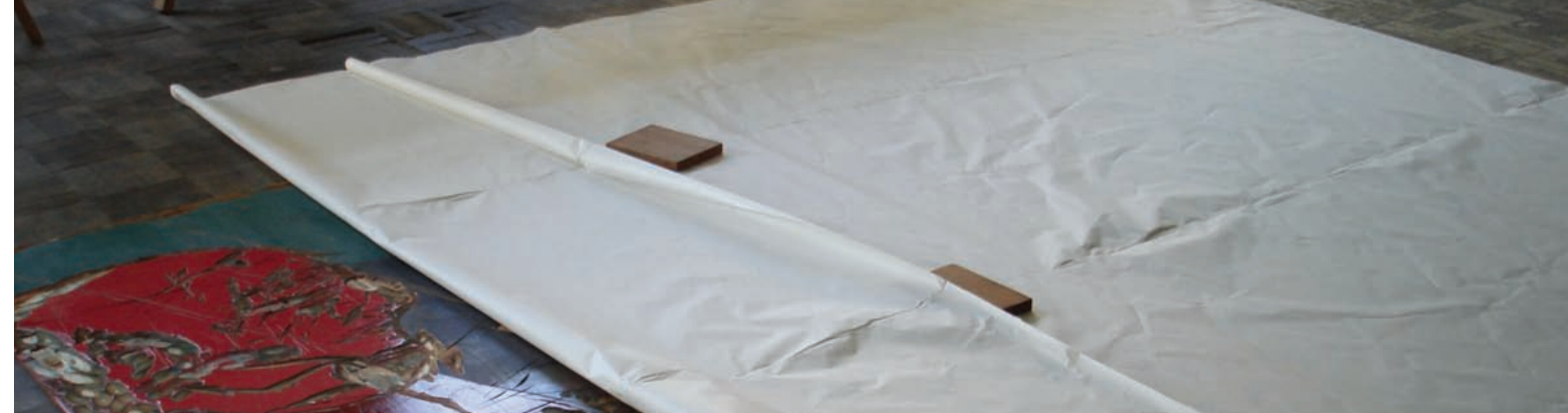

and 


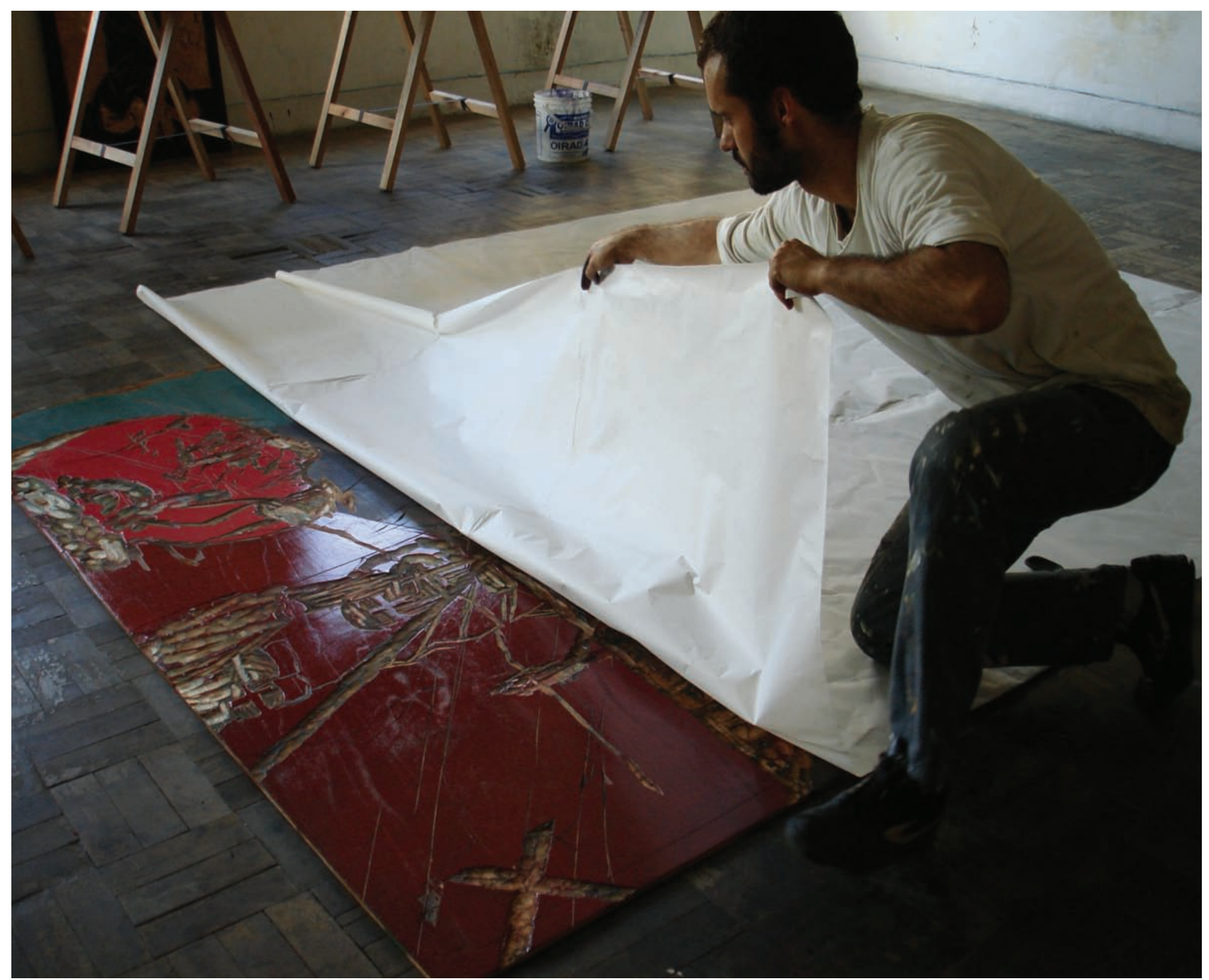



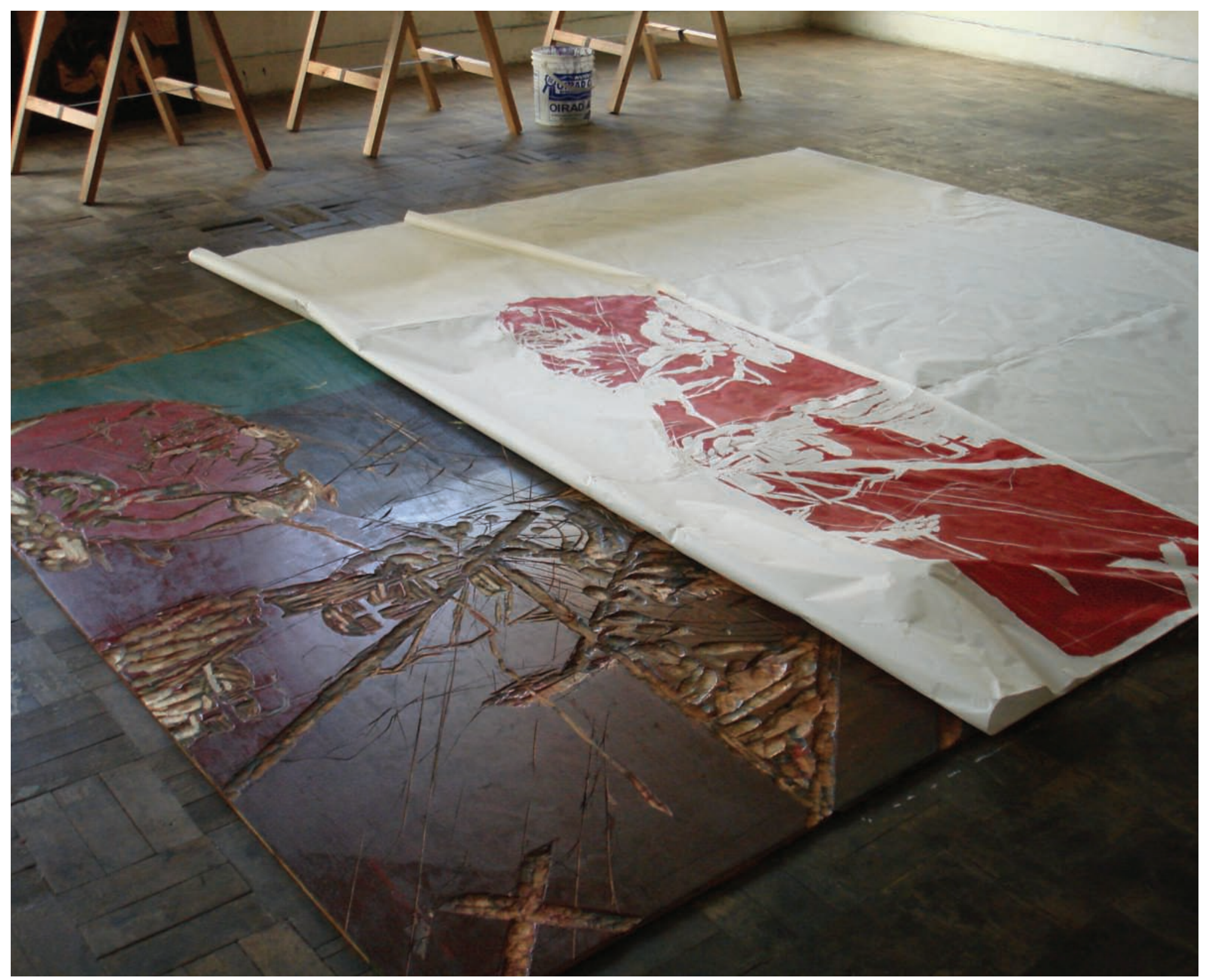


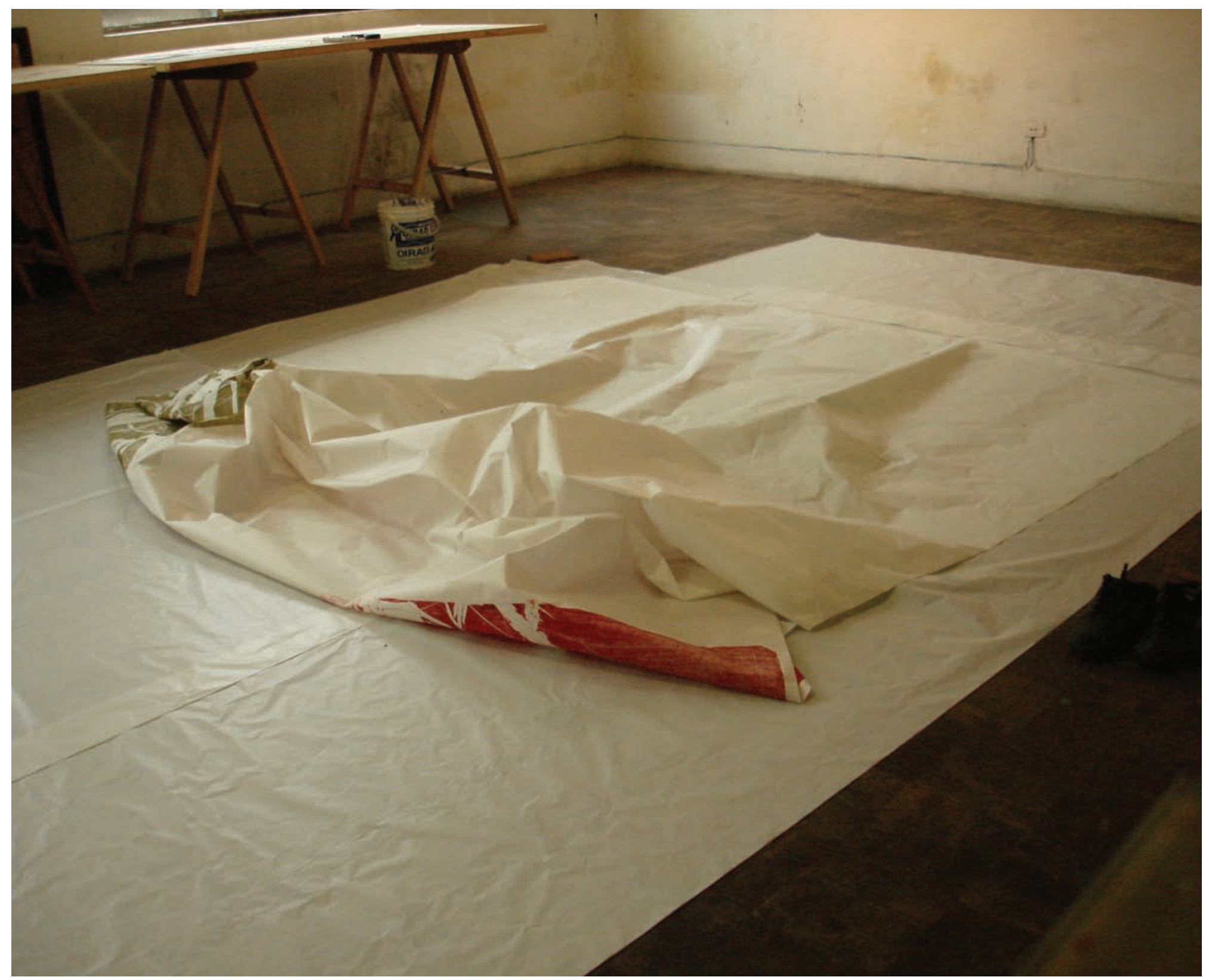




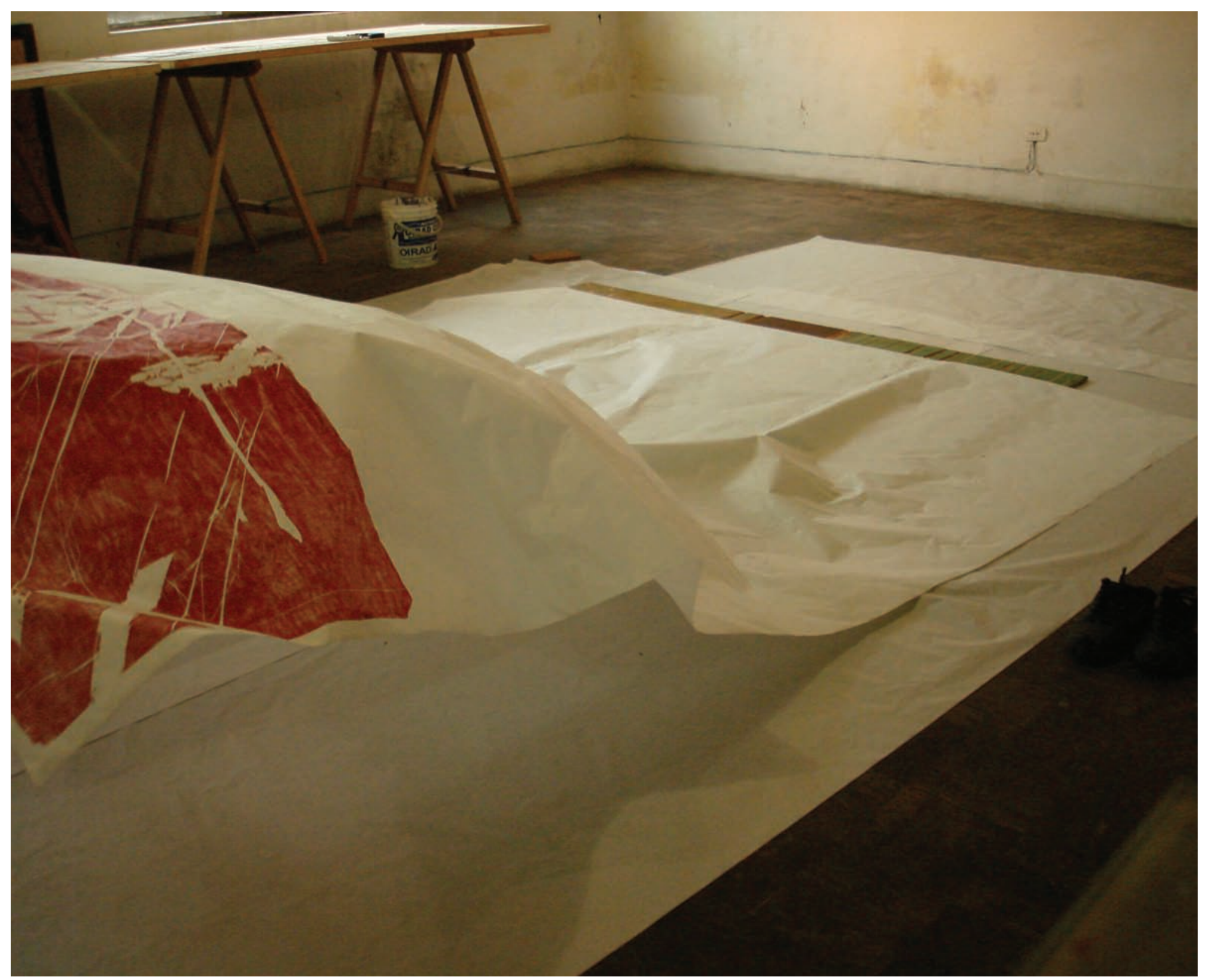

44 


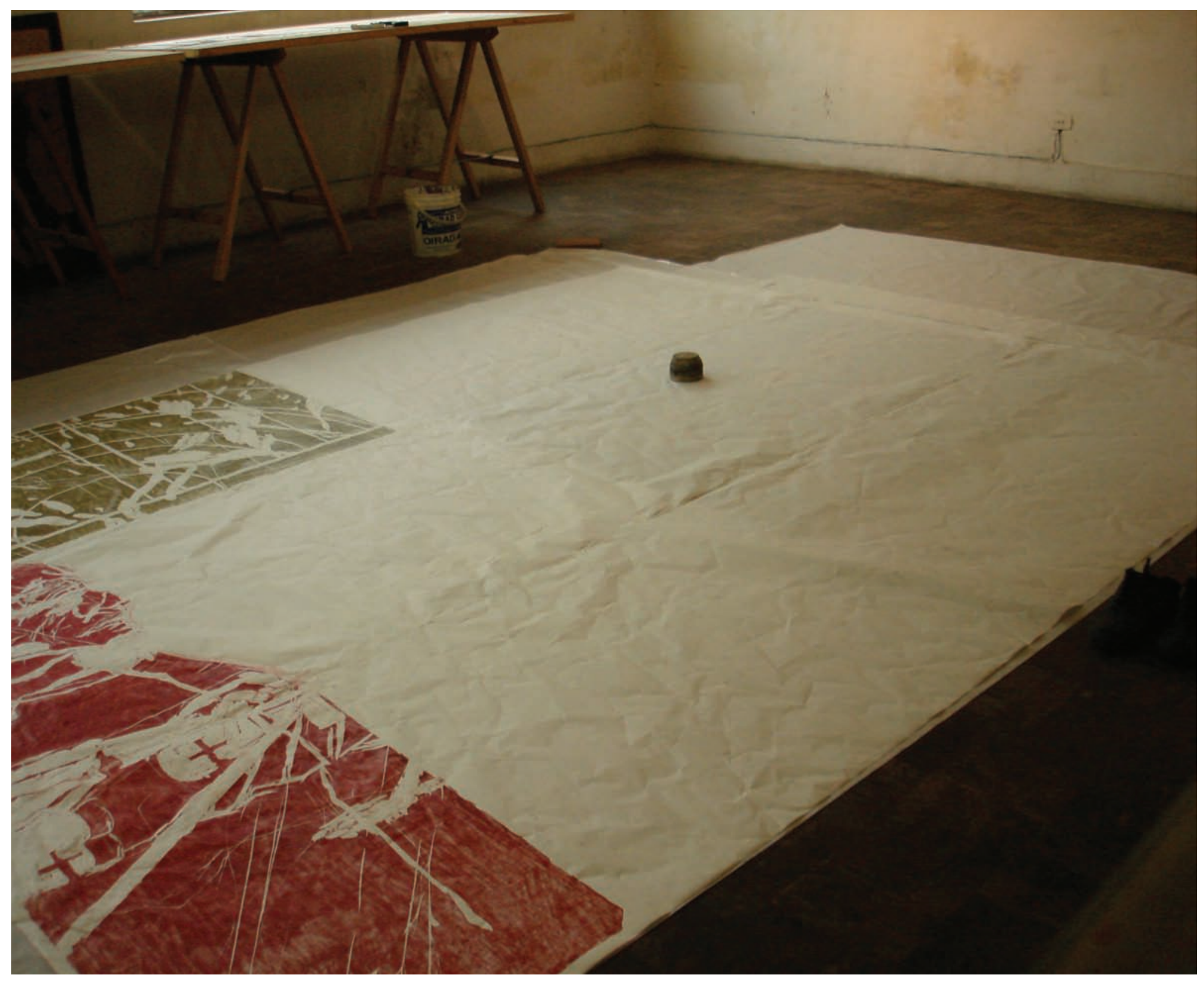




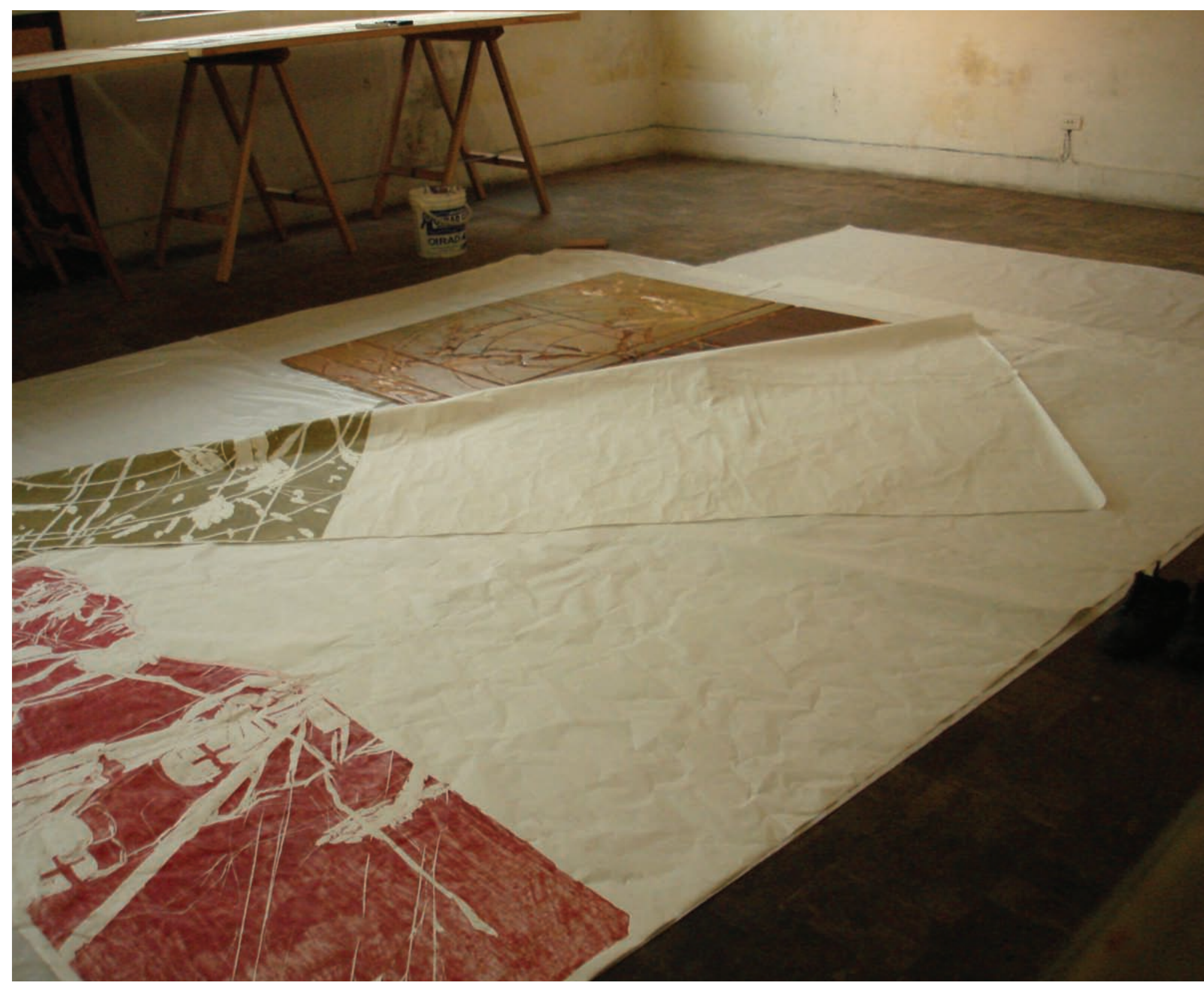

46 


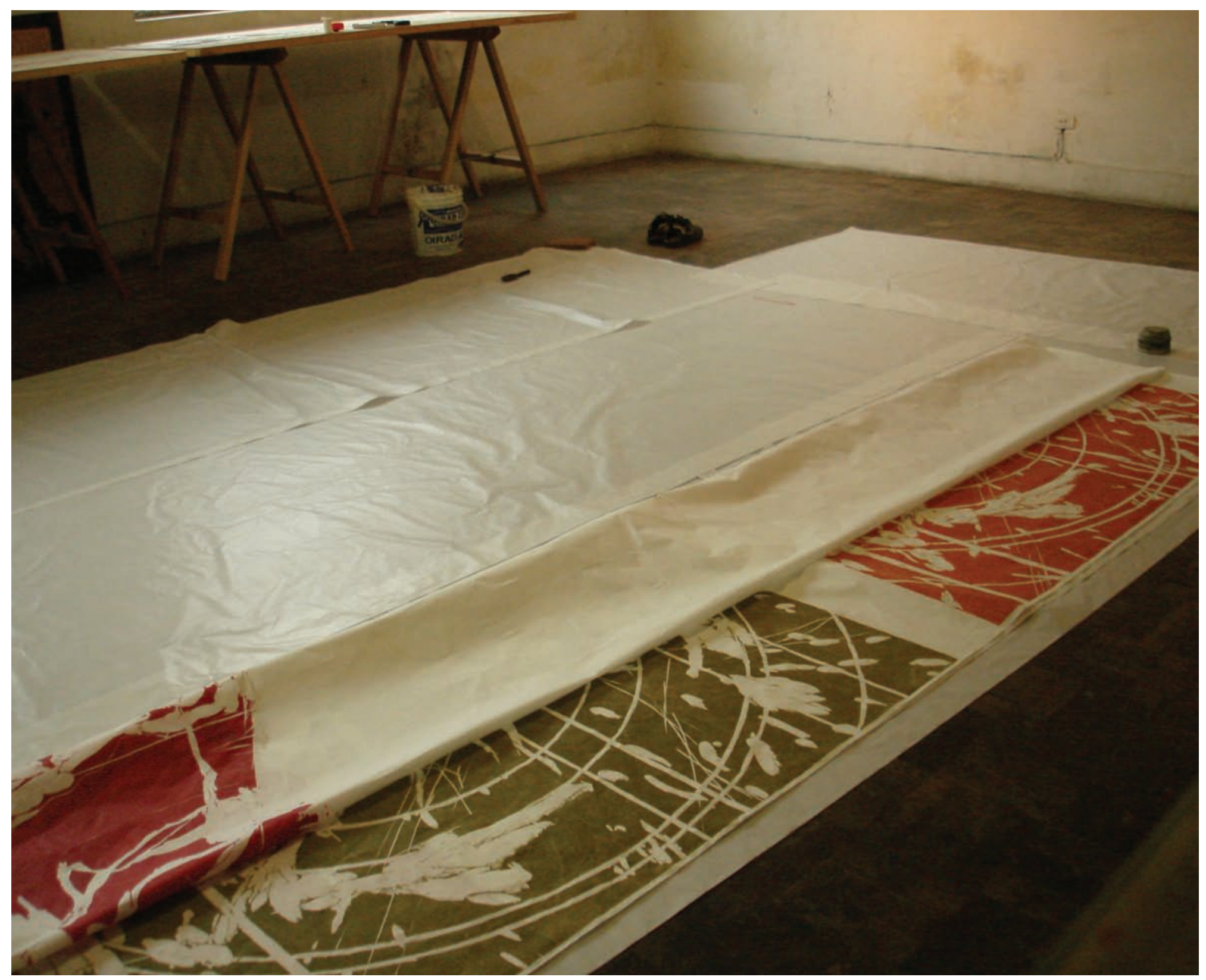




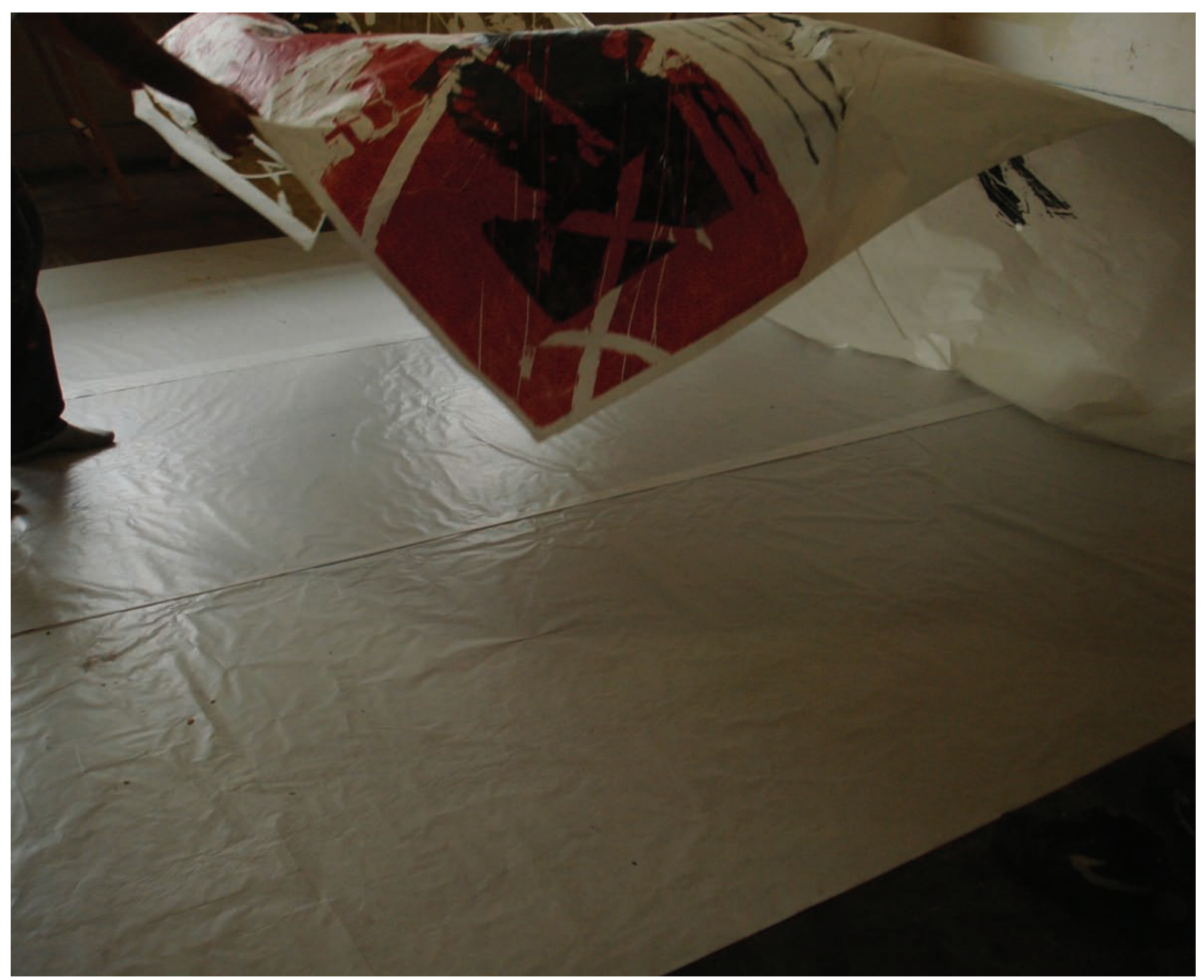




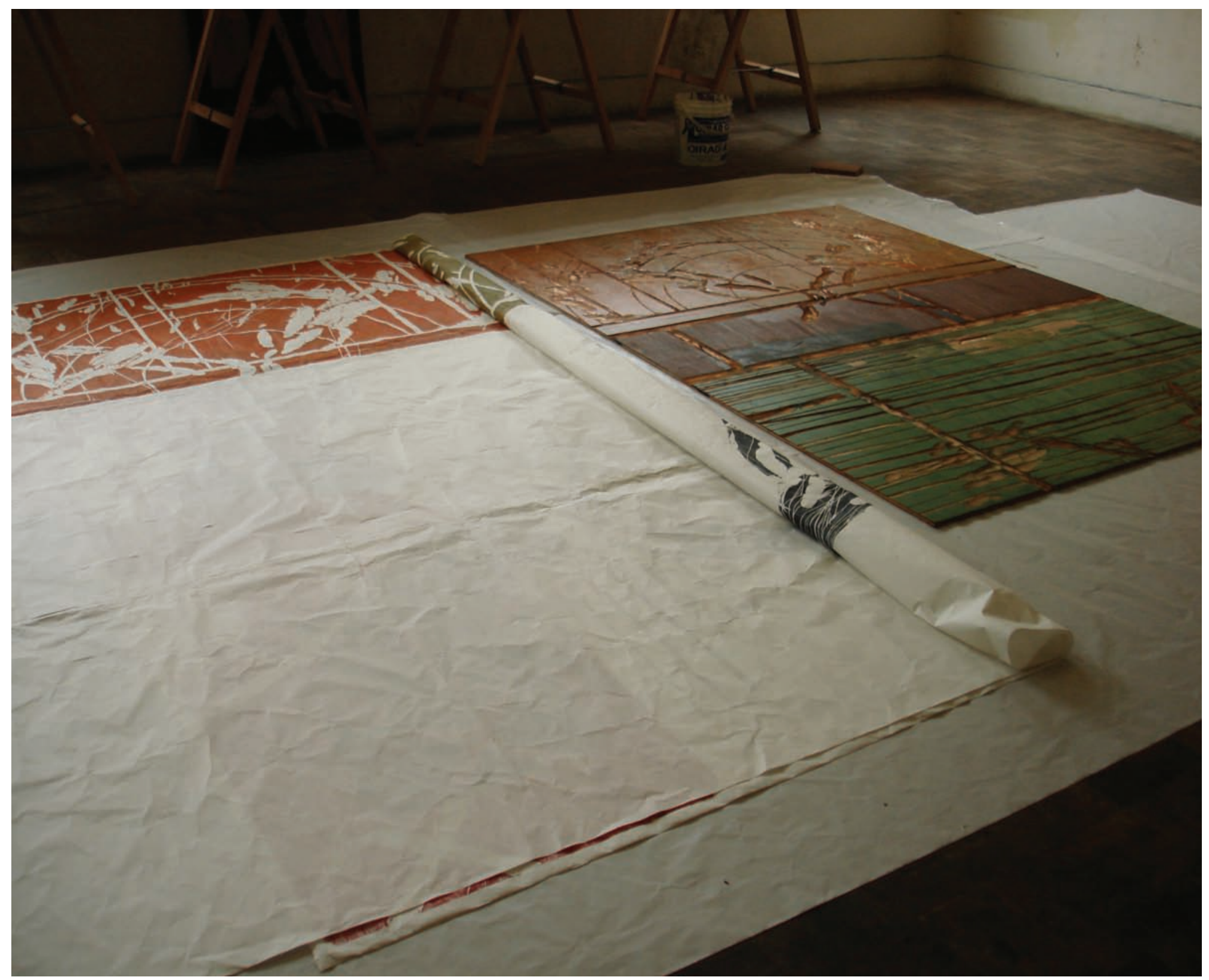




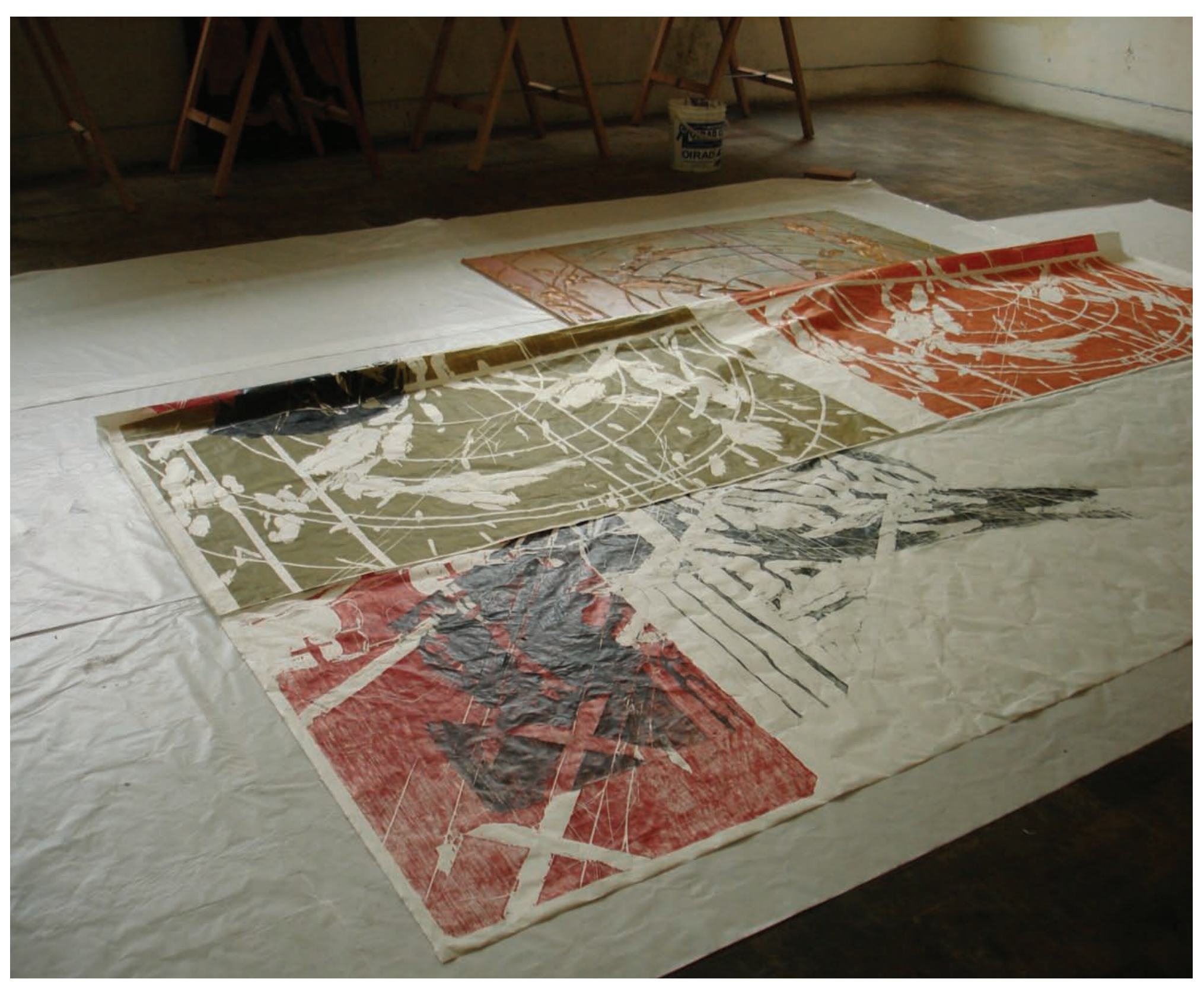




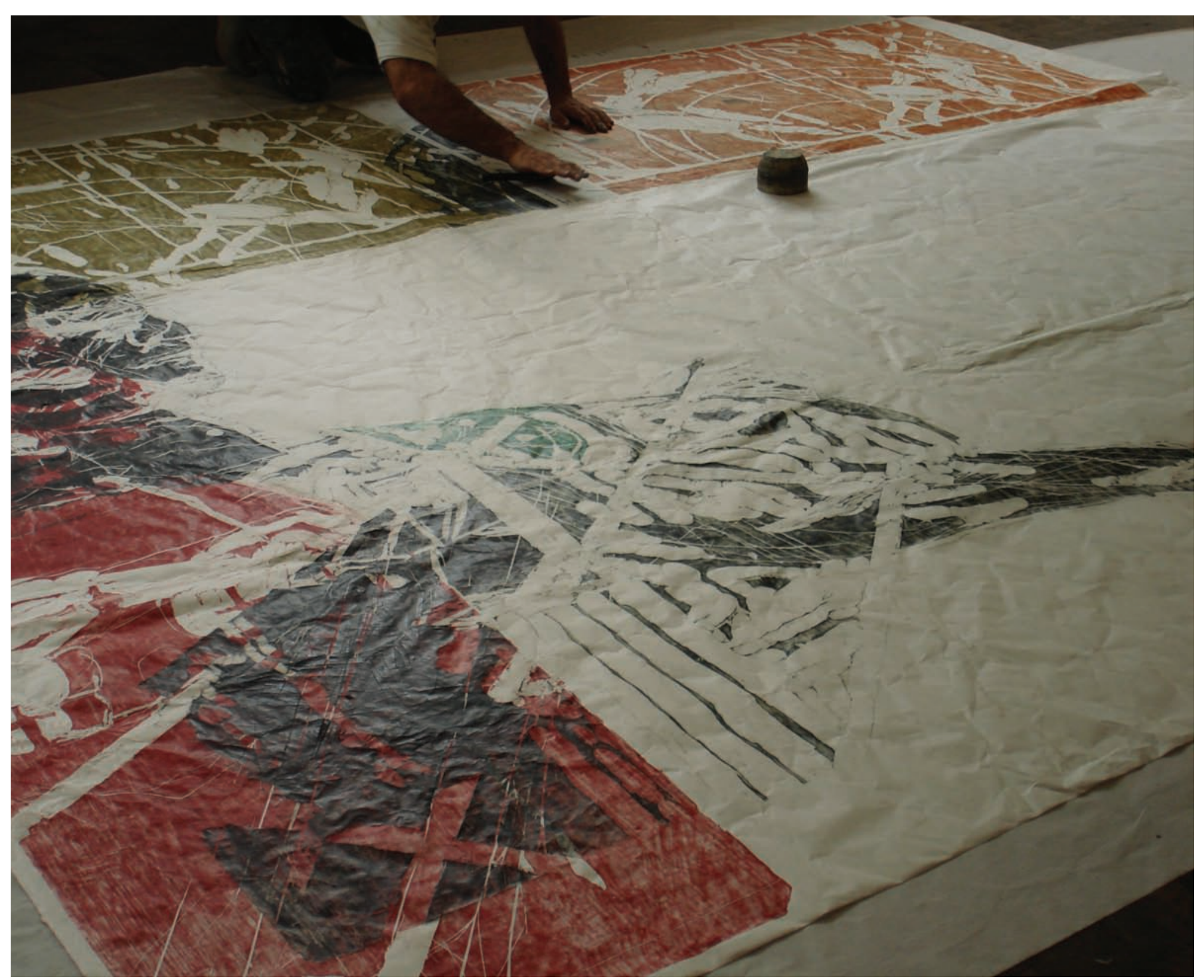




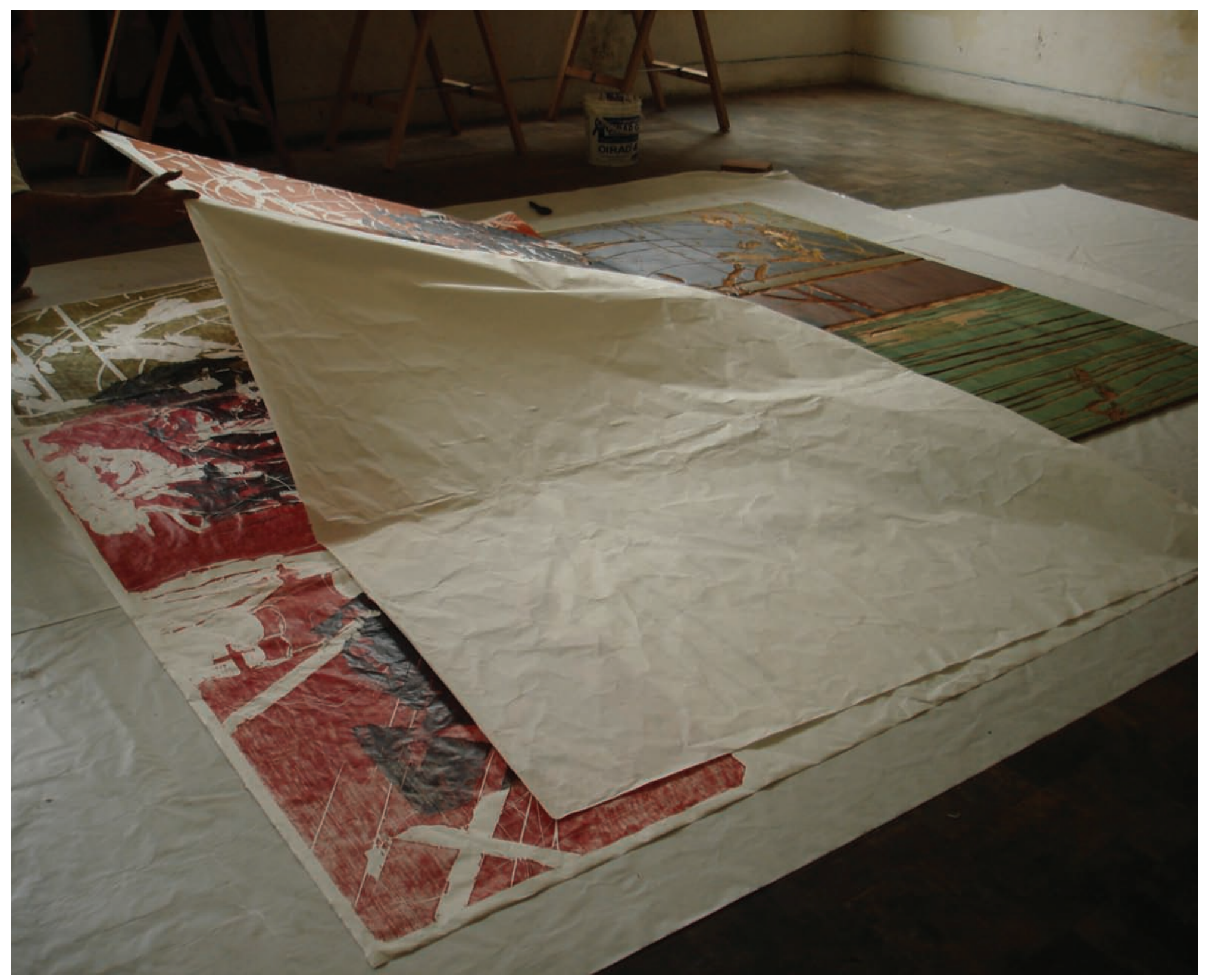




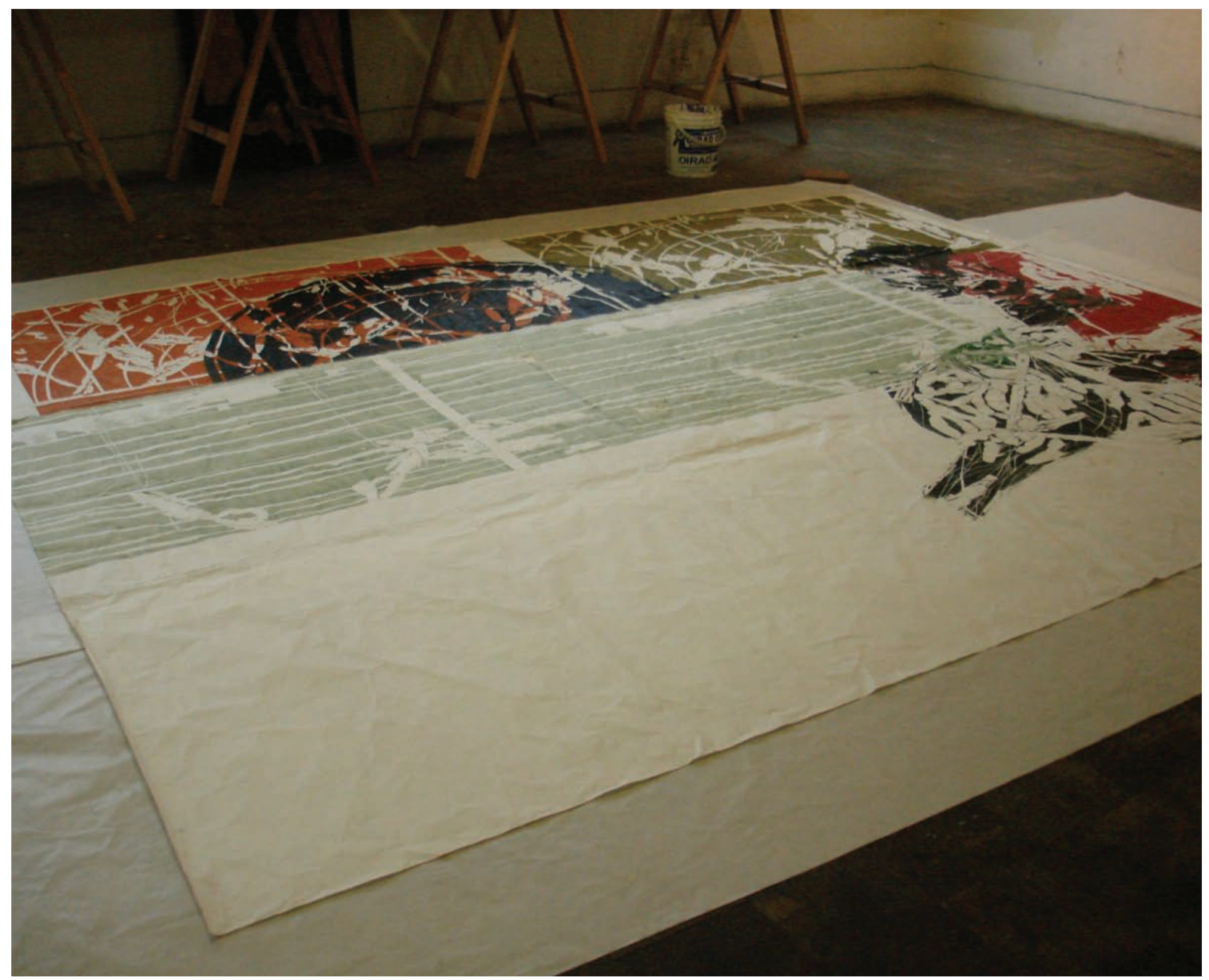




\section{- A SEgUNDA PELE}

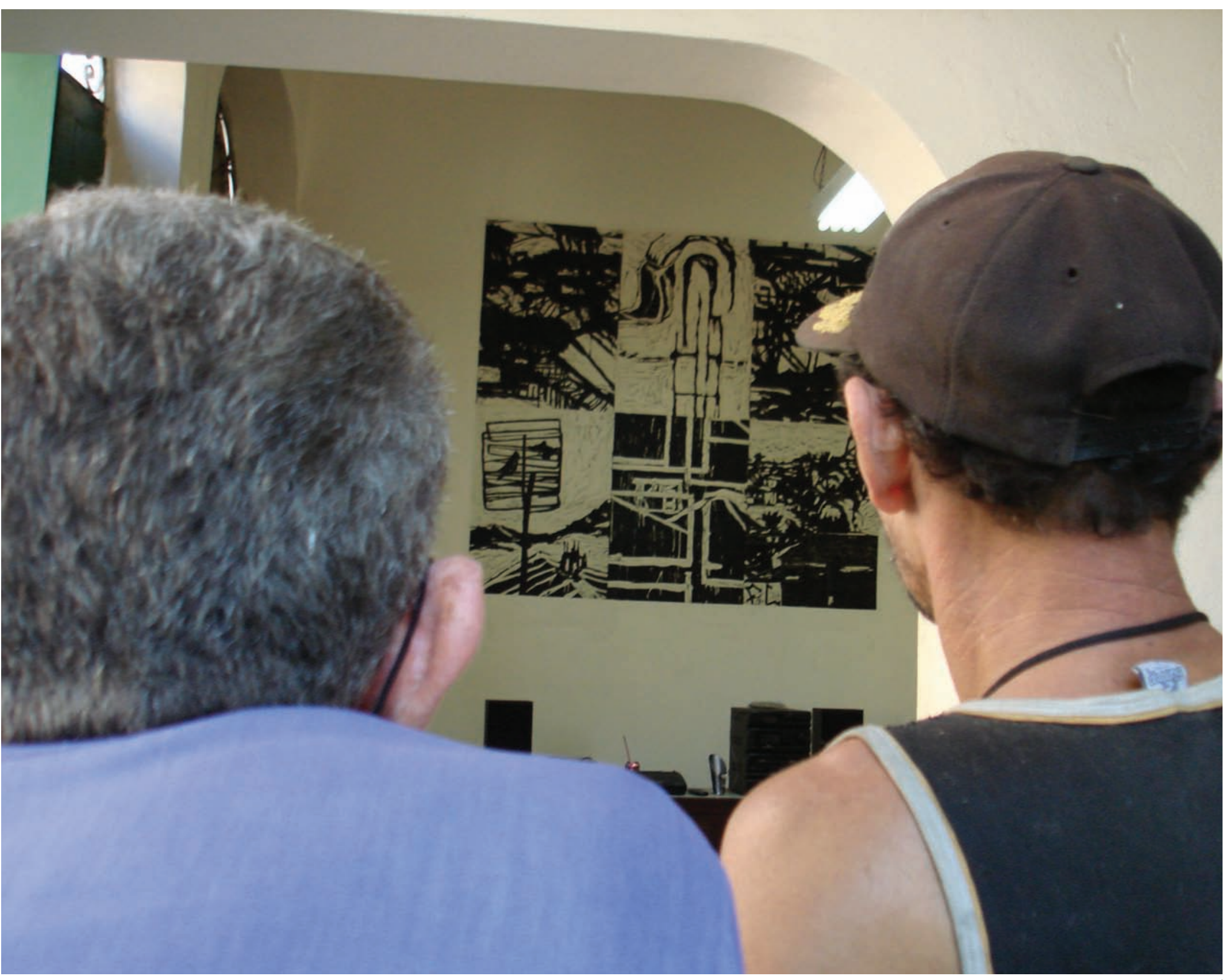




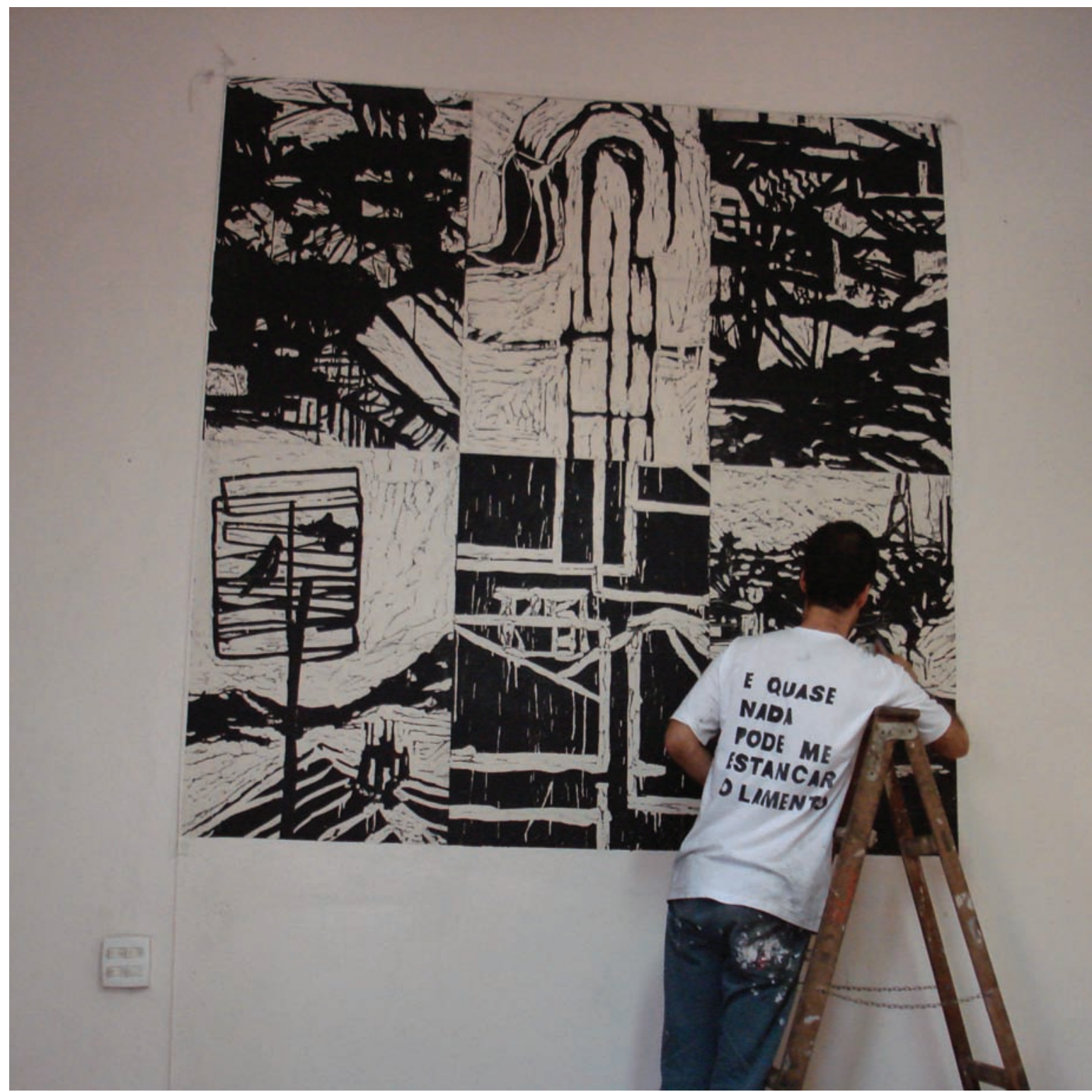

colagem realizada na torrefação 'O Rei do Café' no bairro do Valongo 


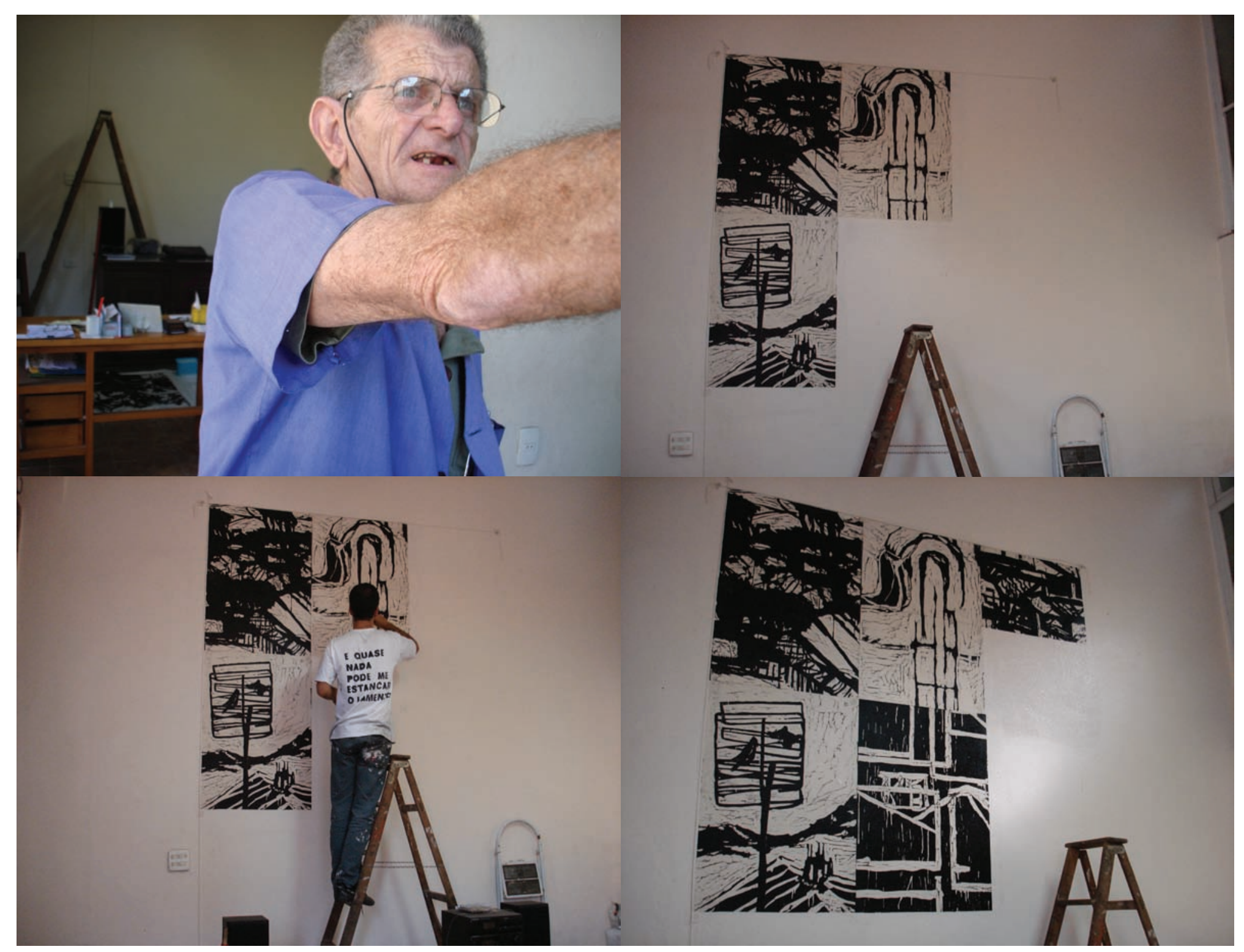




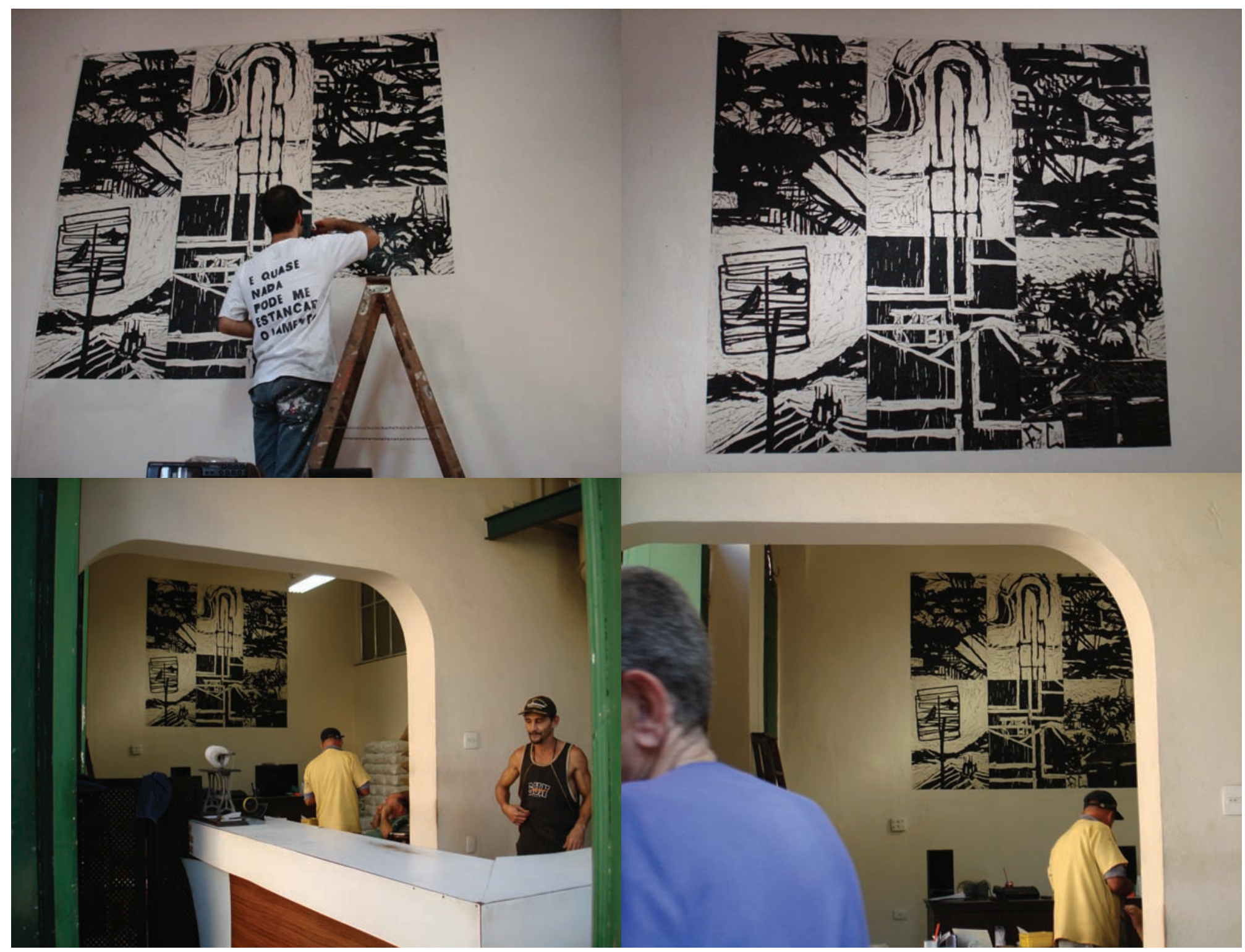




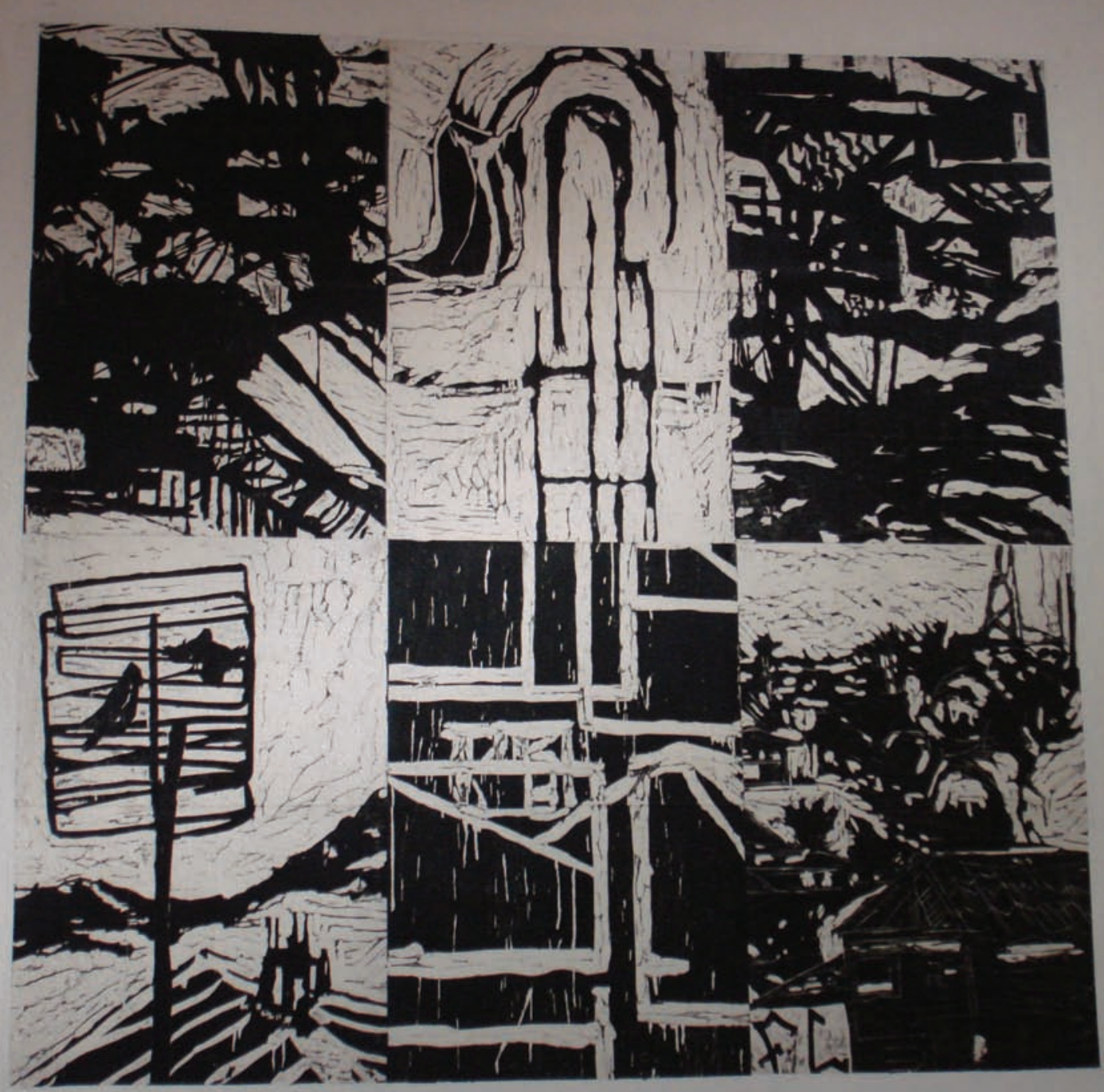




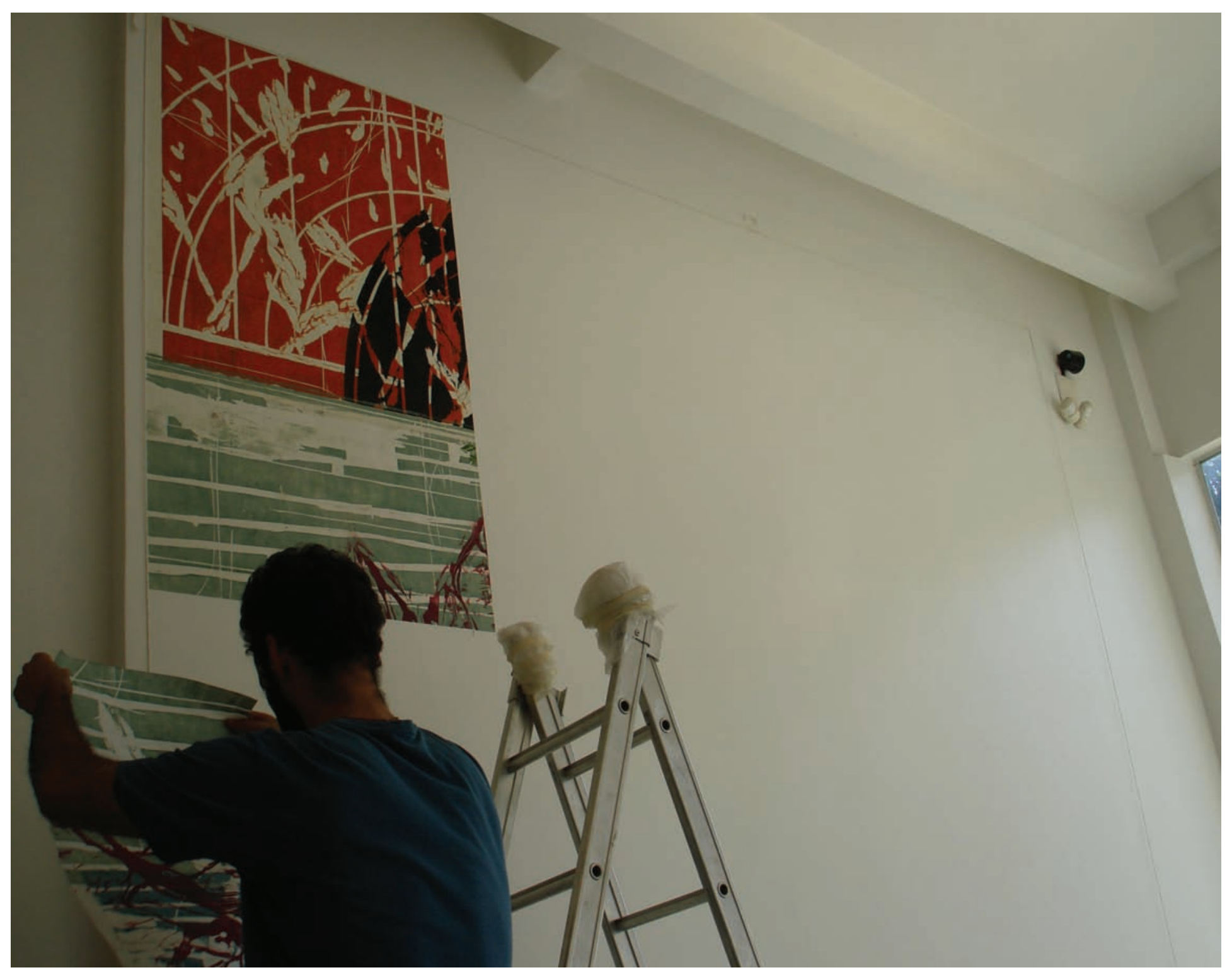

colagem realizada na galeria Gravura Brasileira / SP

59 


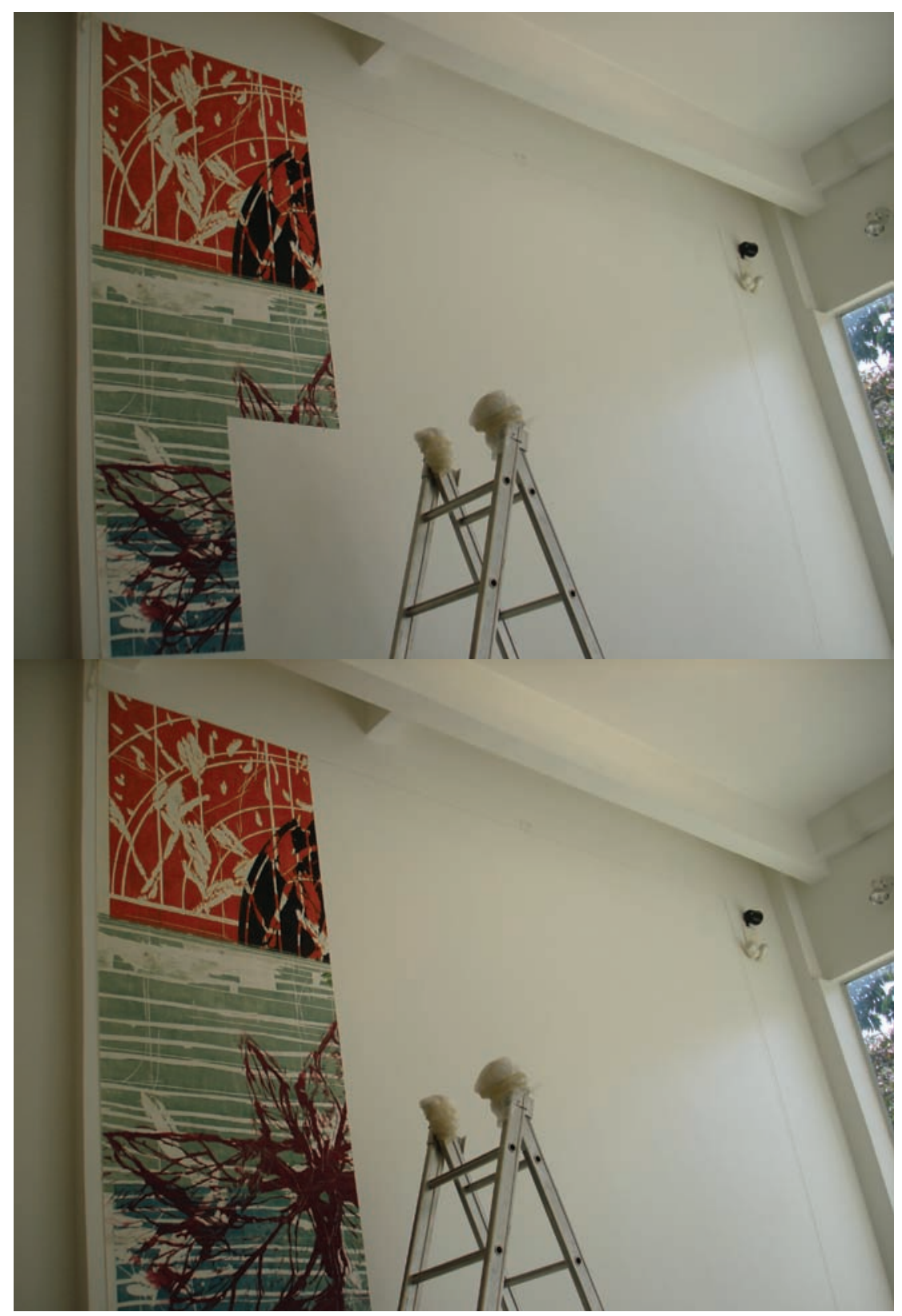

60 


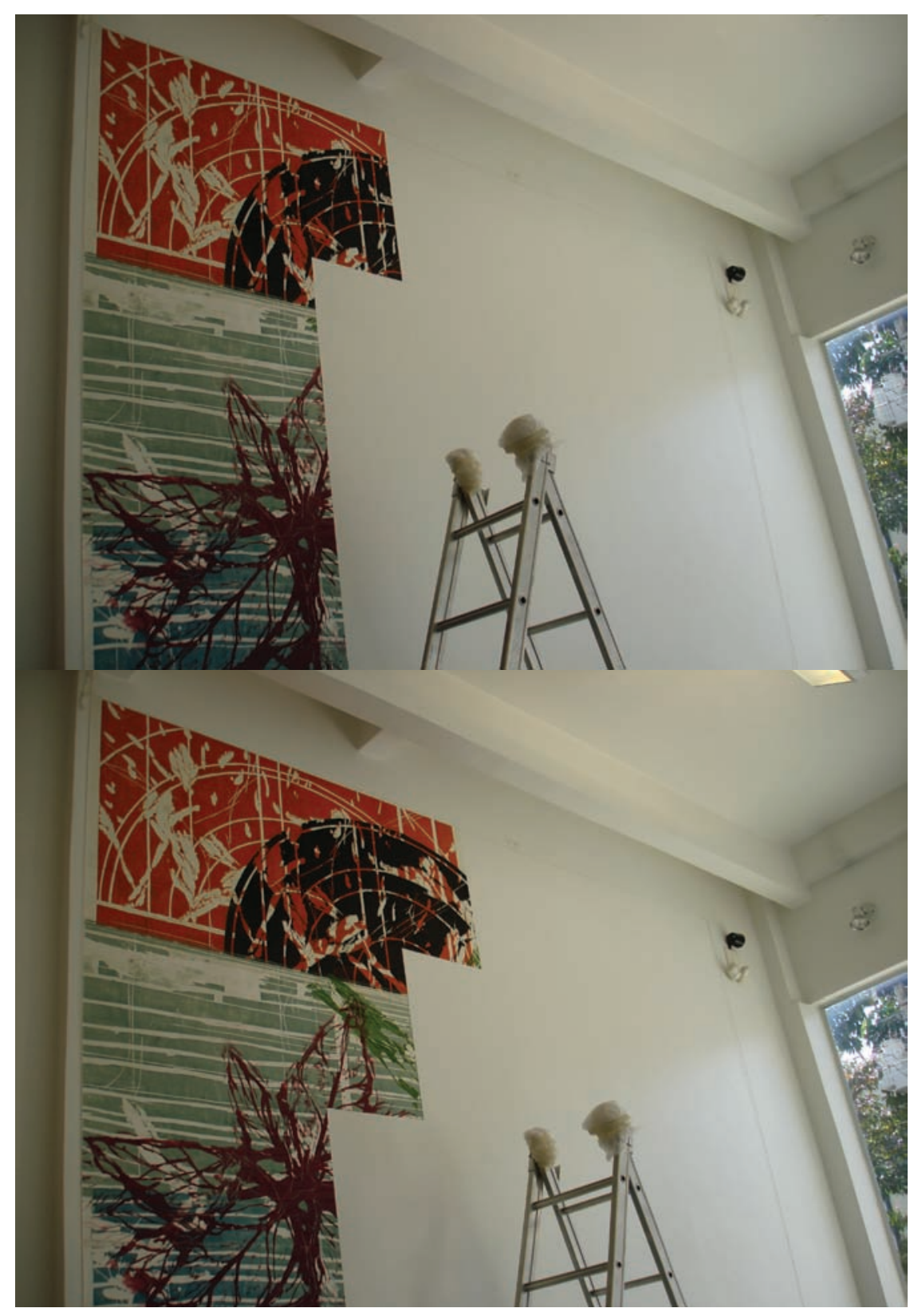

61 


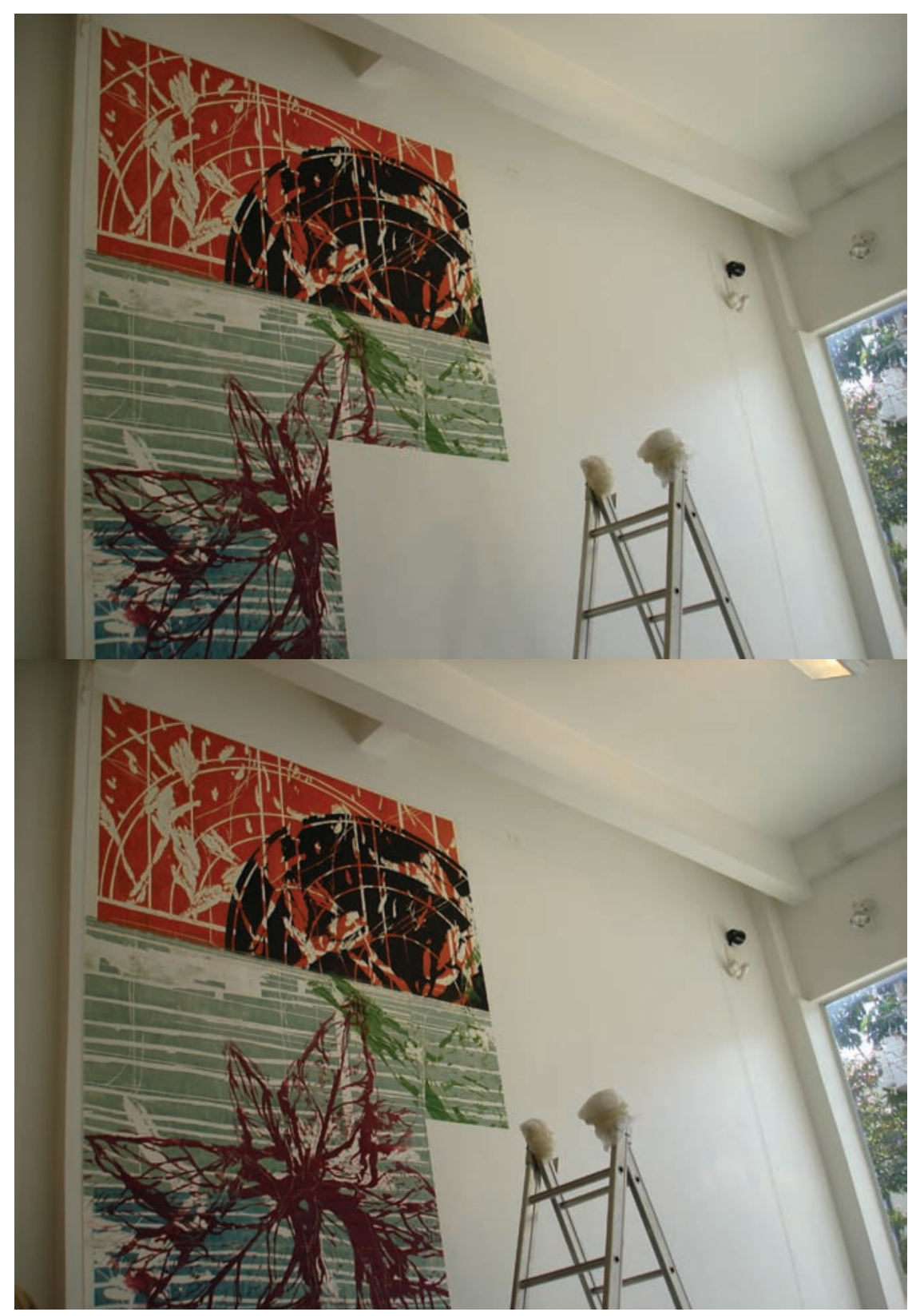

62 


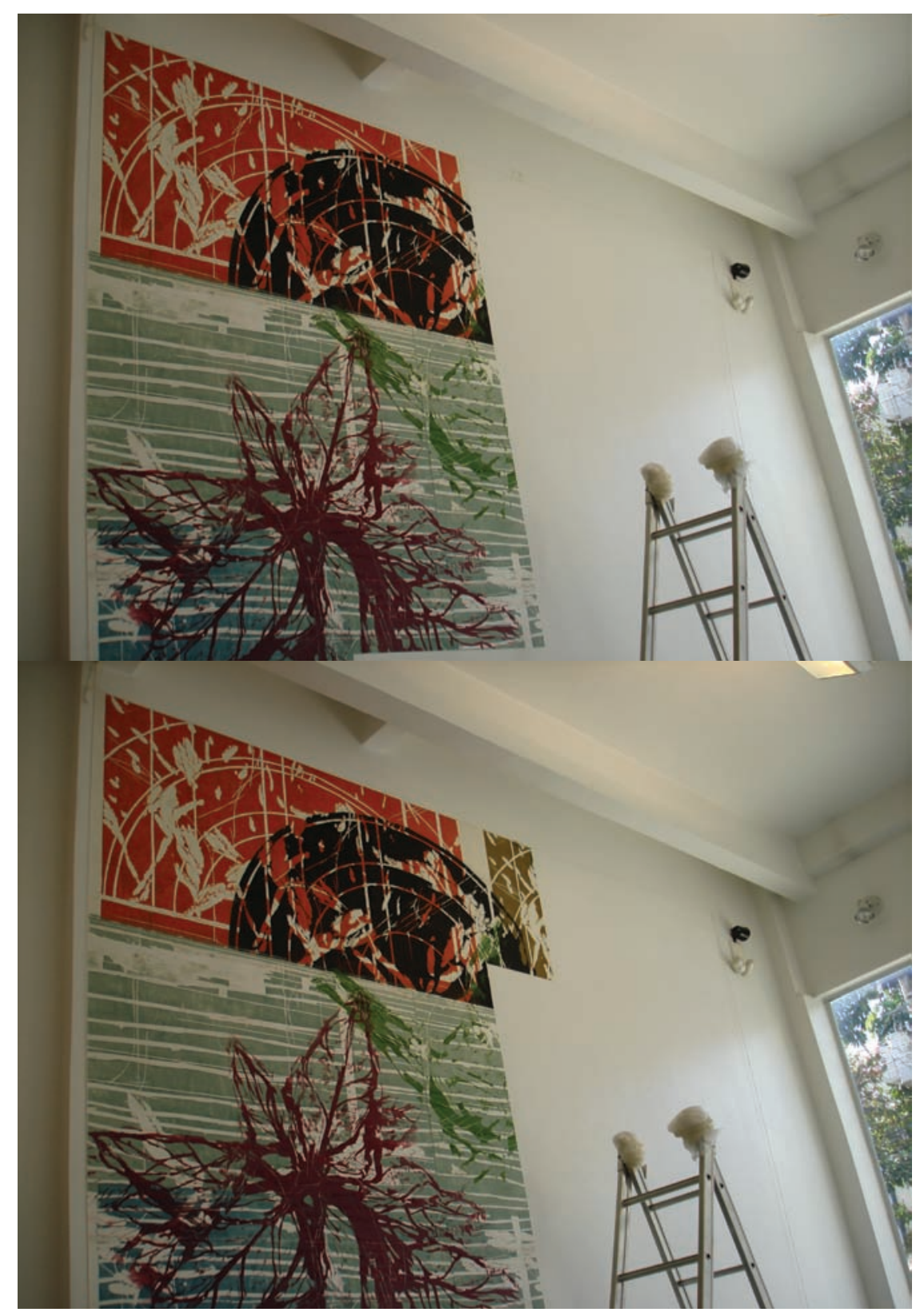

63 


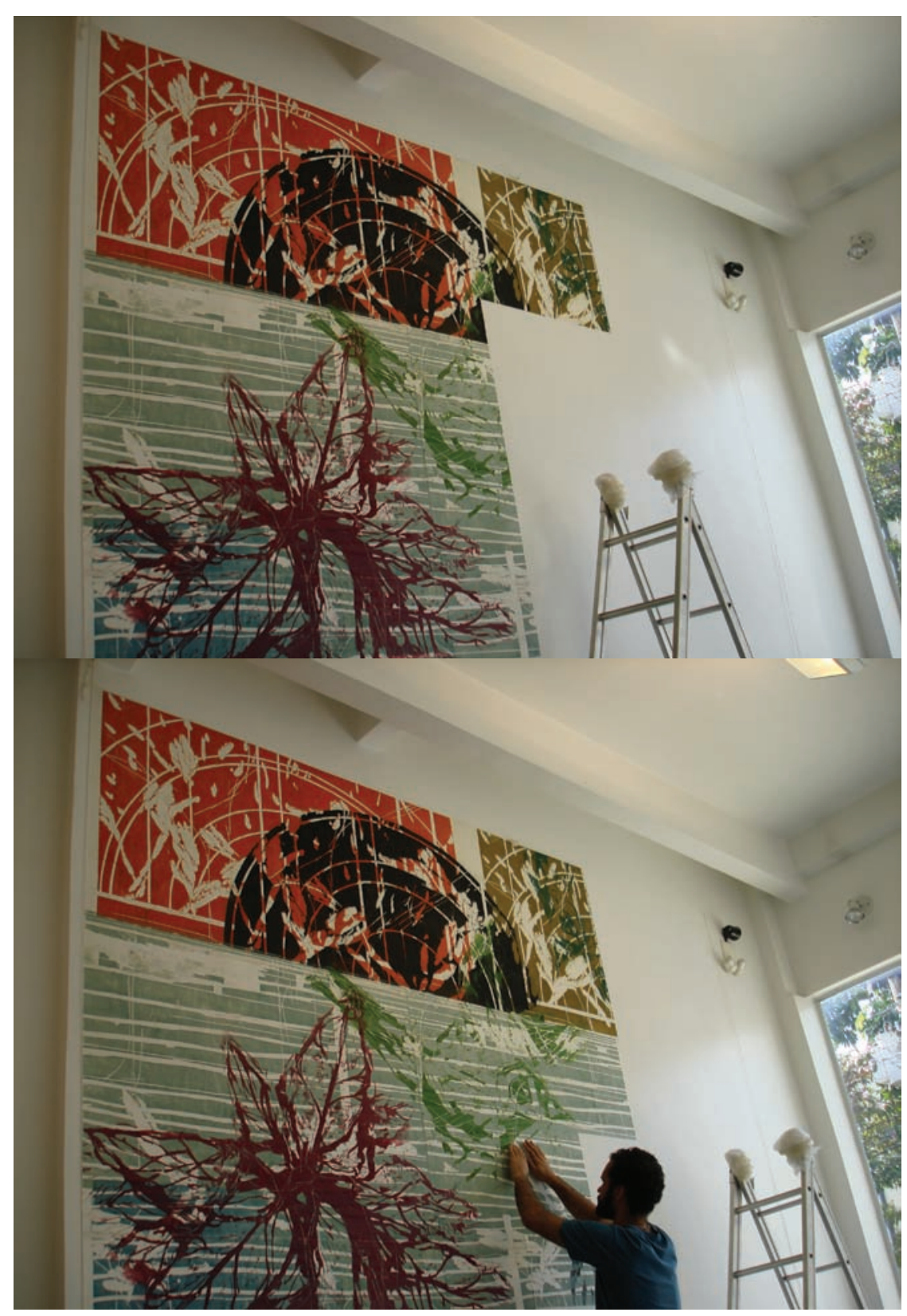

64 


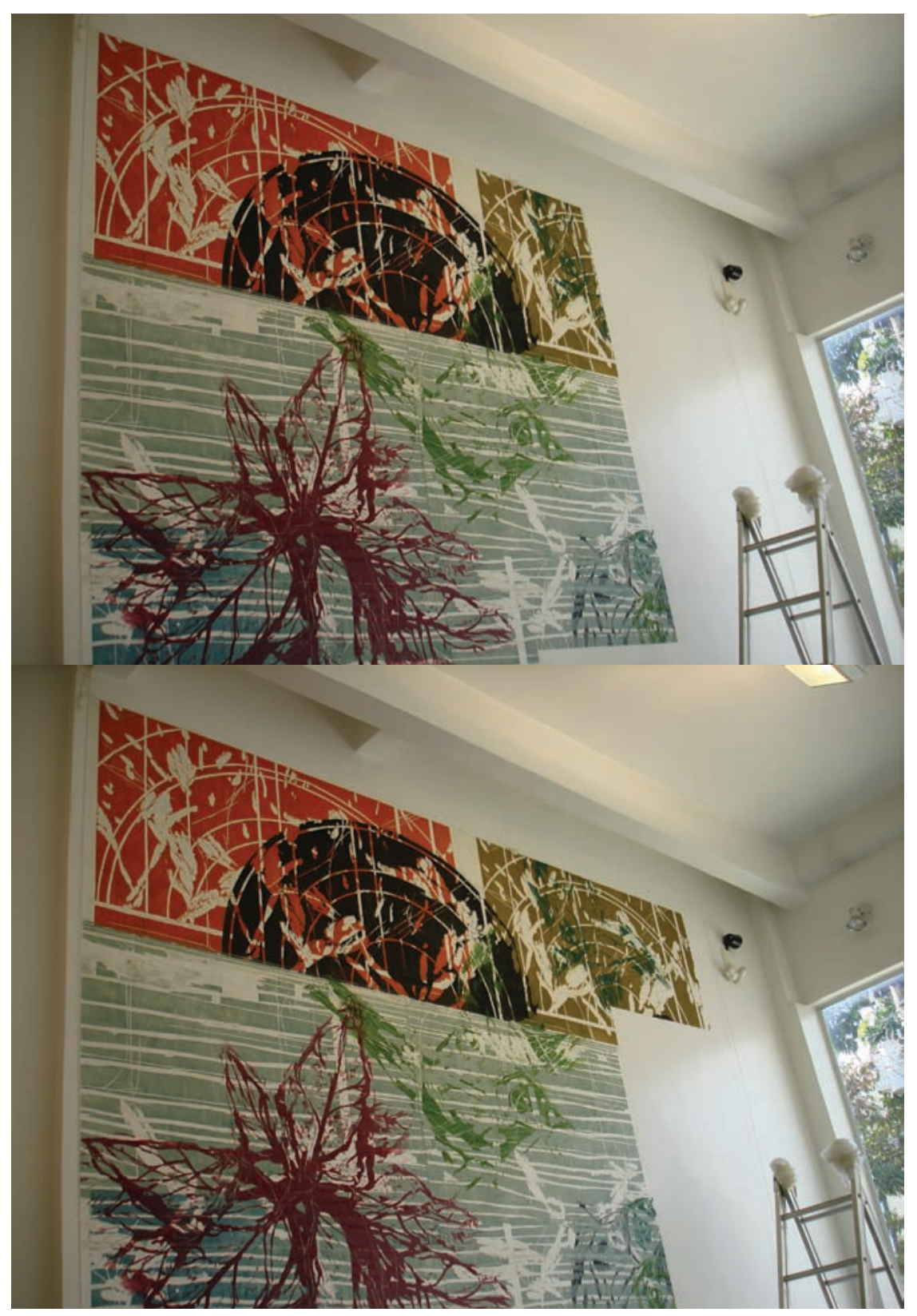

65 

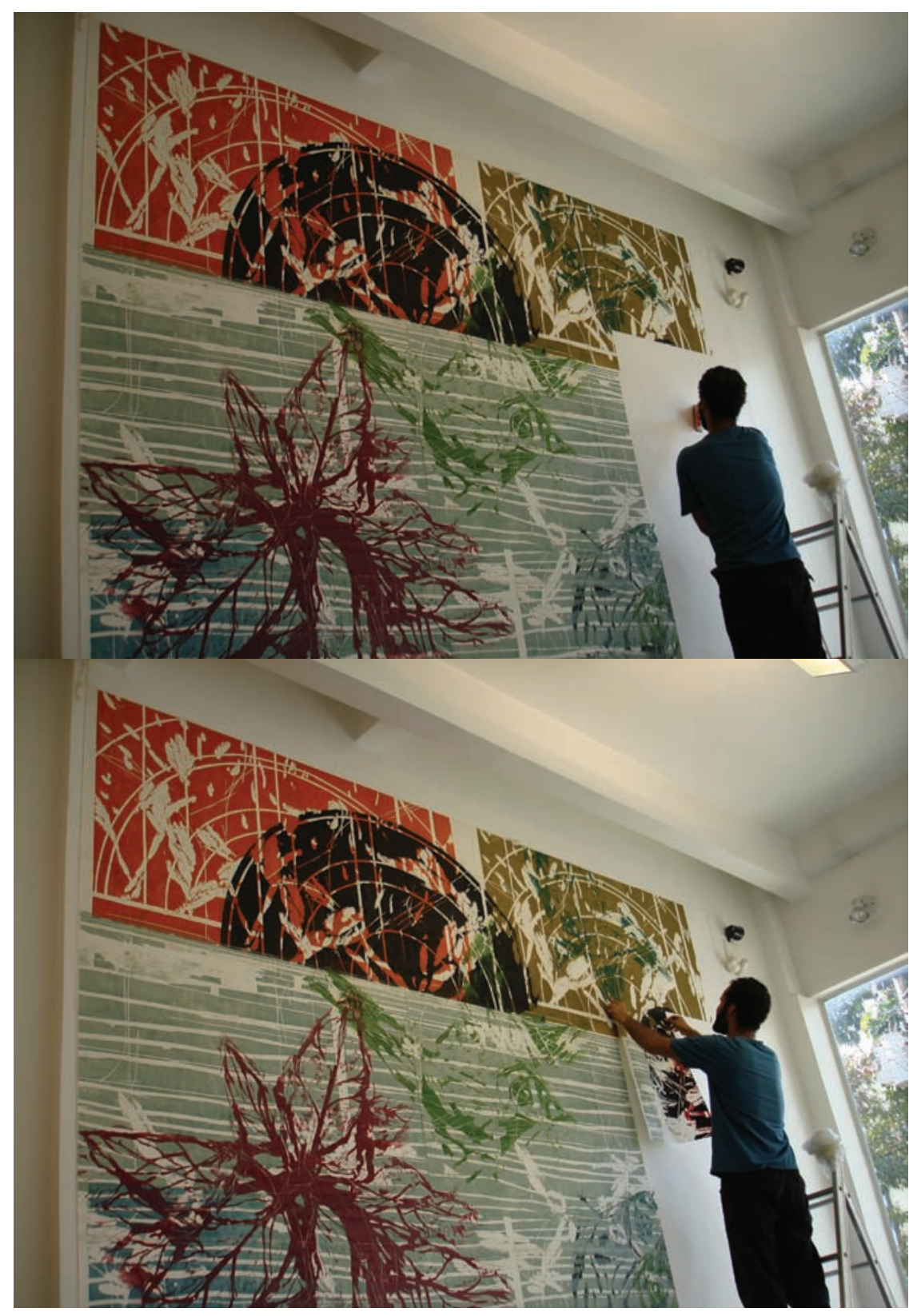

66 


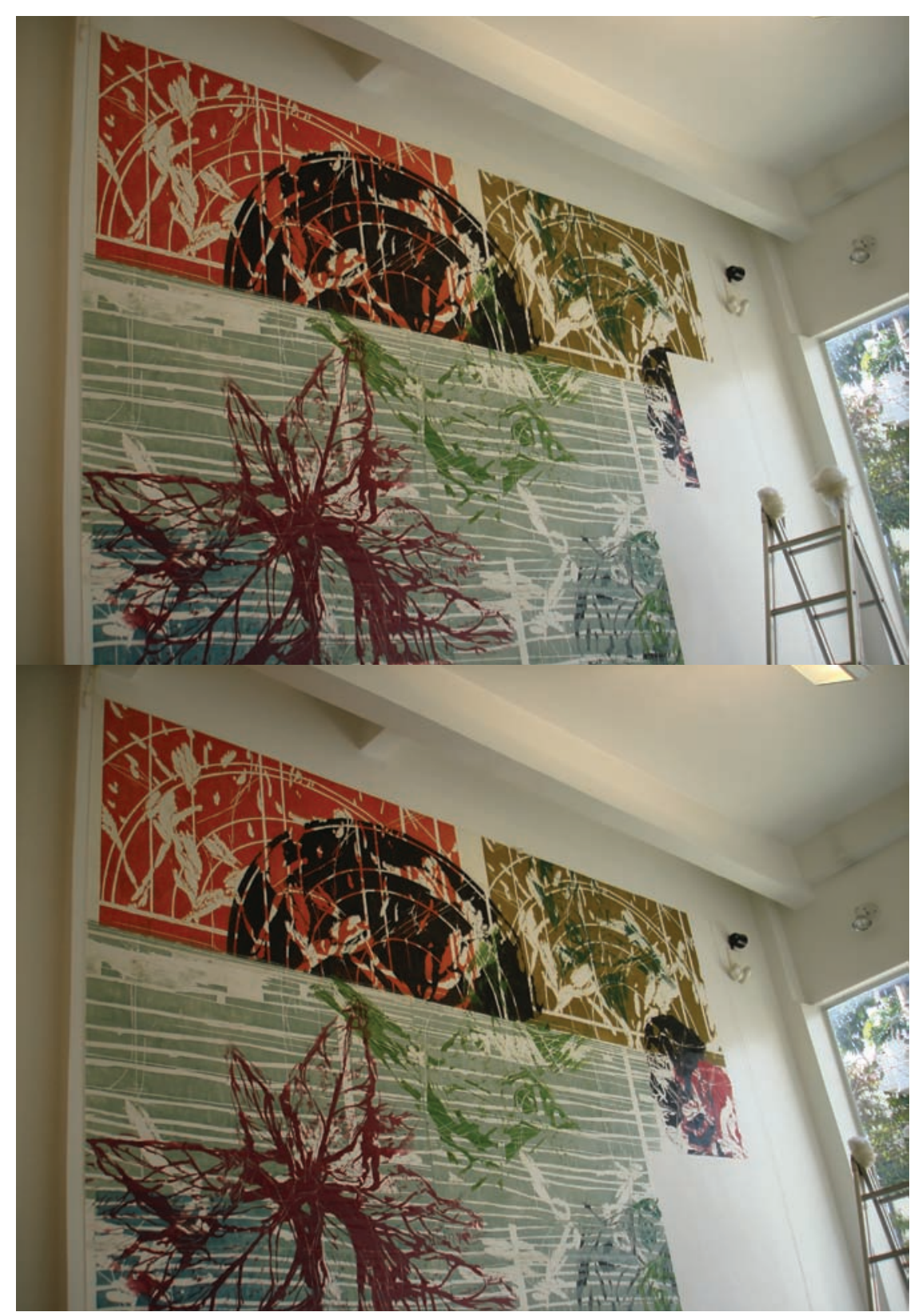

67 


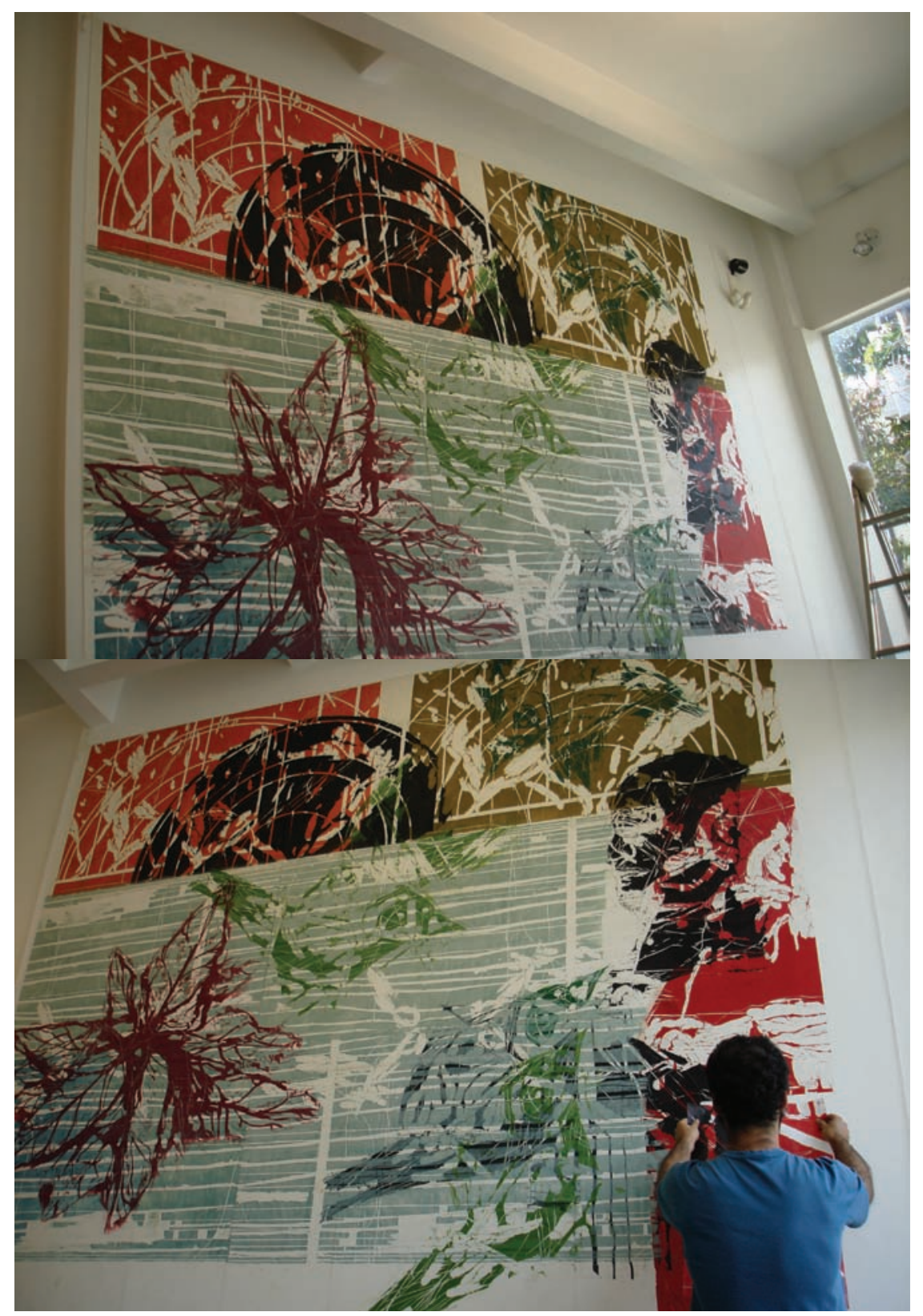

68 

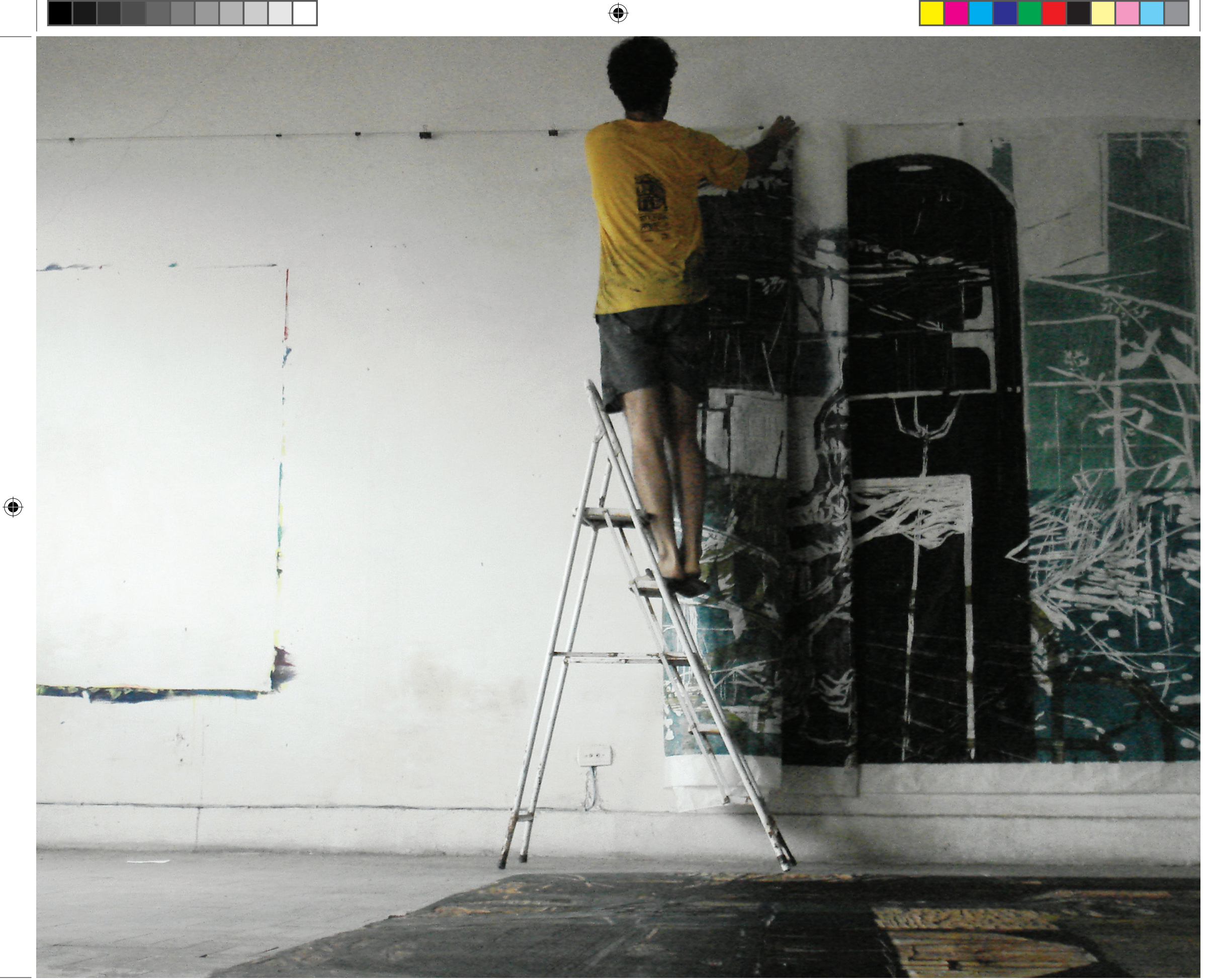


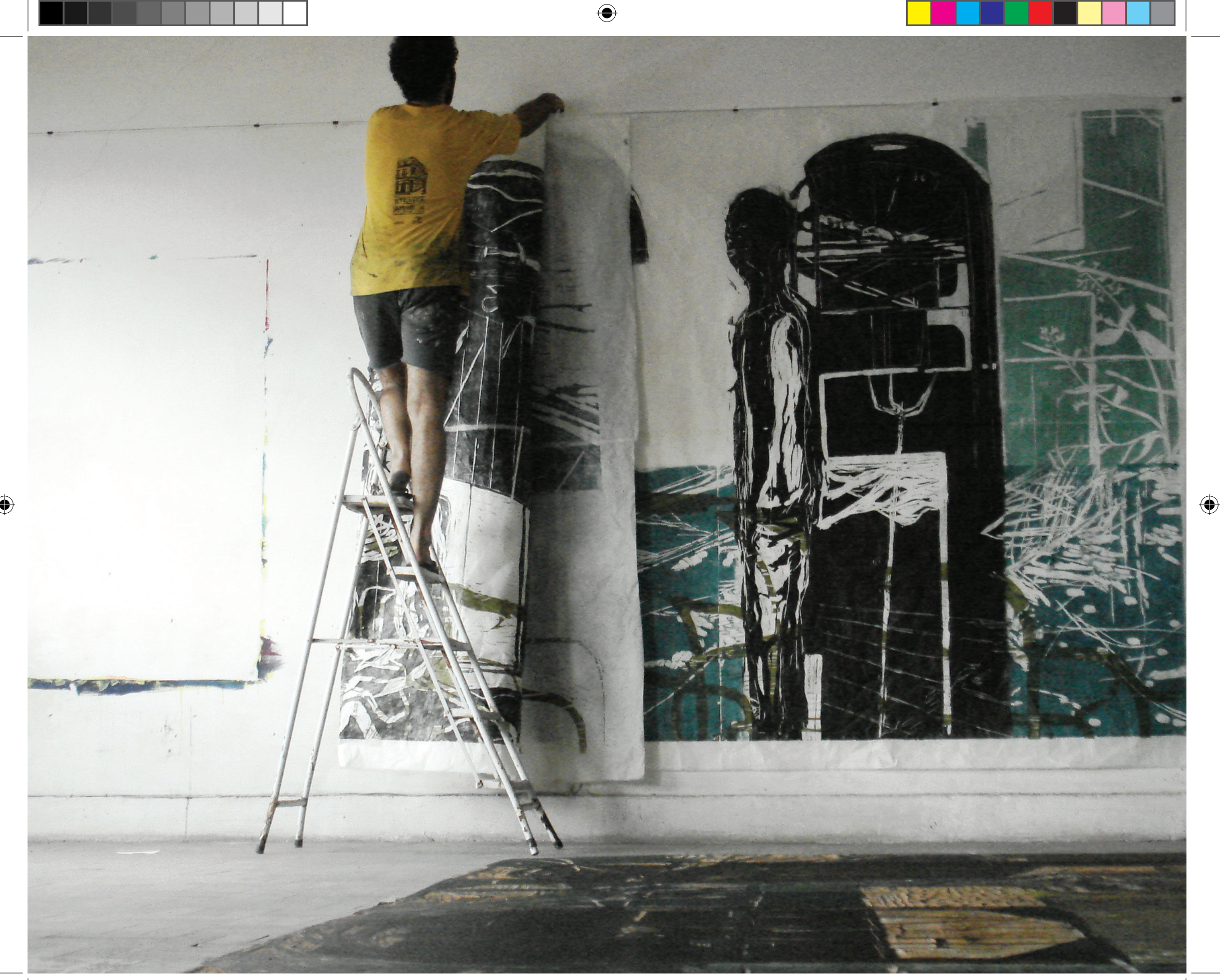




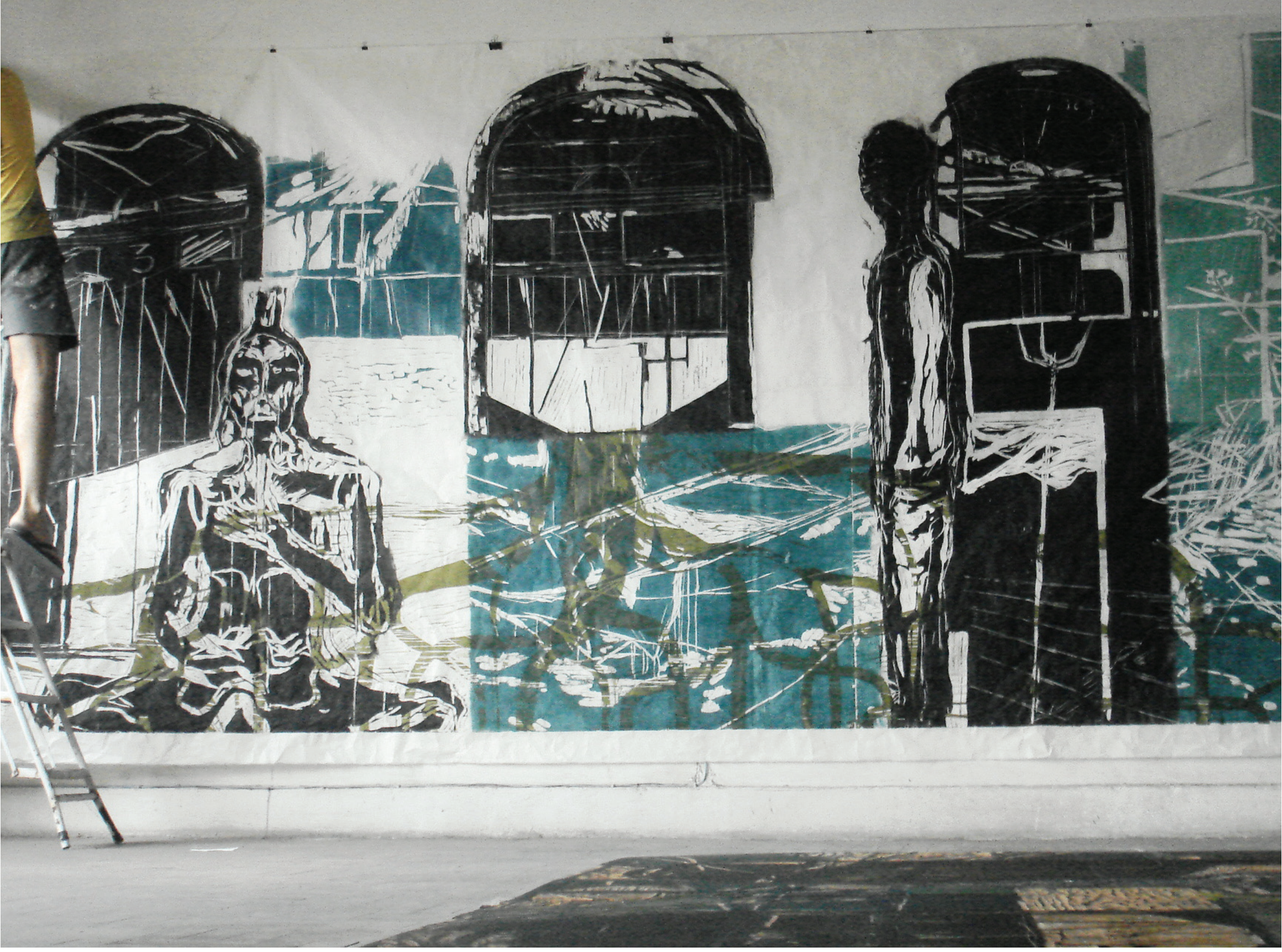




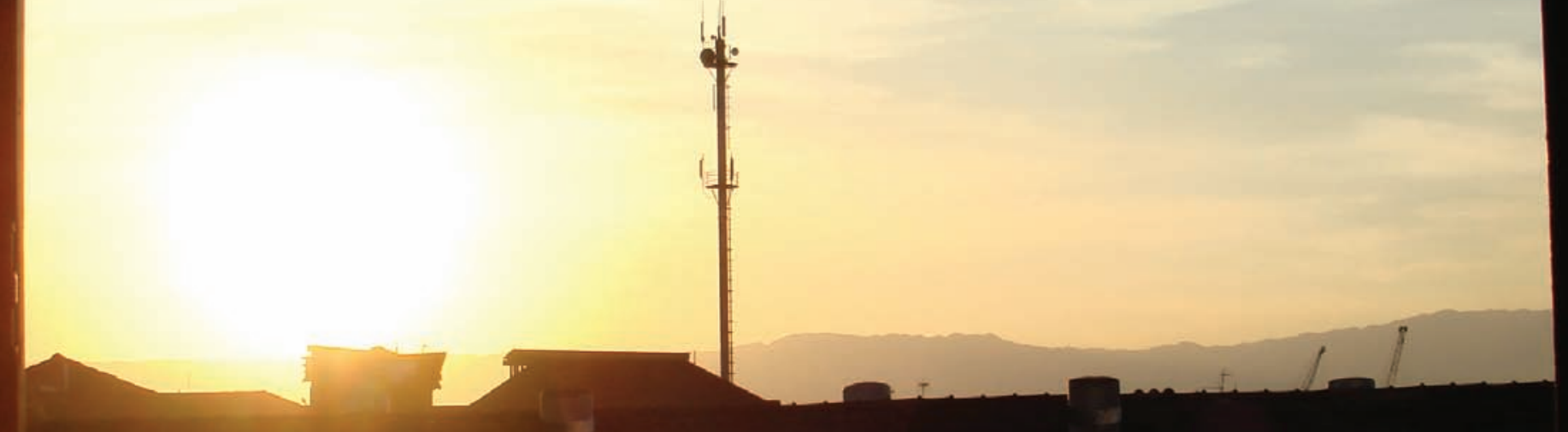




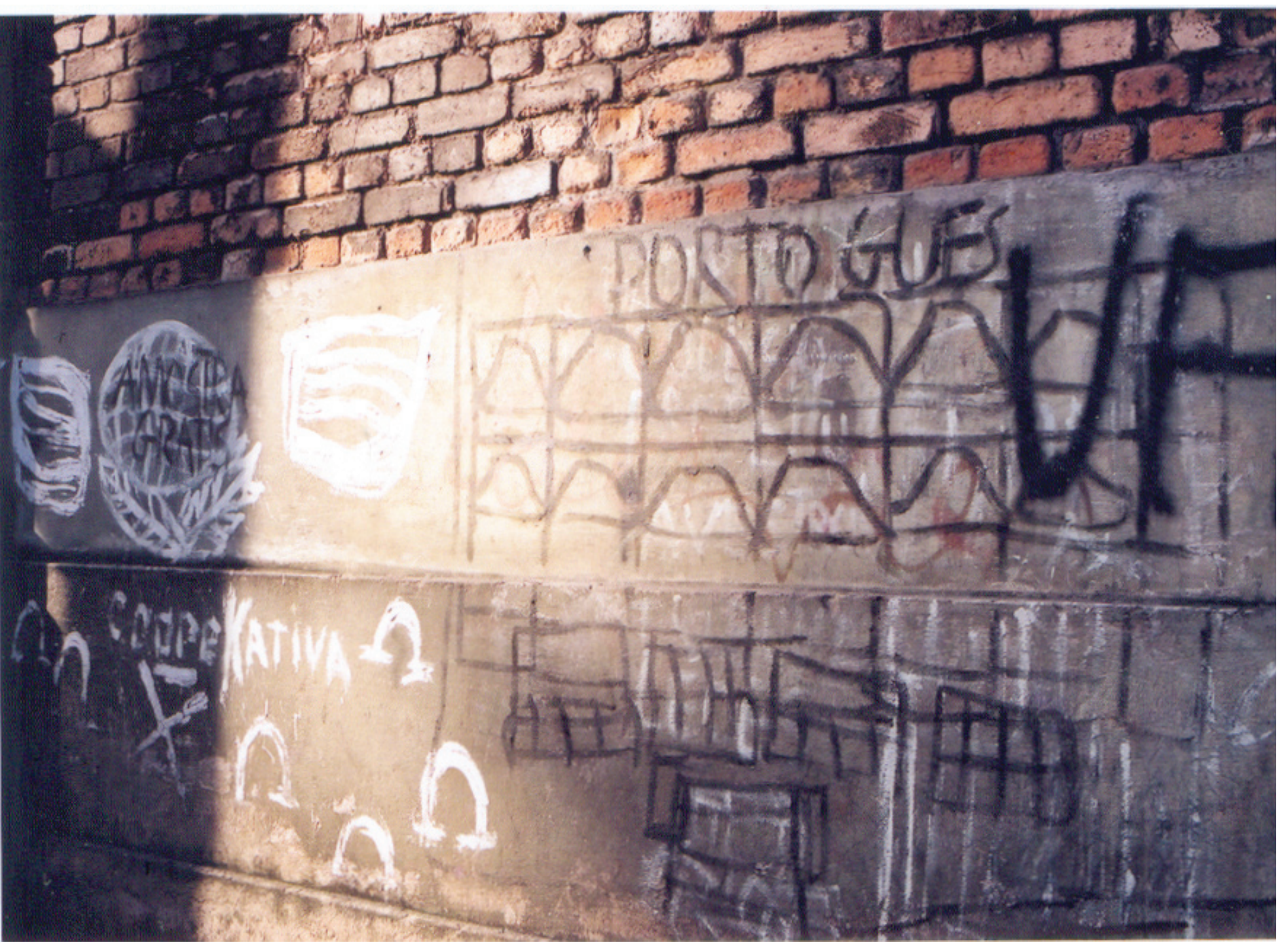

desenhos realizados por artista andarilho na região portuária de Santos 


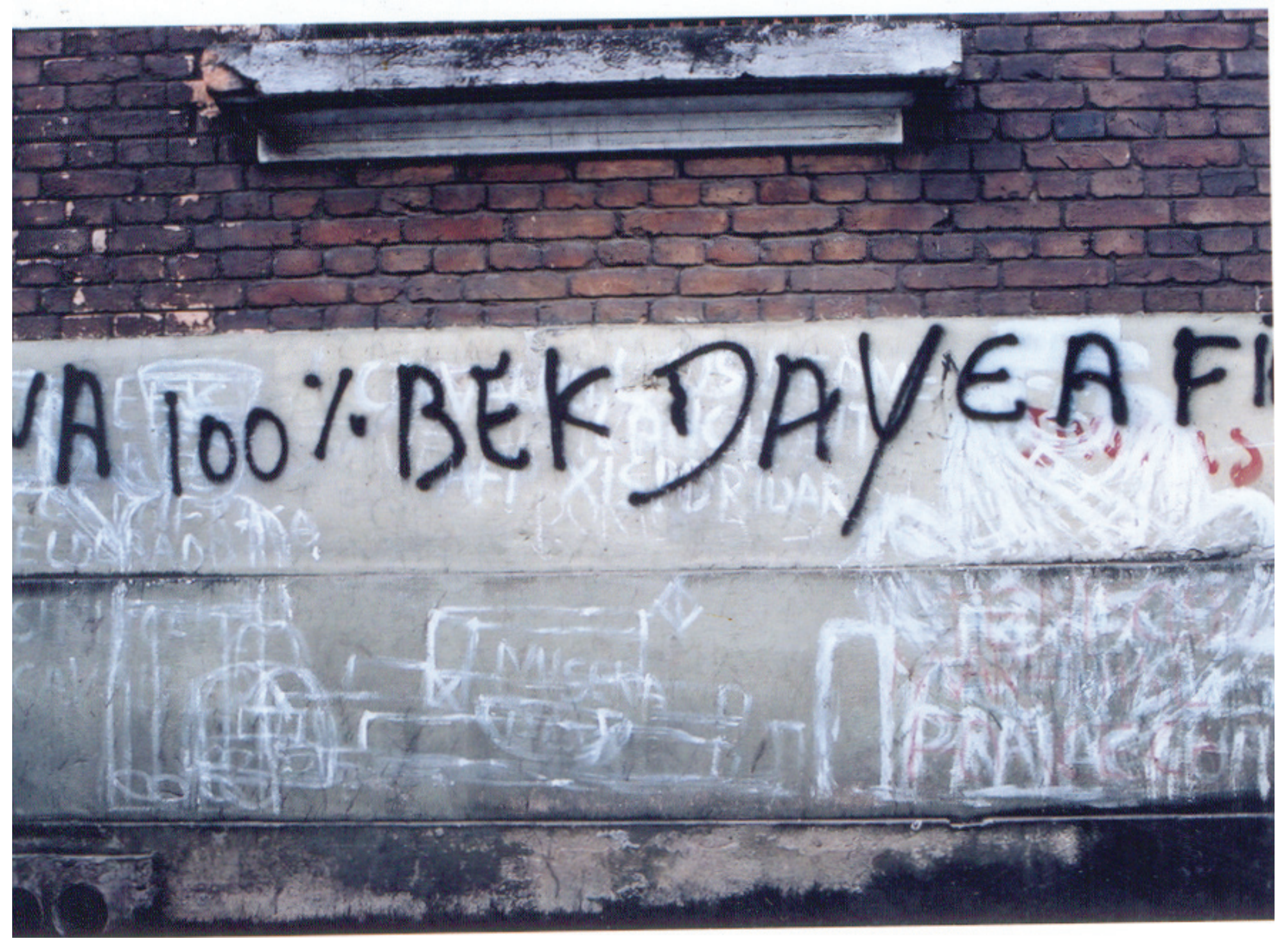




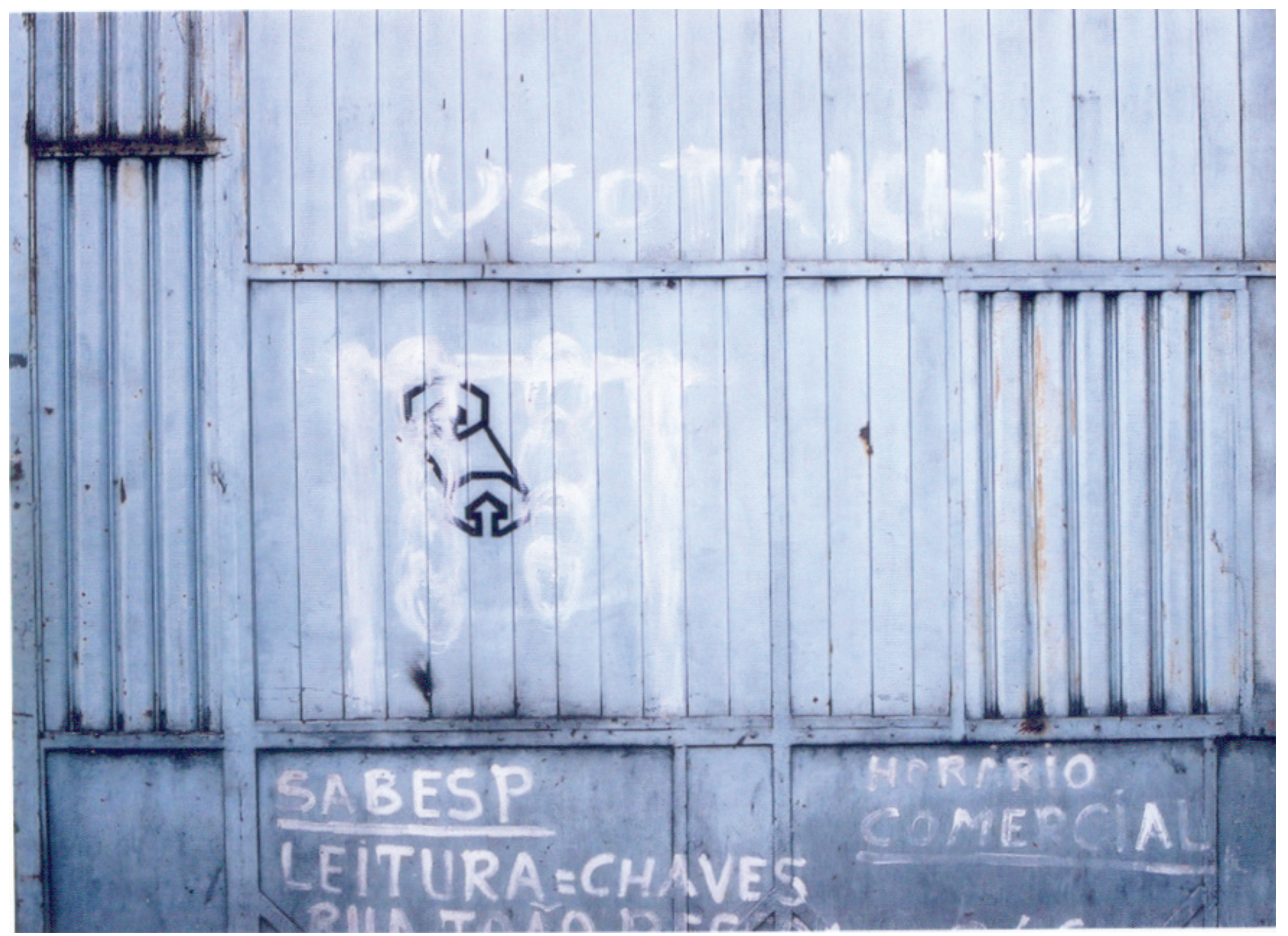

76 


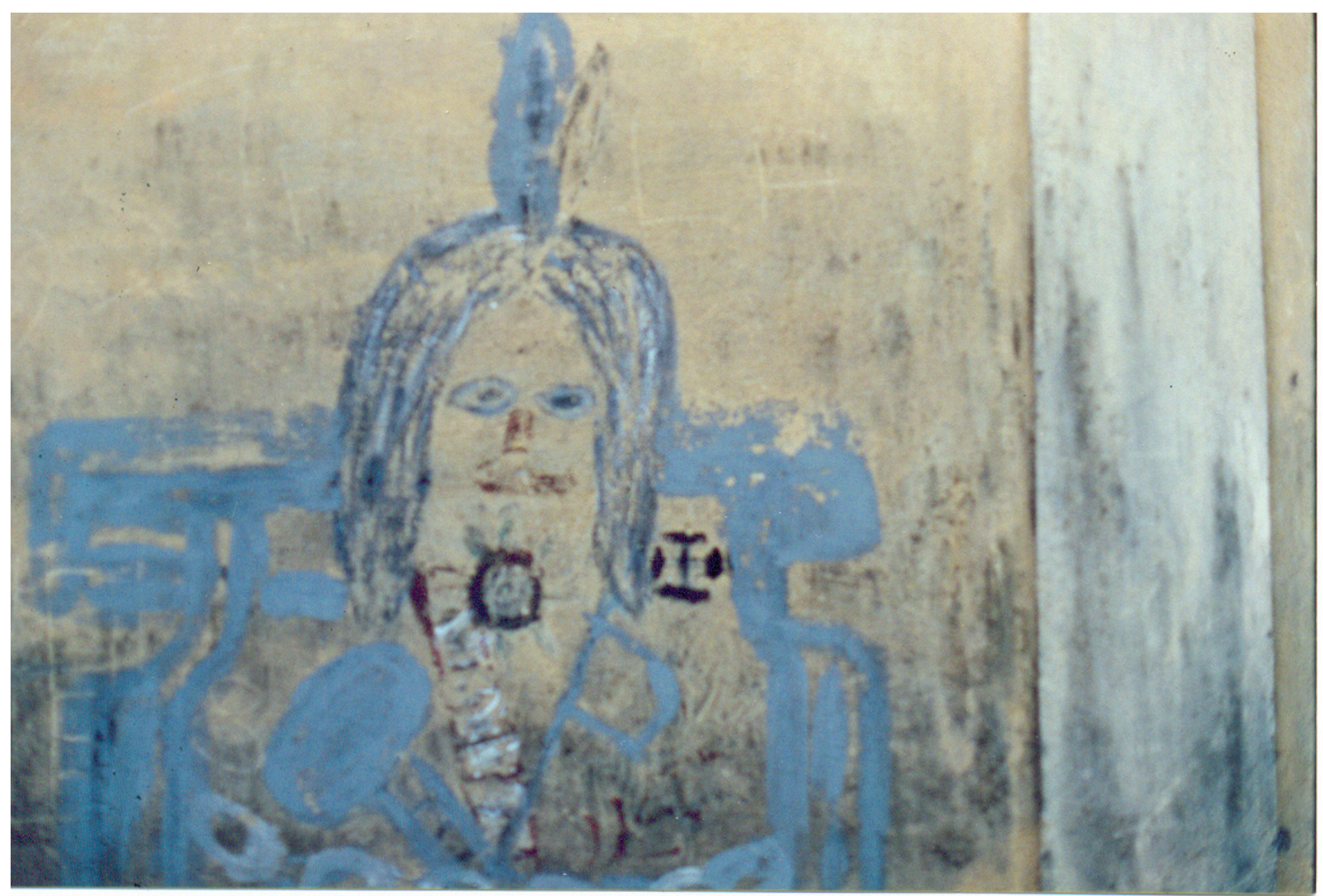




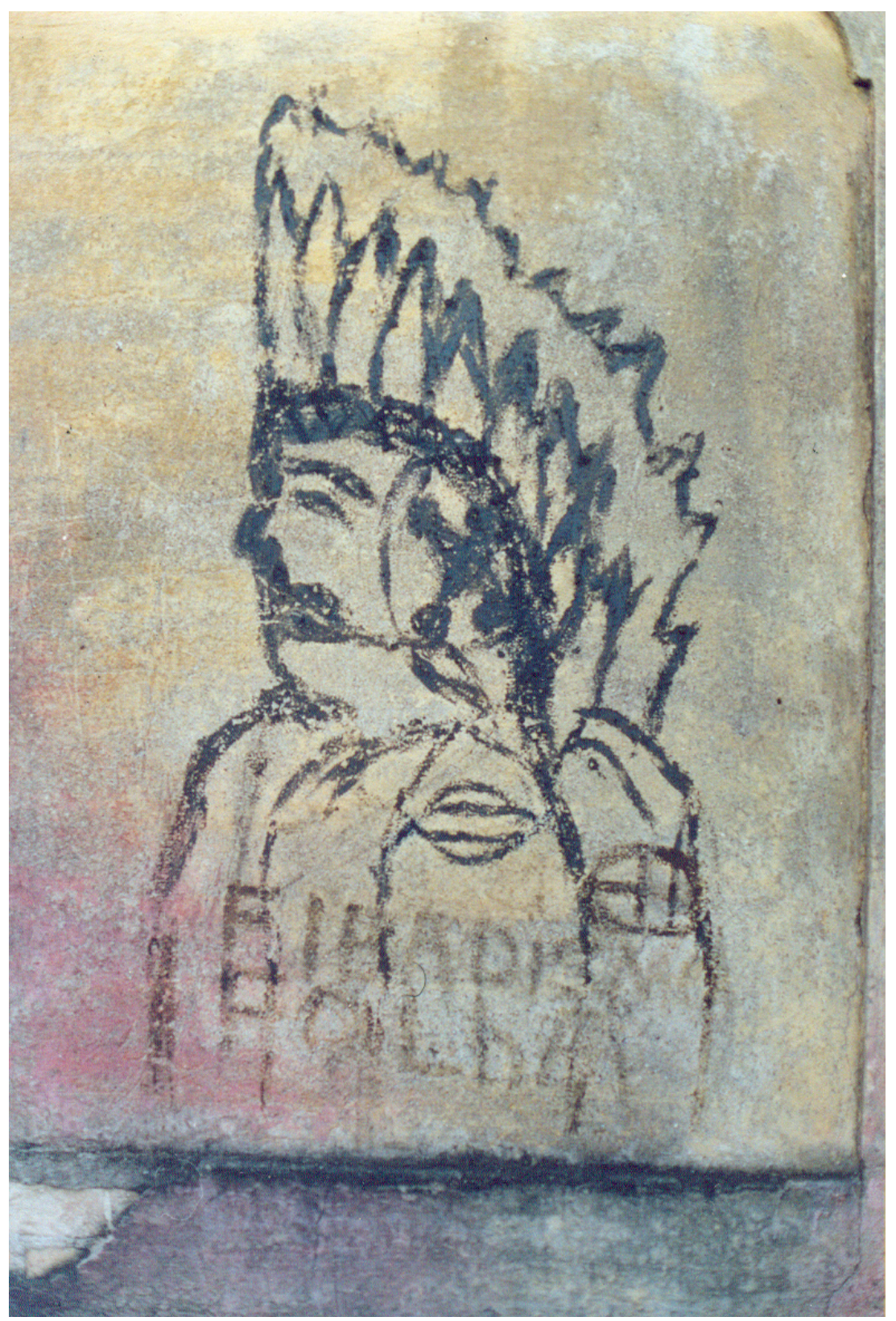

78 


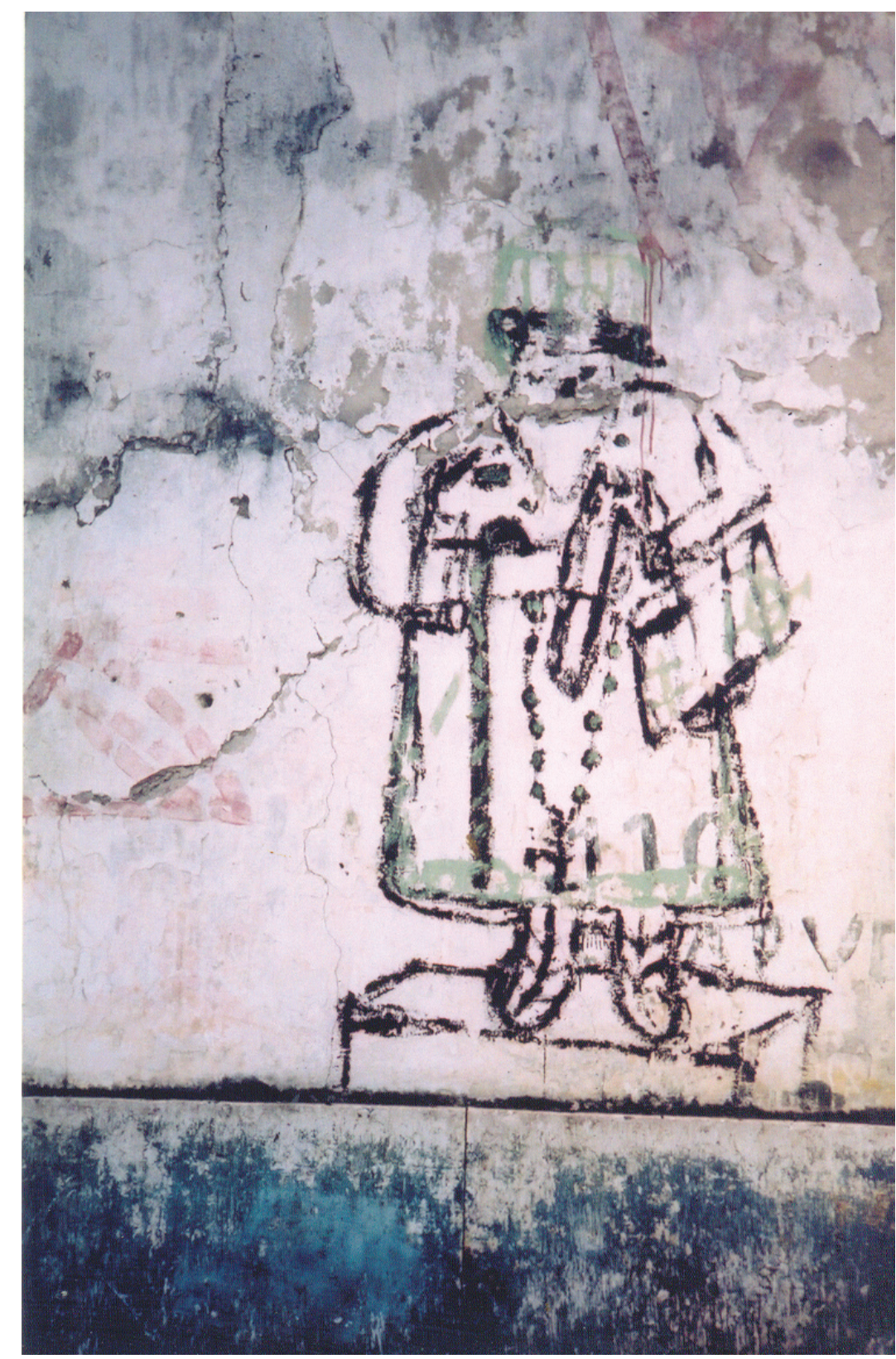

79 


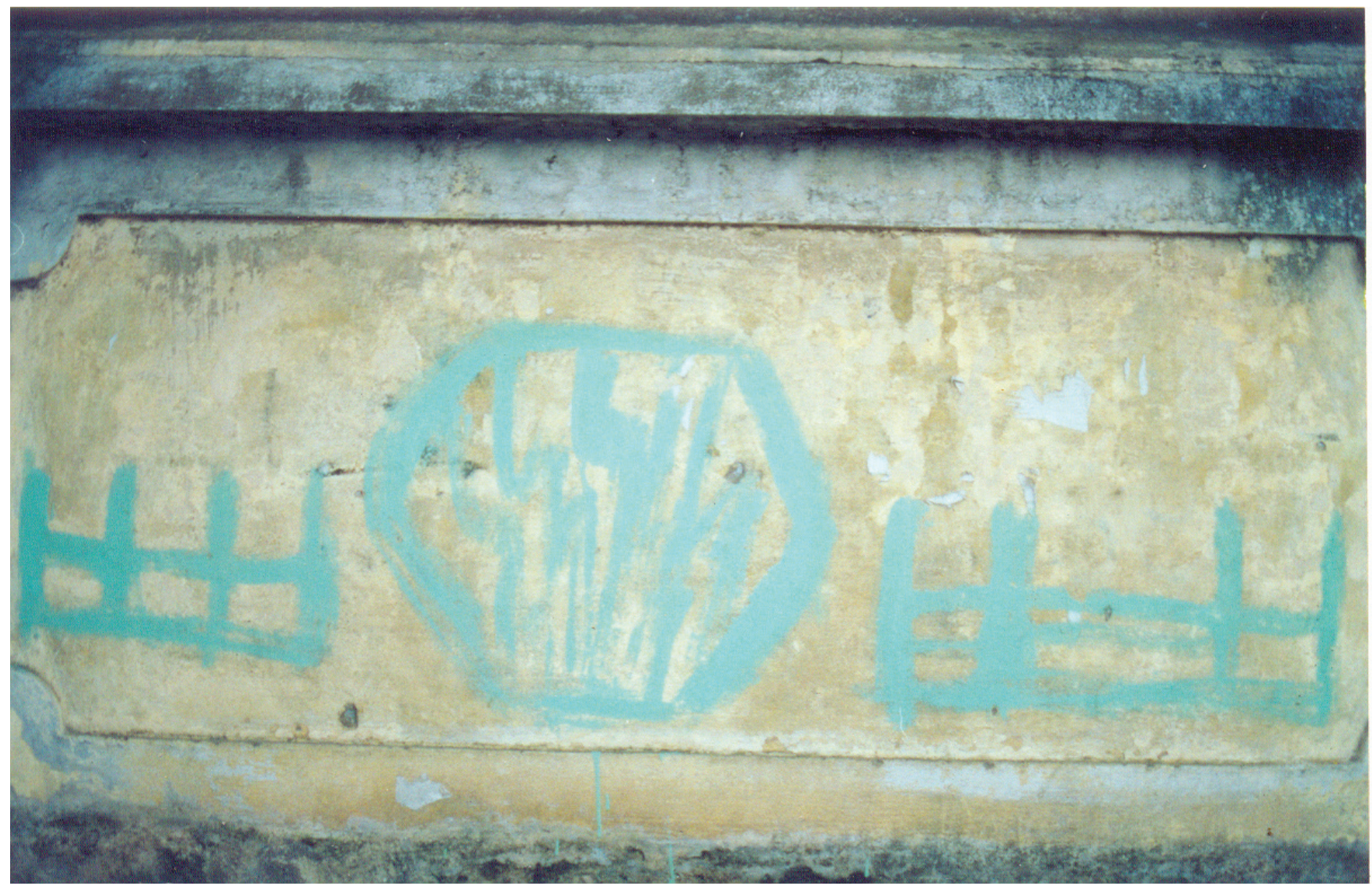




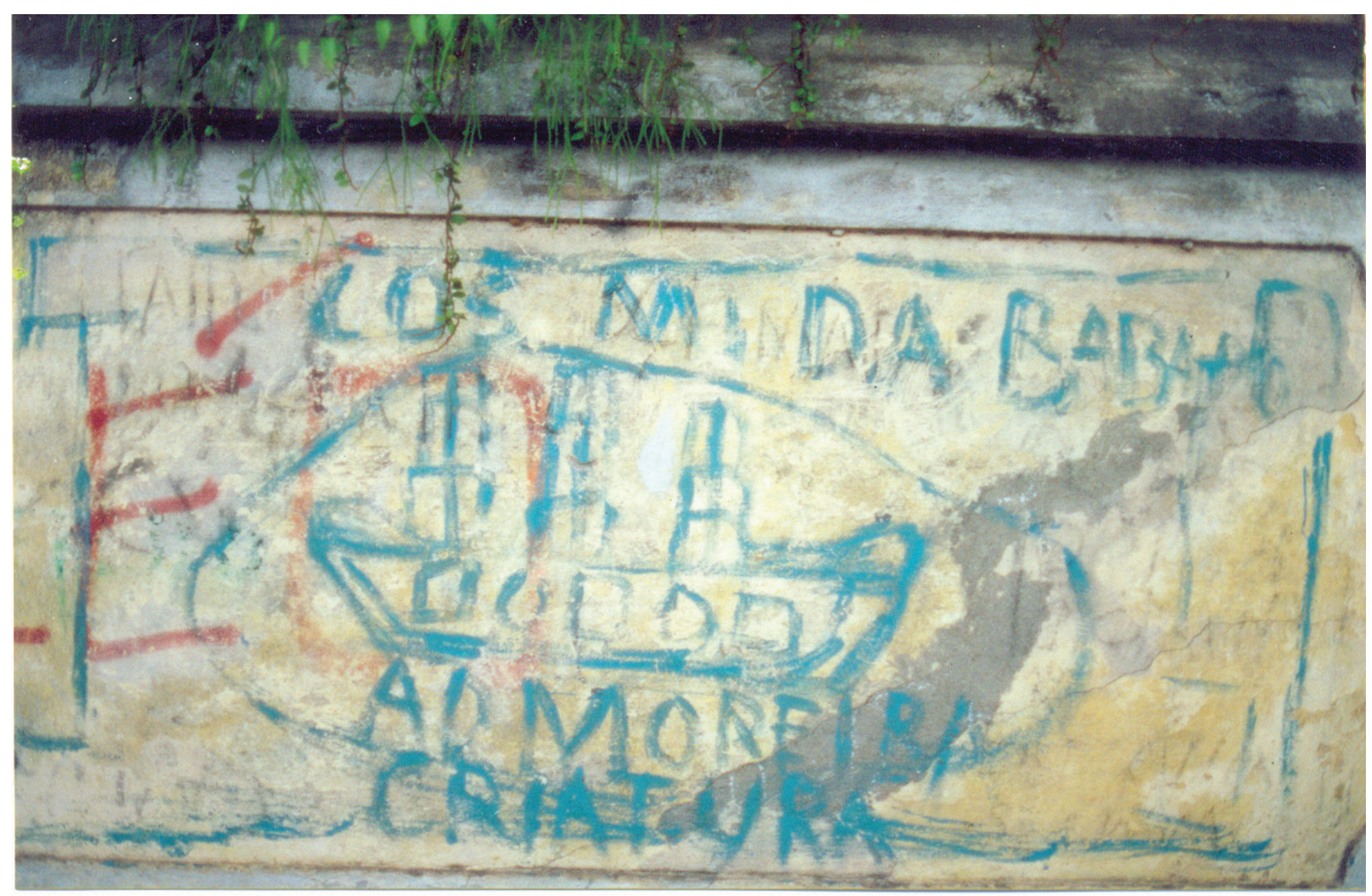




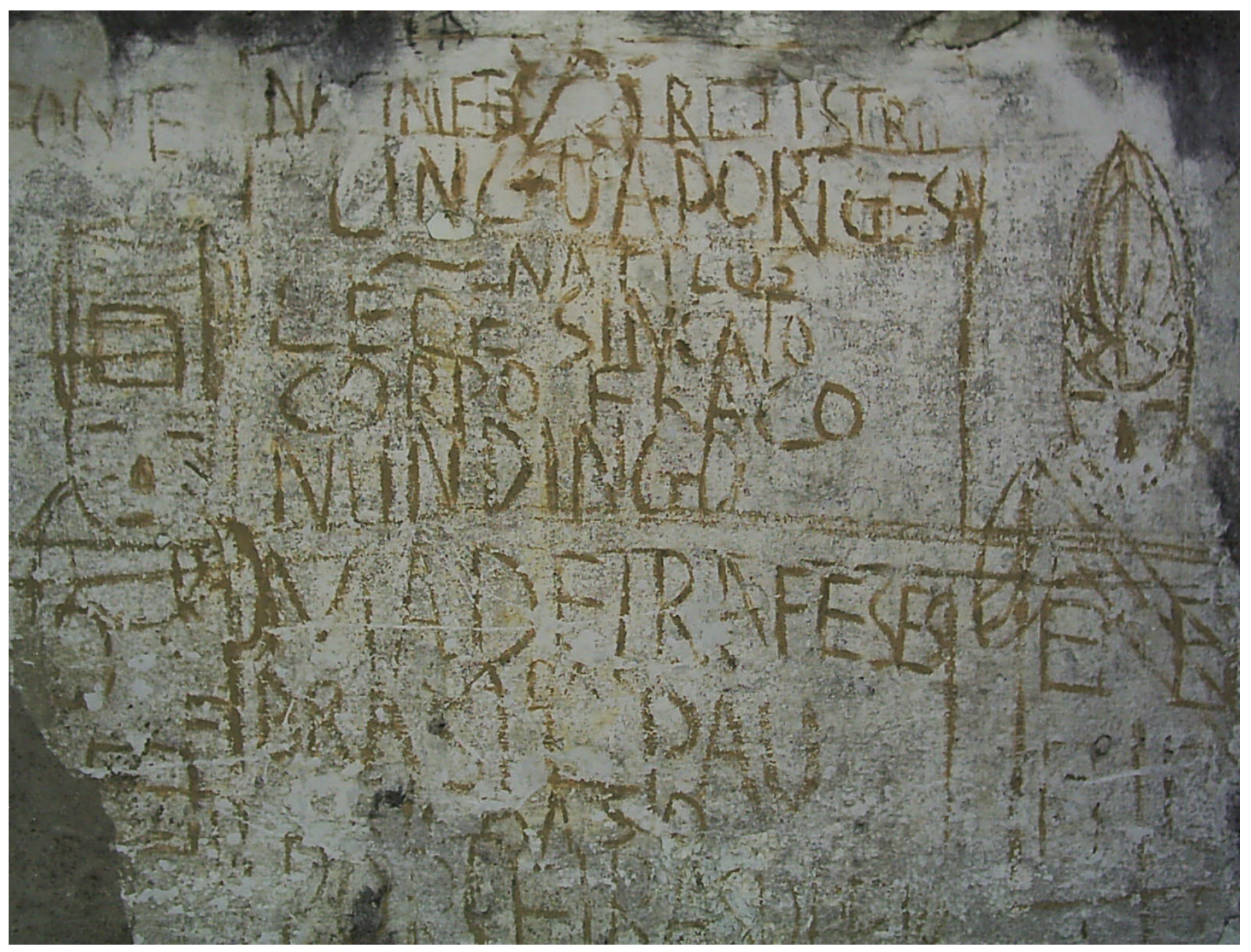



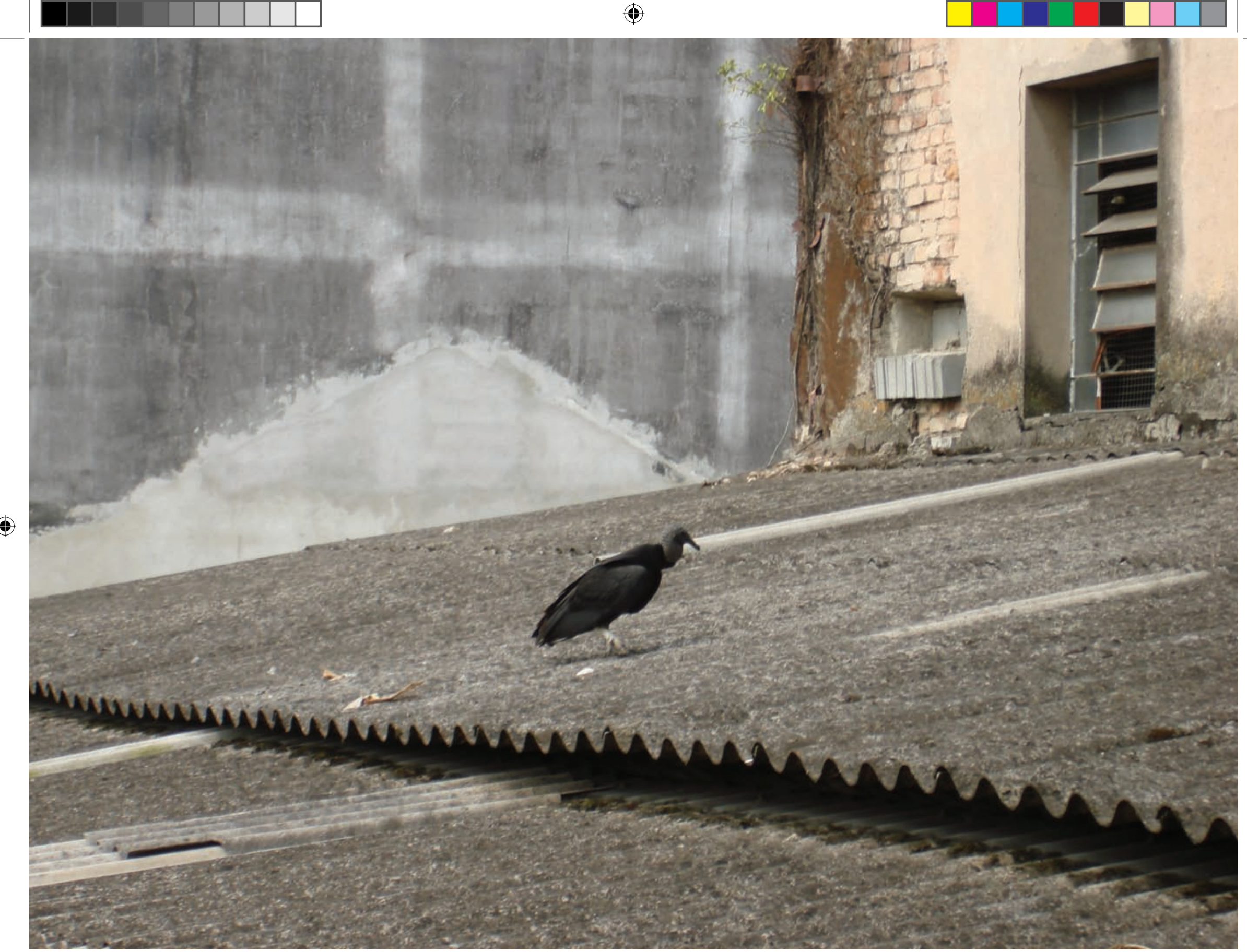


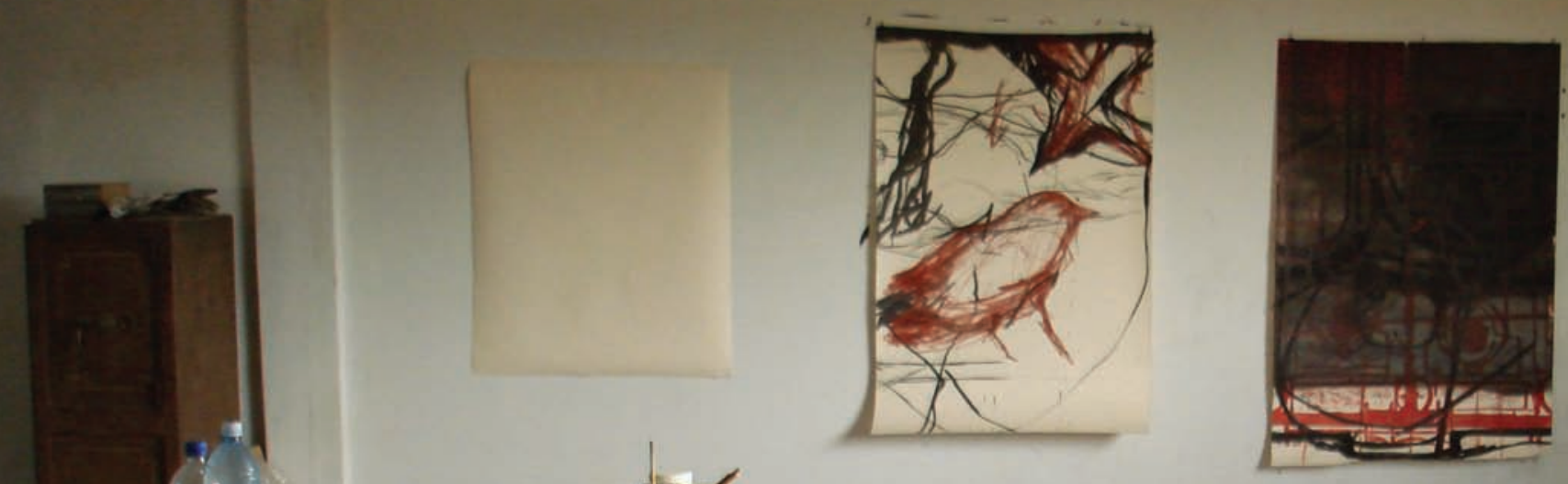

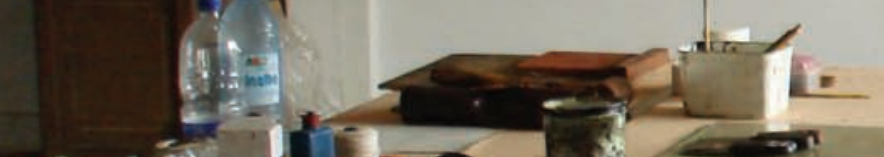

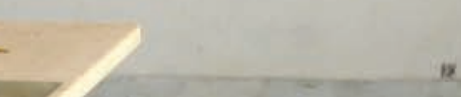

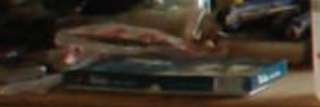
$7 \frac{12}{2}$

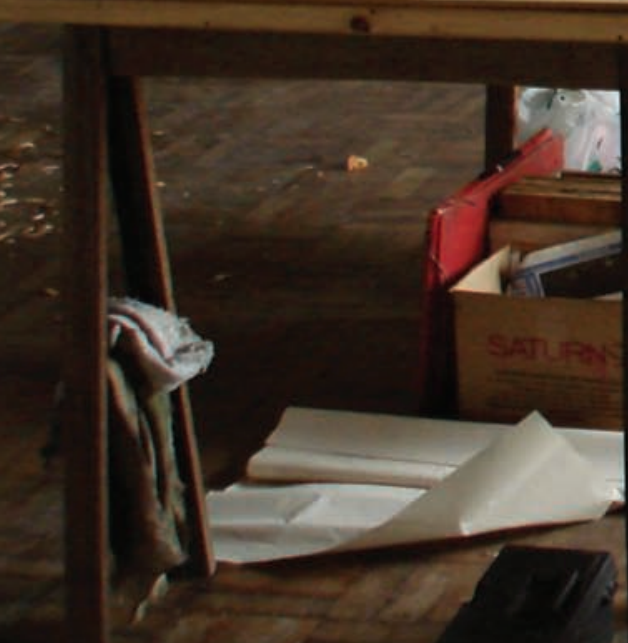

2
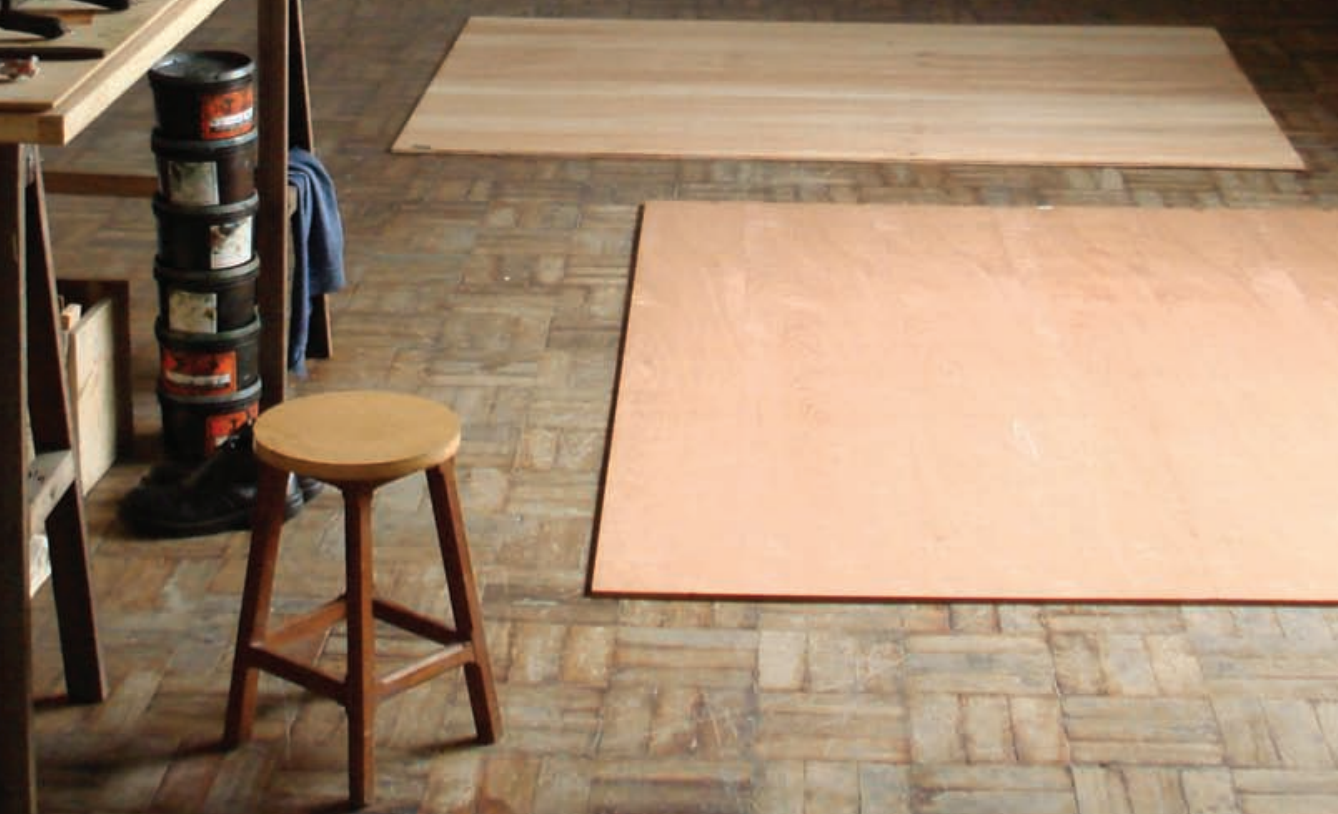

यूत
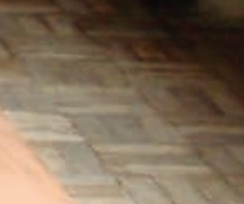


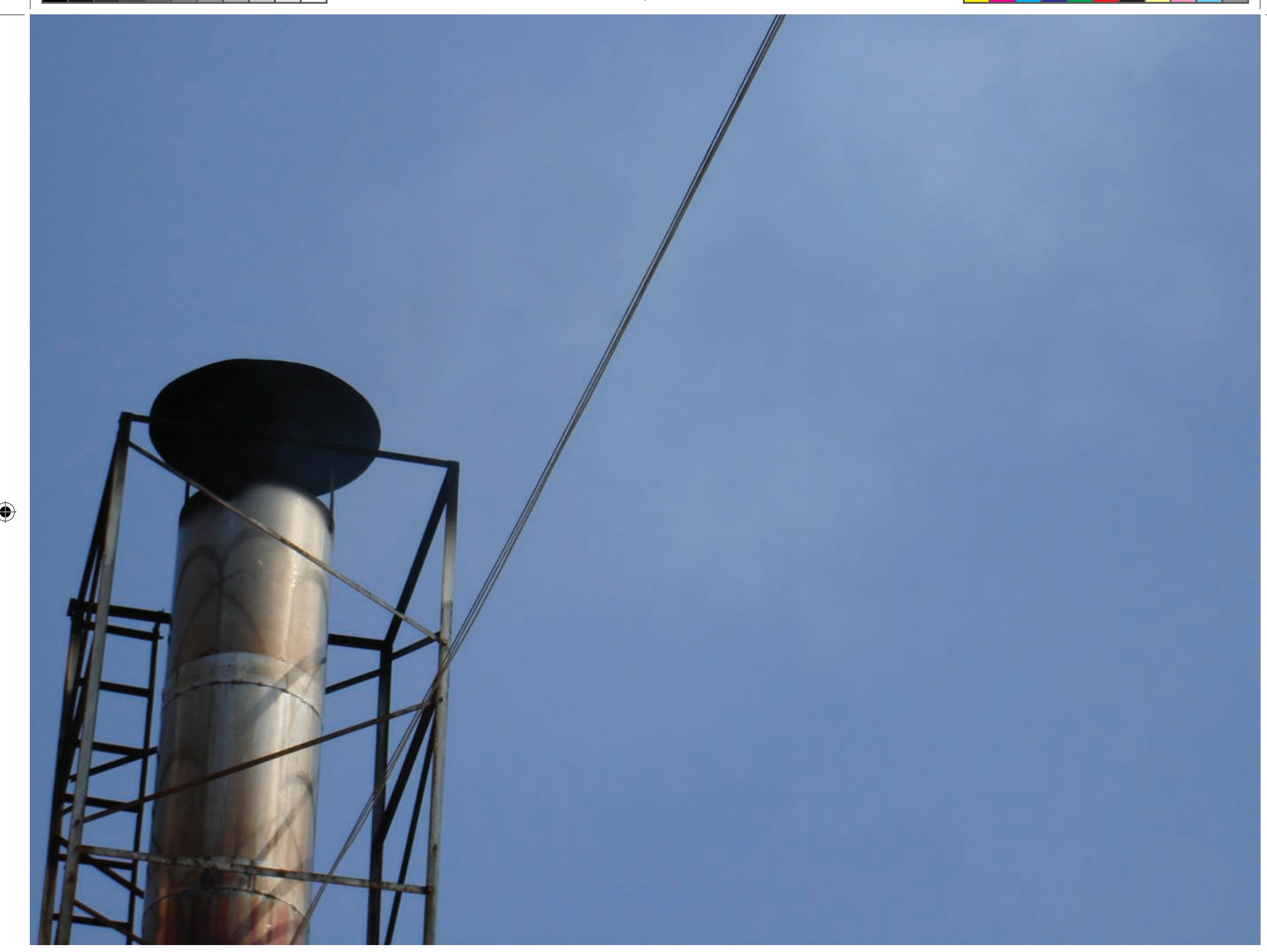


" 0 ateliê será sempre uma questão interna. Algo a ser preenchido, transformado, inflamado dentro do artista. 0 confronto consigo e com o espaço físico nos dá a dimensão deste vazio. 0 momento em que é necessário recolher as vontades e devolvê-las para o mundo através do fazer. 0 ateliê é um habite-se, a natureza de tudo e de cada coisa." 


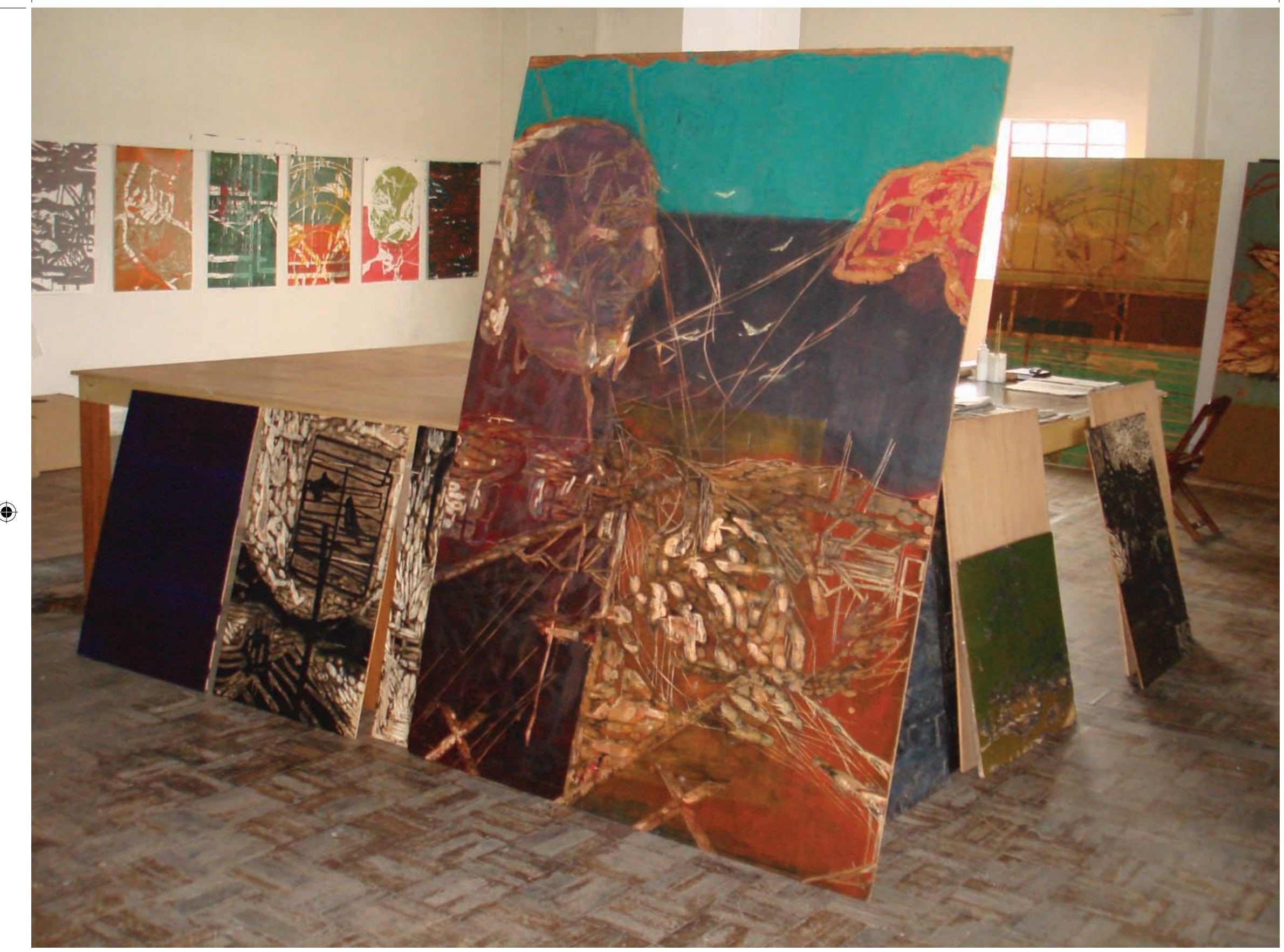



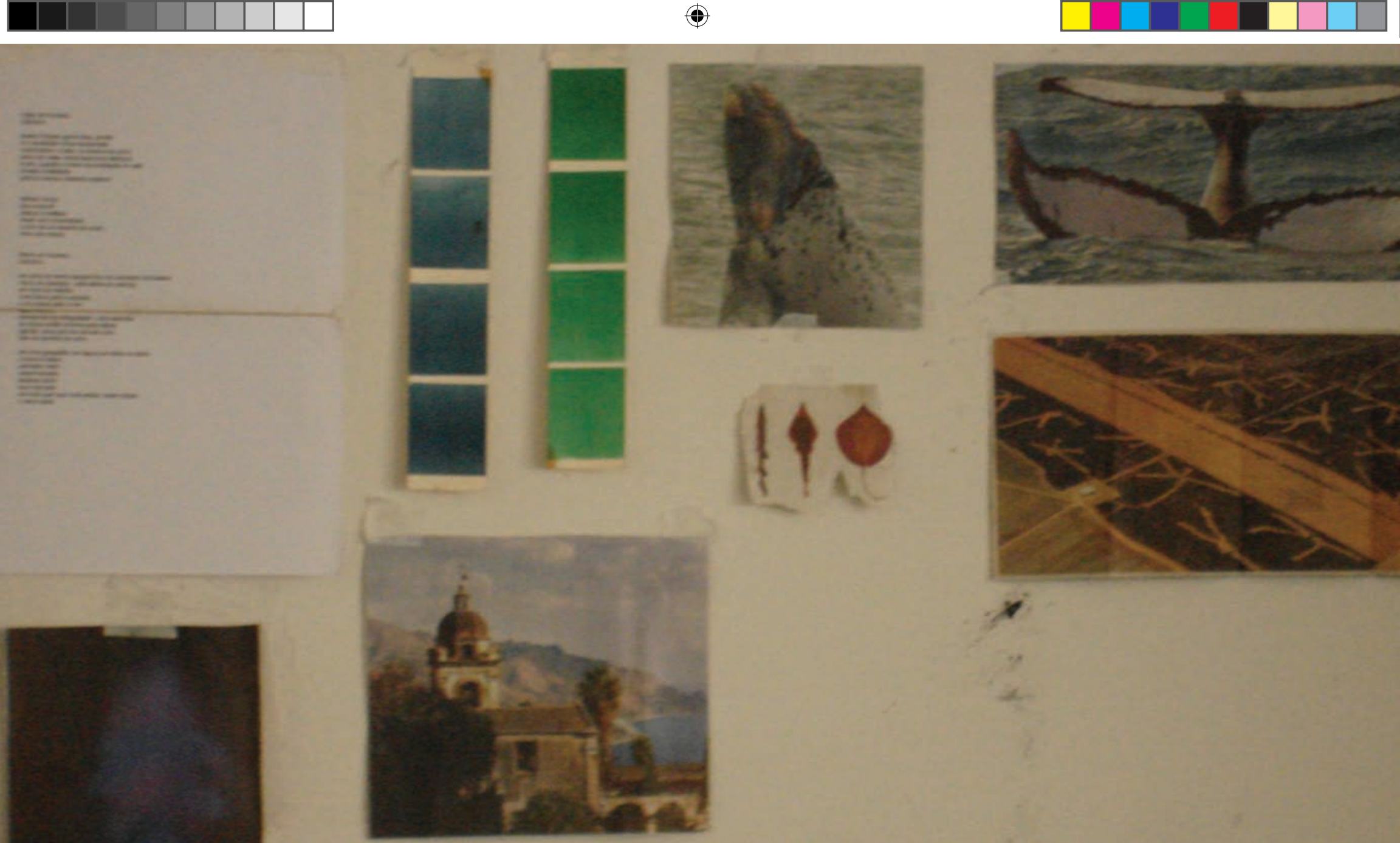

(4)
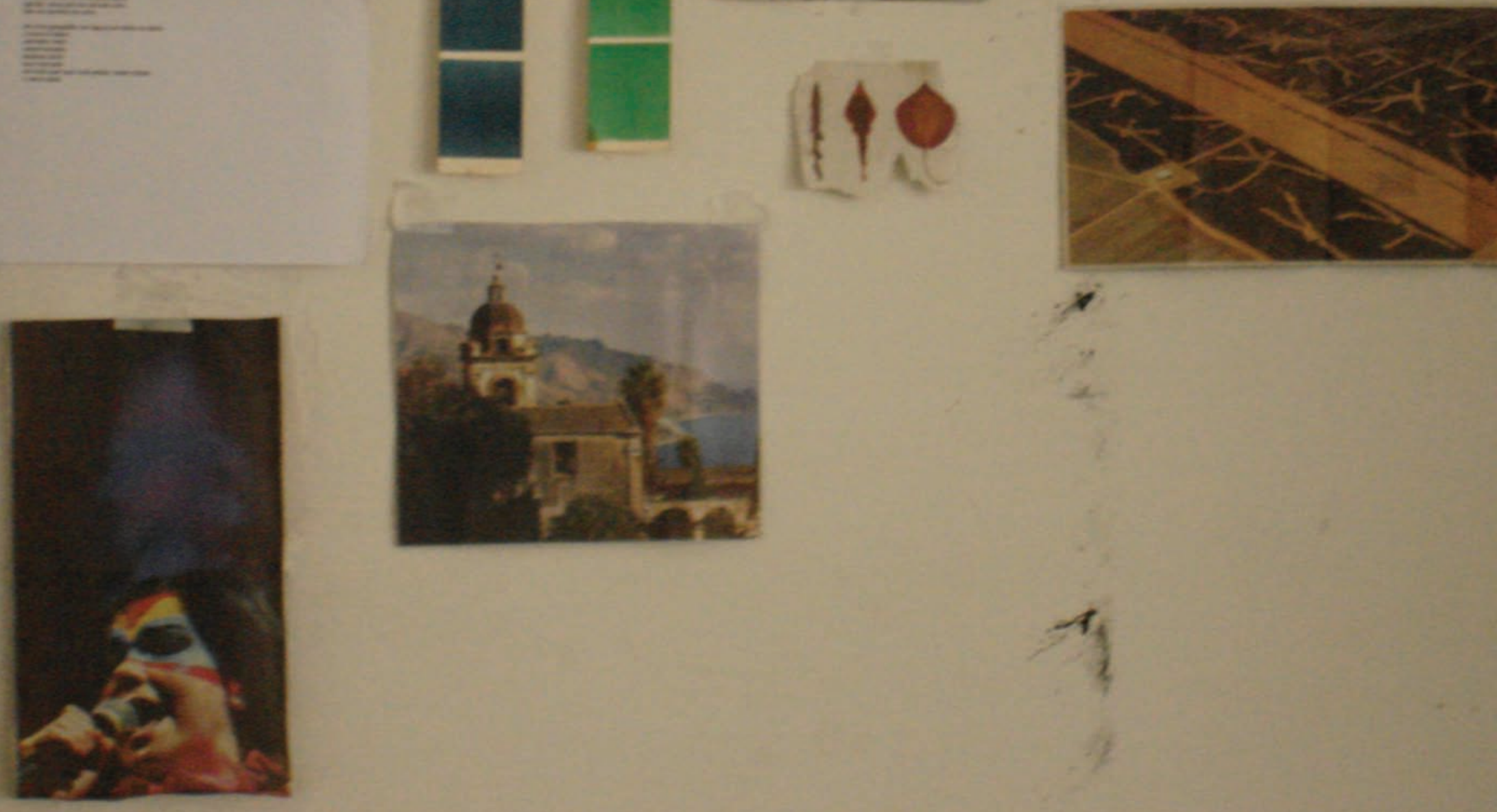

(†)

$-4$ 


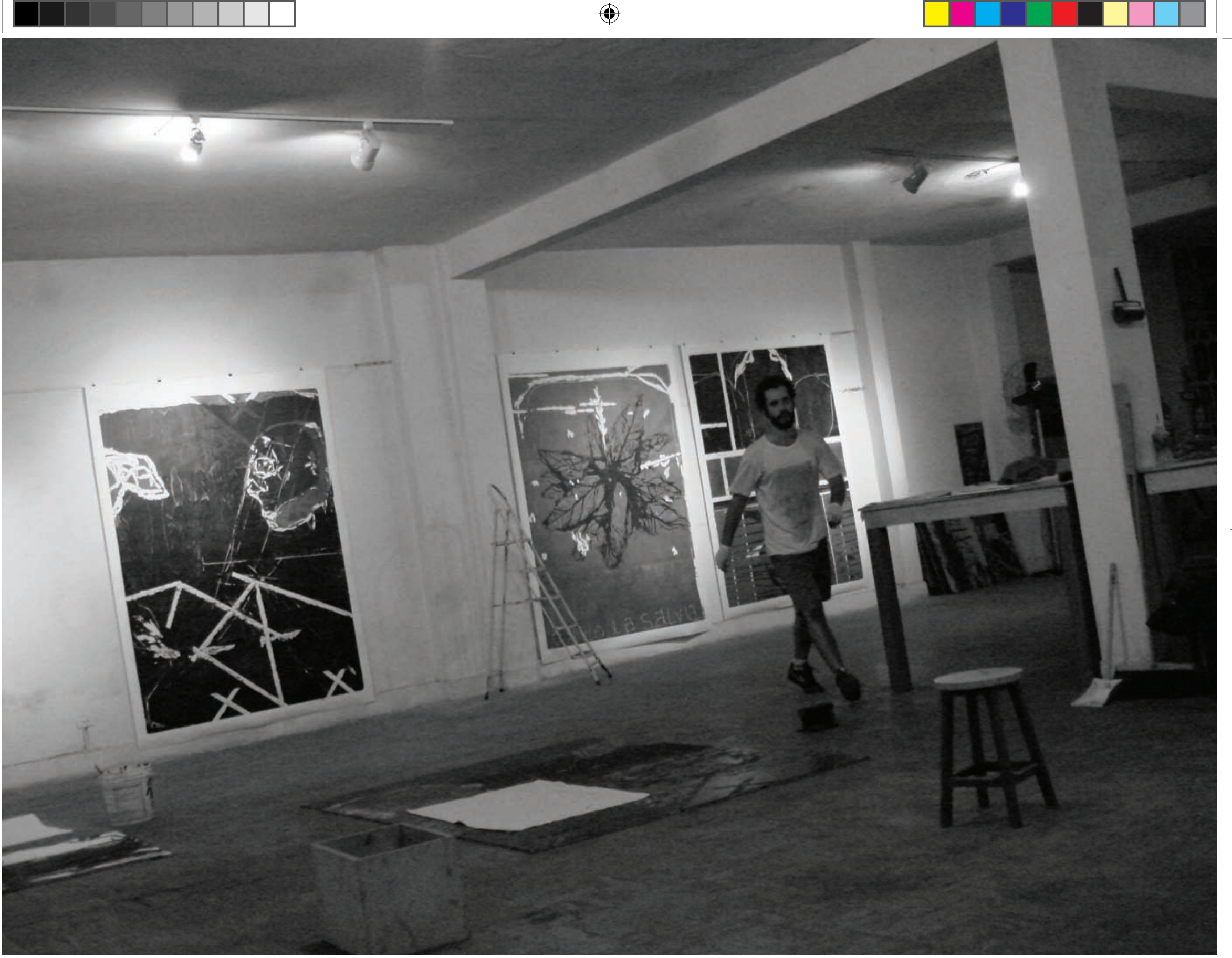




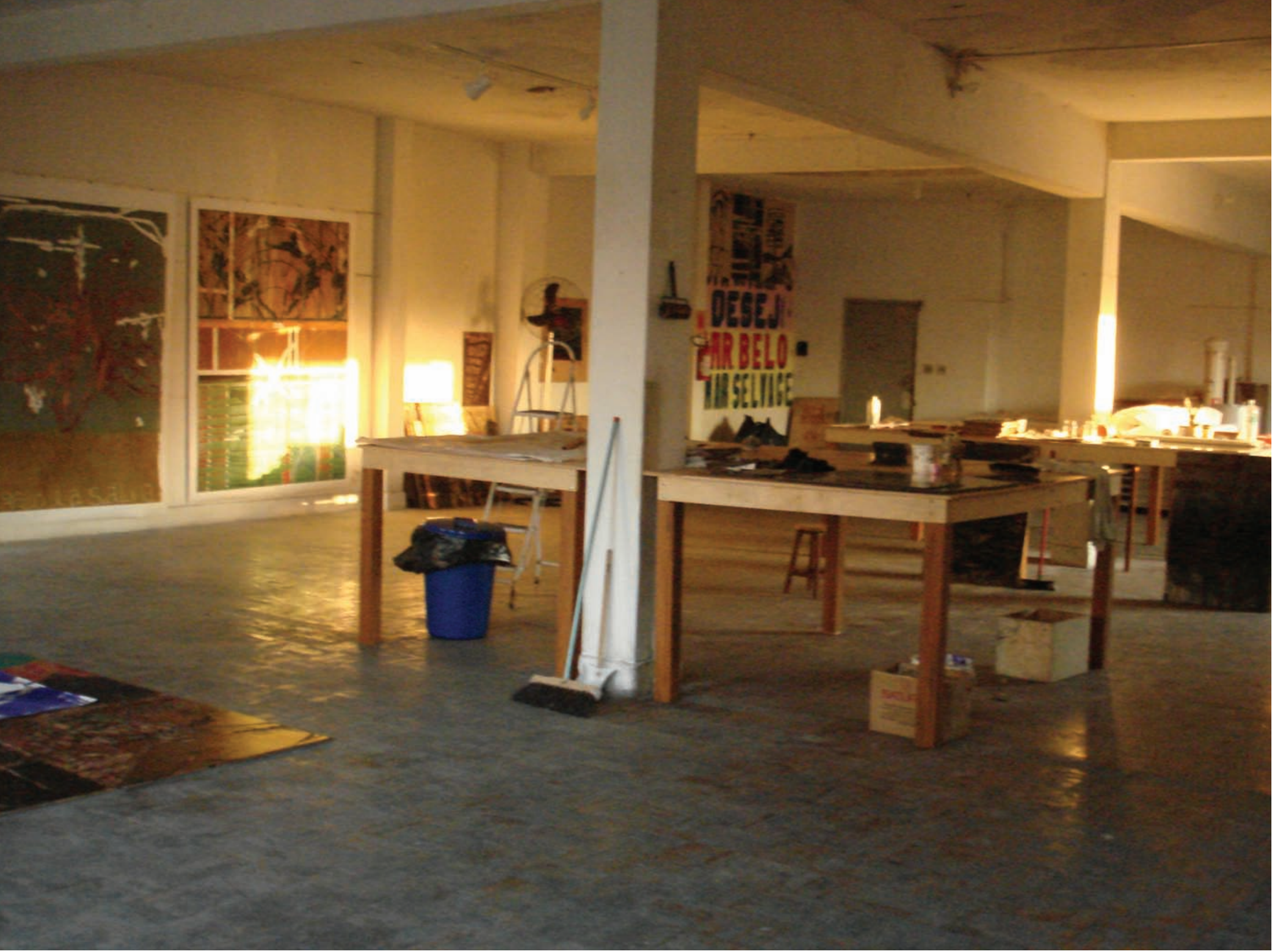



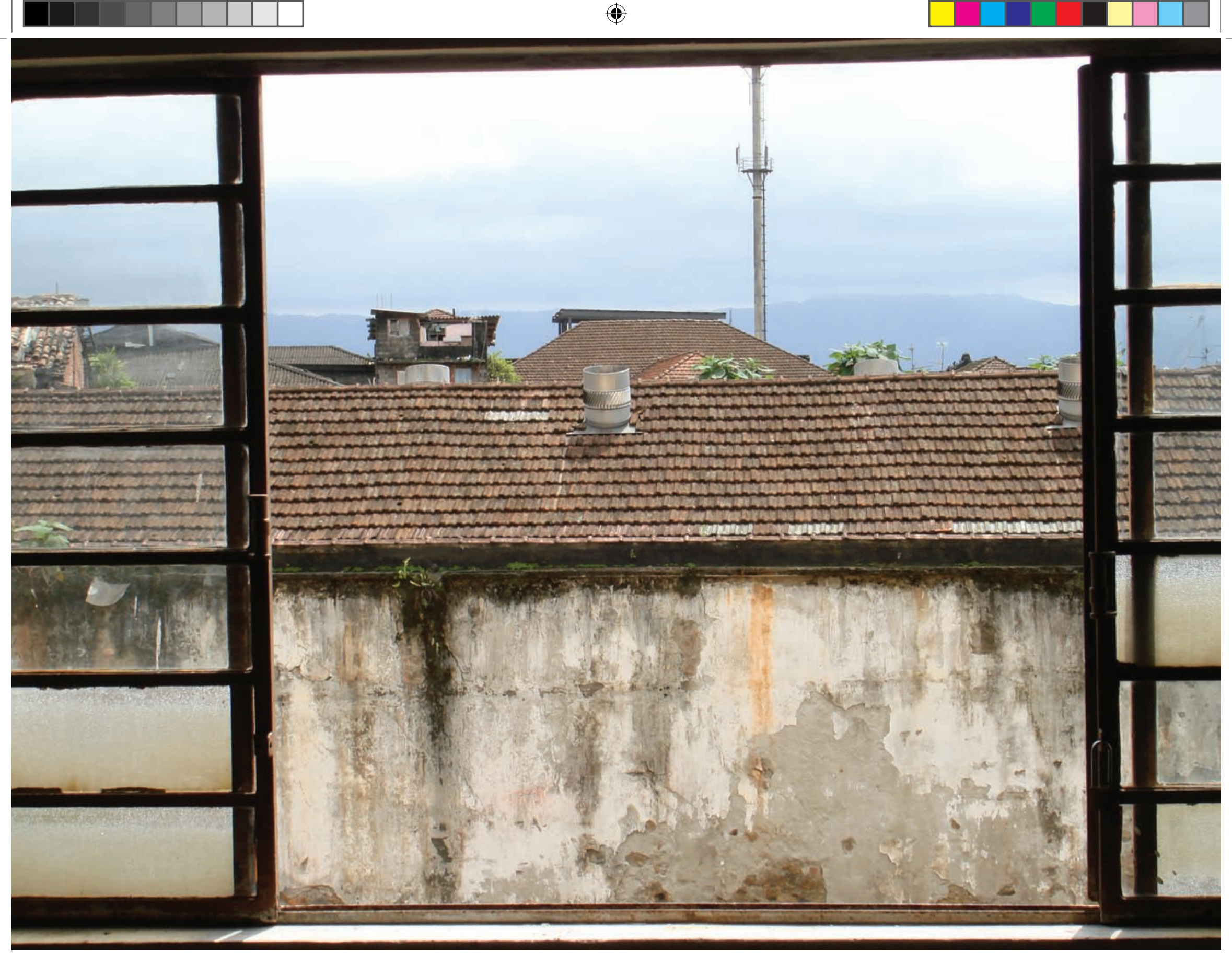
(4)

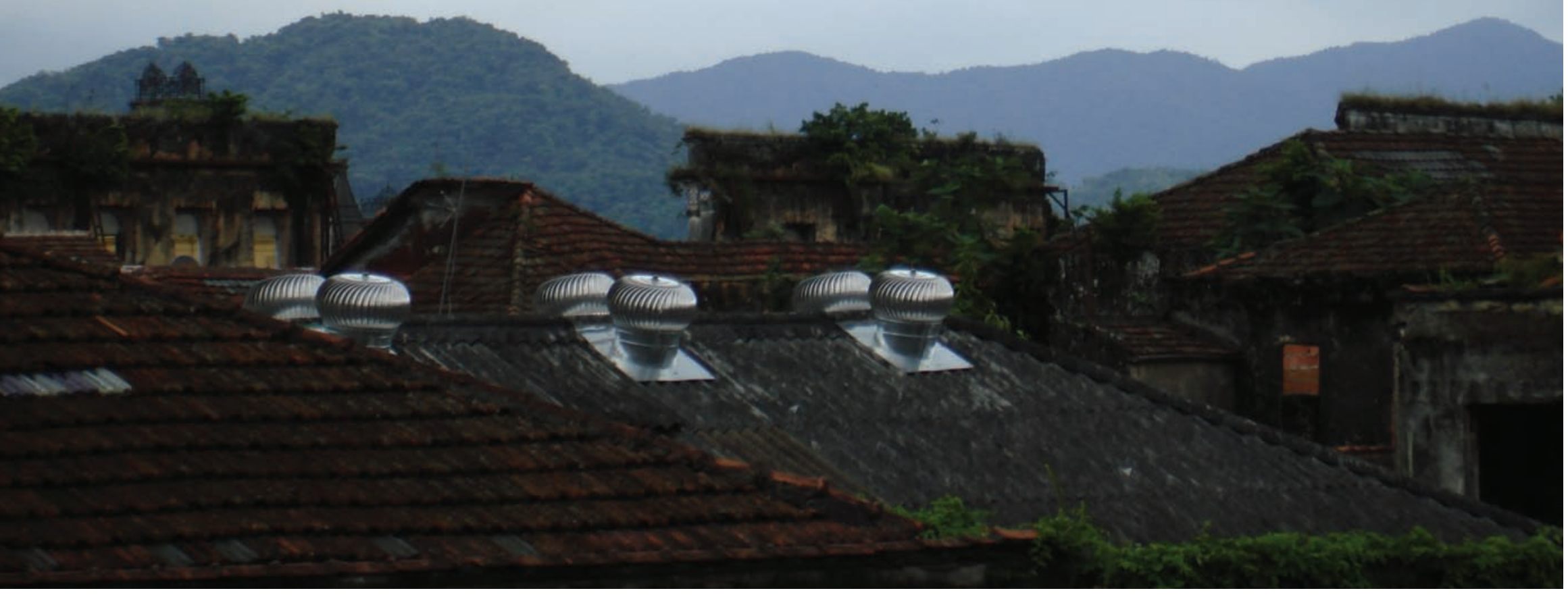




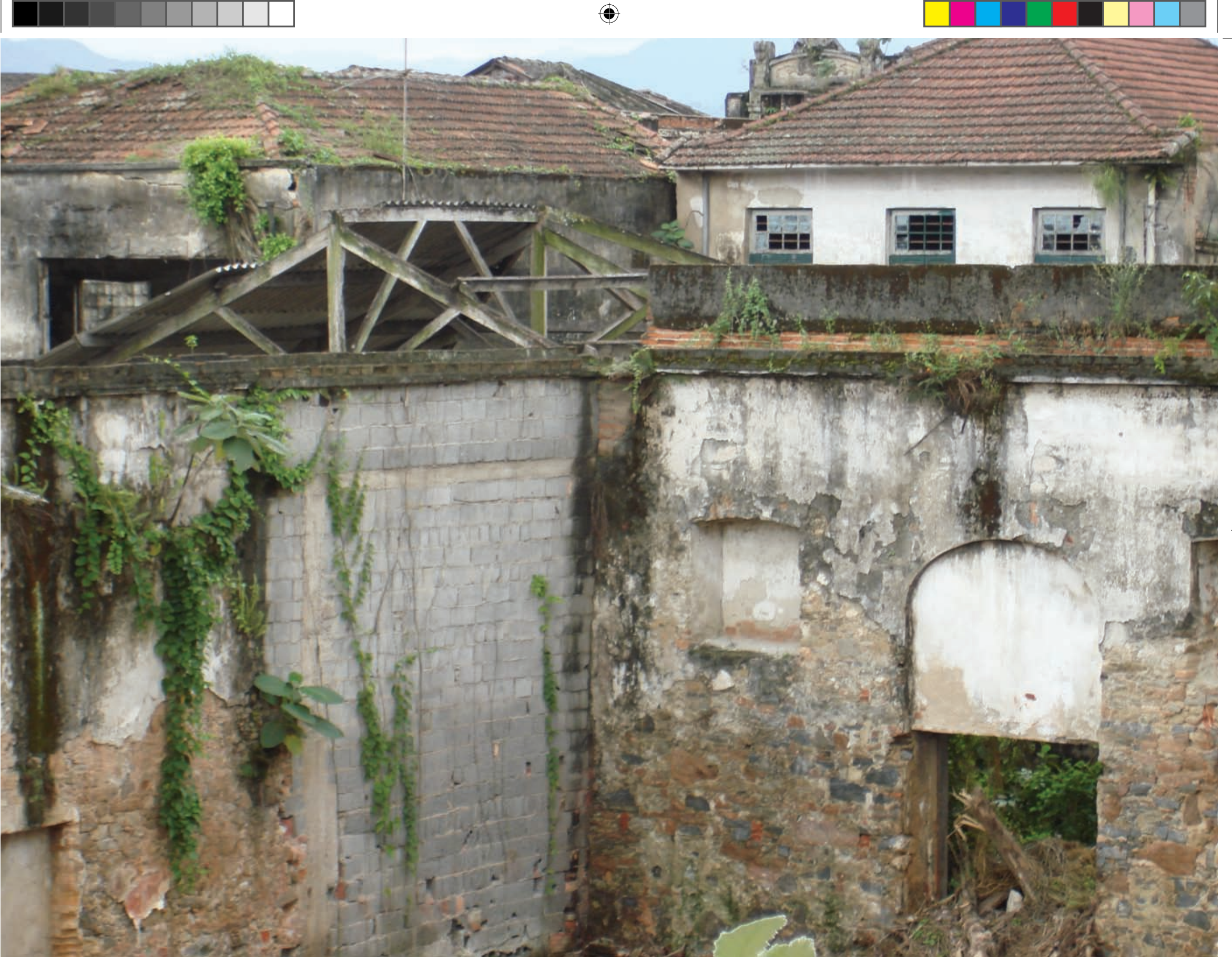




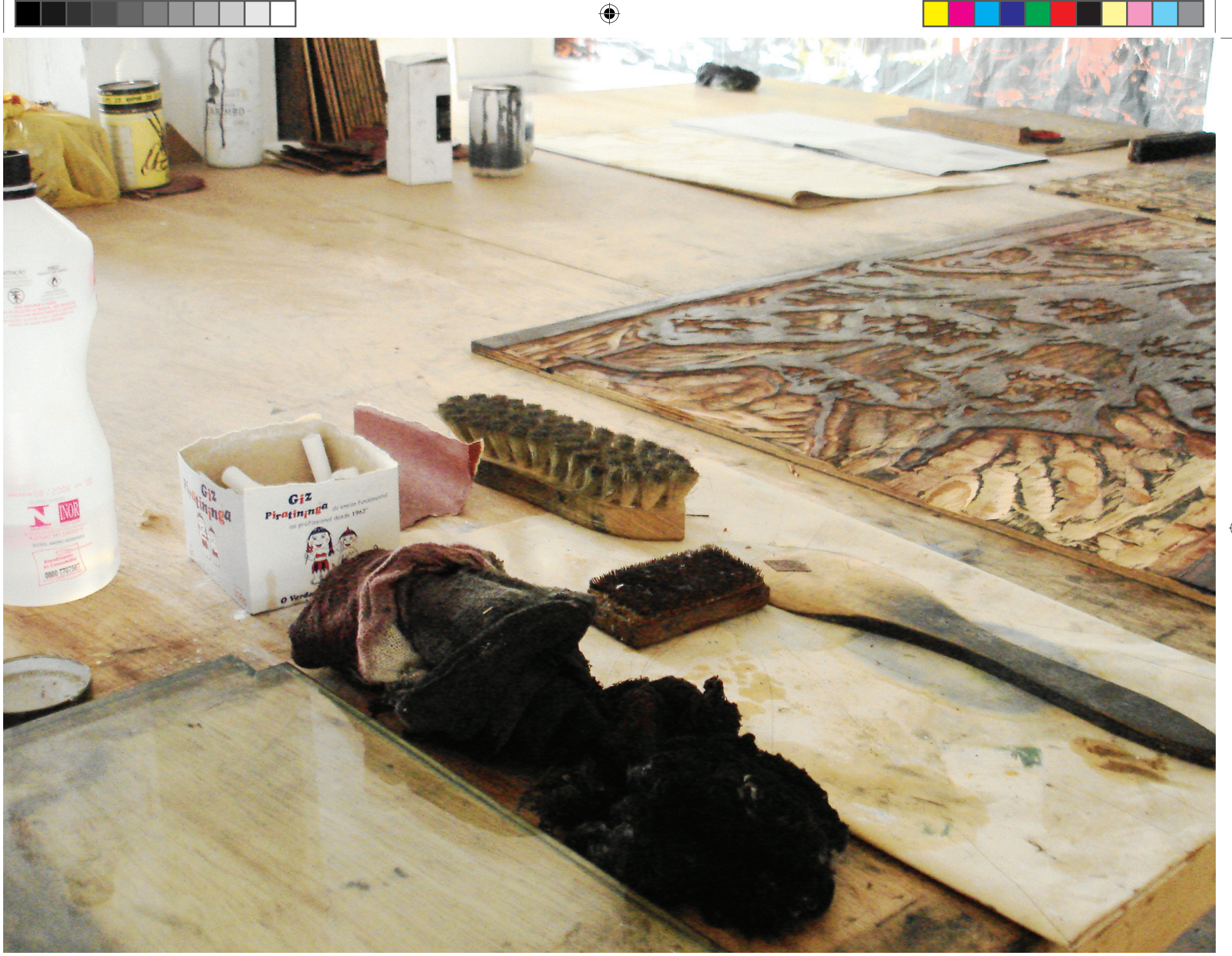




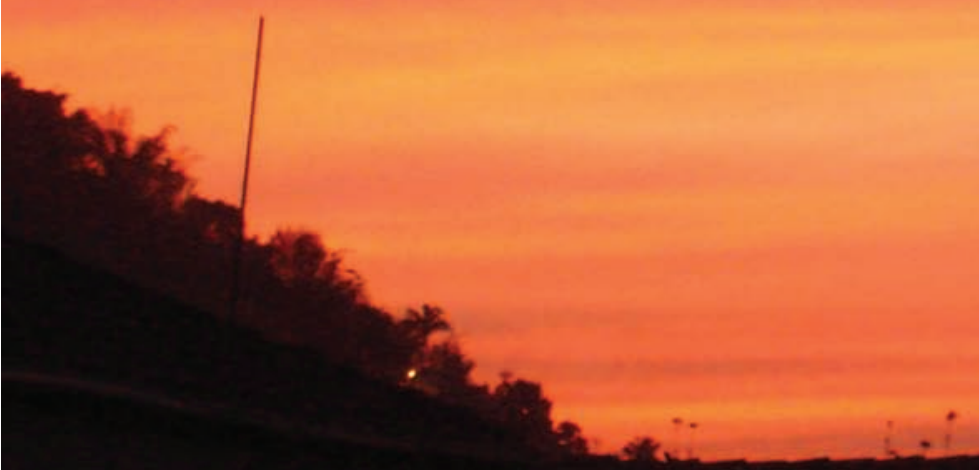




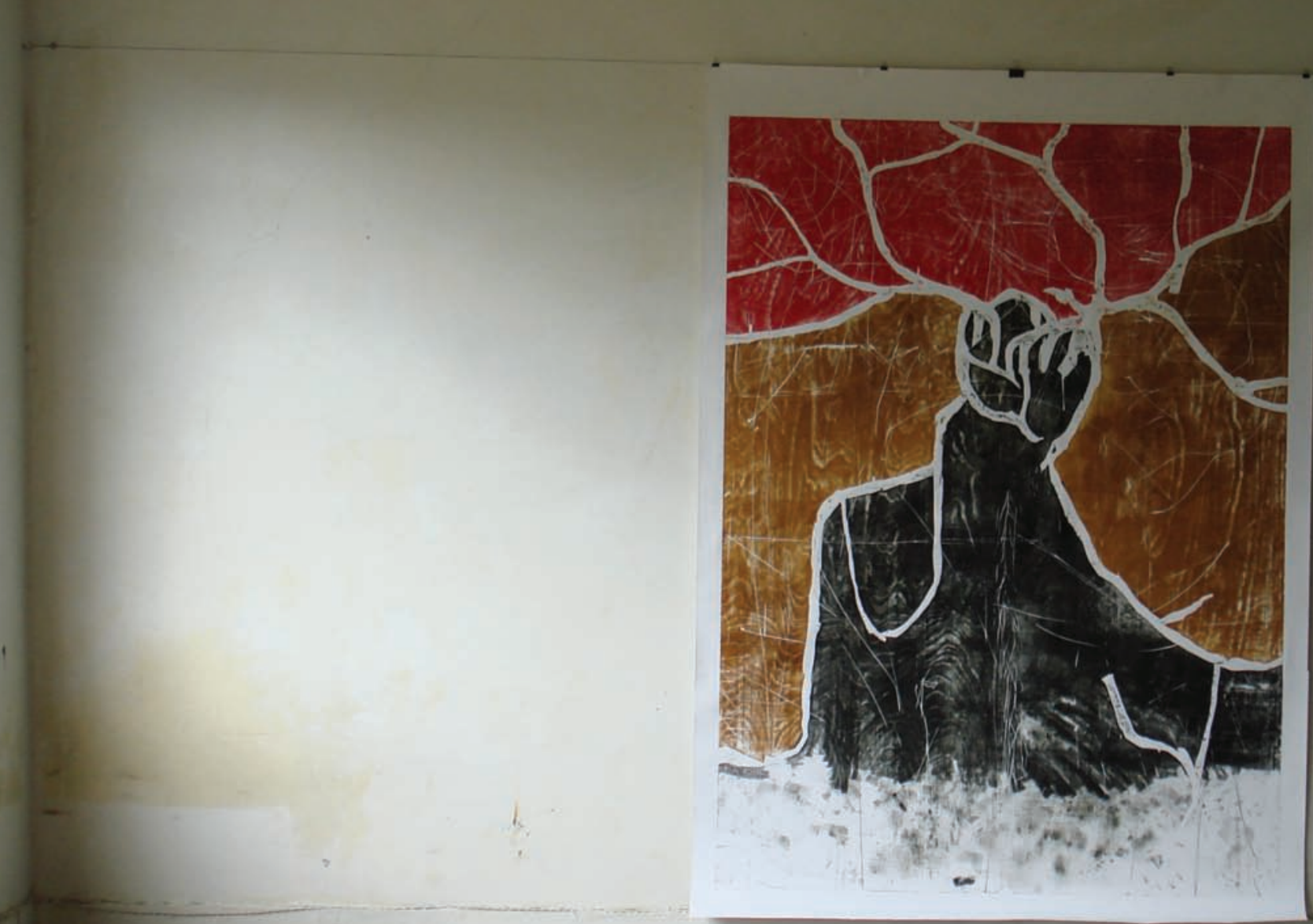

$\oplus$ 
"Fazia sempre diferentes caminhos dentro do ateliê. Era preciso habituar-se a cada movimento e lembrar onde estavam as coisas, os materiais, as ferramentas, as tintas e particularmente, eu mesmo.

0 plano do urubu. Planar: forma em relação as correntes de vento." 
\begin{tabular}{llllll} 
& \\
\hline
\end{tabular}

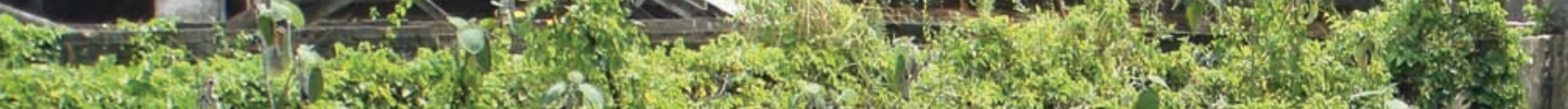

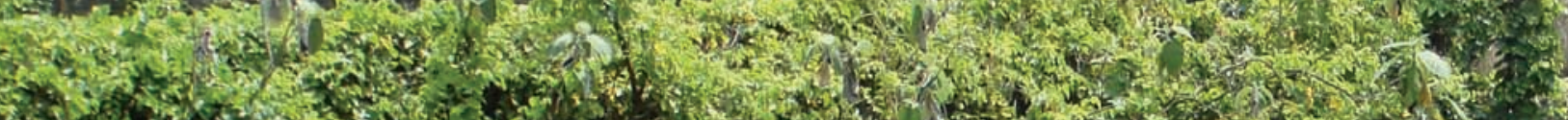

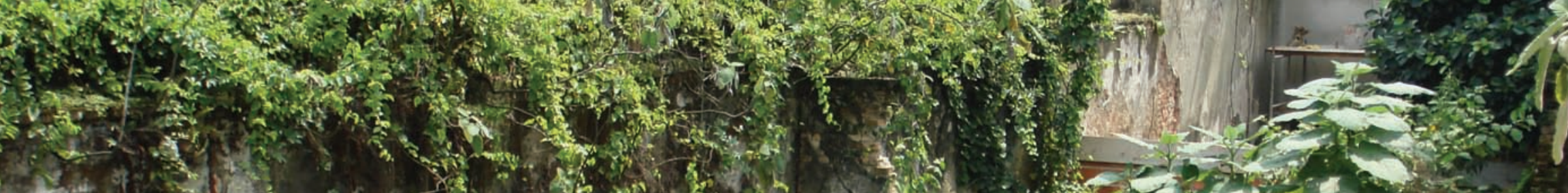

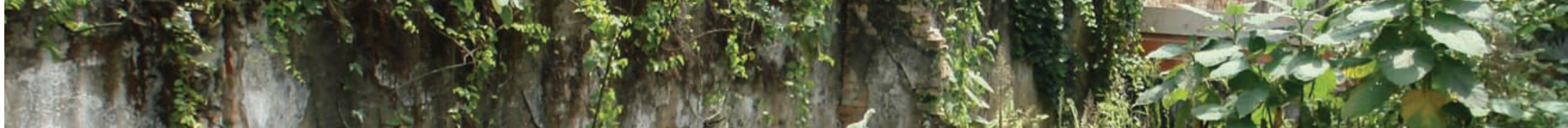
(1)

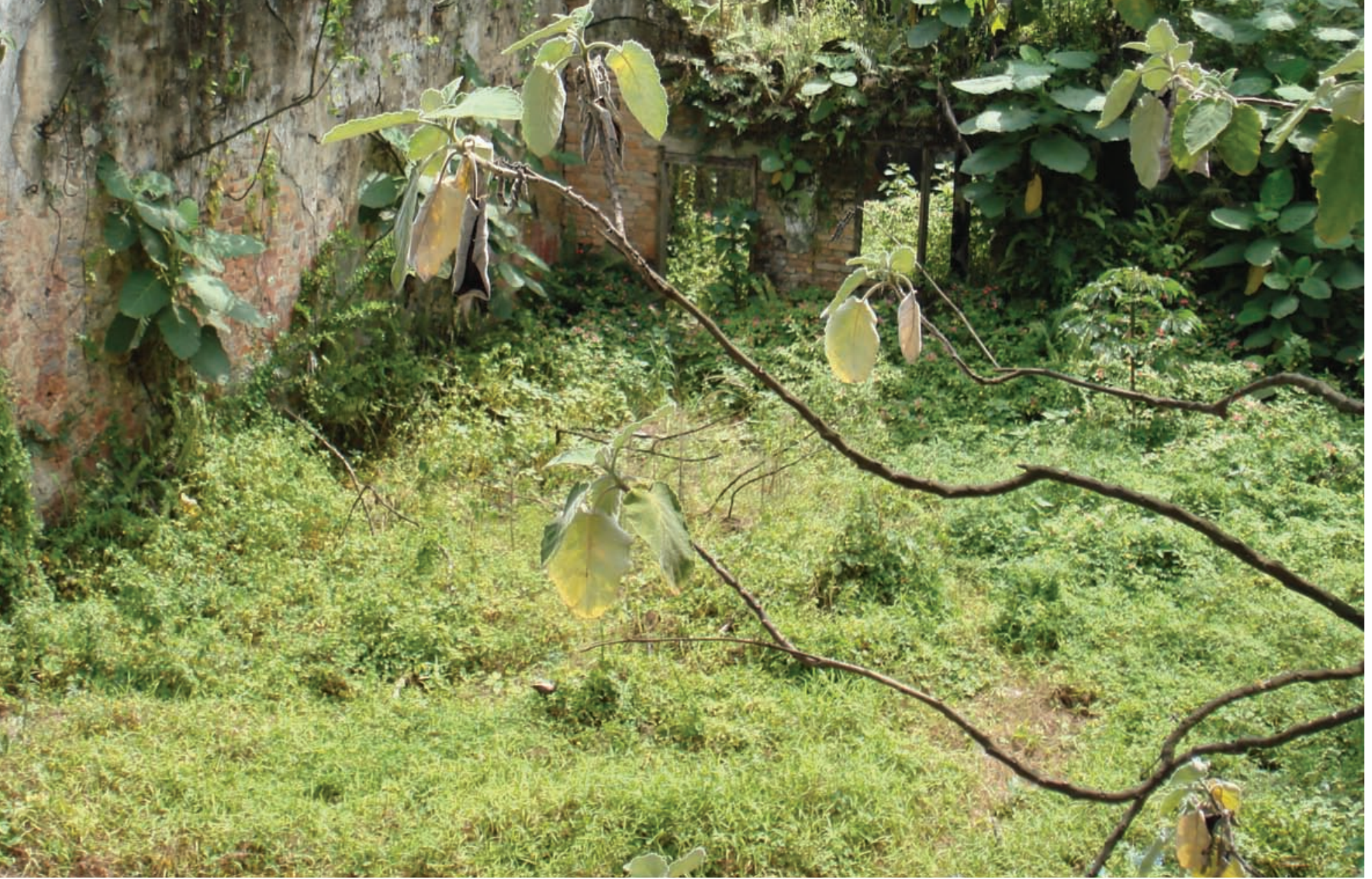

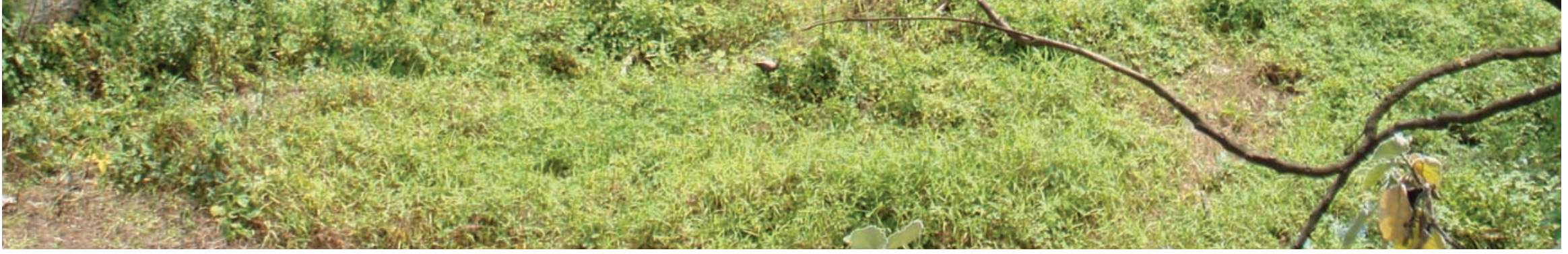




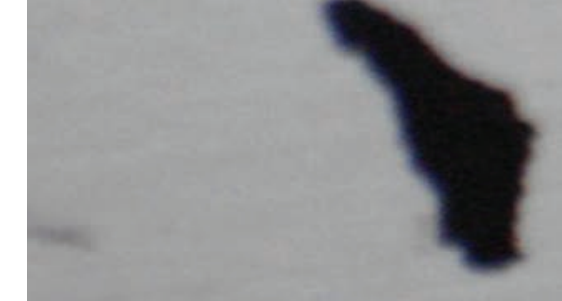




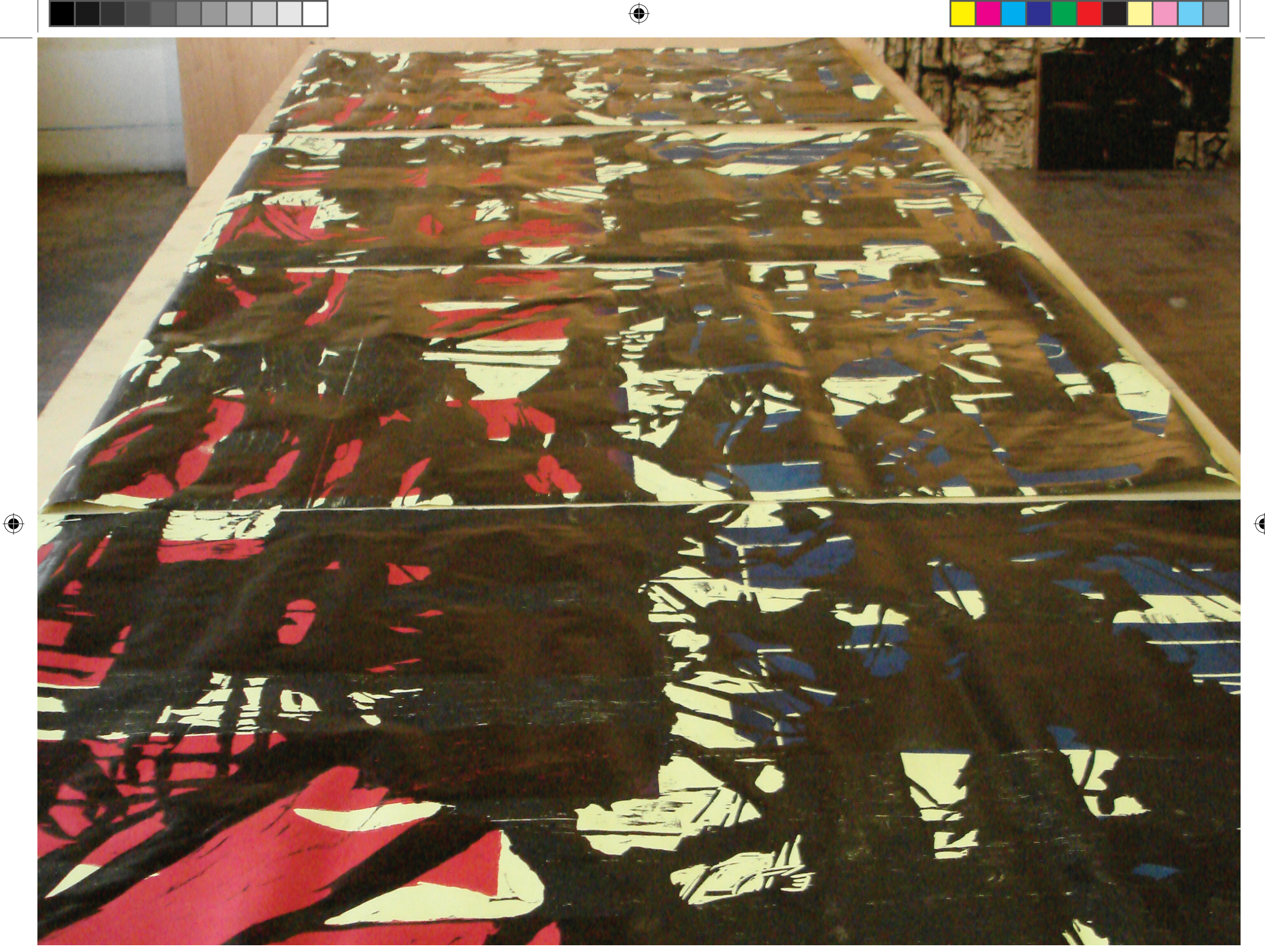




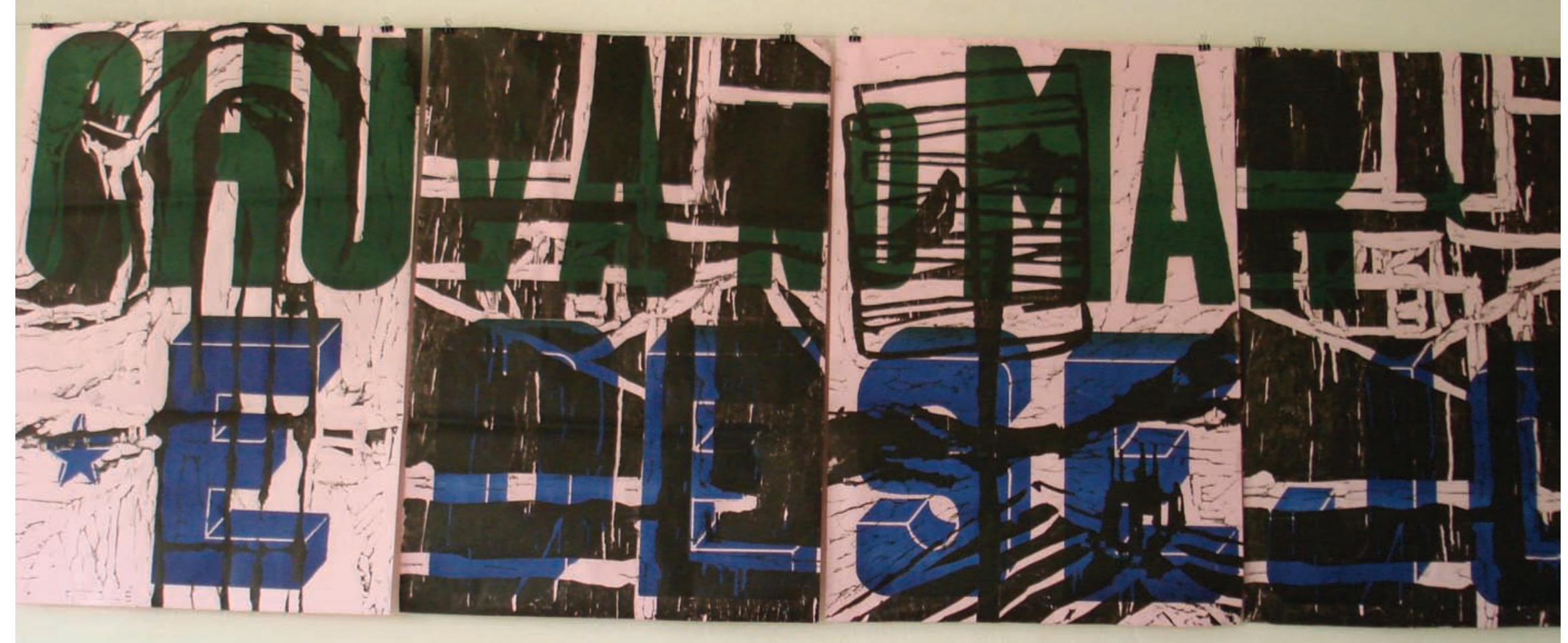




\section{- COR - paleta portuária}

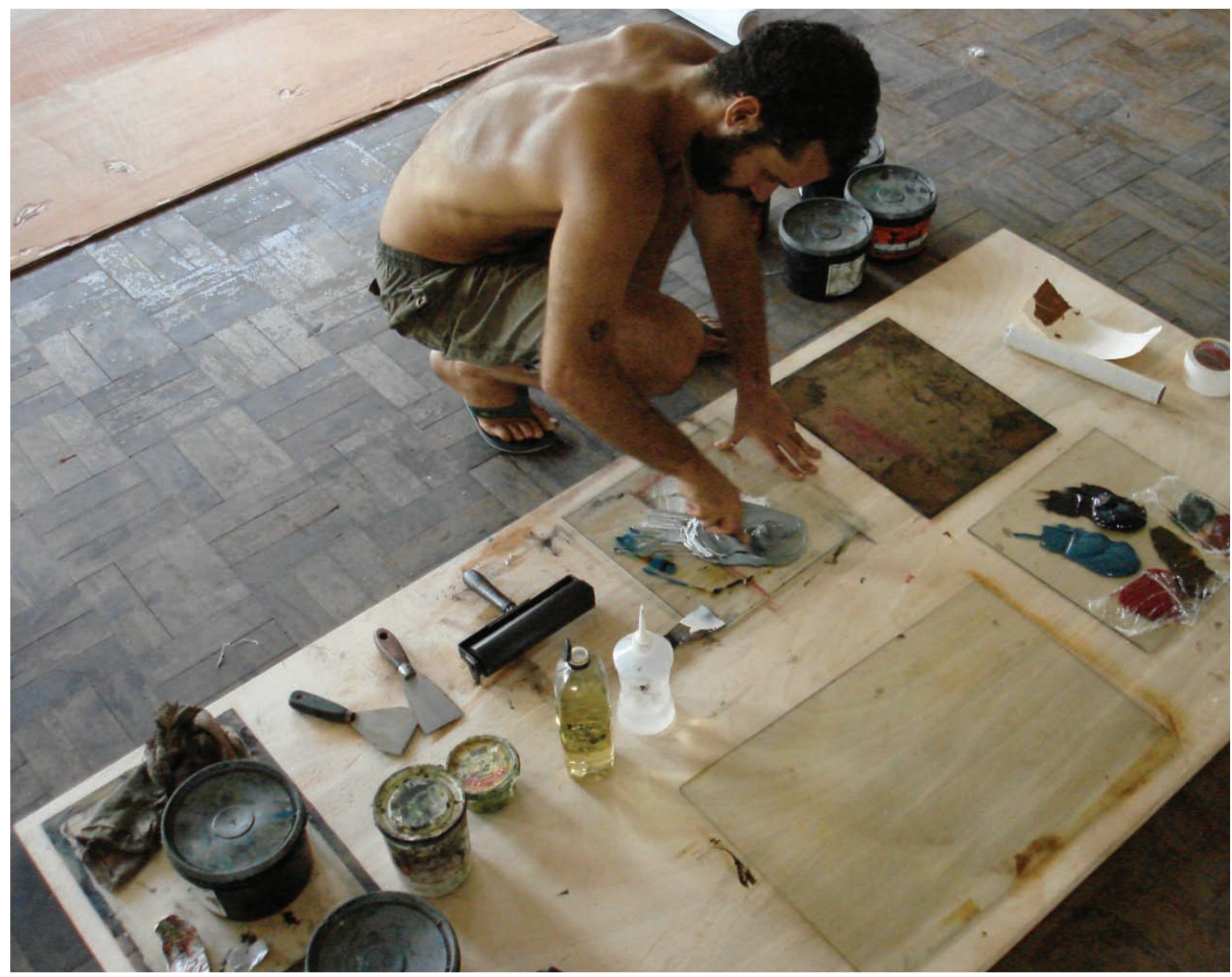


"A fusão do desejo e da técnica viabilizando a imagem e a imagem, por sua vez, exigindo sua própria carne e osso. 0 porto e 0 centro histórico carregam a degradação de atividades comerciais que lutam contra imposições naturais...0 mangue, a água salobra, a presença vibrante da serra do mar, as árvores que nascem nas paredes esquecidas e coloridas pelo tempo. A luz que banha este lugar está impregnada de sal, de fuligem das torrefações de café e enxofre dos galpões do porto.

O lugar é construído desta luz, da memória fixada nas paredes dos casarões que exibem um gradiente de cor indefinida, refletindo a consciência dos passantes acostumados com 0 esquecimento.

Lopes Leão mostrou o vermelho-rosa desta longitude.

A madeira tensiona 0 desenho e a cor principia-se na talha, golpes de luz que indicam a presença e a ausência da ação. A matriz gravada como uma camada pictórica independente.

A imagem impressa aponta para os procedimentos da pintura, e a cor participa como elemento intuitivo, sobrepondo, anulando e somando-se a camadas anteriores. A imagem surge, de forma não linear, transbordando conteúdos de matrizes diversas.

Um jogo de significados entre o desenho gravado, a cor e a imagem impressa.

Muitas vezes um trabalho diverso aponta o caminho, a cor, a trama a ser utilizada em uma outra imagem. Não posso medir esse tempo, tampouco prever as inter-relações de significados que levam meses para clarificar, e por vezes se dissipam sem cerimônia.

A formulação da cor atua de forma independente, e cada imagem exigirá uma necessidade técnica.

A paleta de cores desenvolvida para centro histórico de Santos reflete a vontade de corresponder-se com o meio, oferecer algo que aproxime o trabalho do ambiente, do estado e da natureza das coisas.

0 amarelo porto é uma lama verde do mangue, cor úmida.

0 vermelho índio é o que vibra ao fundo das construções, o vermelho utilizado pelo artista andarilho da cidade, o desenhista portuário, político que constrói seus materiais com restos de gesso, giz, tinta industrial, sobras de armazéns, terra e limo das construções.

0 verde frontaria é a raspagem da Casa da Frontaria Azuleijada - antigo depósito na rua do Comércio.

0 azul mercado alude a água do canal do porto,da bacia do Macuco de onde saem as catraias." 

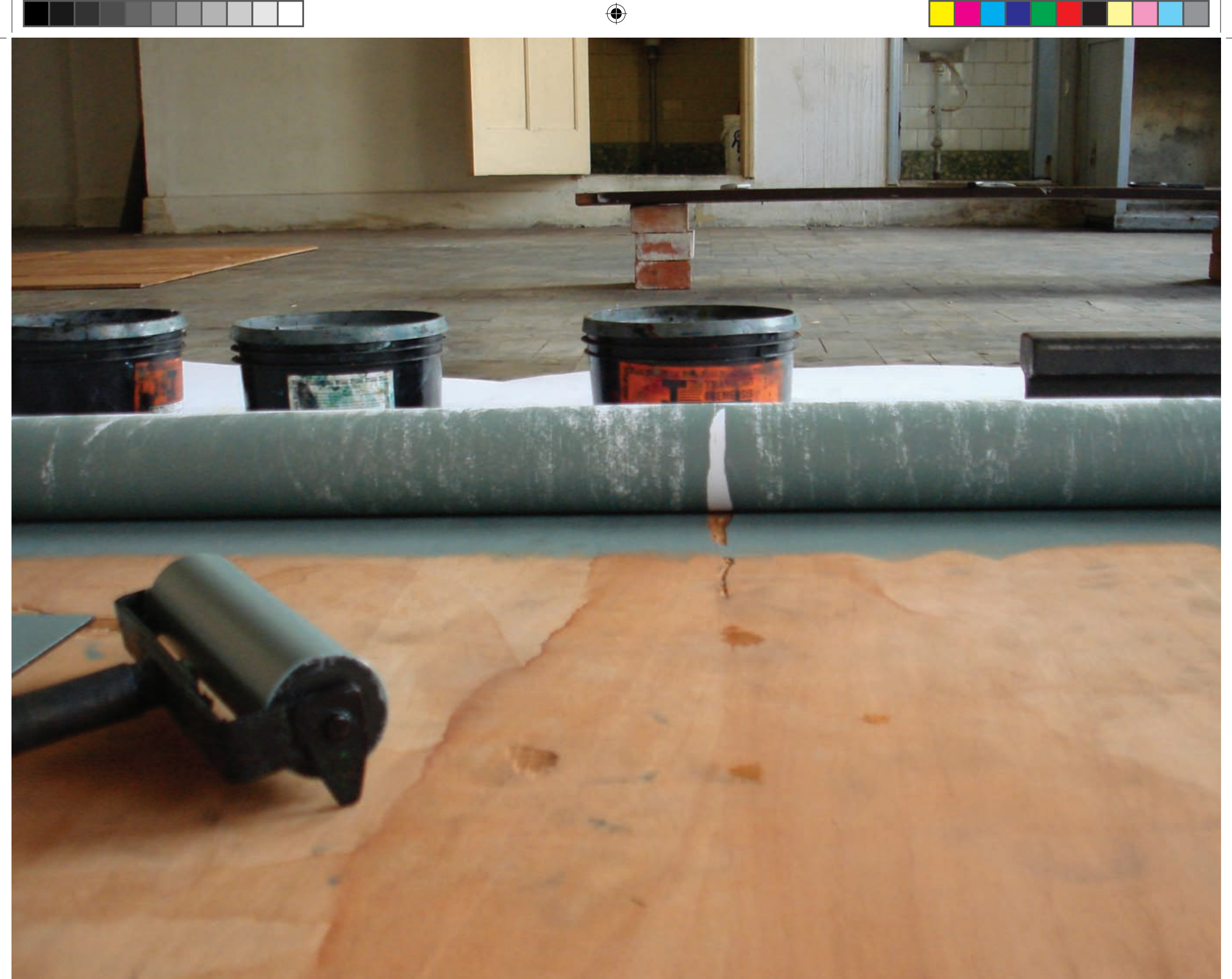


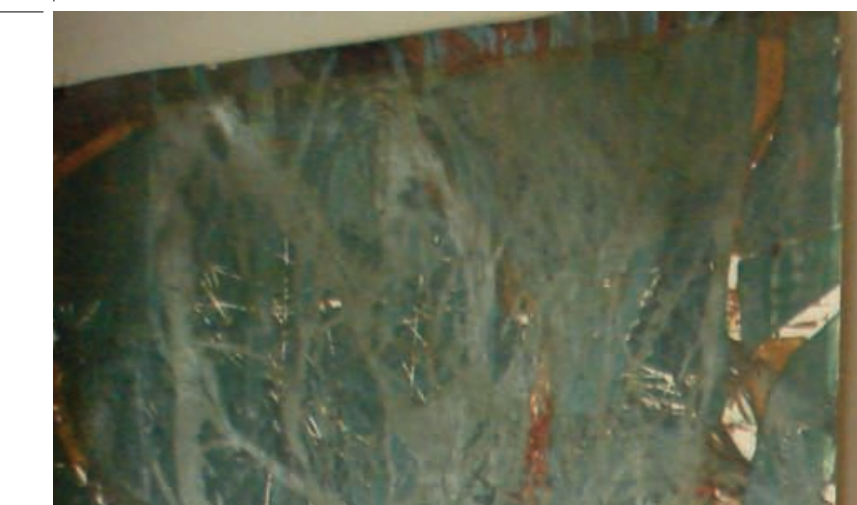

and a d a (1) - $2 x-4=$

๑)

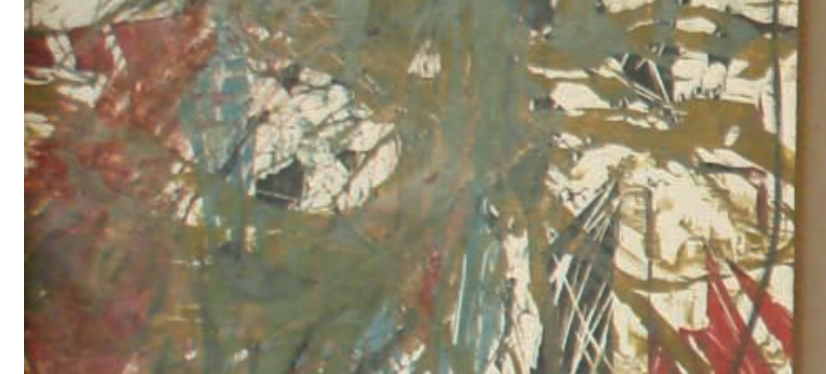

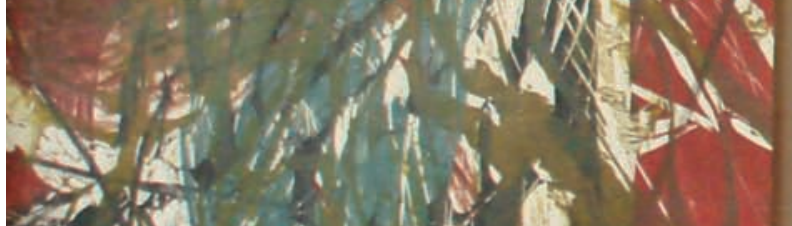

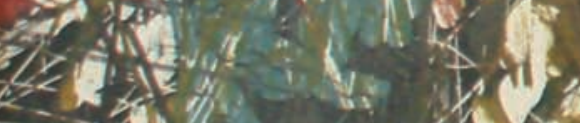
a. 1 (1)

mioloVOL01.indd 109

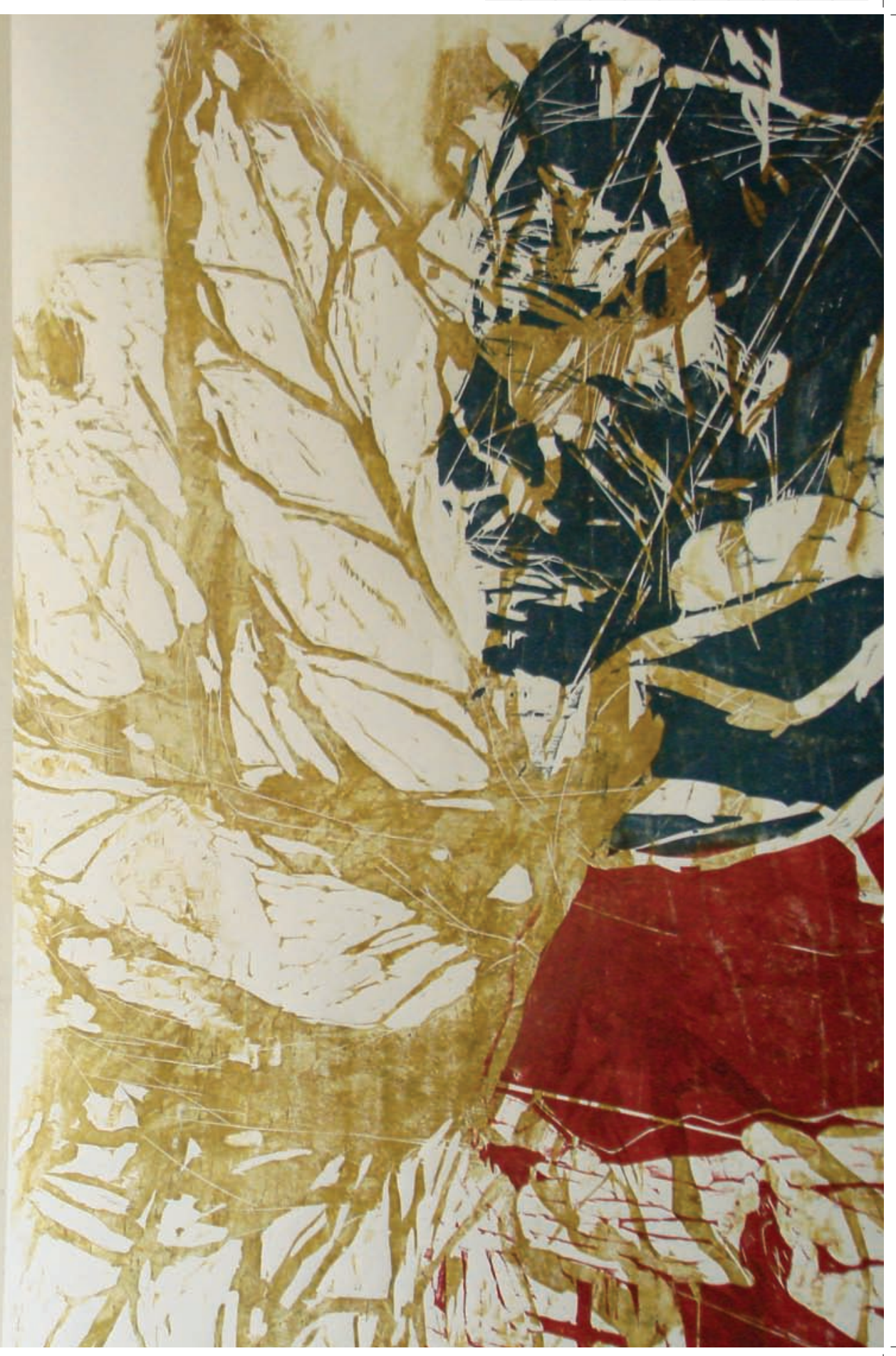

04.03.09 23:23:33 

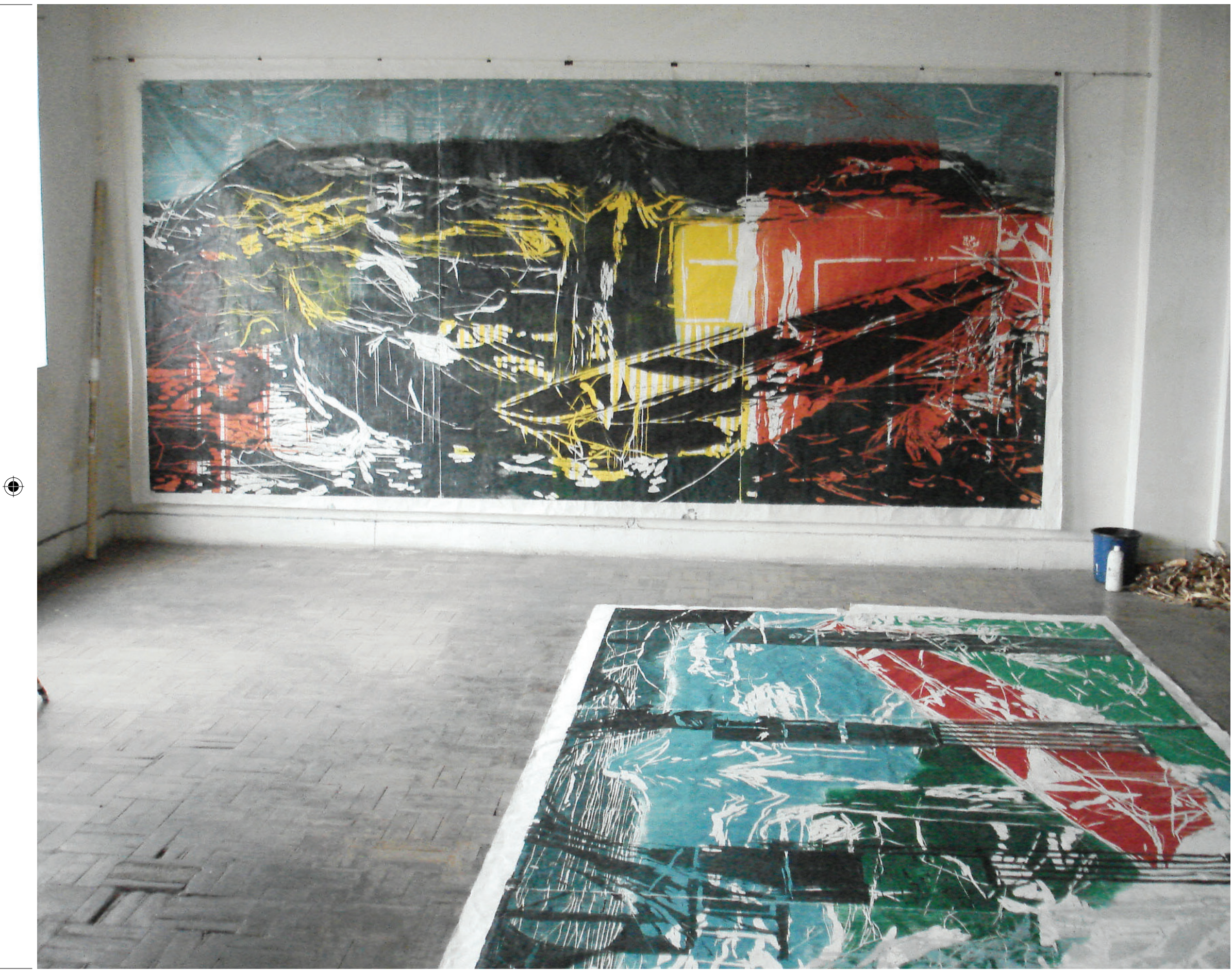


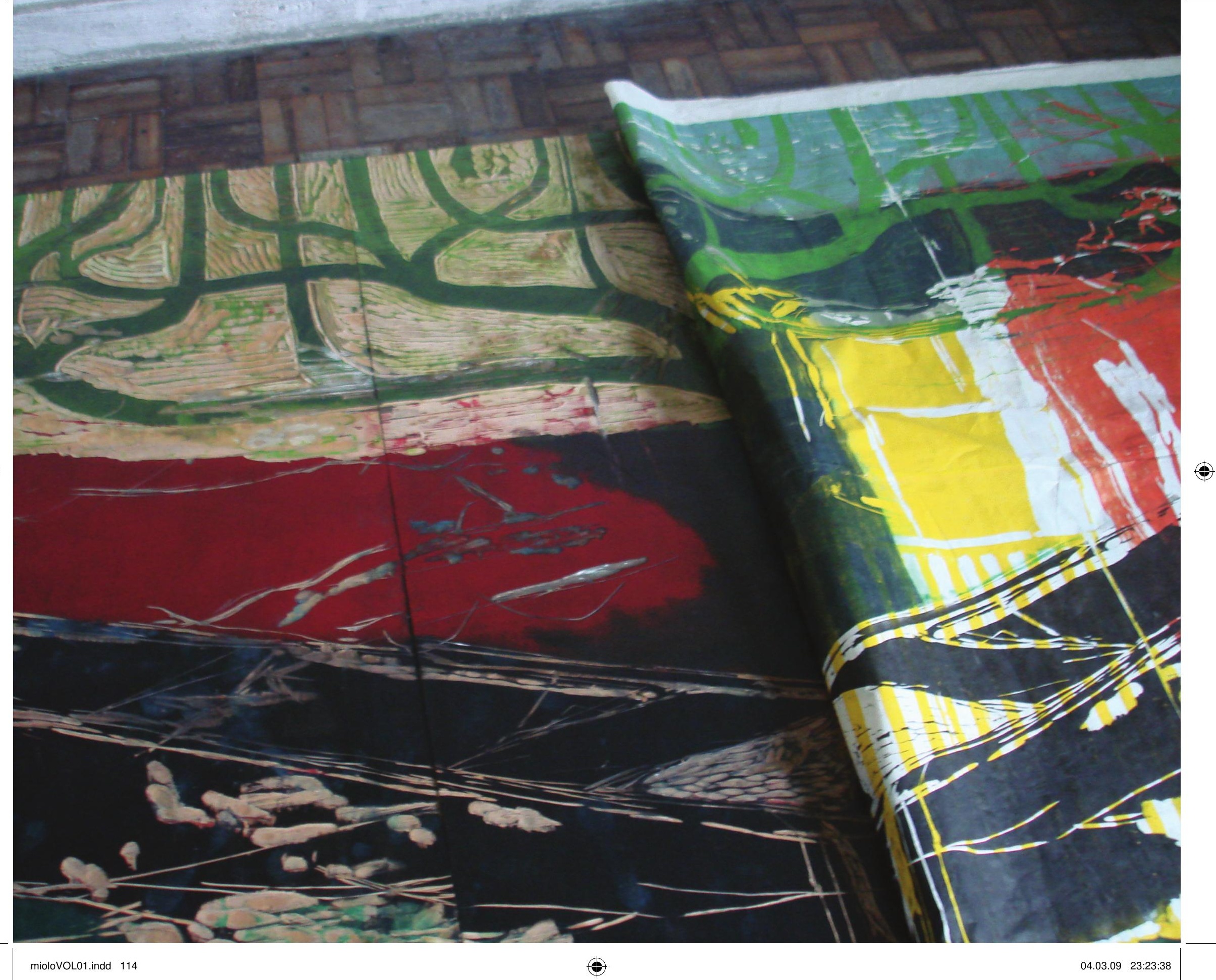




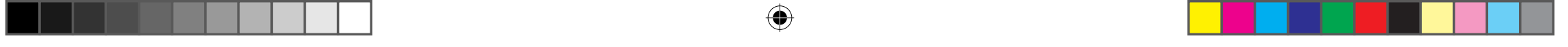

(4)

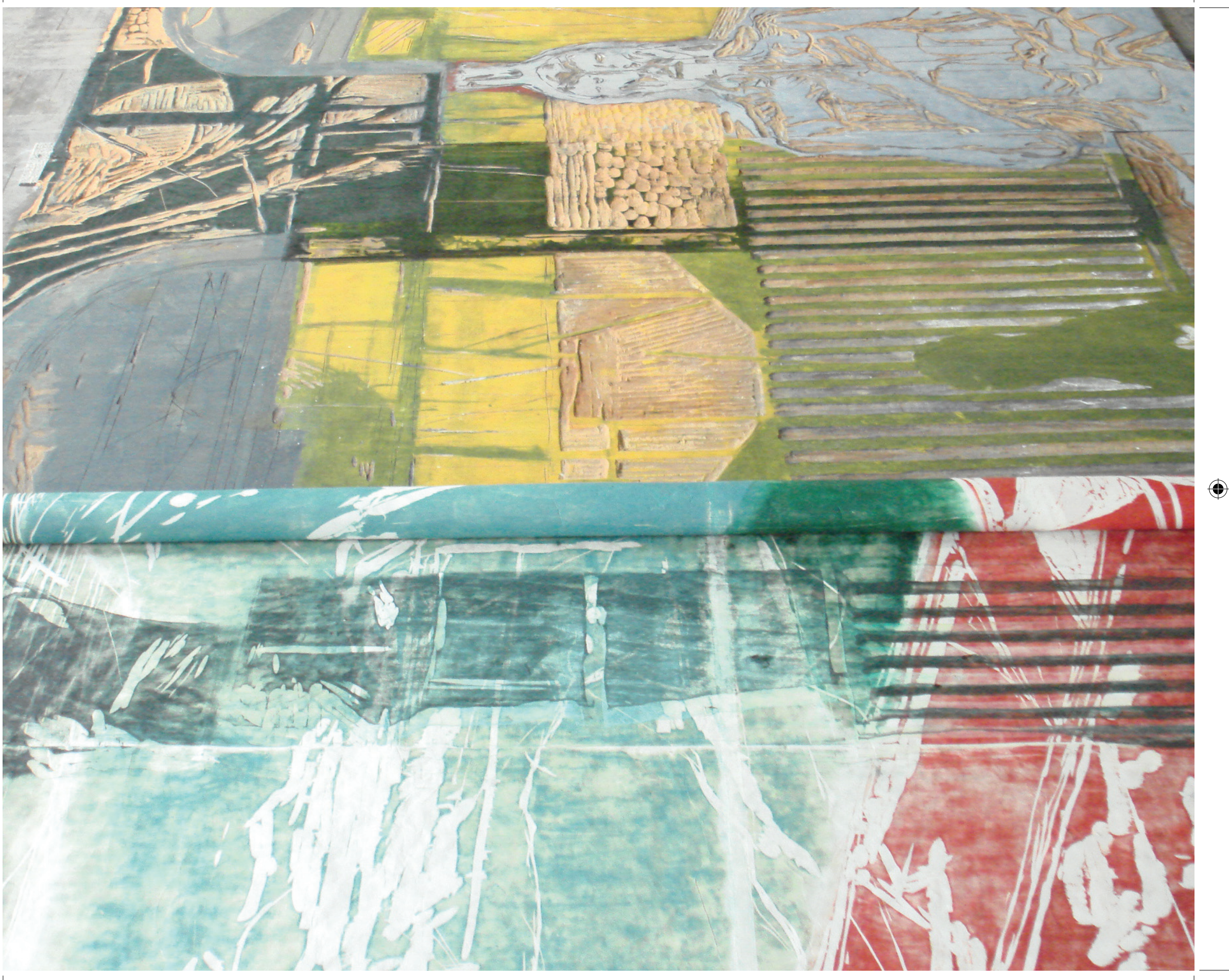




"Demarcação ponto central: trabalho espiritural

Arte e função: resolver os problemas da matéria

Construção imaterial: pensamento e alma

Transbordamento de fora para dentro

\section{Gravação Geral}

Atmosfera: privilegiar os campos de cor e dar ênfase a linha

Trabalhar tons terrosos, cinzas e alaranjados. úmido, com suor.

0 trem emanava da serra. A serra urge! A serra urde. A serra ruge! Muralha verde chumbo.

0 tempo antigo em que arremessava pássaros verde claro/vermelho terra entre 0 continente $e$ a ilha

para habitar a cidade entre os homens

o paredão verde luminoso negro e profundo.

0 tempo modifica-se, tomando o pulso em frequência com este volume de matéria viva com toda lama e animal desconhecido.

Banho de claridade.

0 que é o desejo: a navegação no próprio rio - íntimo e misterioso que logo é mar - não existindo nada mais envolvente do que a água esse mergulho com tempo determinado

é contra a própria natureza do humano.

Enxergar o vale, a cidade estendida

Esparramada entre faixas sinuosas de calda prata

A beleza e 0 medo de remar para 0 inevitável" 
- BIBLIOGRAFIA

Alexander, Caroline. Endurance: a lendária expedição de Shackleton à Antártida. São Paulo, Companhia das Letras, 1999.

Araújo, Hilda Pereira de. Santos: uma história de pioneiros, piratas, revoltas, epidemias, carnaval e futebol. Santos, Realejo Edições, 2007.

Balzac, Honoré de. Le Chef-d'oeuvre inconnu et autres nouvelles. França, Éditions Gallimard, 1994.

Camargo, Iberê. Gaveta dos Guardados. São Paulo, Edusp, 1998.

Carrera, Eduardo. Os estudos de Leonardo da Vinci sobre a arte da pintura. Brasília, Imprensa Oficial, 2000.

Costella, Antonio. Introdução a gravura e a história da xilogravura. Campos do Jordão, Editora Mantiqueira, 1984.

Ferreira, Orlanndo da Costa. Imagem e Letra. São Paulo, Edusp, 1994.

Forrier, Matthi. Hokusai.Paris, Biblioteque de l'Image, 2000.

Hashimoto, Madalena. Pintura e escritura do mundo flutuante. São Paulo, Hedra, 2002.

Hemingway, Ernest. 0 velho e o mar. Rio de Janeiro, Editora Civilização Brasileira, 1960.

Jabes, Edmond. A Obscura Palavra do Deserto. Llsboa, Edições Cotovia, 1991

Klee, Paul. Sobre a arte moderna. Rio de Janeiro, Jorge Zahar editor, 2001.

Klee, Paul. Diários. Editora Martins Fontes, 1990. 
Klink, Amyr. Cem dias entre céu e mar. Rio de Janeiro, José Olympio editora, 1986.

Klink, Amyr. Paratii: entre dois pólos. São Paulo, Companhia das Letras, 1992.

Matisse, Henri. Escritos e reflexões sobre arte. São Paulo, Cosac Naify, 2007.

Mennekes, Friedhelm. Joseph Beuys: Pensar Cristo. Barcelona, Herder, 1997.

Parke-Taylor, Elizabeth Prelinger and Michael. The symbolist prints of Edvard Munch. Yale University Press, 1996.

Pedrosa, Mário. Arte/Forma e Personalidade. São Paulo, Editora Kairos, 1979.

Pedrosa, Mário. Política das Artes; Otília Beatriz Fiori Arantes (org.). São Paulo, Edusp, 1995.

Pedrosa, Mário. Acadêmicos e Modernos; Otília Beatriz Fiori Arantes (org.). São Paulo, Edusp, 1995.

Rilke, Rainer Maria. Frutos e Apontamentos. Lisboa, Relógio d’agua editores, 1996.

Rothko, Mark. La réalitè de l'artiste. Paris, Flammarion, 2004.

Rufinoni, Priscila Rossinetti. Oswaldo Goeldi: iluminação, ilustração. São Paulo, Cosac Naify e Fapesp, 2006.

Silver, Larry and Wyckoff, Elisabeth. Grand Scale - Monumental Prints in the Age of Durer and Titian. Yale University Press, 2008.

Sylvester, David. Entrevistas com Francis Bacon. São Paulo, Cosac Naify, 1995.

The Complete Woodcuts of Albrecht Durer. New York, Dover Publications, 1998. 


\title{
Fotografias:
}

\author{
Fabricio Lopez
}




\section{Agradecimentos}

Thaís Badim / Flora Badim Lopez / Cláudio Mubarac / Elisa Bracher / Ulysses Bôscolo / Samuel Ornellas / Estúdio Diálogo Uriama T. Menezes / Ana Calzavara / Xiloceasa / Daniel García / Ateliê Espaço Coringa / Associação Cultural Jatobá / Ernesto Bonato / Juvelina e Diamantino / Brunel Ricci / Evandro Carlos Jardim / Marcelo Mattos Araújo / José Reinaldo Rema 


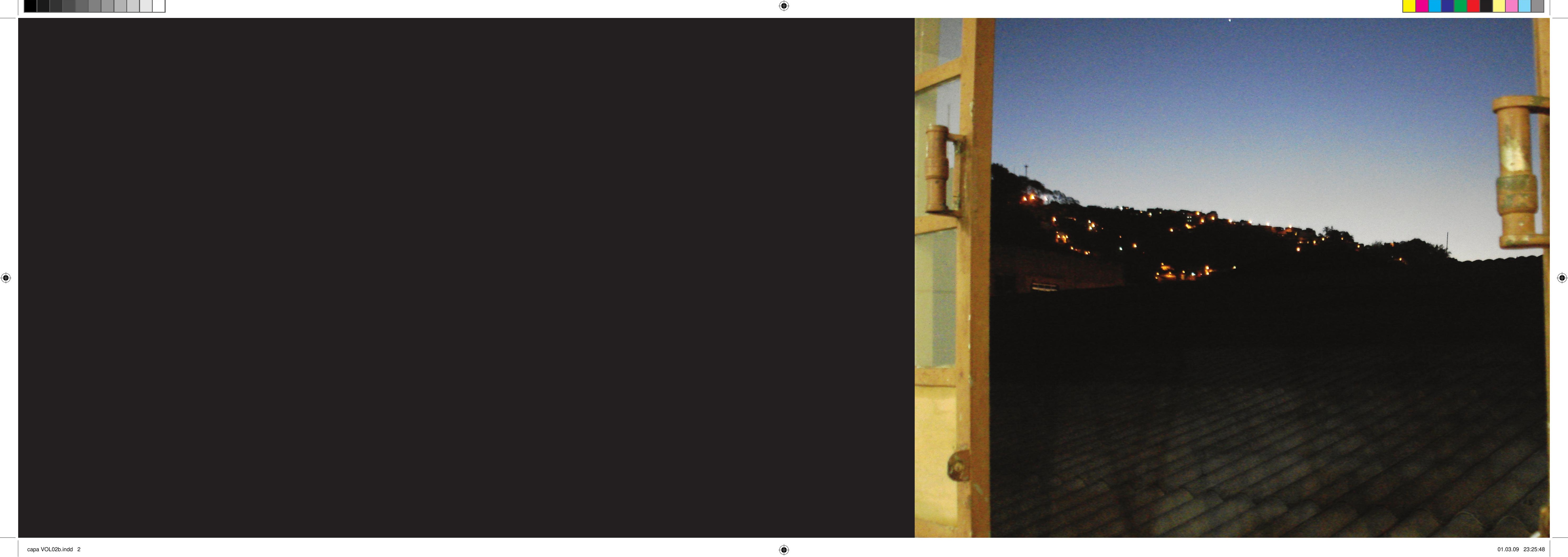




\section{ATELIÊ SANTOS}

*

vol. 02 


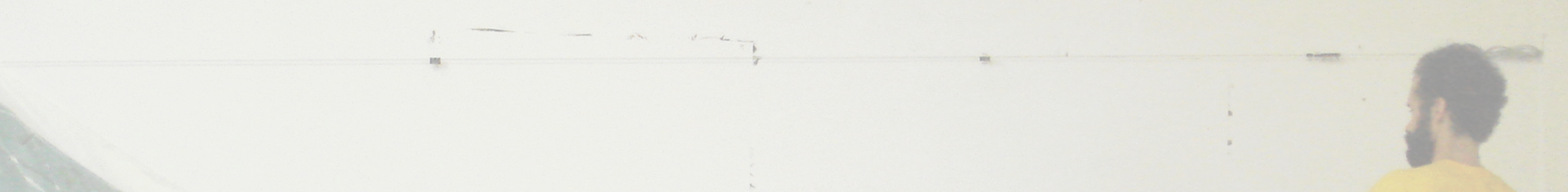


A madeira e a luz - ATELIÊ SANTOS

\section{FABRICIO DE JESUS BARRIO LOPEZ}

Dissertação de mestrado apresentada ao Departamento de Artes Plásticas da Escola de Comunicação e Artes da Universidade de São Paulo

orientador

Prof. Dr. LUIZ CLÁUDIO MUBARAC

\section{POÉTICAS VISUAIS}

ECA - USP

2009

vol. 02 


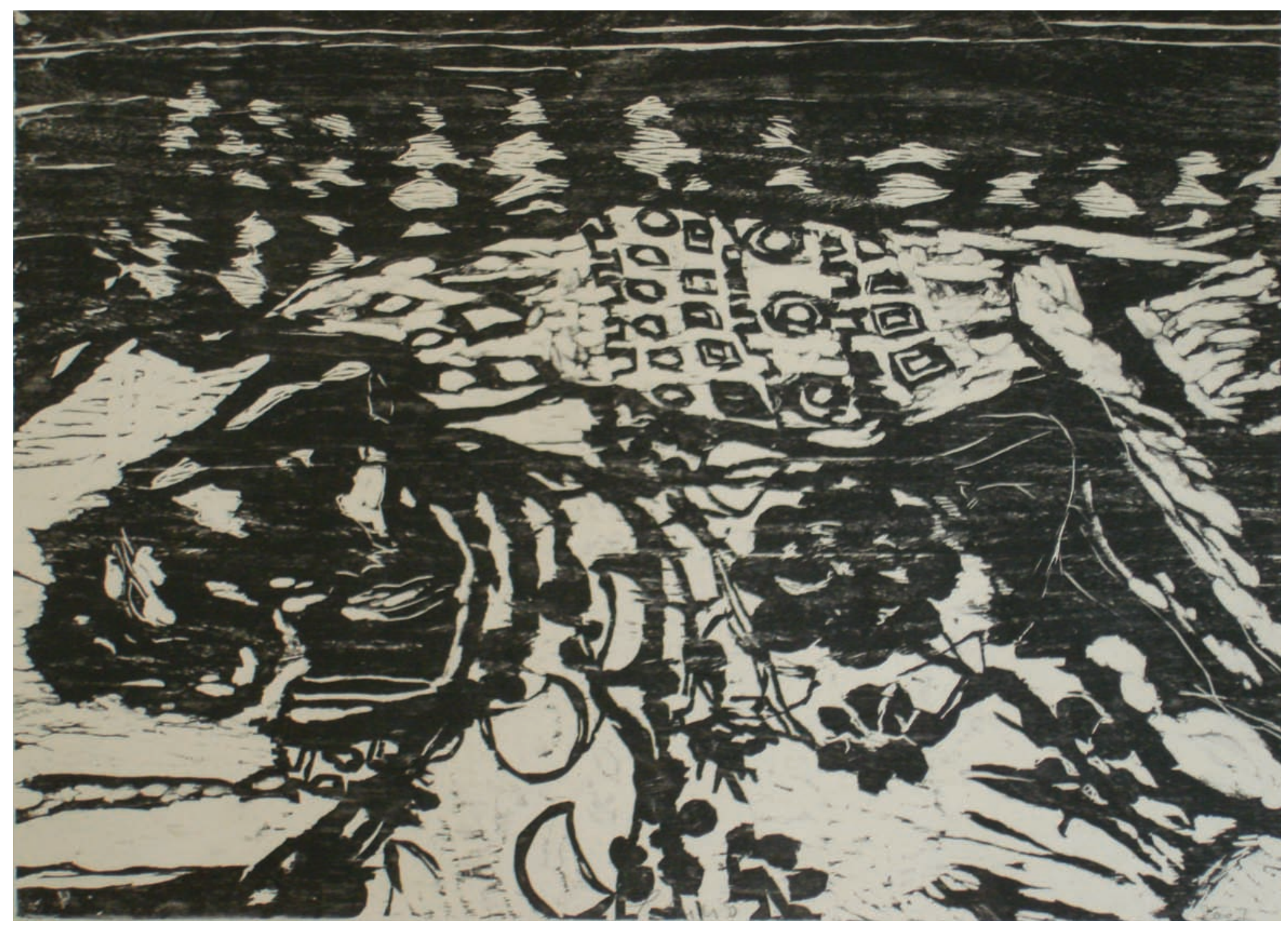


para Thaís e Flora 


\section{ÍNDICE:}

04 tailândia

$90 \times 110 \mathrm{~cm}$

2007

xilogravura sobre papel wenzhou aplicado na parede

11 casa da frontaria azuleijada

$340 \times 450 \mathrm{~cm}$

2004

xilogravura em cores sobre papel debret

12 morro do pacheco

$340 \times 450 \mathrm{~cm}$

2004

xilogravura em cores sobre papel debret

14 guindaste

$340 \times 450 \mathrm{~cm}$

2002

xilogravura sobre papel debret

15 livro do início I

$67 \times 115 \mathrm{~cm}$

2004

xilogravura em cores sobre papel debret

16 são jorge - (l.d.i. II)

$67 \times 115 \mathrm{~cm} \quad 2004$

xilogravura em cores sobre papel debret
17 mangue - (I.d.i. III)

$67 \times 115 \mathrm{~cm}$

2004

xilogravura em cores sobre papel debret

18 álcool e sangue - (I.d.i. IV)

$67 \times 115 \mathrm{~cm} \quad 2004$

xilogravura em cores sobre papel debret

19 encarnacion

$180 \times 150 \mathrm{~cm} \quad 2003$

xilogravura em cores sobre papel debret

20 serra do mar

$190 \times 150 \mathrm{~cm}$

2003

xilogravura em cores sobre papel debret

$21 \mathrm{~s} / \mathrm{t}$

$100 \times 75 \mathrm{~cm} \quad 2003$

xilogravura em cores sobre papel debret

$22 \mathrm{~s} / \mathrm{t}$

$100 \times 75 \mathrm{~cm} \quad 2003$

xilogravura em cores sobre papel debret 
23 estandarte

$100 \times 70 \mathrm{~cm}$

2005

xilogravura em cores sobre papel sommerset

$24 \mathrm{~s} / \mathrm{t}$

$100 \times 70 \mathrm{~cm} \quad 2005$

xilogravura em cores sobre papel sommerset

$25 \mathrm{~s} / \mathrm{t}$

$100 \times 70 \mathrm{~cm} \quad 2005$

xilogravura em cores sobre papel sommerset

26 triunfo

$170 \times 110 \mathrm{~cm} \quad 2005$

xilogravura em cores sobre papel debret

27 desejo e sorte

$160 \times 220 \mathrm{~cm}$

2005

xilogravura sobre papel wenzhou

28 fim de linha

$10 \times 8,5 \mathrm{~cm}$

2006

xilogravura e texto tipográfico sobre papel japonês texto Márcia Vinci
29 enterro

$10 \times 8,5 \mathrm{~cm} \quad 2006$

xilogravura e texto tipográfico sobre papel japonês texto Márcia Vinci

30 historinha

$10 \times 8,5 \mathrm{~cm} \quad 2006$

xilogravura e texto tipográfico sobre papel japonês texto Márcia Vinci

31 la lutte

$100 \times 70 \mathrm{~cm} \quad 2005$

xilogravura sobre papel sommerset

$32 \mathrm{~s} / \mathrm{t}$

$96 \times 66 \mathrm{~cm} 2006$

xilogravura sobre papel jornal

$33 \mathrm{~s} / \mathrm{t}$

$96 \times 66 \mathrm{~cm} 2006$

xilogravura sobre papel jornal

$34 \mathrm{~s} / \mathrm{t}$

$170 \times 115 \mathrm{~cm} \quad 2007$

xilogravura em cores sobre papel debret 
35 série valongo I

$100 \times 70 \mathrm{~cm} \quad 2007$

xilogravura em cores sobre papel sommerset

36 série valongo II

$100 \times 70 \mathrm{~cm} \quad 2007$

xilogravura em cores sobre papel sommerset

37 série valongo III

$100 \times 70 \mathrm{~cm}$

xilogravura em cores sobre papel sommerset

38 série valongo IV

$100 \times 70 \mathrm{~cm}$

xilogravura em cores sobre papel sommerset

39 série valongo $\mathrm{V}$

$100 \times 70 \mathrm{~cm}$

xilogravura em cores sobre papel sommerset

40 série valongo $\mathrm{VI}$

$100 \times 70 \mathrm{~cm}$

xilogravura em cores sobre papel sommerset
41 série valongo VII

$100 \times 70 \mathrm{~cm} \quad 2007$

xilogravura em cores sobre papel sommerset

42 muguet

$160 \times 140 \mathrm{~cm} 2007$

xilogravura em cores sobre papel canson

43 o galo e a sálvia

$220 \times 160 \mathrm{~cm} 2007$

xilogravura em cores sobre papel debret

$44 \mathrm{~s} / \mathrm{t}$
$220 \times 160 \mathrm{~cm}$
2007
xilogravura em cores sobre papel debret

$45 \mathrm{~s} / \mathrm{t}$

$220 \times 160 \mathrm{~cm} 2007$

xilogravura em cores sobre papel debret

$46 \mathrm{~s} / \mathrm{t}$

$220 \times 160 \mathrm{~cm}$

xilogravura em cores sobre papel debret 


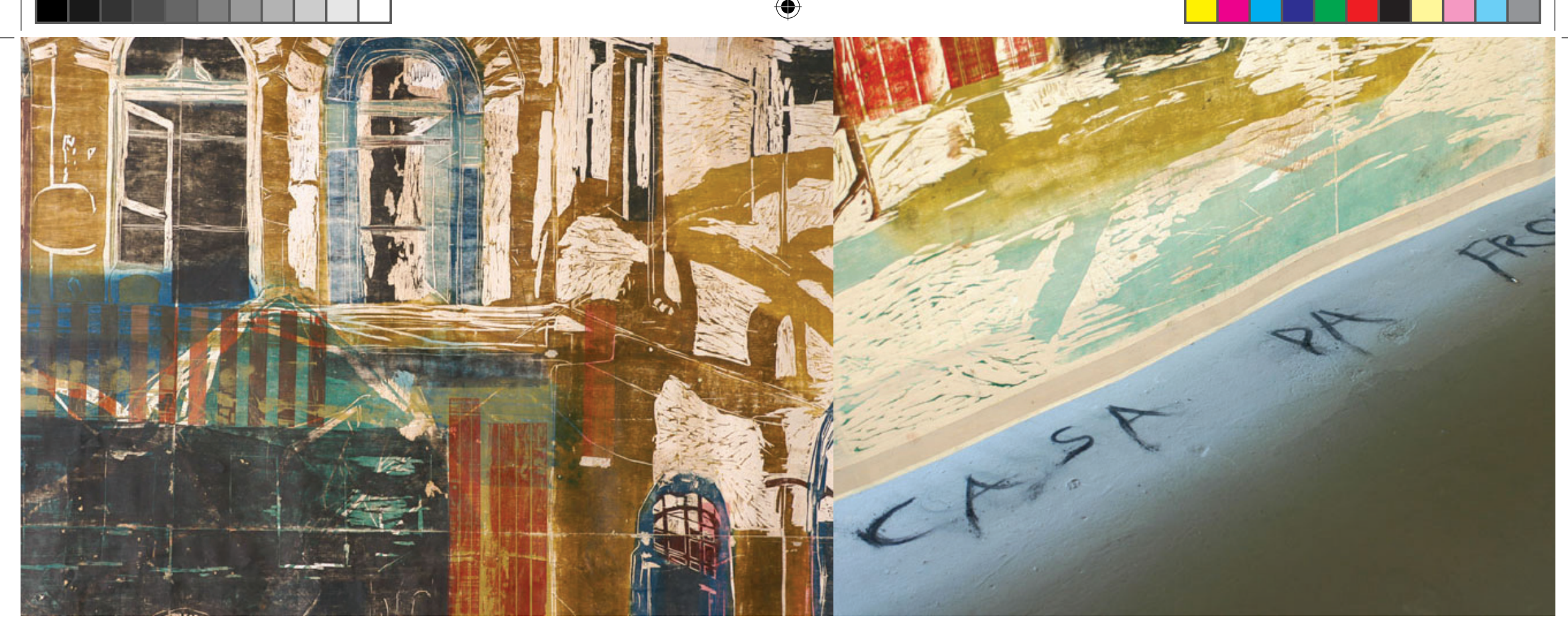

(†)

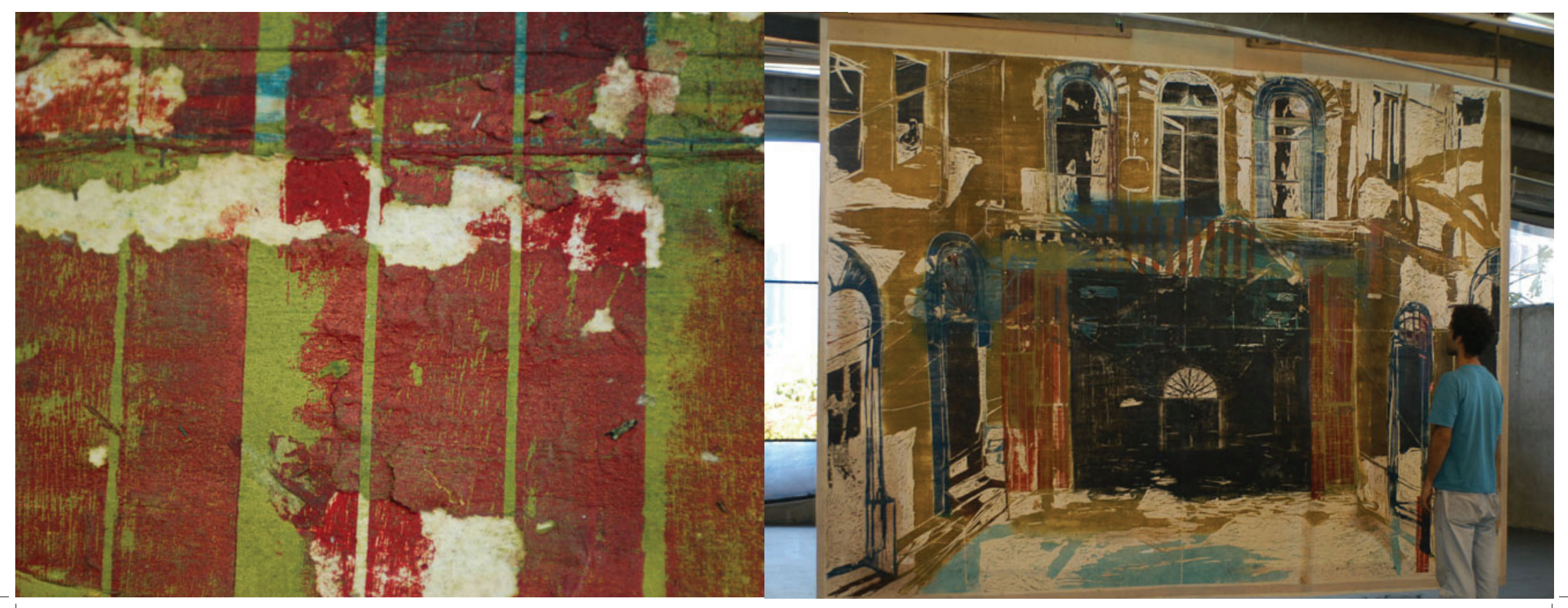




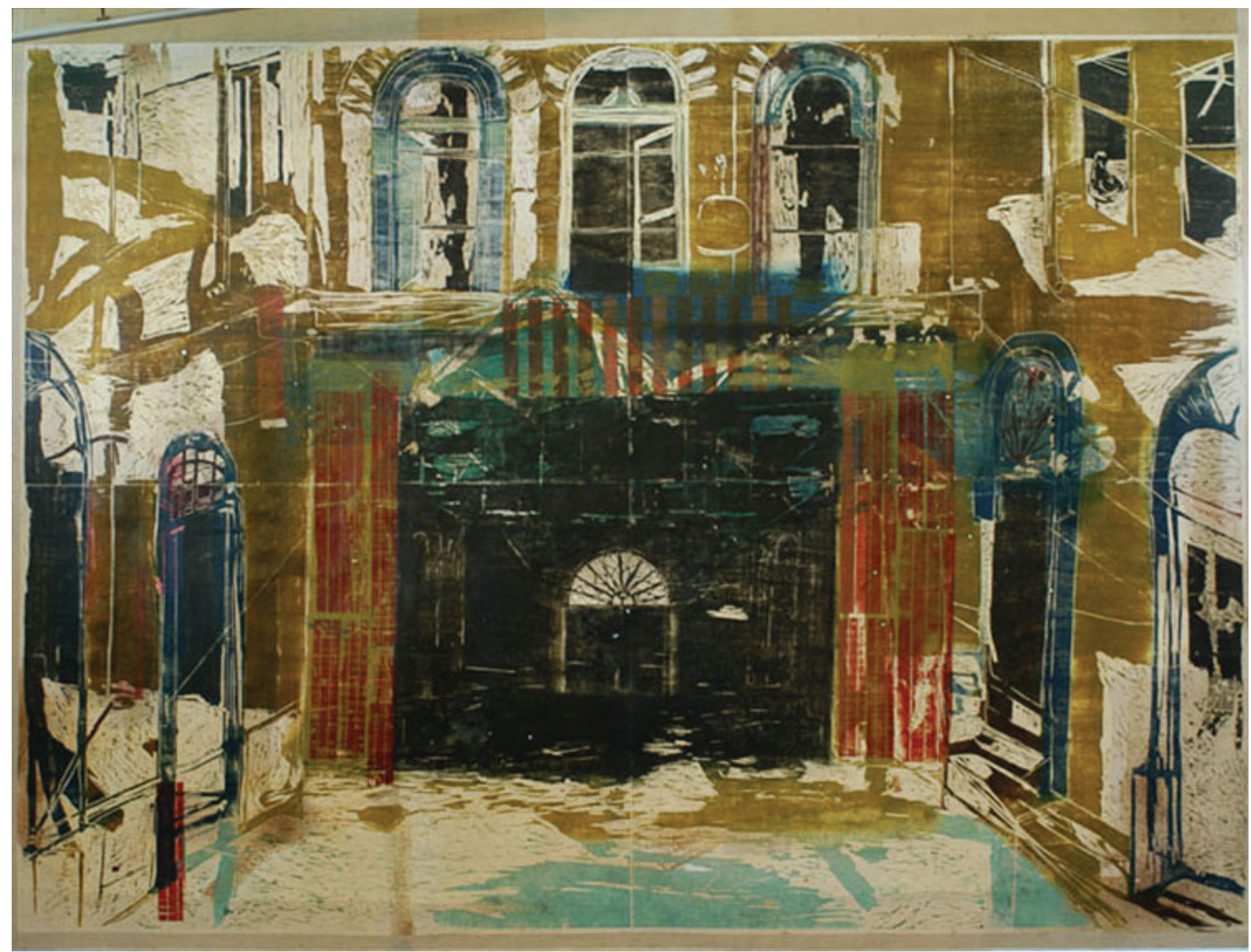




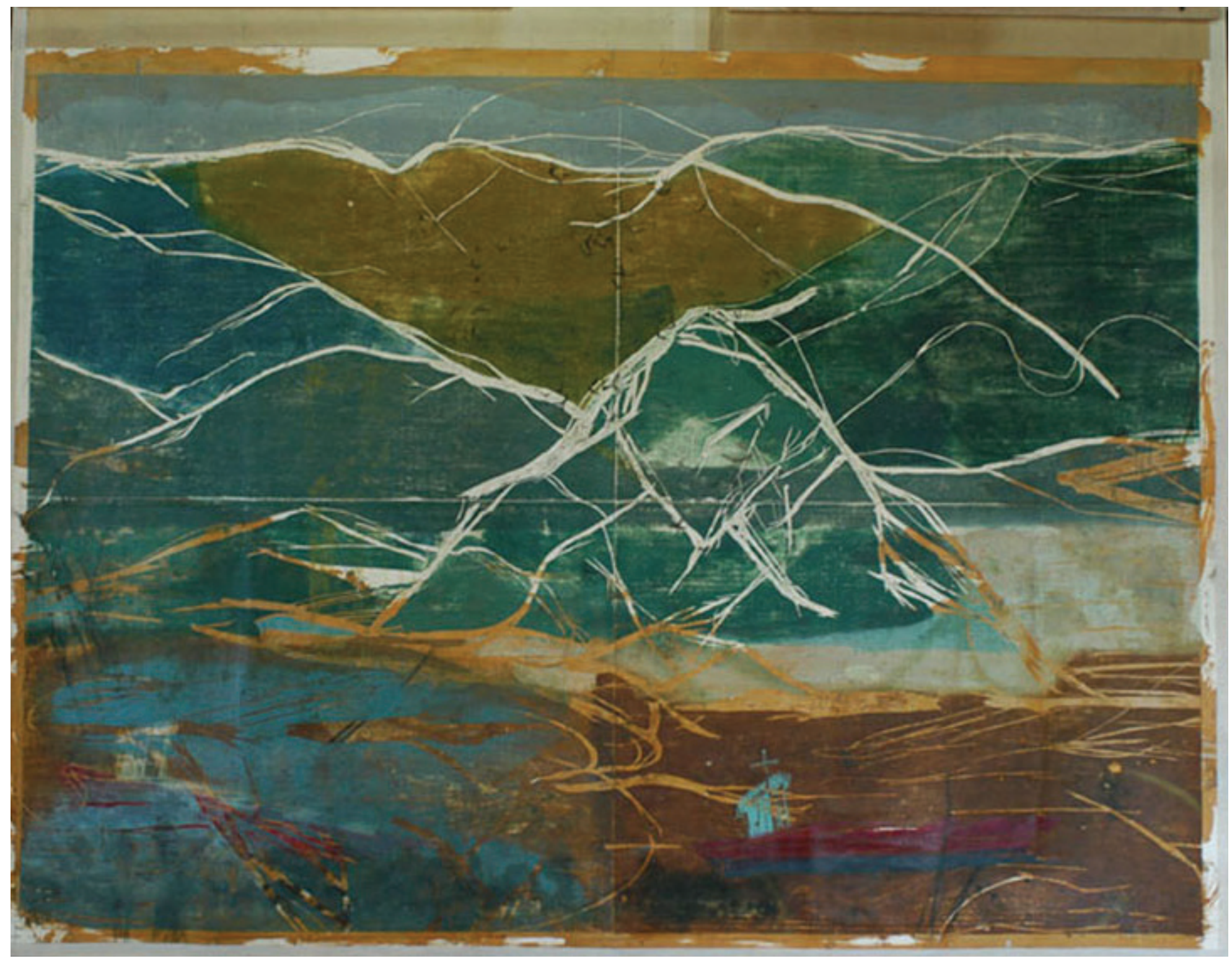




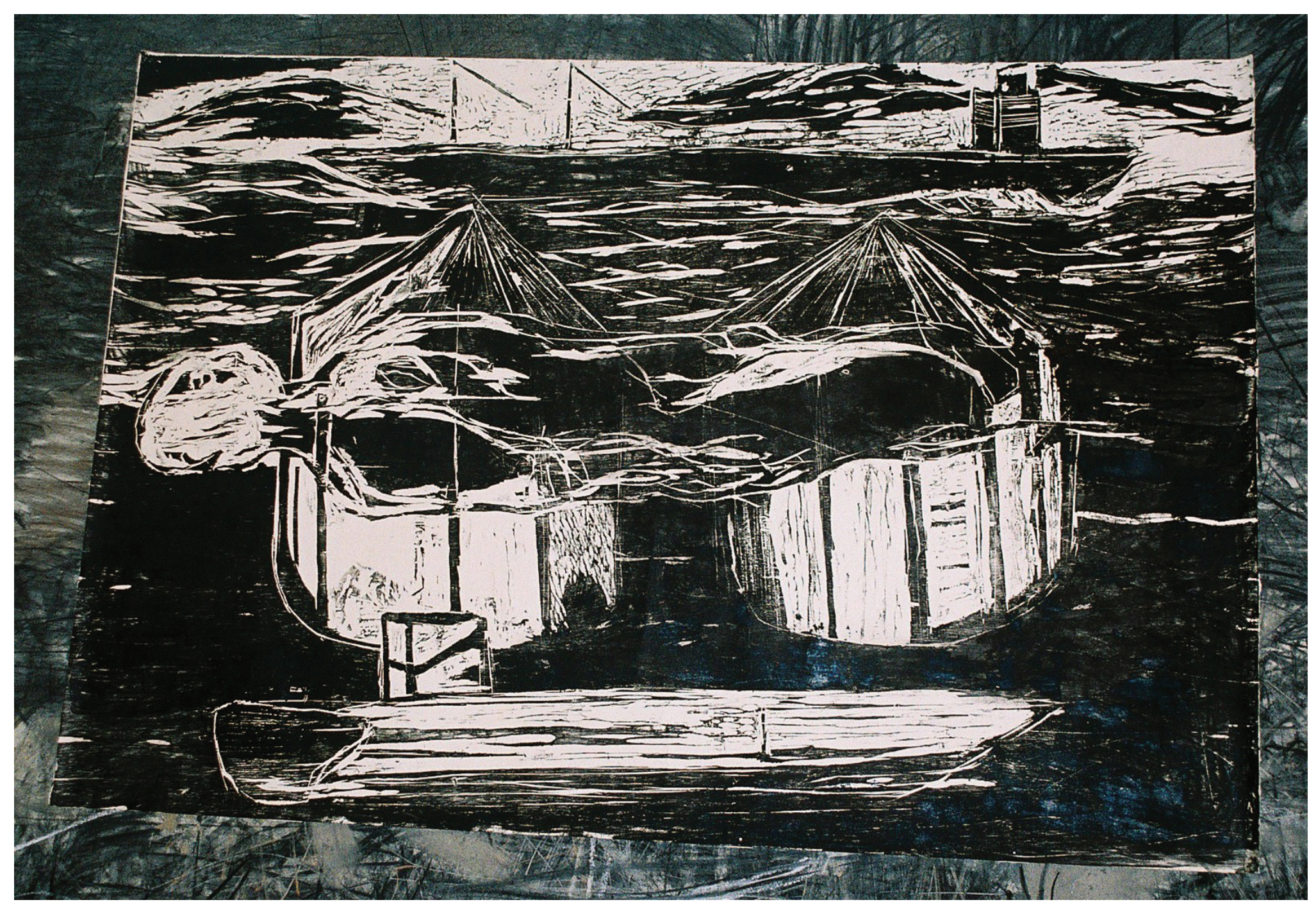




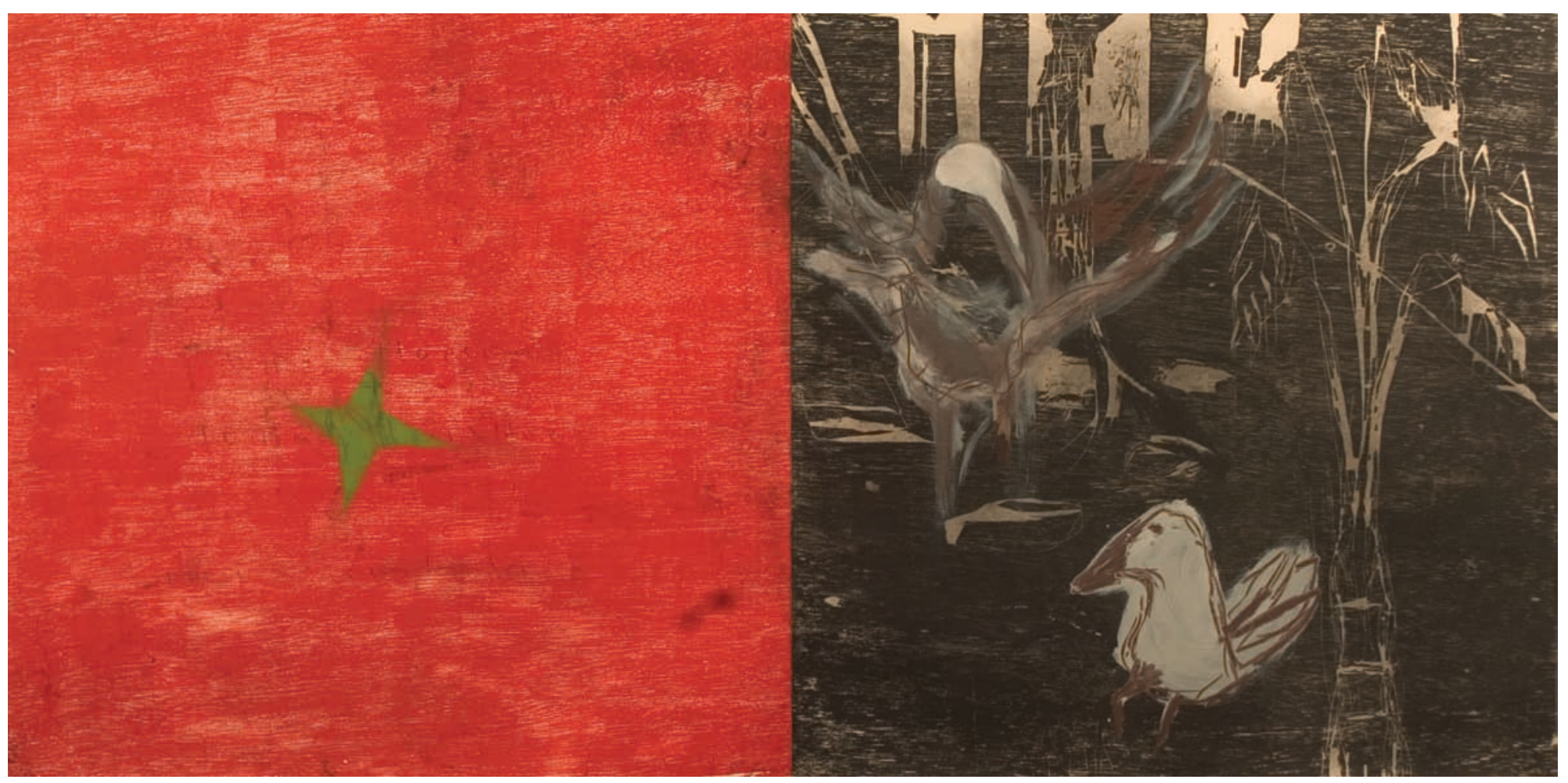

15 


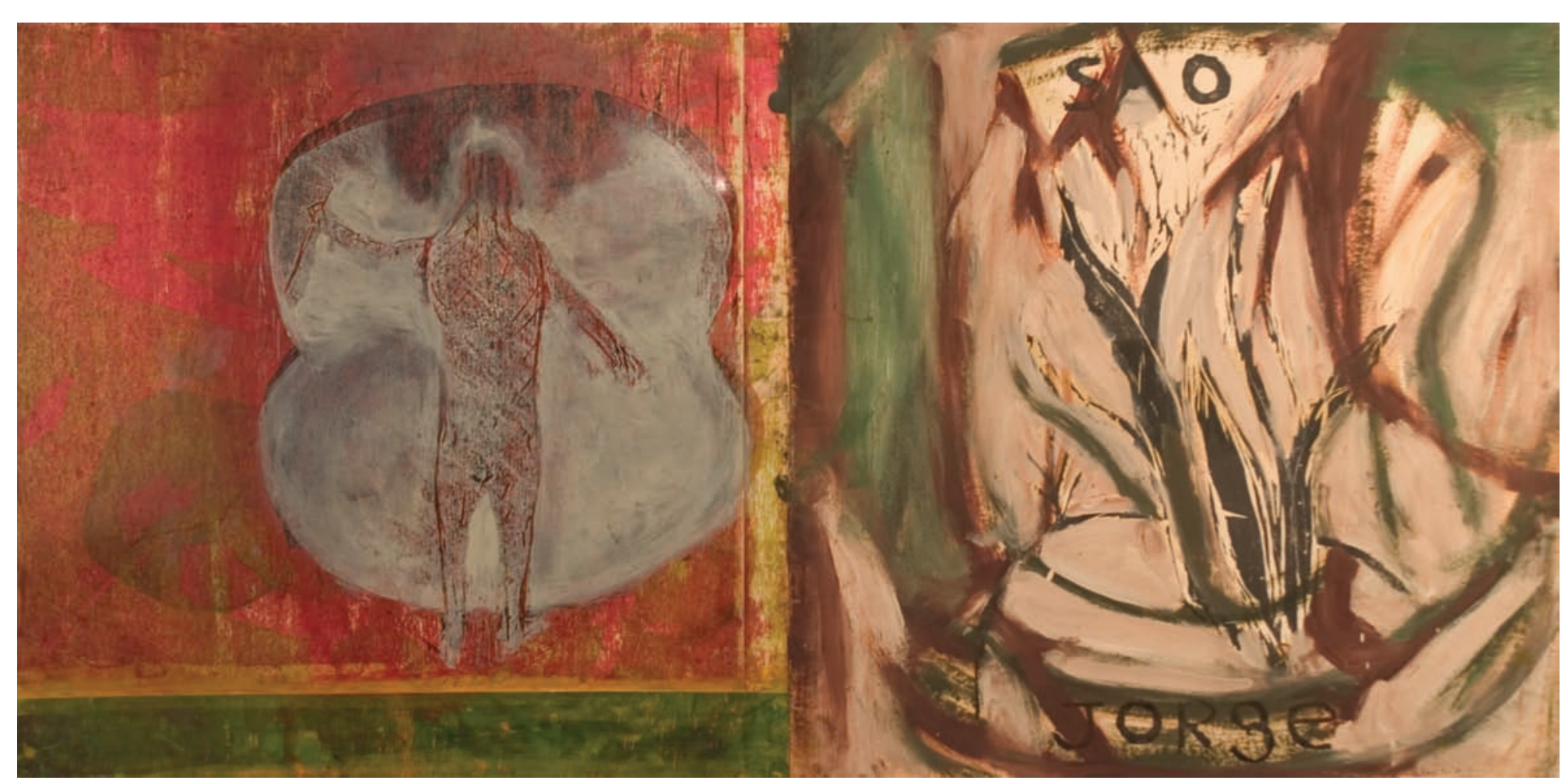




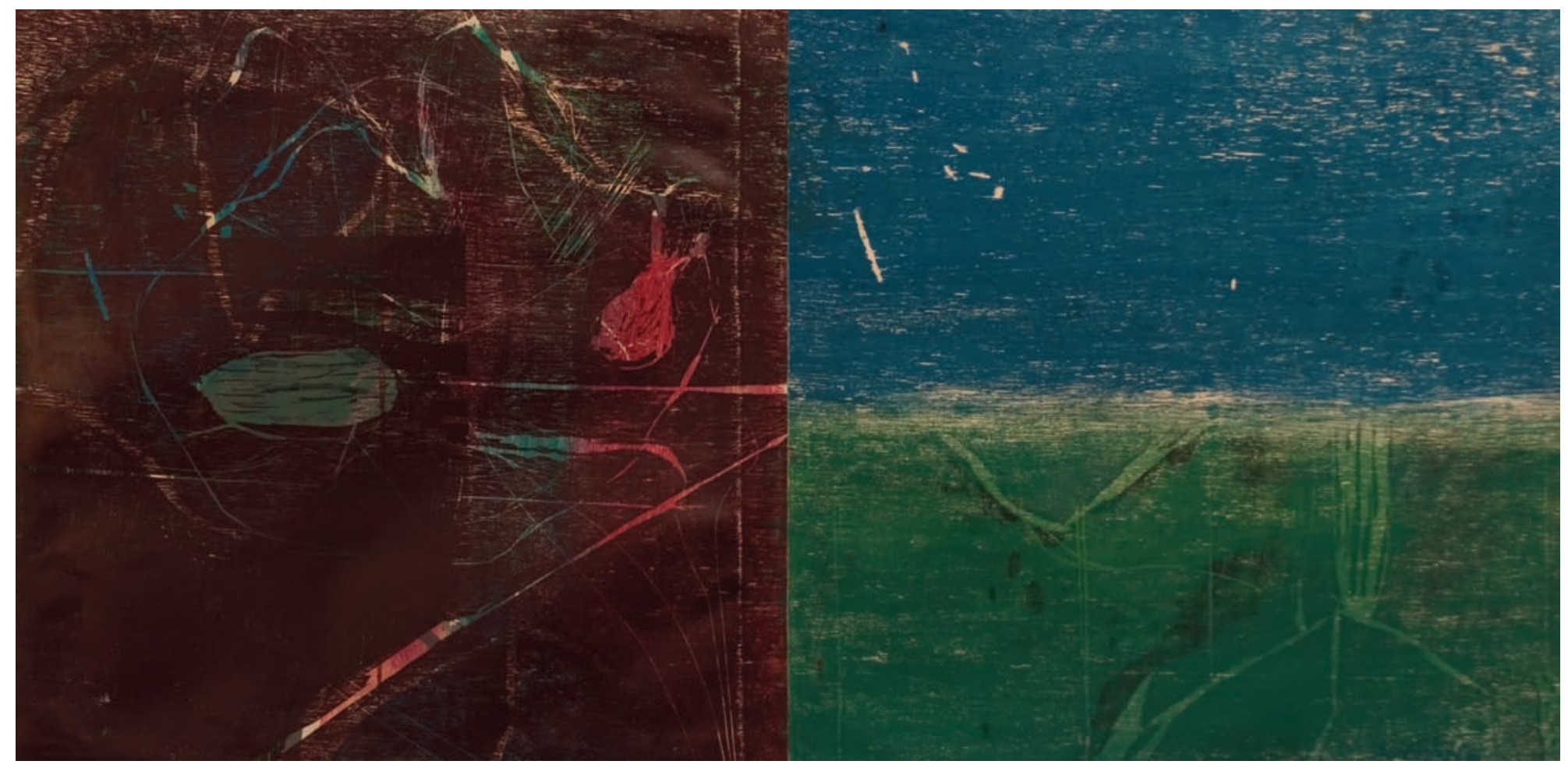




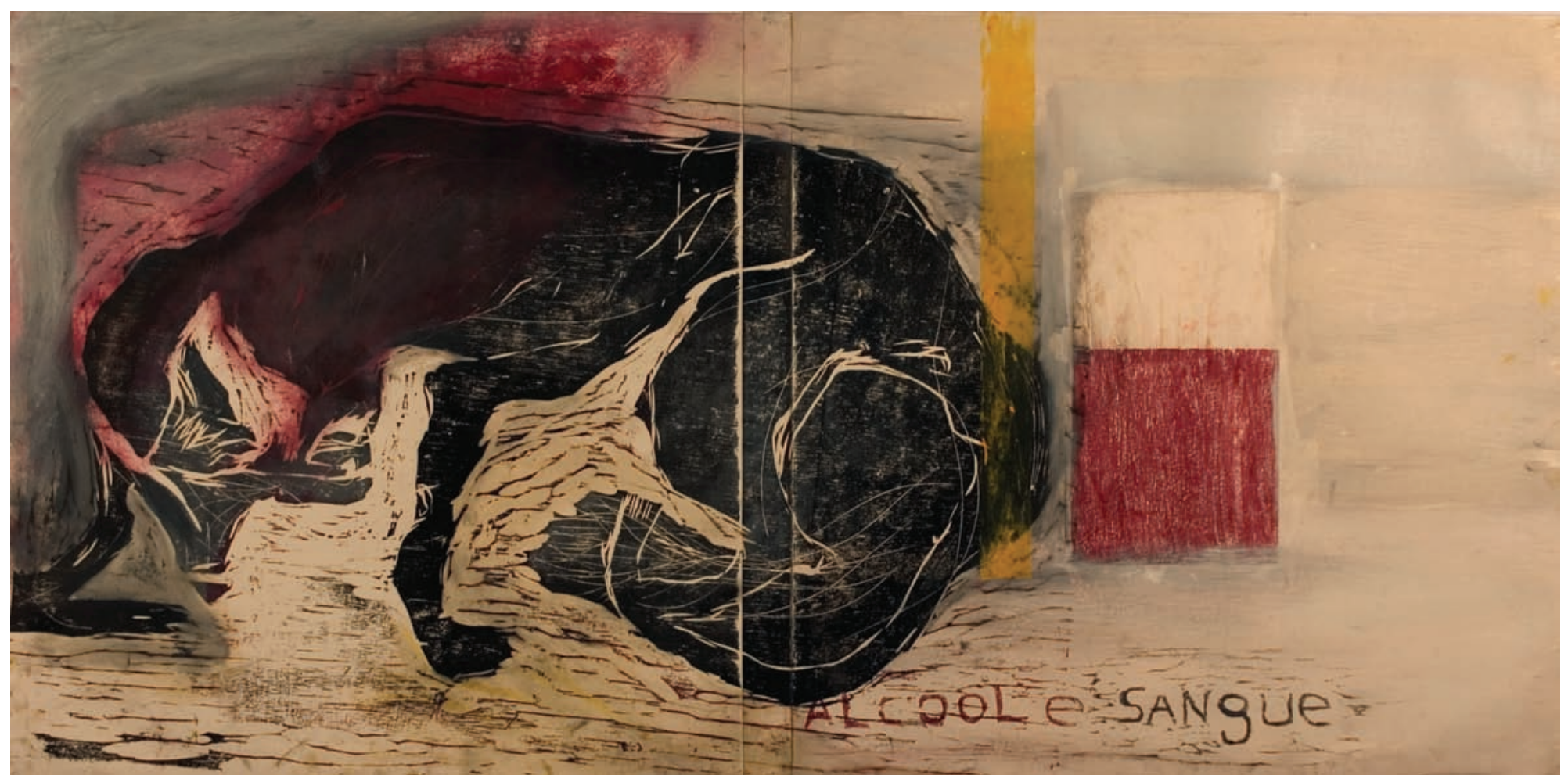




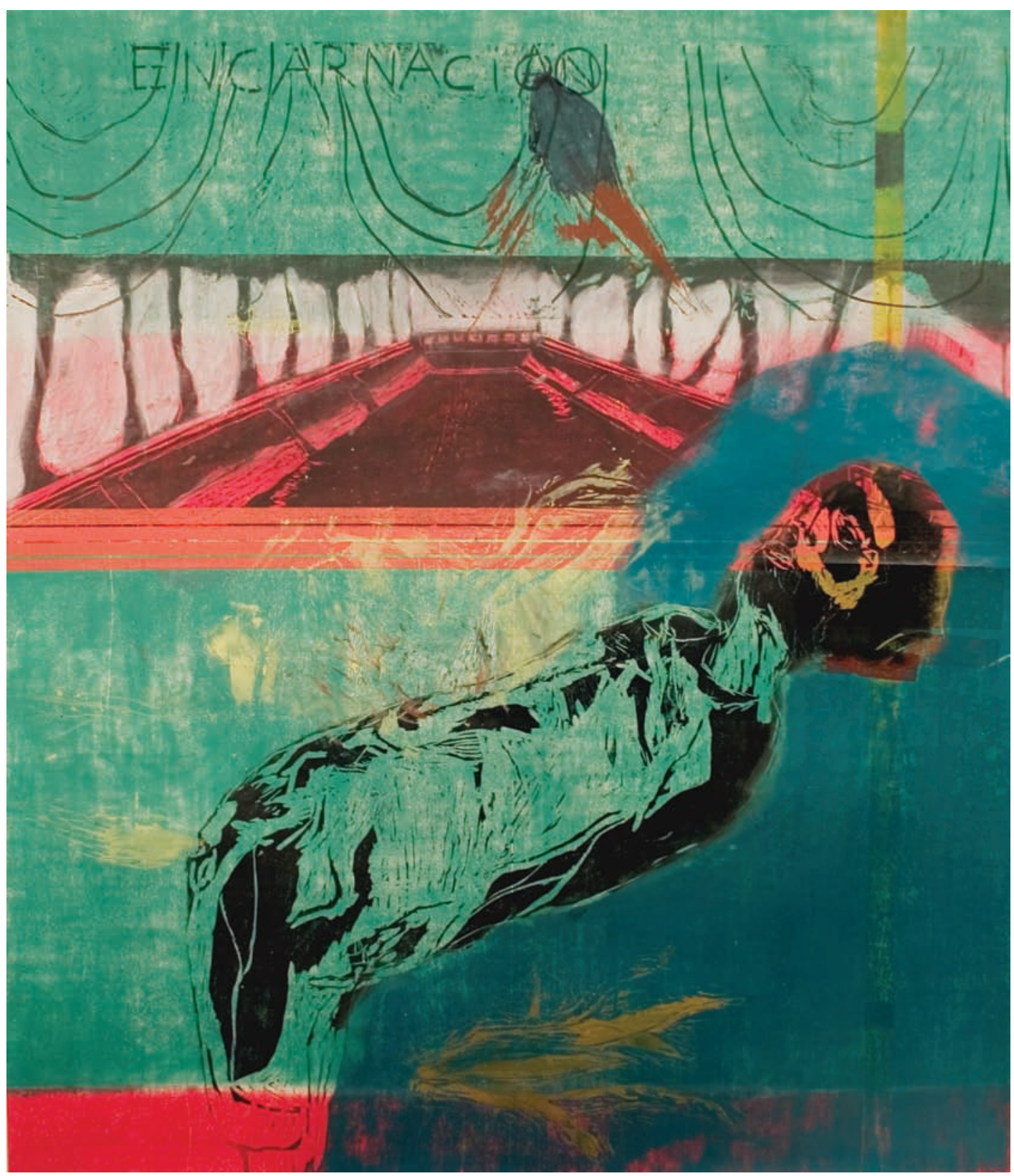

19 


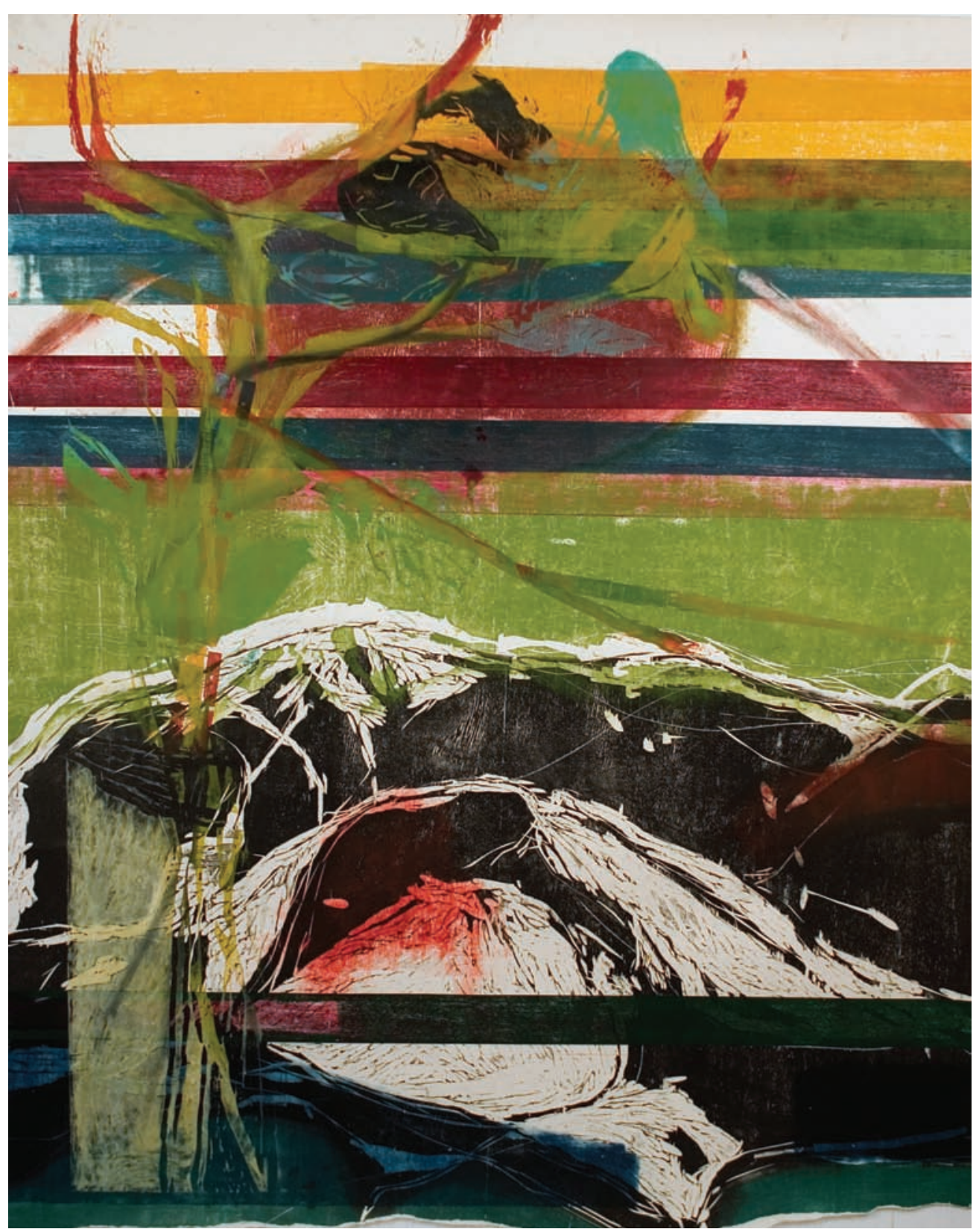

20 


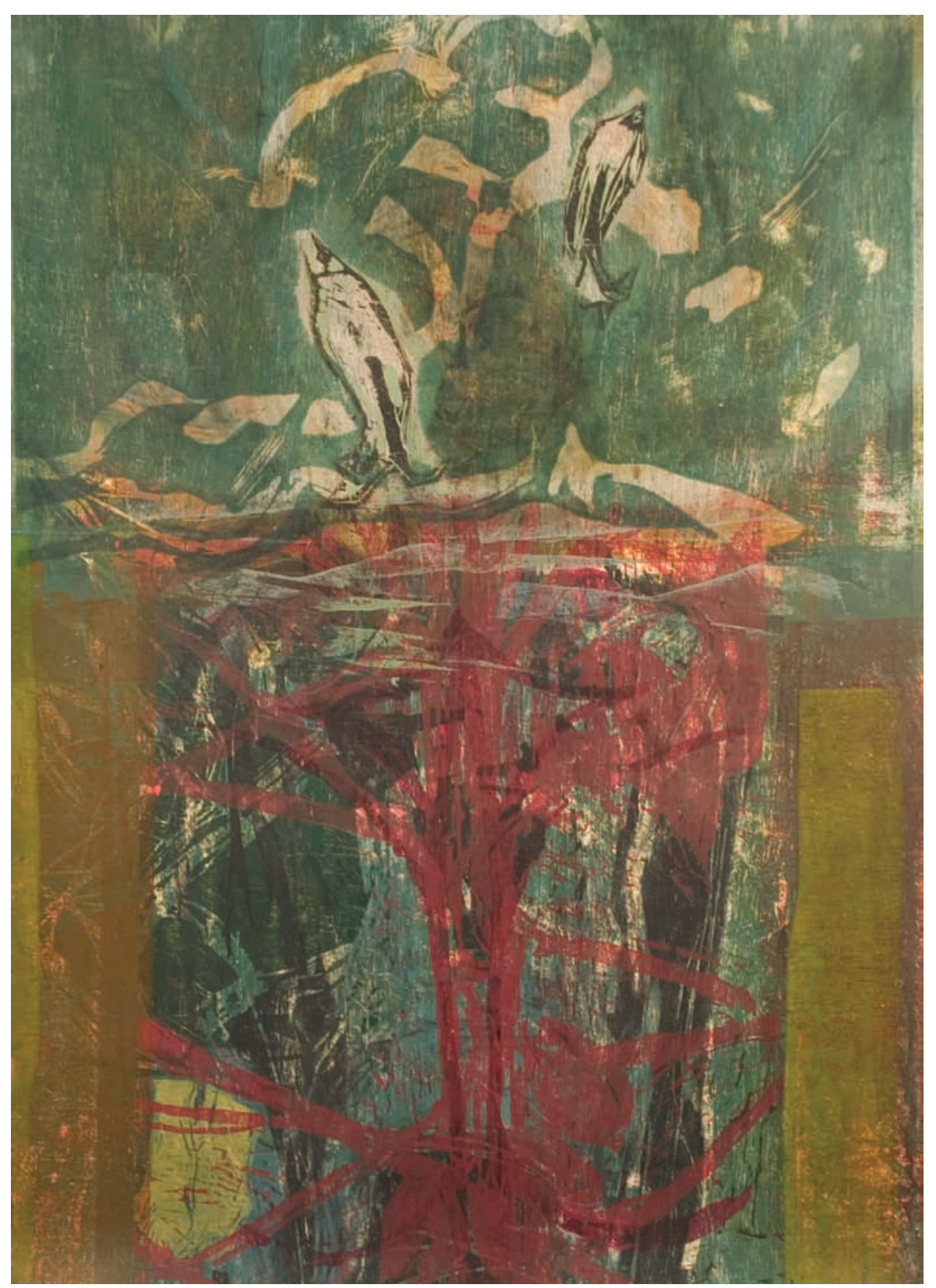

21 


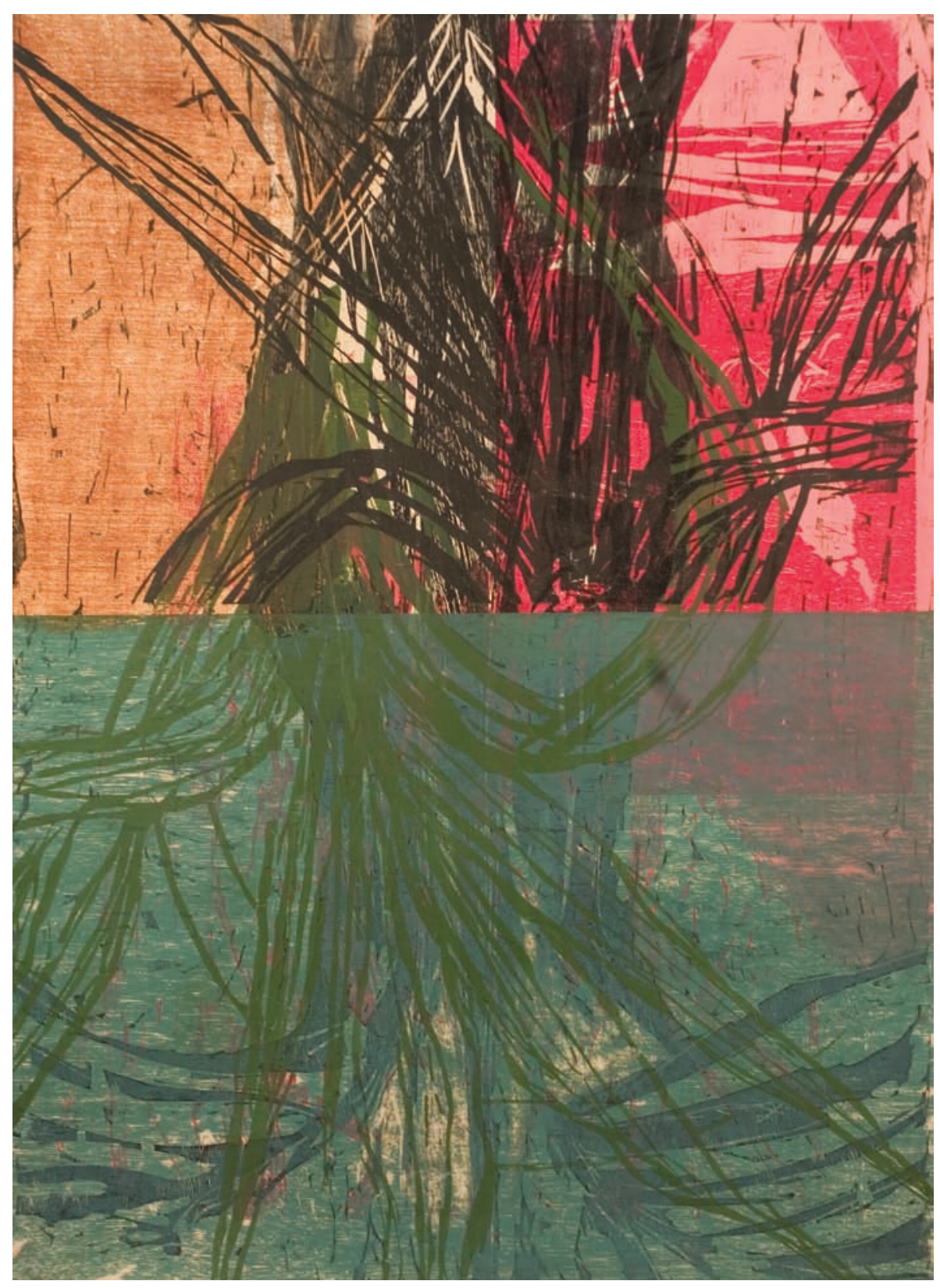

22 


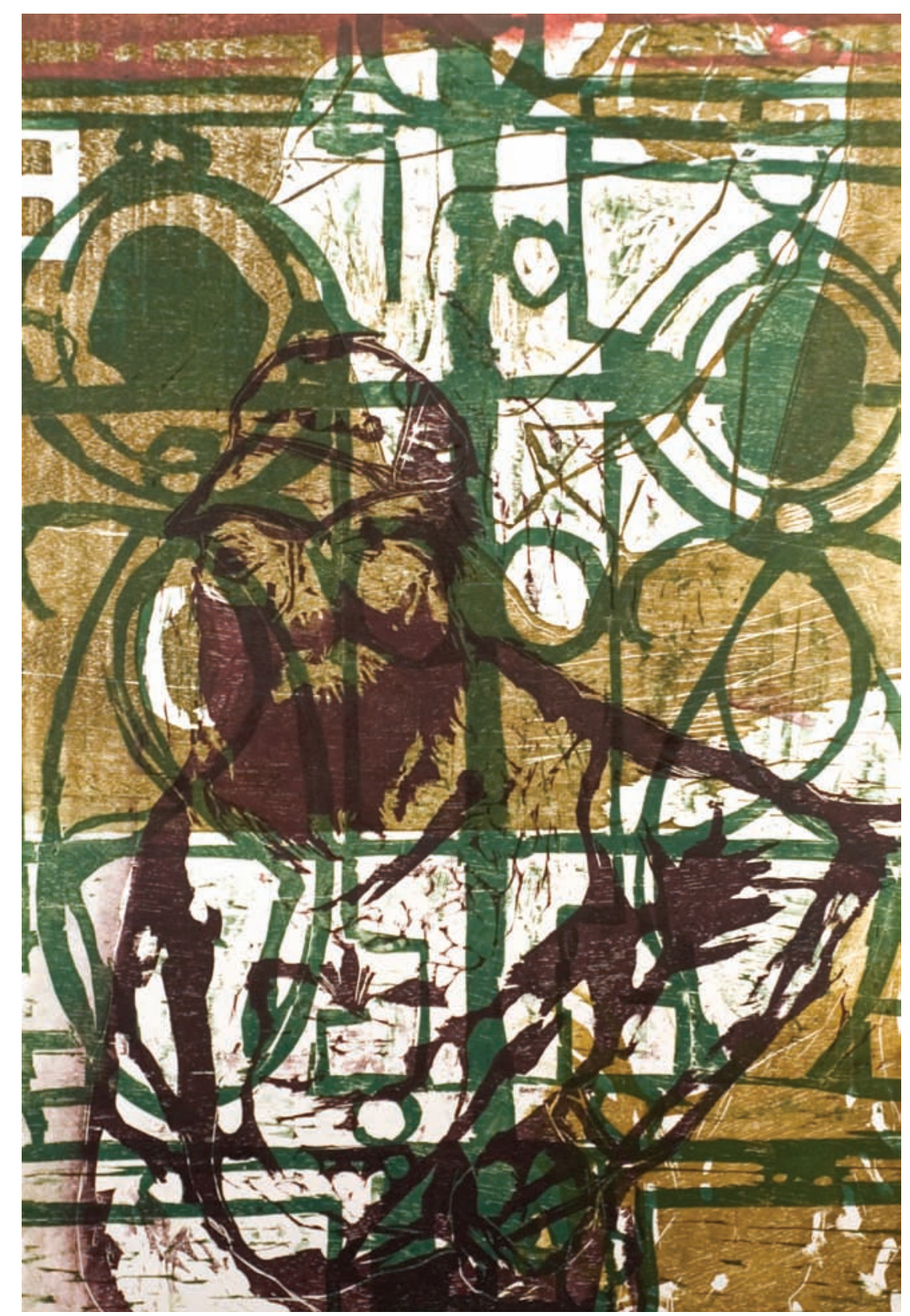




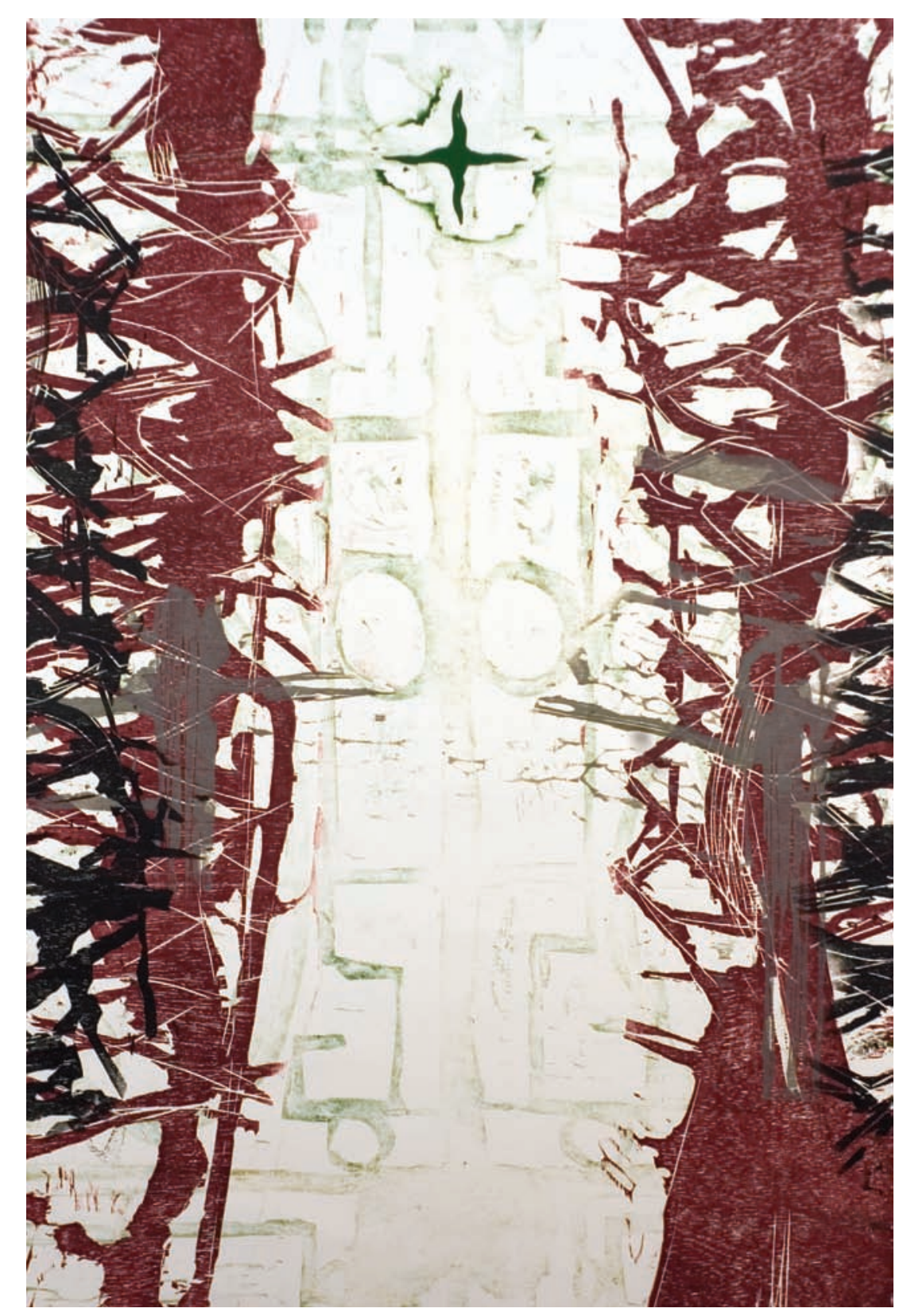

24 


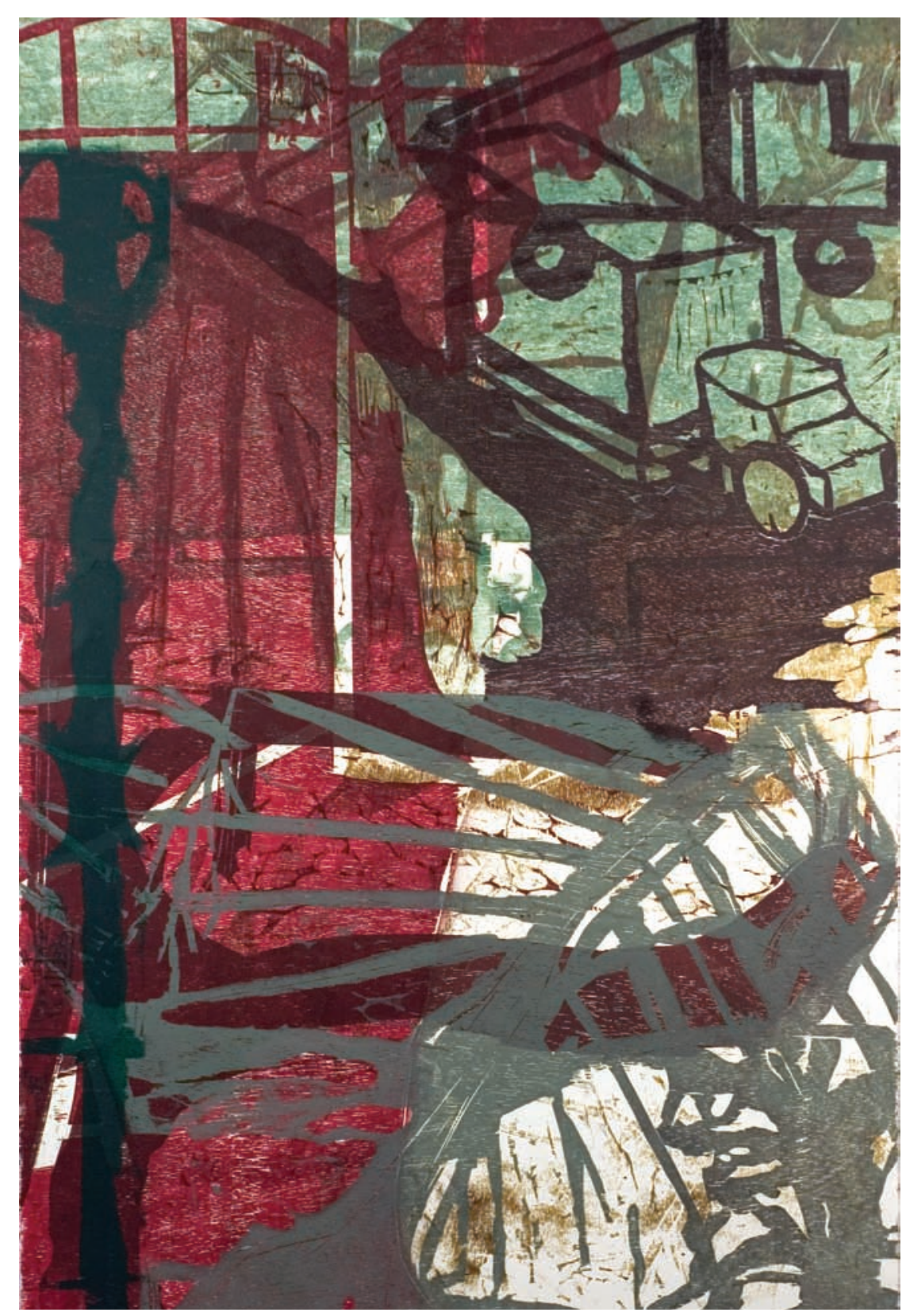

25 


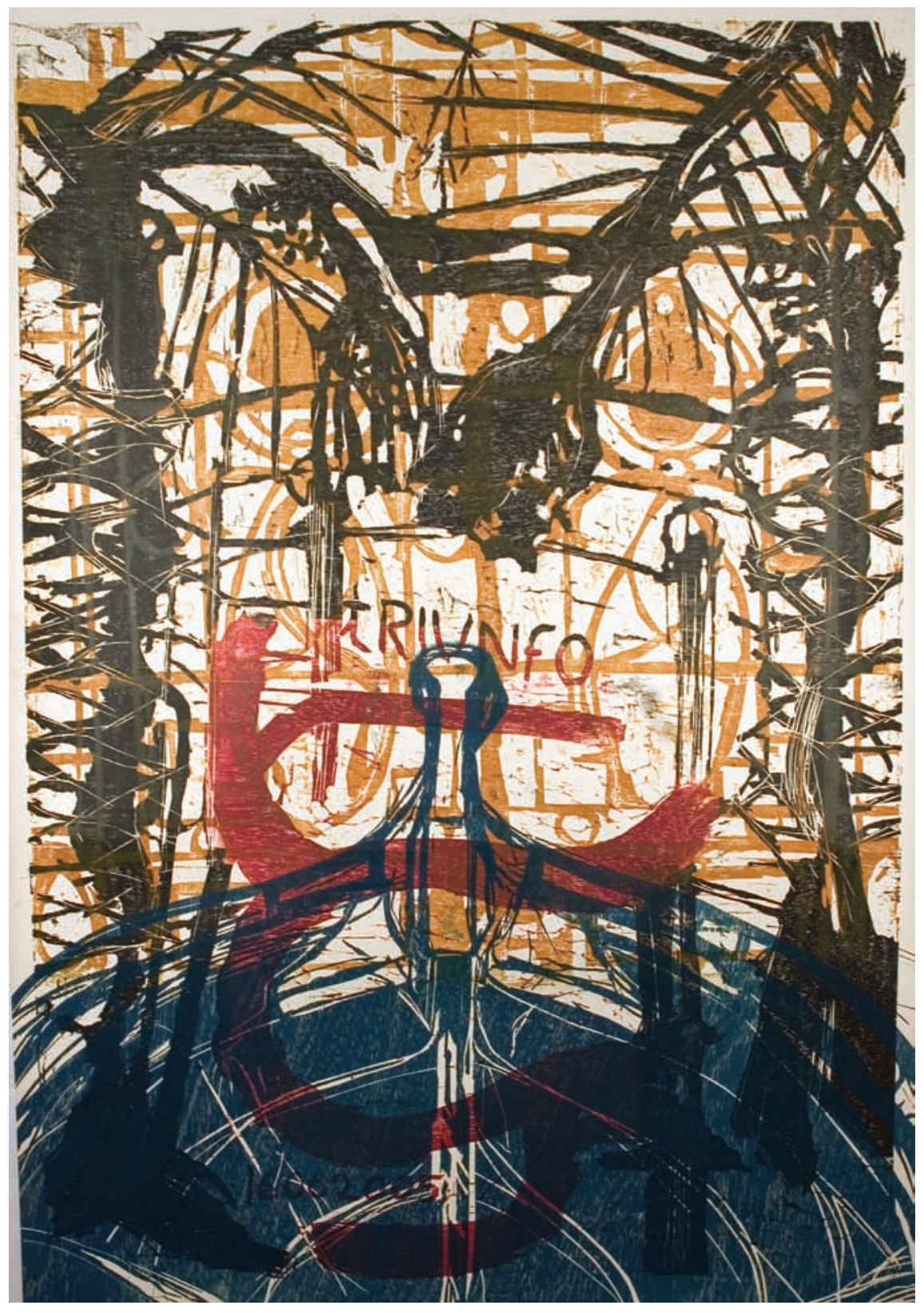




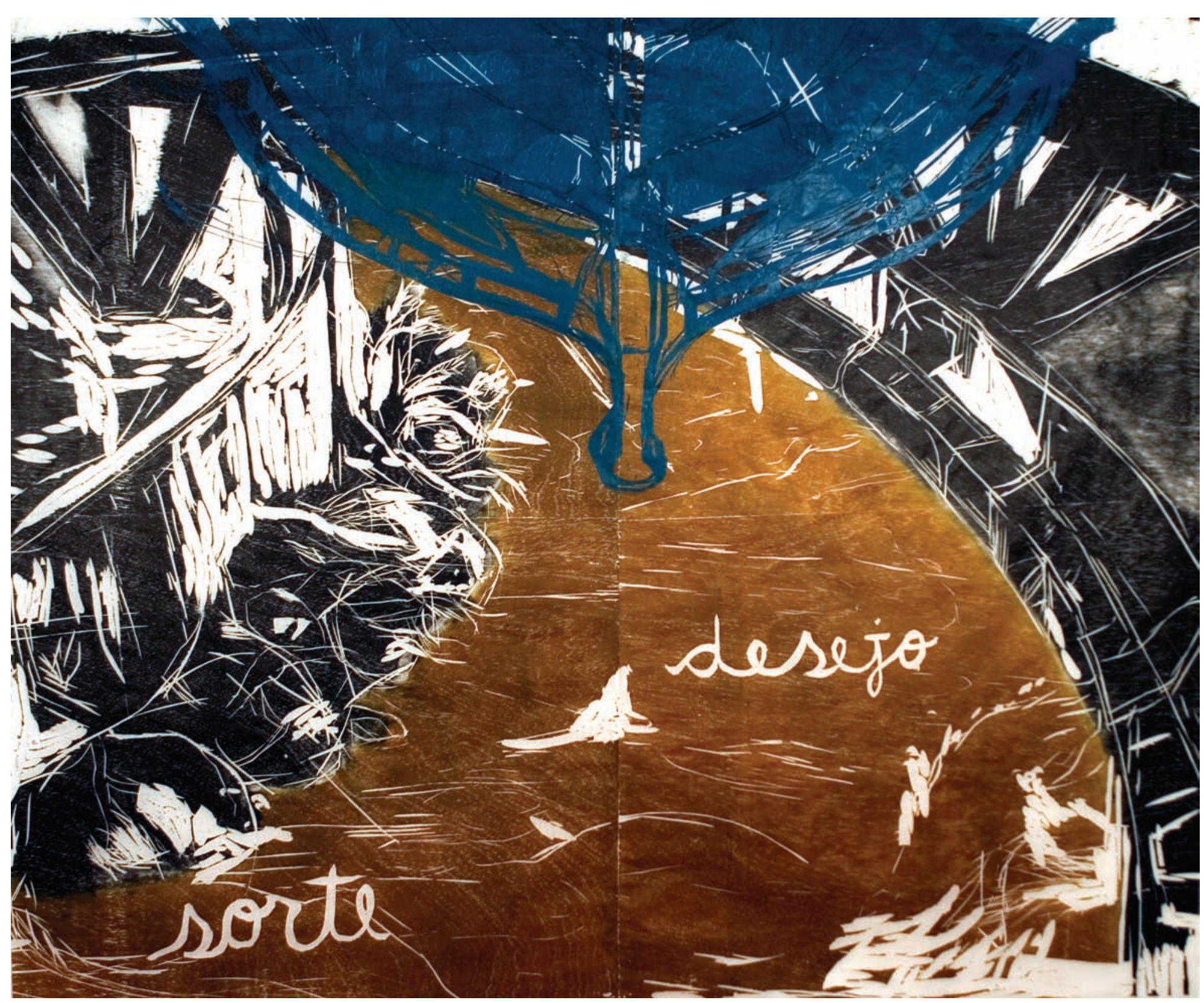


FIM OE LINHA

ANJO ACAGAOO

DEPONHO

MEU PESD

DE ASAS

METALIICAS

SO VOLIAREI

PASSARO

M. V..

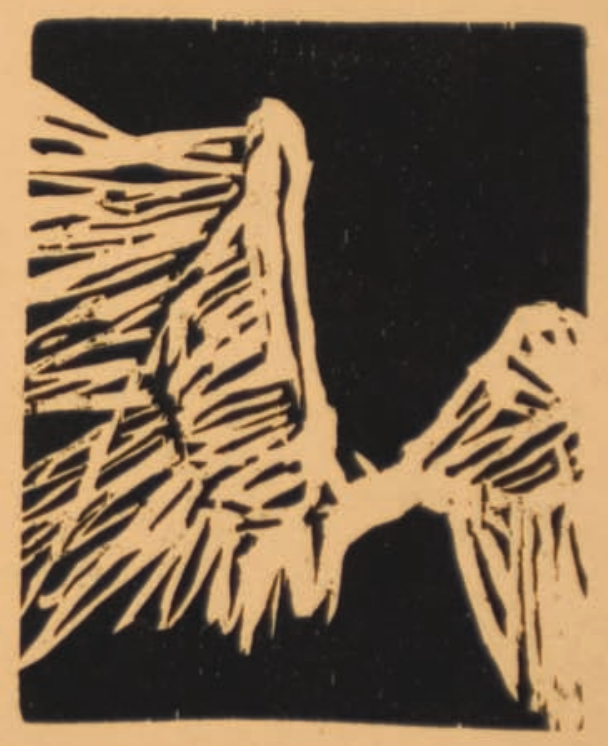

F.. L: 
ENTERRO

O ENJÖO OEPOIS

DA FOME

A CULPA DEPOIS

DO 6020

o AMARgo

OEPOIS DO DOCE

A BILLIS DEPQIS

OA FESTA

UM CANCER AINOA

PAIRA SOBRE

O CHA

COM BOLO DE

CHOCOLATE

M.V.

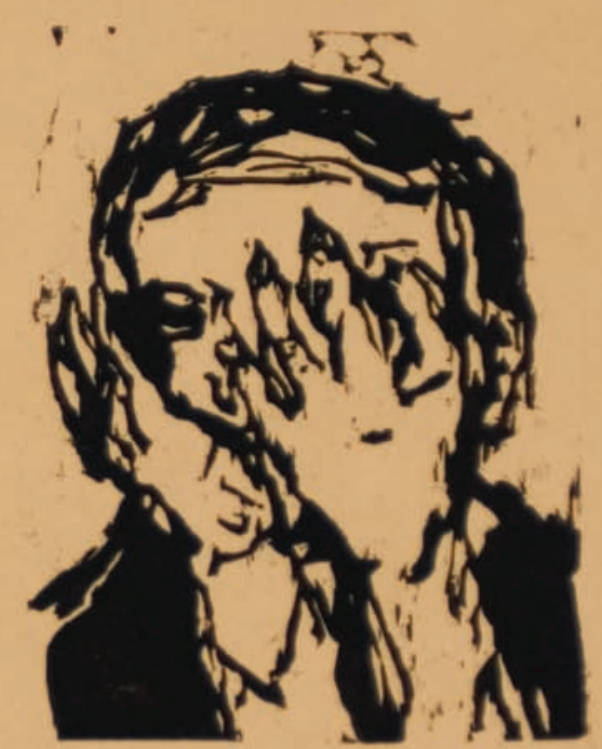

F..L: 
HISTORINHA

ACOROEI

OE LONGO SONO

VI KEU ÚTERO

NO FORMOL

VOLIEI

QUEIMEI A CASA

SUAS VASSOURA广

E INSETOS

CAI NA VIDA

SEUS DESCAMINHOS

ATE QUE UH DIA

UM ARCO IRIS

OE CORES LOJUCAS

ME POSSUIU

M.V. .

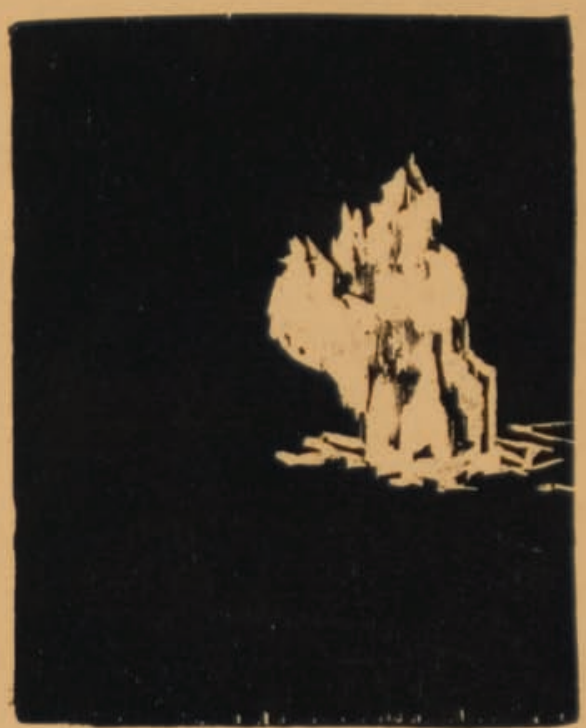

F..L: 


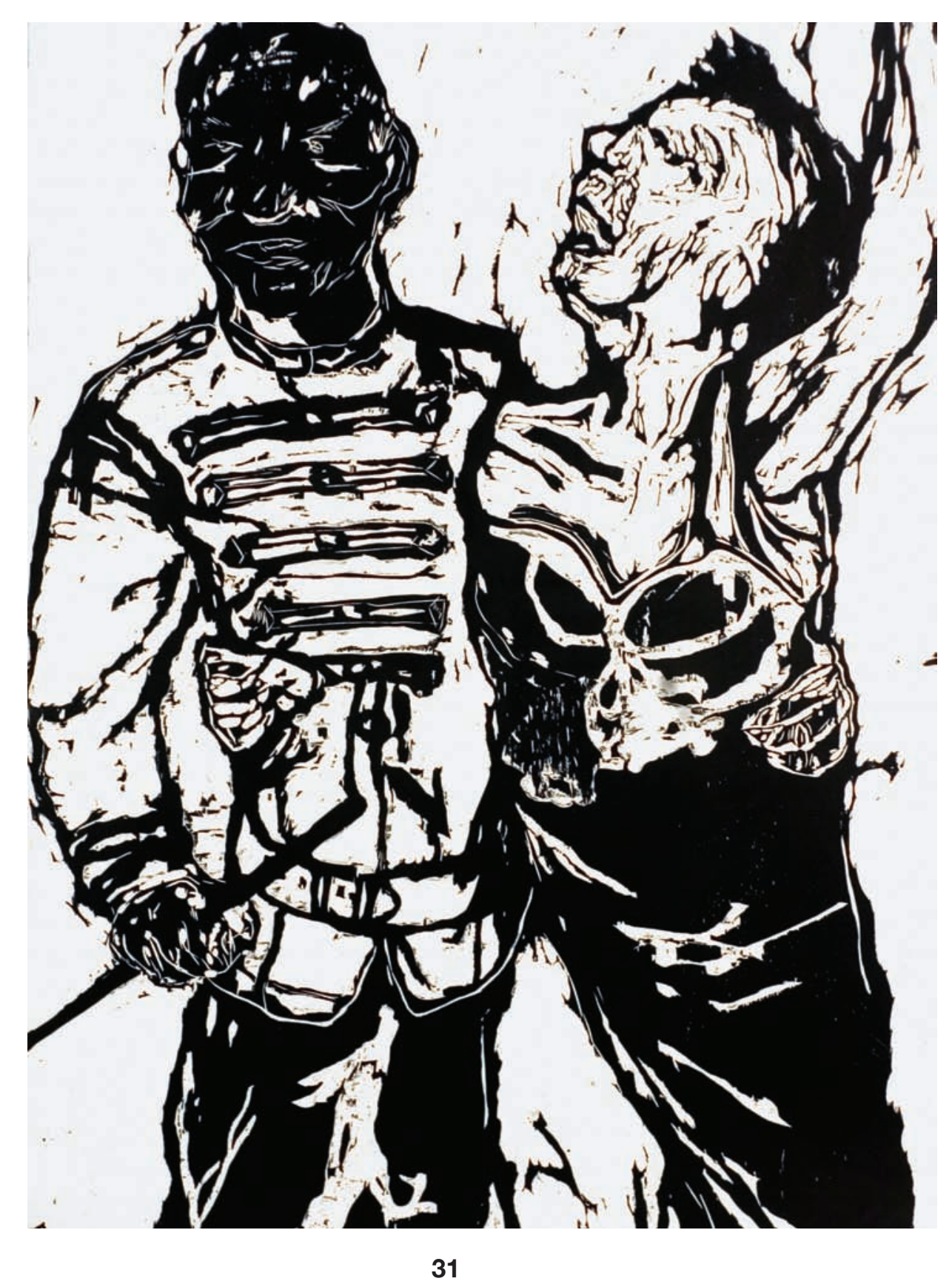




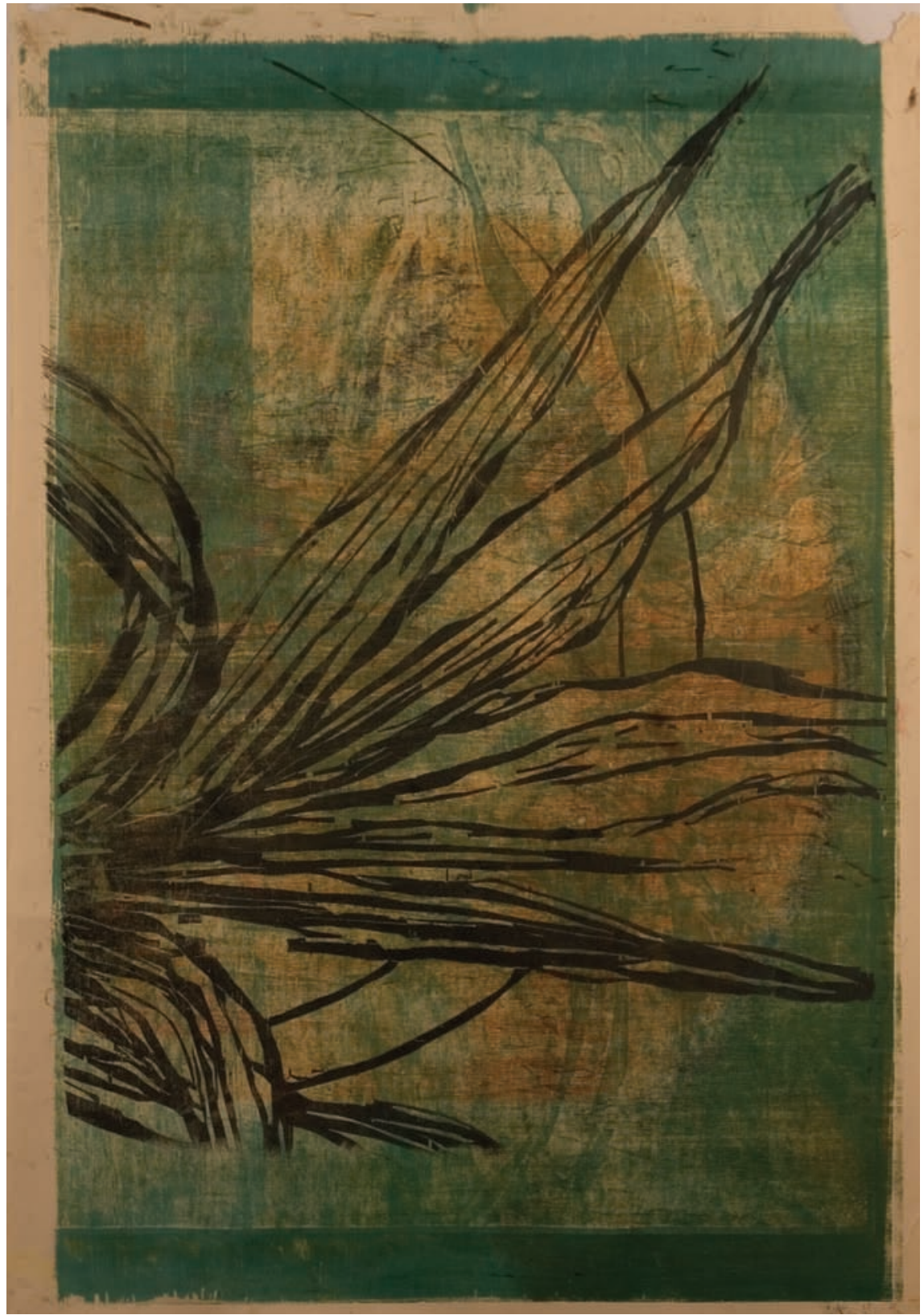

32 


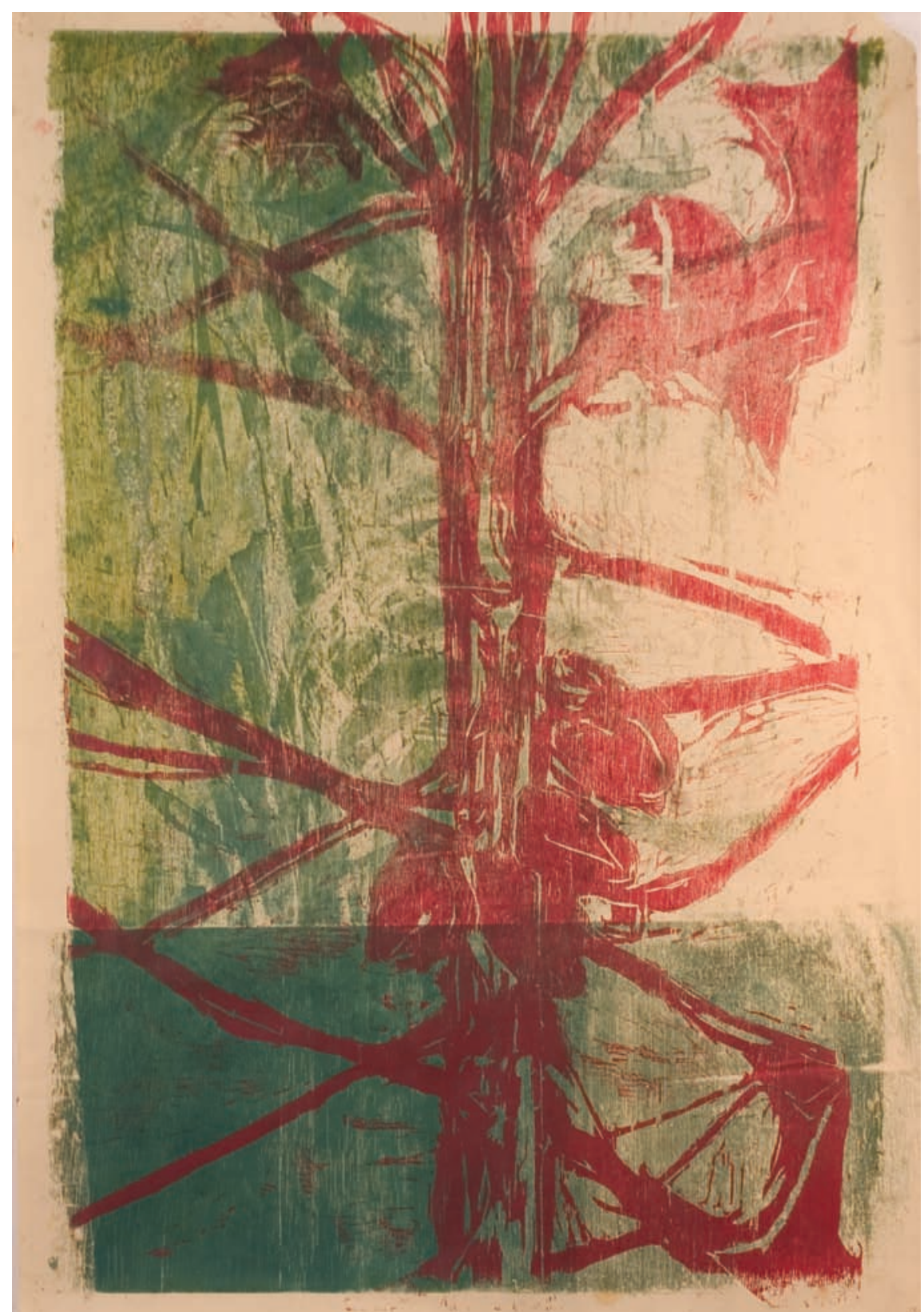

33 


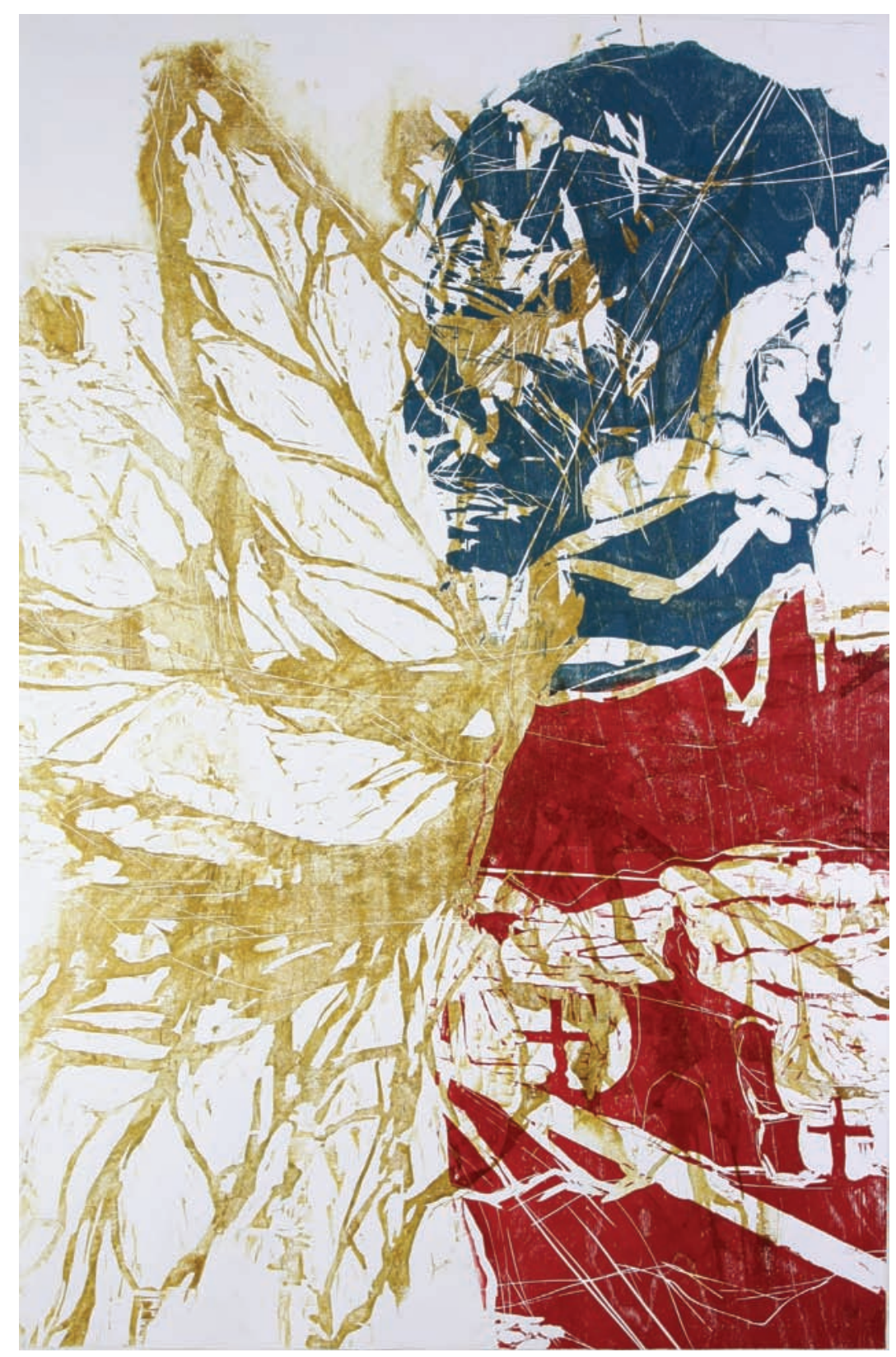

34 


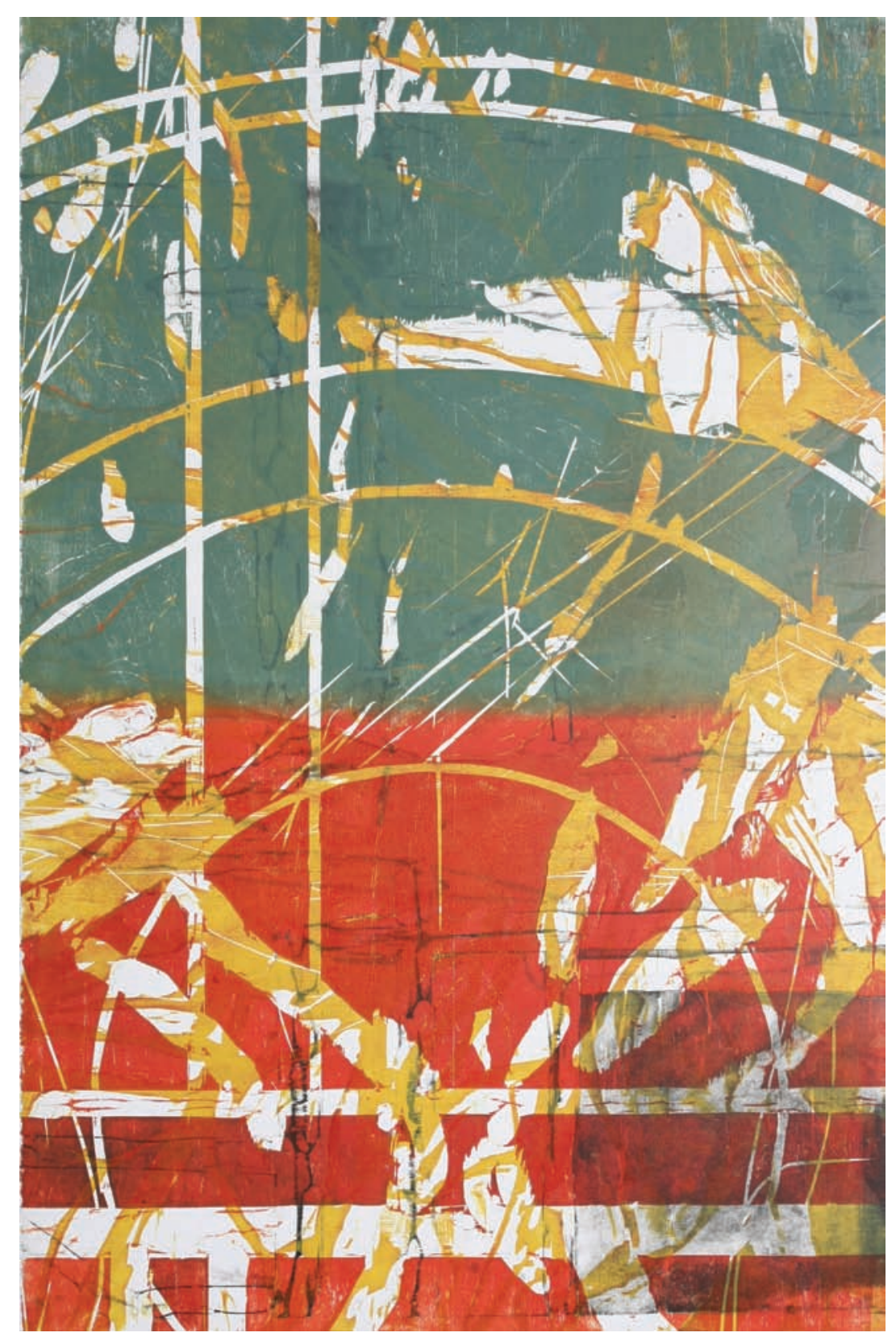

35 


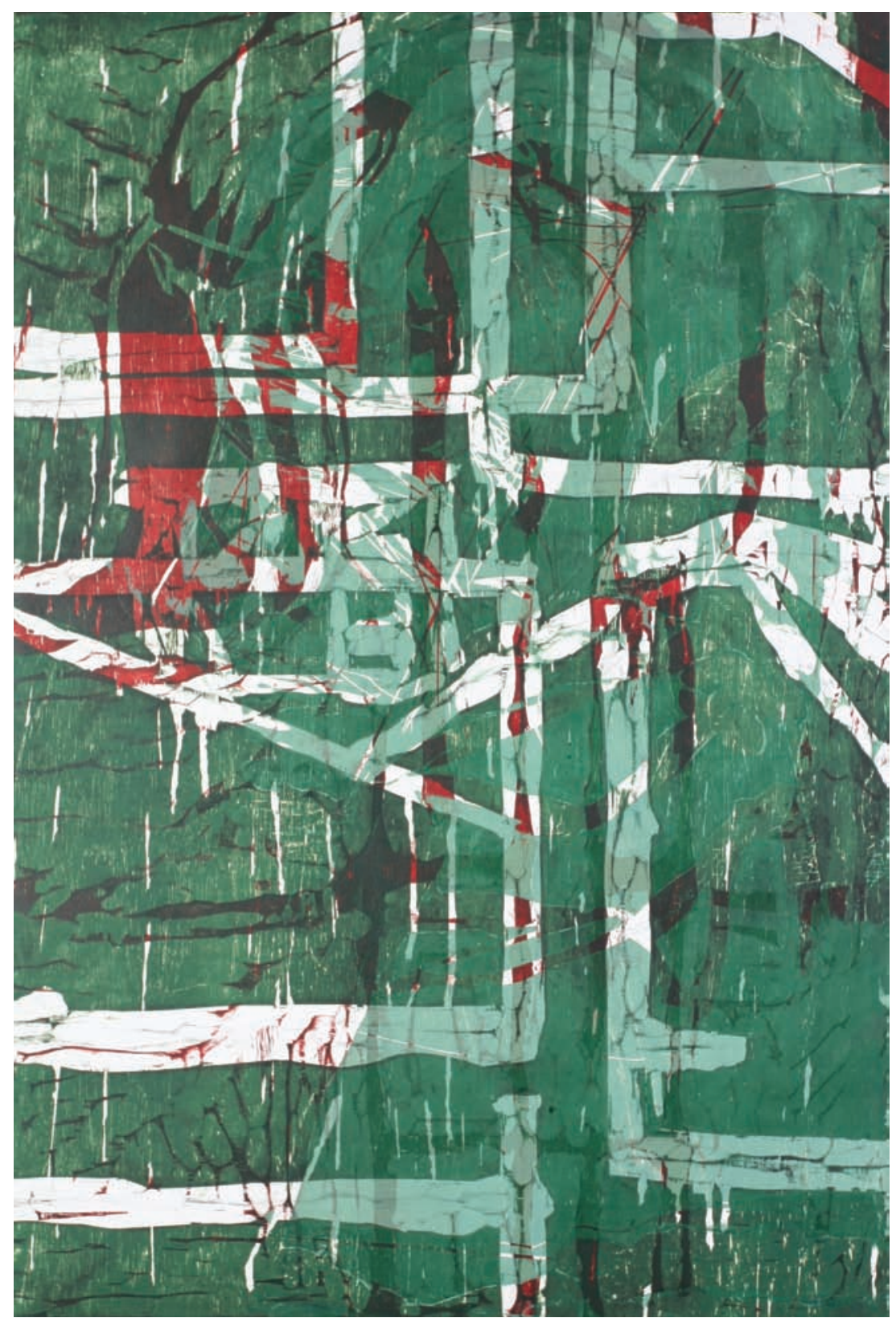




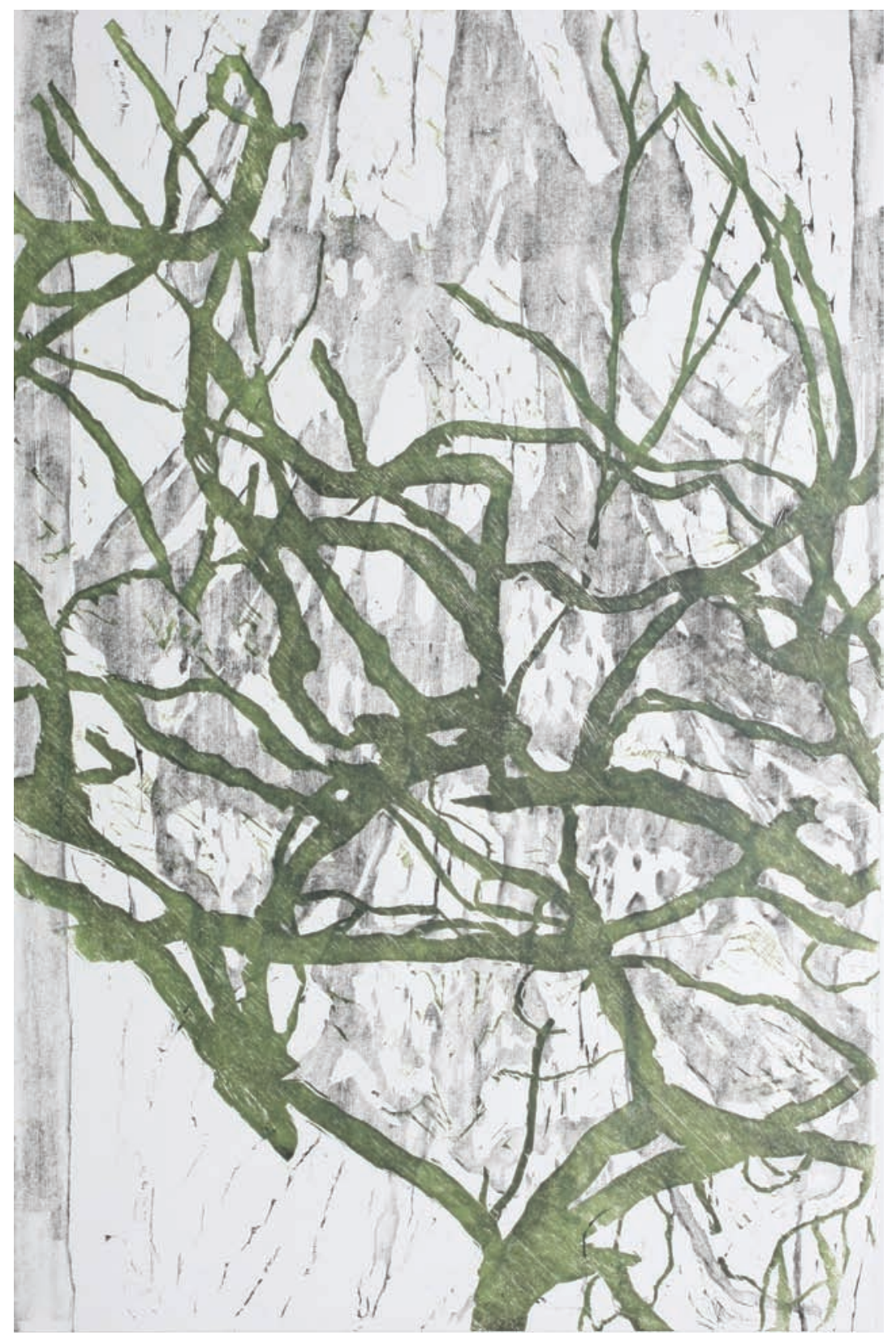

37 


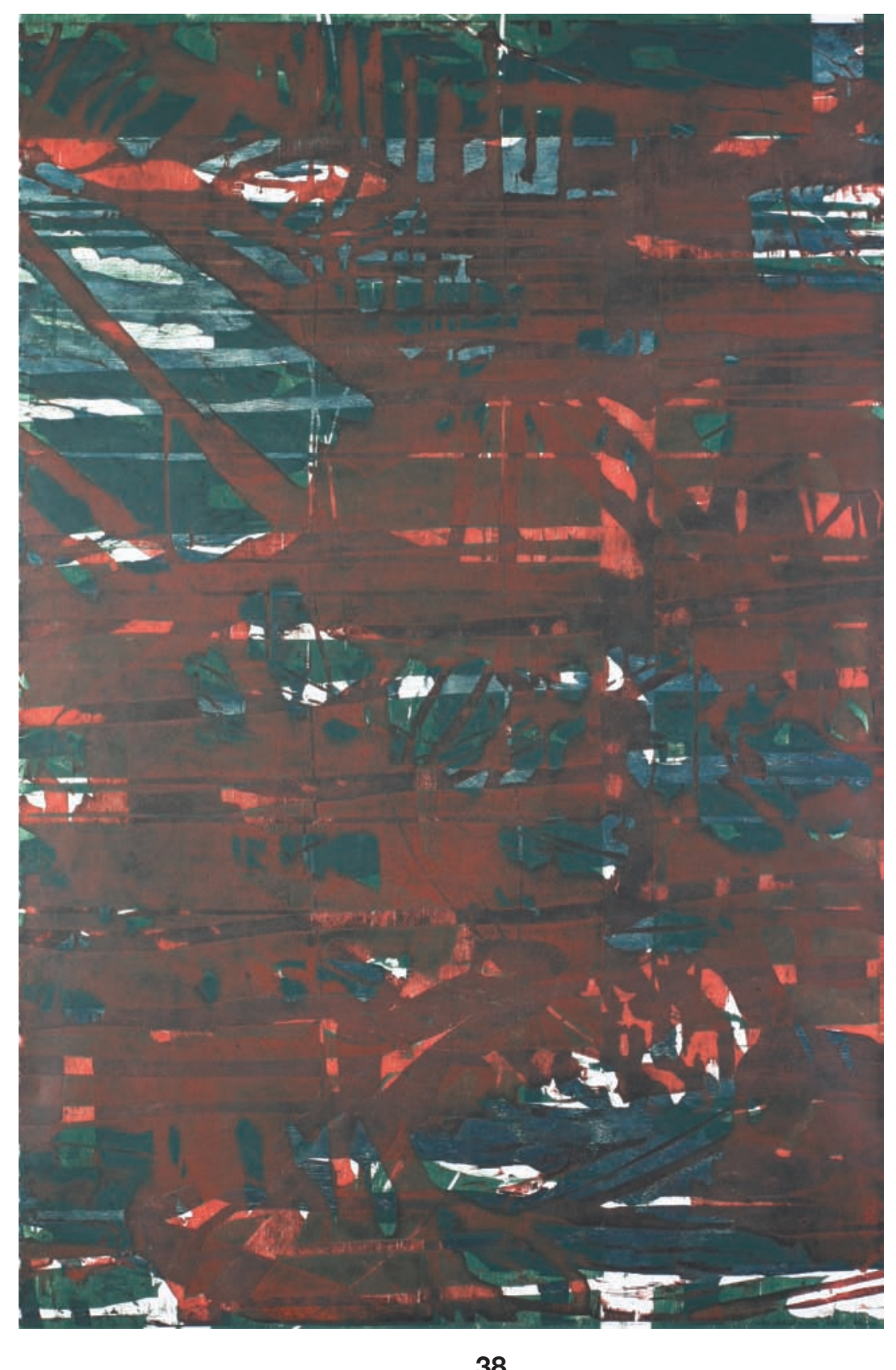




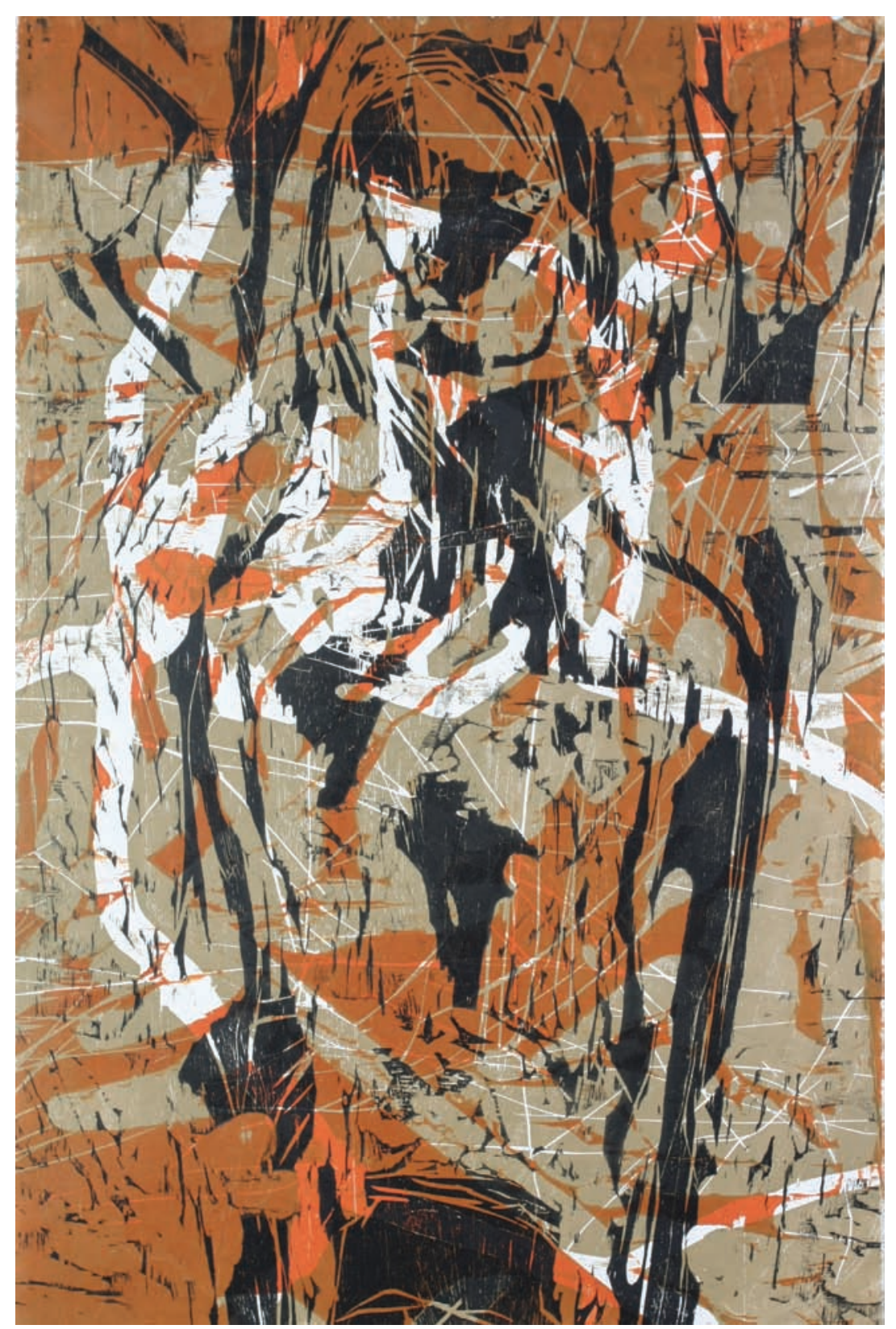

39 


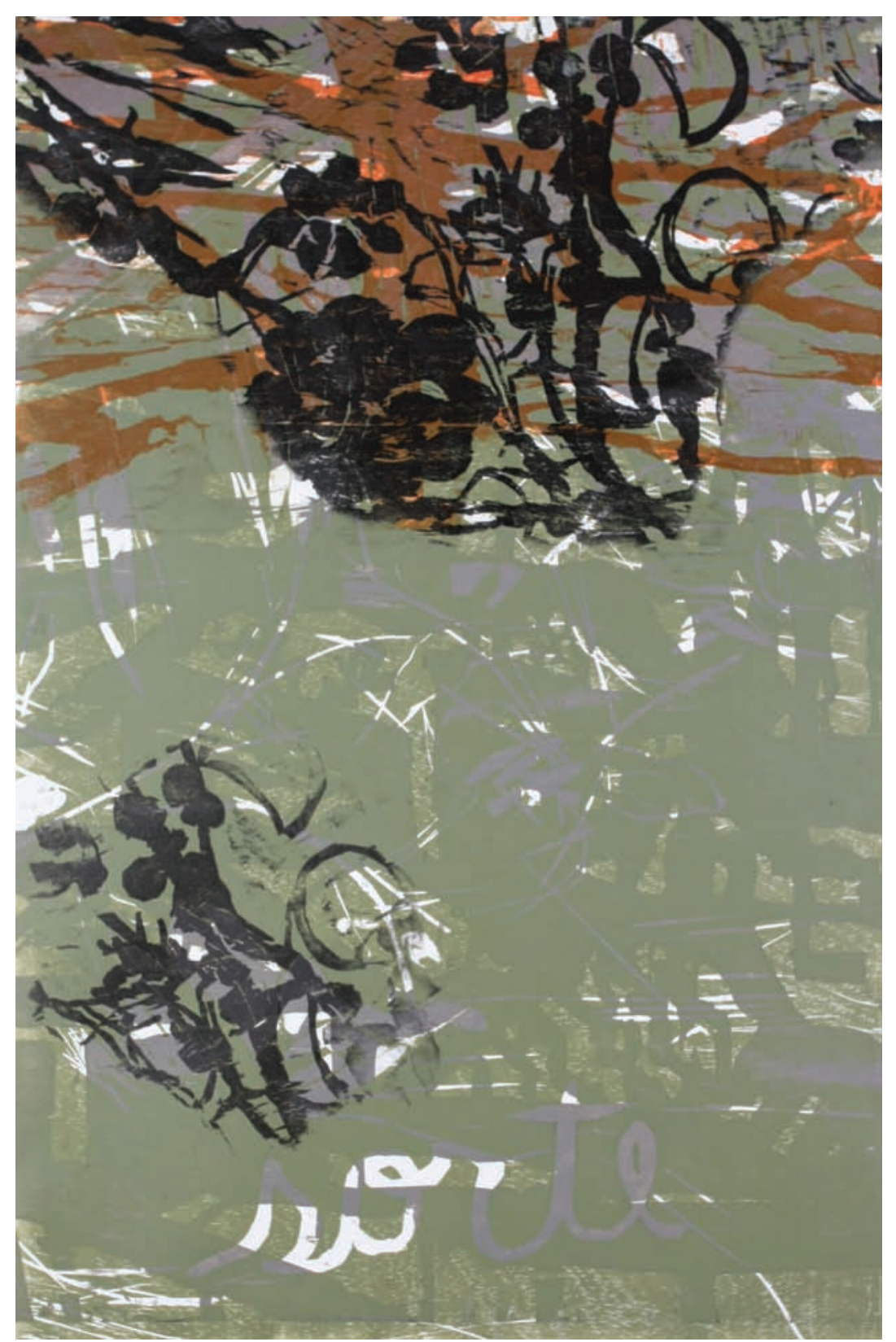




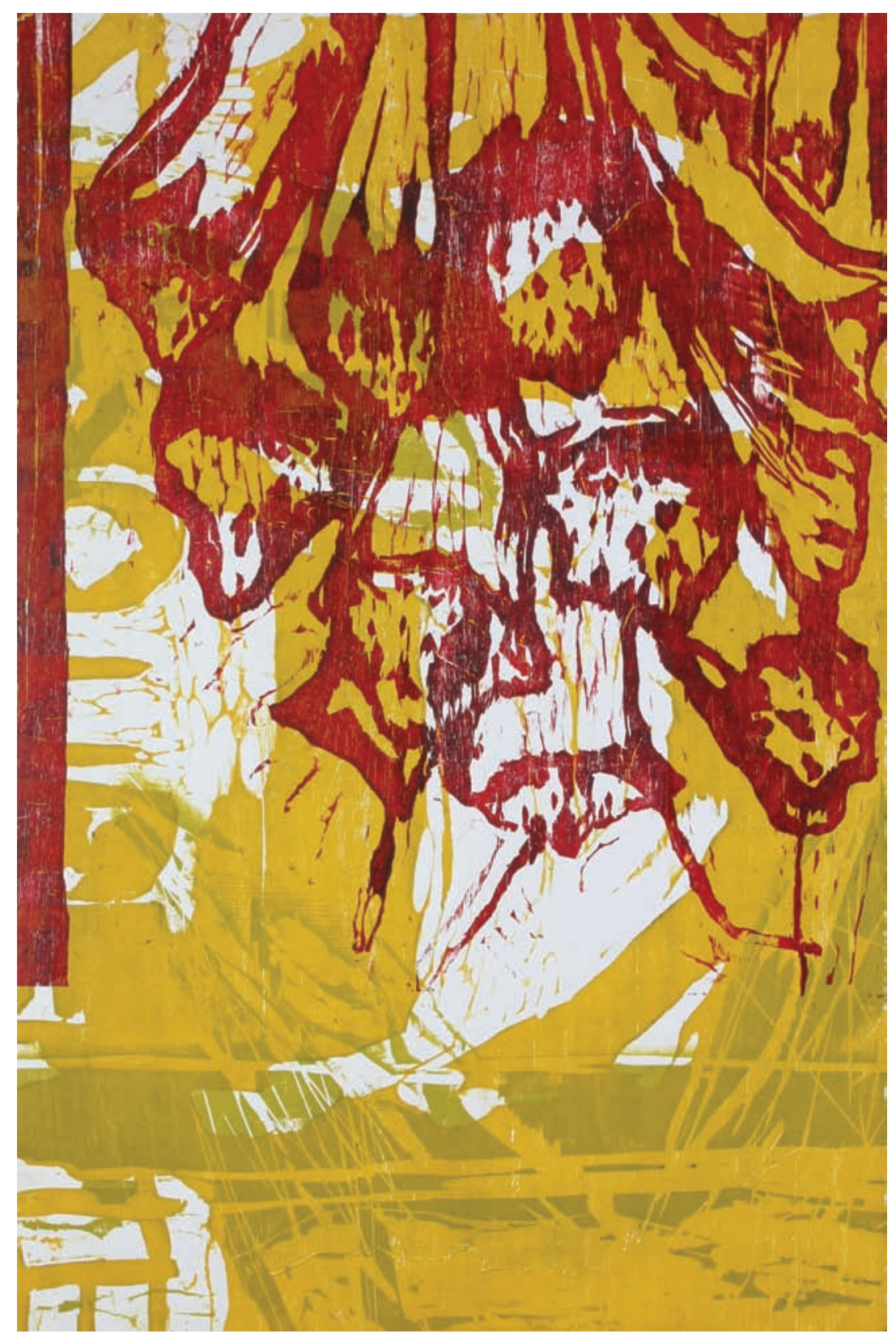

41 


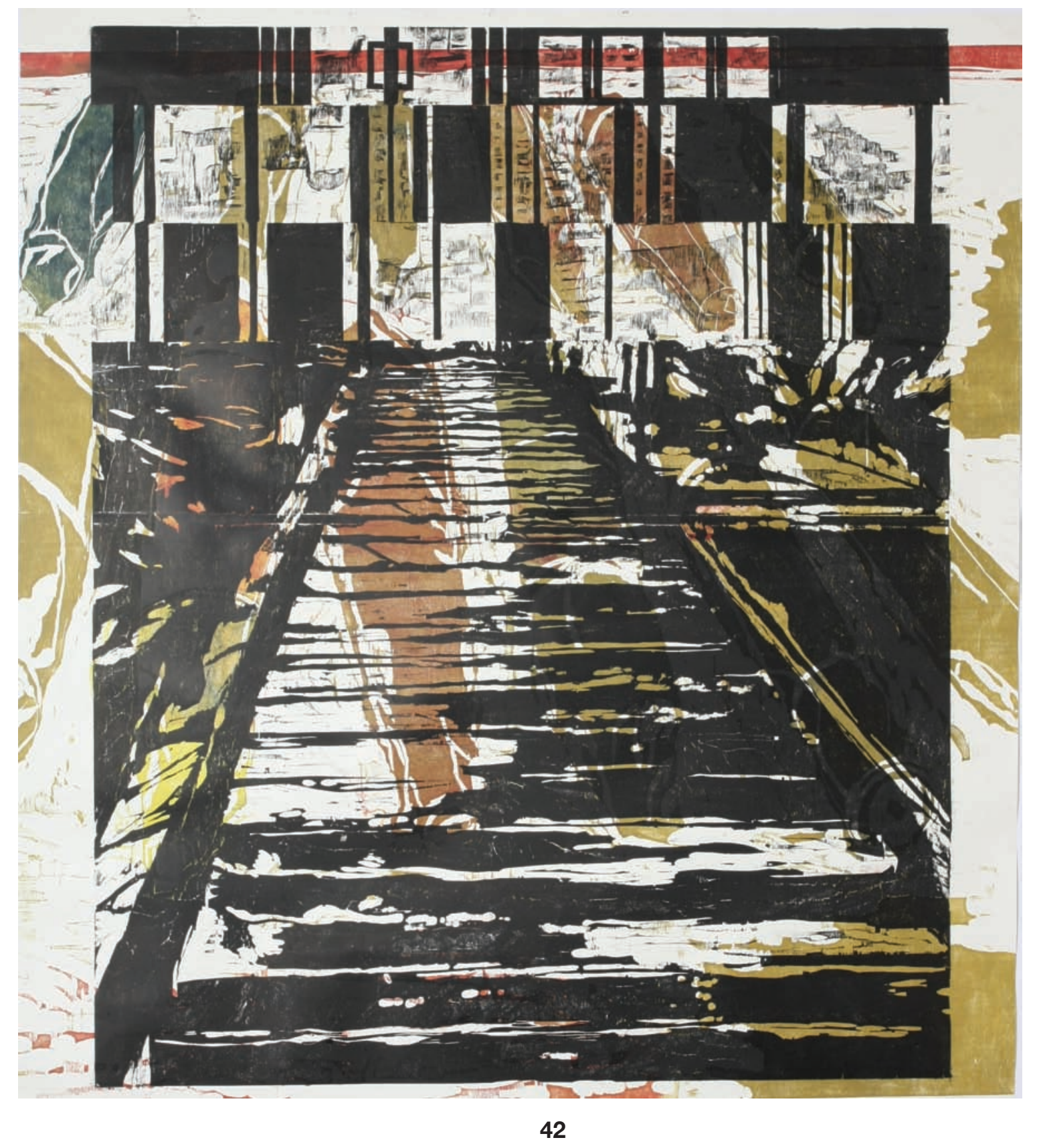




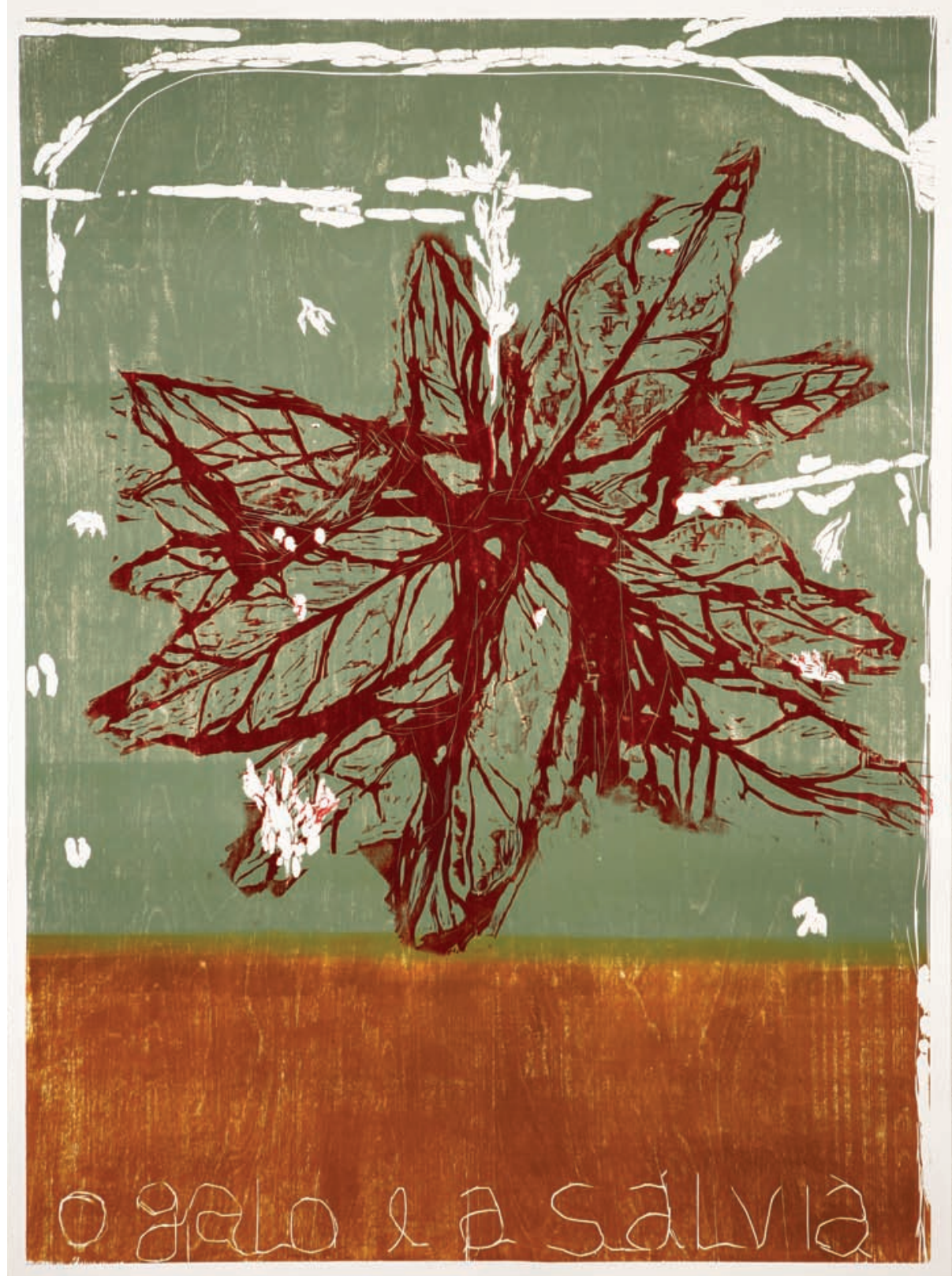

43 


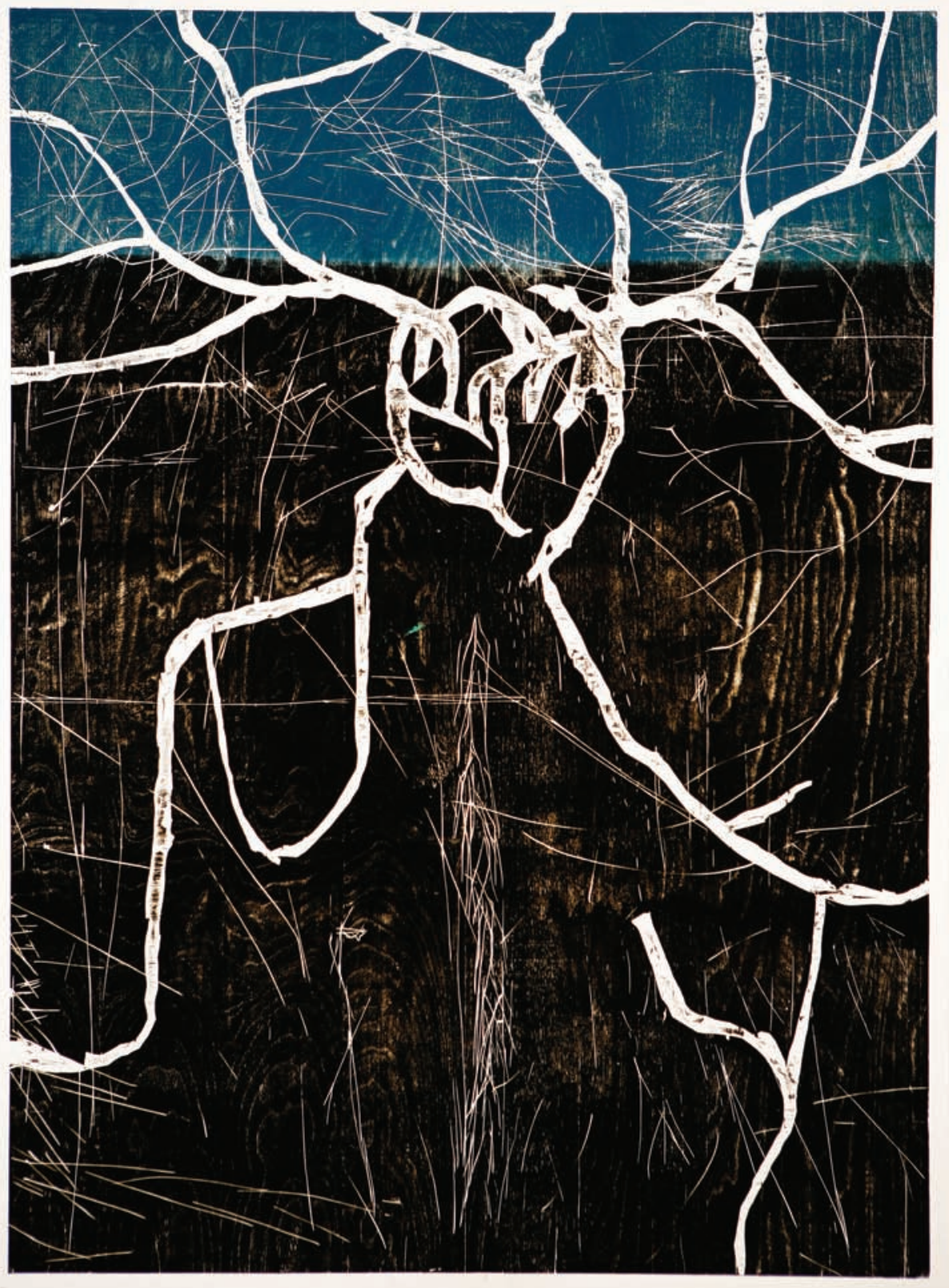



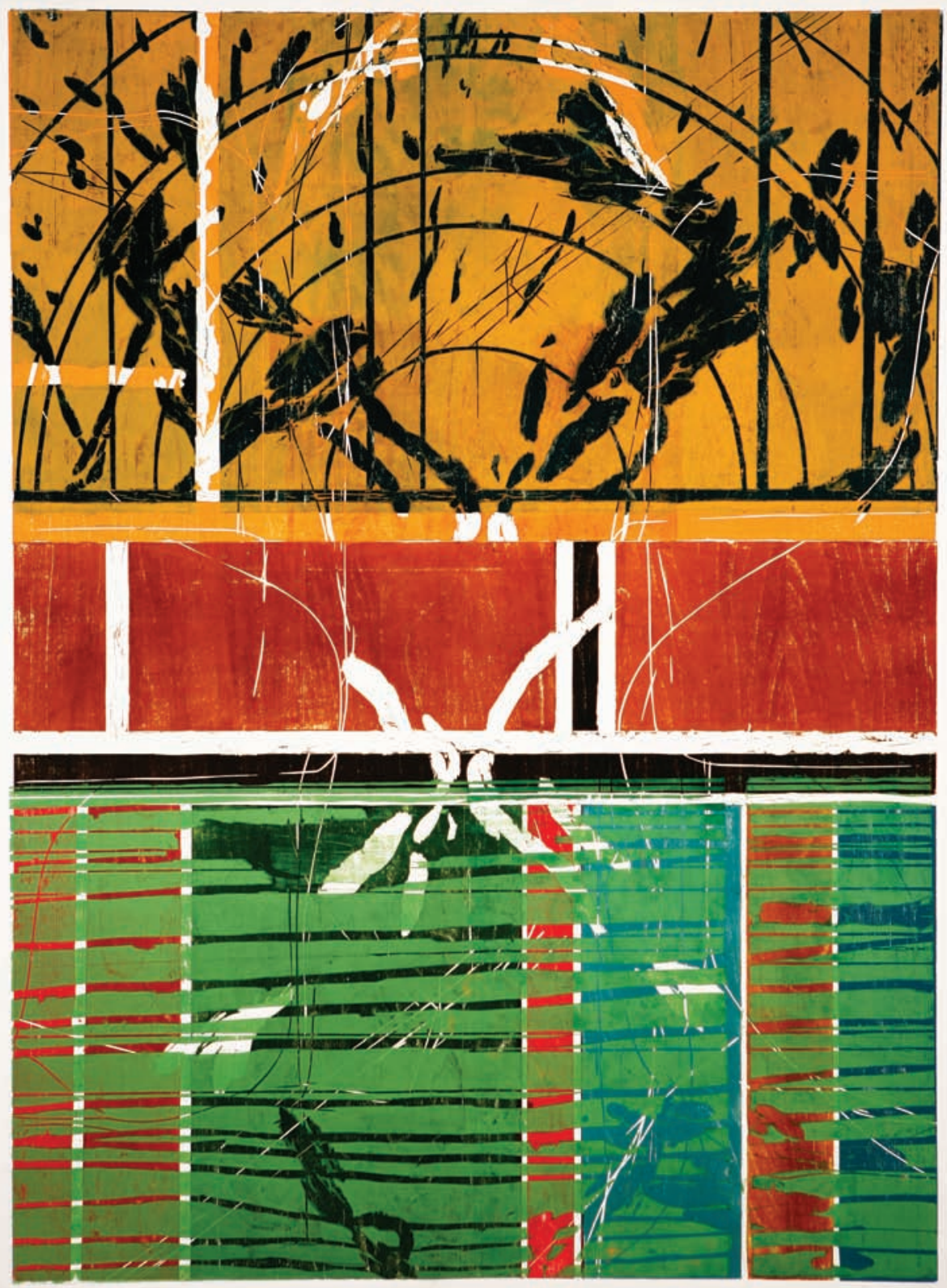

45 


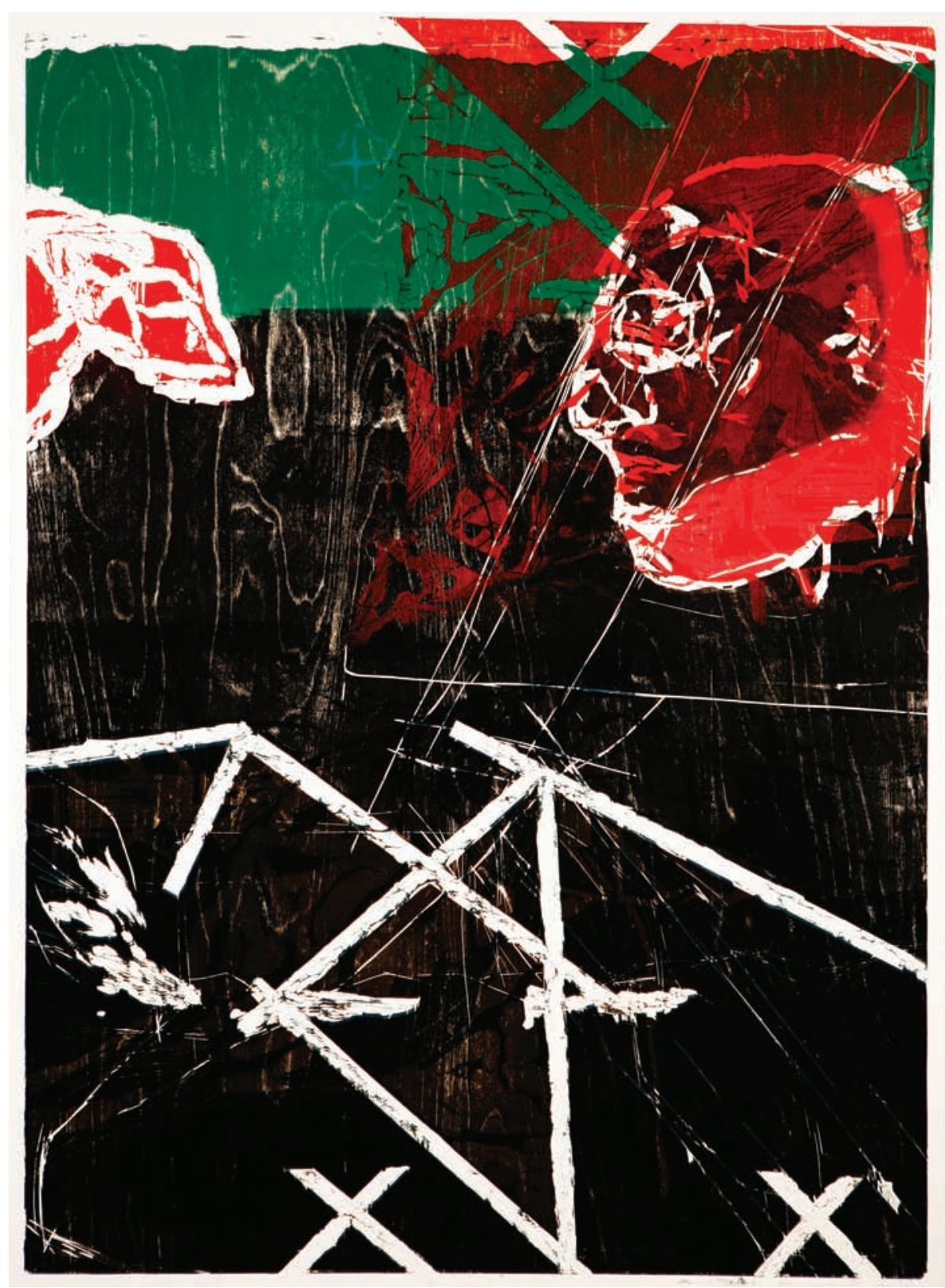

46 


\section{Fotografias:}

páginas

04 e 14

Fabricio Lopez

$11,12,15$ à 34

Rogério Nagaoka

35 à 42

Brunel Ricci

43 à 46

Everton Ballardin 


\section{Agradecimentos}

Thaís Badim / Flora Badim Lopez / Cláudio Mubarac / Elisa Bracher / Ulysses Bôscolo / Samuel Ornellas / Estúdio Diálogo Uriama T. Menezes / Ana Calzavara / Xiloceasa / Daniel García / Ateliê Espaço Coringa / Associação Cultural Jatobá / Ernesto Bonato / Juvelina e Diamantino / Brunel Ricci / Evandro Carlos Jardim / Marcelo Mattos Araújo / José Reinaldo Rema 
FONTES helvetica neue e myriad pro PAPEL couché fosco 150 g/m2 TIRAGEM 9 exemplares IMPRESSÃo Inove 